Maren Ermisch, Ulrike Kruse, Urte Stobbe (Hg.)

\title{
Ökologische Transformationen und literarische Repräsentationen
}

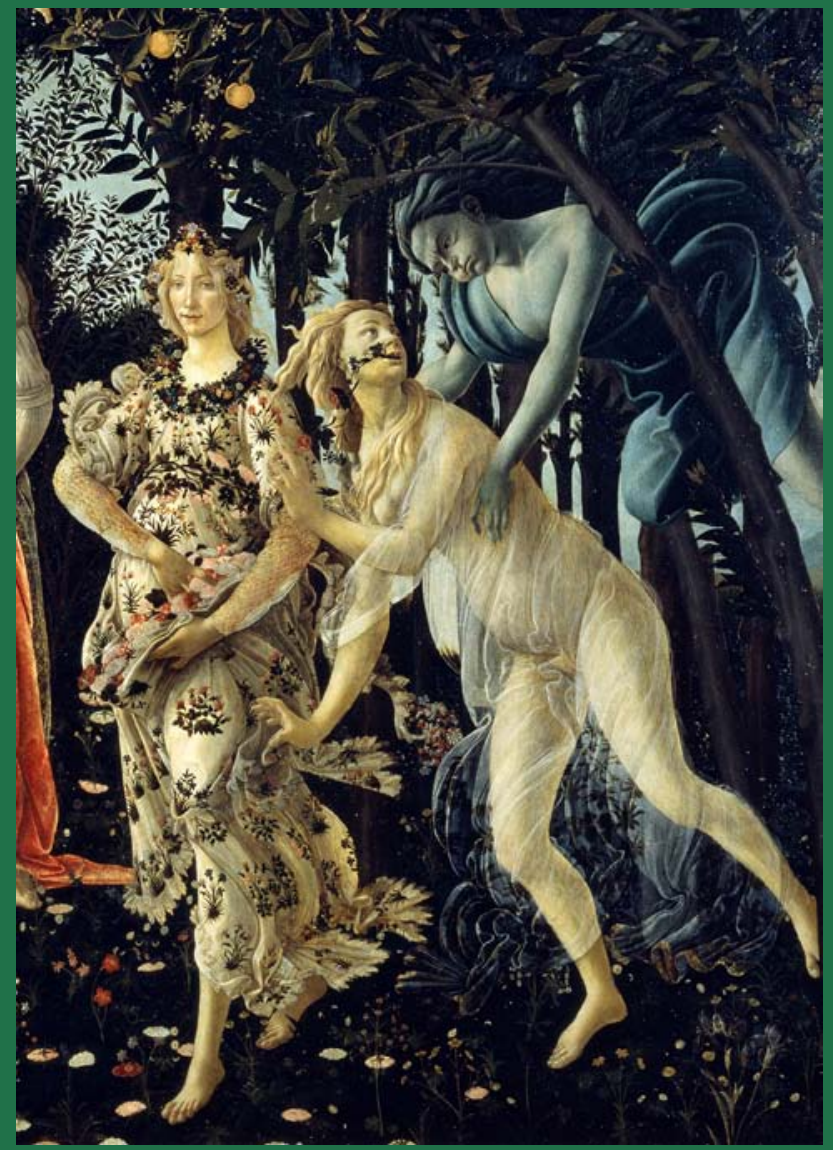

Universitätsverlag Göttingen 

Maren Ermisch, Ulrike Kruse, Urte Stobbe (Hg.) Ökologische Transformationen und literarische Repräsentationen

This work is licensed under the Creative Commons License 3.0 "by-nd", allowing you to download, distribute and print the document in a few copies for private or educational use, given that the document stays unchanged and the creator is mentioned. You are not allowed to sell copies of the free version.

SORERTIGHIS RESERVED 
erschienen im Universitätsverlag Göttingen 2010 
Maren Ermisch, Ulrike Kruse, Urte Stobbe (Hg.)

\section{Ökologische}

Transformationen

und literarische

Repräsentationen

Graduiertenkolleg Interdisziplinäre Umweltgeschichte

Seminar für Deutsche Philologie

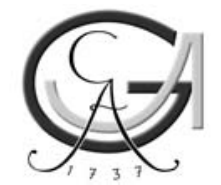

Universitätsverlag Göttingen 2010 


\section{Bibliographische Information der Deutschen Nationalbibliothek}

Die Deutsche Nationalbibliothek verzeichnet diese Publikation in der Deutschen Nationalbibliographie; detaillierte bibliographische Daten sind im Internet über $<$ http://dnb.ddb.de $>$ abrufbar.

Herausgeberinstitutionen:

Graduiertenkolleg Interdisziplinäre Umweltgeschichte

Naturale Umwelt und gesellschaftliches Handeln in Mitteleuropa

Seminar für Deutsche Philologie der Georg-August-Universität Göttingen

Gedruckt mit Unterstützung der Deutschen Forschungsgemeinschaft

\section{DFG}

Dieses Buch ist auch als freie Onlineversion über die Homepage des Verlags sowie über den OPAC der Niedersächsischen Staats- und Universitätsbibliothek (http://www.sub.uni-goettingen.de) erreichbar und darf gelesen, heruntergeladen sowie als Privatkopie ausgedruckt werden. Es gelten die Lizenzbestimmungen der Onlineversion. Es ist nicht gestattet, Kopien oder gedruckte Fassungen der freien Onlineversion zu veräußern.

Redaktion: Maren Ermisch, Ulrike Kruse, Urte Stobbe

Satz: Ulrike Kruse

Umschlaggestaltung: Margo Bargheer

Titelbild: Primavera, Sandro Botticelli, Tempera auf Holz, Galleria degli Uffizi Firenze, Inventarnr. 1890, N 3860

(C) 2010 Universitätsverlag Göttingen

http://univerlag.uni-goettingen.de

ISBN: 978-3-941875-86-9 


\section{Inhaltsverzeichnis}

Grußwort

Manfred Jakubowski-Tiessen

1

Ökologische Transformationen und literarische Repräsentationen

Urte Stobbe, Ulrike Kruse, Maren Ermisch.

Always already green. Zur Entwicklung und den

literaturtheoretischen Prämissen des amerikanischen Ecocriticism

Alexander Starre

Blumenkinder. Kinder- und Jugendliteratur ökokritisch betrachtet

Julia Hoffmann

Die fleißige und nützliche Biene.

Natur als Gegenstand und Metapher in der Hausväterliteratur

Ulrike Kruse

Natura morte im Delikatessenladen oder Wie viele Divisionen hat die Natur?

Bernd Herrmann

Die Ringe des Saturn und Solar. Sinnbilder und Schreibstrategien in literarischen

Stellungnahmen zur ökologischen Krise von W.G. Sebald und Ian McEwan

Axel Goodbody

Oikos, kosmos, textum: Ovids Metamorphosen

Stefanie Schub

Ecology / Economy. Henry David Thoreau geht spazieren

Frank Kelleter

Der verbrecherische Hahnenfuß: Wilhelm Lehmanns Bukolisches Tagebuch

Heinrich Detering

Der Schwarm und das Netzwerk im multiskalaren Raum.

Umweltdiskurse und Naturkonzepte in Schätzings Ökothriller

Gabriele Dürbeck, Peter H. Feindt.

Autorenverzeichnis 



\section{Grußwort}

\section{Manfred Jakuboreski-Tiessen}

In Wilhelm Raabes 1884 erschienenem Roman Pfisters Müble, der als der erste „Umweltroman" der deutschen Literatur gilt, werden die durch eine Zuckerfabrik verursachte Verschmutzung eines Flusses und deren Folgen in ironisierender Weise thematisiert:

Damit begann nämlich in jeglichem neuen Herbst seit einigen Jahren das Phänomen, daß die Fische in unserm Mühlwasser ihr Mißbehagen an der Veränderung ihrer Lebensbedingungen kundzugeben anfingen. Da sie aber nichts sagten, sondern nur einzeln oder in Haufen, die silberschuppigen Bäuche aufwärts gekehrt, auf der Oberfläche des Flüßchens stumm sich herabtreiben ließen, so waren die Menschen auch in dieser Beziehung auf ihre eigenen Bemerkungen angewiesen. (Raabe)

Die Natur, in diesem Fall die devastierte Natur, hat keine Stimme, ihr Protest ist vielmehr zeichenhaft. Es ist der Mensch, der Literat, welcher ihr seine Stimme leiht; er versucht die Zeichen der Natur zu deuten, in der Natur Wahrgenommenes zur Sprache zu bringen und seine Erfahrungen schließlich zu versinnbildlichen. Jedoch kann der Mensch sich die Natur nur mit seinen eigenen Begriffen erschließen. Dass im Reden und Schreiben über Natur diese zugleich auch zur Projektionsfläche kultureller Entwürfe wird, zeigt sich - wie den Beiträgen dieses Bandes zu entnehmen ist - nicht allein in Wilhelm Raabes Roman. Diesen Zusammenhang zu beleuchten sowie Fragen nach dem Verhältnis zwischen den Veränderungen in der naturalen Umwelt und deren literarischen Repräsentationen in der Literatur zu analysieren, stand im Mittelpunkt des Workshops, der am 15. und 16. Juli 2010 in Göttingen im Rahmen des Graduiertenkollegs „Interdisziplinäre Umweltgeschichte“ stattfand und dessen Beiträge nun in diesem Band gesammelt vorliegen.

Workshops gehören von Beginn an zu den wichtigen Bausteinen der inhaltlichen Arbeit im Graduiertenkolleg „Interdisziplinäre Umweltgeschichte“. Im Laufe der vergangenen sechs Jahre hat es auf einzelnen Workshops eine Reihe unterschiedlicher Formen interdisziplinärer Zusammenarbeit gegeben. Ein mit Literaturwissenschaftlern gemeinsam veranstalteter Workshop ist ein Novum, dessen Fruchtbarkeit der vorliegende Sammelband trefflich nachweist.

Ich habe herzlich zu danken meinen Kollegen Prof. Dr. Dr. h.c. Heinrich Detering und Prof. Dr. Bernd Herrmann für ihre Initiative, das inneruniversitäre Gespräch zwischen Literaturwissenschaftlern und Umwelthistorikern gesucht zu haben und es in einem inhaltsreichen Workshop münden zu lassen. Desgleichen danke ich allen an der Organisation des Workshops beteiligten sowie den Referenten für Ihre engagierte Teilnahme am Workshop und für Ihre Beiträge zu diesem Band. 



\title{
Ökologische Transformationen und literarische Repräsentationen
}

\author{
Urte Stobbe, Ulrike Kruse, Maren Ermisch
}

Im Zeichen der interdisziplinären Annäherung von Umwelthistorikern, Naturwissenschaftlern und Literaturwissenschaftlern haben am 15. und 16. Juli 2010 das Graduiertenkolleg 1024 „Interdisziplinäre Umweltgeschichte“ und das Seminar für Deutsche Philologie der Universität Göttingen gemeinsam eine Tagung in Göttingen ausgerichtet. Deren Ergebnisse werden in diesem Tagungsband publiziert.

Schon seit den 1990er Jahre werden gerade in der Anglistik und Amerikanistik Fragen nach den literarischen Repräsentationsformen von Natur unter Begriffen wie Ecocriticism oder Ökokritik subsumiert und diskutiert. Cheryl Glotfelty etwa definiert Ecocriticism als ,the study of the relationship between literature and the physical environment" (Glotfelty 1996, S. XVIII), wobei es im anglophonen Bereich mittlerweile zu teils erheblichen Verwerfungen innerhalb dieses Diskussionszusammenhangs gekommen ist. Auch wenn die meisten Studien zu diesem Interpretationsansatz in der Anglistik entstehen, sind doch inzwischen ebenfalls im deutschsprachigen Bereich einige Studien und Sammelbände zum Thema Literatur und Ökologie entstanden. Hervorzuheben sind vor allem die Sammelbände von Axel Goodbody (1998), Peter Morris-Keitel/Michael Niedermeier (2000) und Catrin Gersdorf/Sylvia Mayer (2005). In einer dezidiert textanalytischhermeneutisch ausgerichteten Variante ökokritischer Lektüren argumentiert Heinrich Detering (1992; 2009) beispielsweise hinsichtlich Wilhelms Raabes oder 
Urte Stobbe, Ulrike Kruse, Maren Ermisch

der Weltuntergangsszenarien in der Literatur des 18. Jahrhunderts. In Bezug auf Peter Handkes Werk hebt Stefan Hofer (2007) auf eine Kombination aus systemtheoretischer Literaturanalyse und Ökokritik ab.

Selbstredend sind gerade der Naturbegriff und die Landschaftsdarstellung in literarischen Werken auch ohne ausdrückliche Berufung auf die theoretischen Modellbildungen des Ecocriticism untersucht worden. Verwiesen sei beispielsweise auf die Geschichte des Horizonts (1990) von Albrecht Koschorke und die Untersuchung zu Organisch-ganzheitlichem Denken in Wissenschaft, Dichtung und Philosophie (2000) von Klaus Deterding. Auch der Tagungsband Das Erdbeben von Lissabon (2008) von Gerhard Lauer und Thorsten Unger wäre in diesem Zusammenhang zu nennen, geht er doch den Auswirkungen einer der zentralen Naturkatastrophen des 18. Jahrhunderts auf die literarischen, naturkundlichen und gesellschaftlichen Diskurse nach.

Zurecht betont also Ursula Heise, dass „die Anfänge ökologischen Denkens in der Literaturkritik weiter zurück" reichen als die Theoriedebatten um den Ecocriticism. (Heise 2001, S. 129) So präzise Heise allerdings den Begriff definitorisch eingrenzt, so schwer ist er ins Deutsche zu übersetzen - was auch damit zu tun haben mag, dass er infolge thematischer und theoretischer Voraussetzungen, die sehr spezifisch für den angloamerikanischen Bereich zu gelten scheinen, anderswo eher verhalten rezipiert wird:

Die ökologisch orientierte Lit.[eratur]- und Kulturkritik analysiert Konzepte und Repräsentationen der Natur, wie sie sich in verschiedenen historischen Momenten in bestimmten Kulturgemeinschaften entwickelt haben. Sie untersucht, wie das Natürliche definiert und der Zusammenhang zwischen Menschen und Umwelt charakterisiert wird und welche Wertvorstellungen und kulturellen Funktionen der Natur zugeordnet werden. (Heise 2001, S. 128)

Evident ist nach diesem Verständnis eine Nähe oder mehr noch Verbindung zur ebenfalls interdisziplinären Umweltgeschichte, wenn man sich die Definition von Vera Winiwarter und Martin Knoll vergegenwärtigt, wonach sich Umweltgeschichte „mit der Rekonstruktion von Umweltbedingungen in der Vergangenheit sowie mit der Rekonstruktion von deren Wahrnehmung und Interpretation durch die damals lebenden Menschen" beschäftigt. (Winiwarter/ Knoll 2007, S. 14f.) Goodbody betont in seiner überaus fundierten Einleitung die Rolle der Literatur für unsere Wahrnehmung von Natur und Umwelt:

,Natur ${ }^{6}$ und ,Umwelt ${ }^{6}$ sind kulturell bedingte Konstrukte, an deren Konstituierung, schöne' Literatur in der Vergangenheit wesentlichen Anteil gehabt hat und die sie heute noch beeinflussen kann. (Goodbody 1998, S. 25)

Vor diesem Hintergrund bietet es sich laut Urte Stobbe (2008) gerade an, Texte der Literatur umwelthistorisch $\mathrm{zu}$ untersuchen, weil sie als Speicher für Wahrnehmungsweisen und kulturelle Deutungsmuster betrachtet werden können, die sich mittelbar bzw. indirekt als handlungsleitend im Umgang mit der naturalen 
Umwelt erweisen können. Ohne es so zu nennen, argumentiert Hansjörg Küster (2009) ganz ähnlich, wenn er mit Blick auf die Landschaftsschutzkonventionen betont, dass den kulturellen Wahrnehmungsmustern wie etwa Arkadien, Wildnis, Paradies, etc. besondere Aufmerksamkeit zu widmen sei, da gerade sie es sind, die unsere Vorstellung davon prägen, wie naturräumliche Umgebung idealer Weise gestaltet sein soll.

Nach wie vor scheint also die Frage virulent zu sein, in welchem Verhältnis die Transformationen der naturalen Umwelt und literarische Repräsentationsformen zueinander stehen bzw. zu sehen sind. Undeutlich - oder jedenfalls nicht hinreichend expliziert - scheint in vielen Beiträgen auch die Verwendung unterschiedlicher Konzeptualisierungen von „Natur“, die sowohl deskriptive als auch (und nicht selten bis ins Weltanschauliche, ja Parareligiöse reichende) normative Kategorien voraussetzen können und wiederum innerhalb der deskriptiven Gegenstandsbestimmungen den Menschen manchmal in Opposition zu, manchmal als Teil von „Natur" sehen. Wünschenswert wäre weiterhin, dass die vielschichtigen Zusammenhänge zwischen ökologischen Transformationsprozessen und literarischen Darstellungsformen in methodischen Klärungsversuchen und Fallstudien systematisch differenziert würden.

Dabei wäre dann einerseits zu fragen, wie der Wandel im menschlichen Verhältnis zur „Natur“ - und den sich wandelnden Bedeutungsnuancen dieses Begriffs! - zu unterschiedlichen Zeiten in literarischen Texten verhandelt wird und welche neuen literarischen Ausdrucksformen er womöglich provoziert. Andererseits wären die Beziehungen zwischen Ecocriticism und anderen kulturwissenschaftlich ausgerichteten Paradigmen literaturwissenschaftlicher Arbeit zu klären (etwa im Blick auf Ecocriticism und Gender Studies). Und schließlich müsste auch in den Blick genommen werden, wie literarisch codierte kulturelle Muster sich ihrerseits auf die Gestaltung der naturalen Umwelt auswirken können. Schließlich bliebe in komparatistischer Perspektive zu fragen, wie dabei literarische Modellierungen des Wandels in unterschiedlichen Kulturen diachron und synchron mit Veränderungsprozessen in der Natur korrespondieren. Diese Fragestellung schließt auch Möglichkeiten einer wechselseitigen Kritik umwelthistorischer und literarischer Perspektiven ein.

In diesem Zusammenhang wäre auch eine entsprechende Anthologie bzw. ein deskriptiv inventarisierender Kanon dringend zu wünschen, um Ökokritik stärker in der germanistischen und komparatistischen Ausbildung zu etablieren, zumal Bayerl/Troitzsch in ihrer Anthologie Quellentexte zur Geschichte der Umwelt von der Antike bis heute (1998) bereits punktuell literarische Texte aufgenommen haben. Die häufig in diesem Zusammenhang genannten, mittlerweile geradezu kanonischen Texte wie Wilhelm Raabes Roman Pfisters Müble (1884) oder Kleists Das Erdbeben in Chili (1807) sind um weitere Titel zu ergänzen. Gerade bei letzterem Titel böte es sich an, Wellberys verschiedene literaturwissenschaftlichen Ansätze und Lesarten zu eben jenem Text um eine umweltkritische Interpretation zu erweitern. Dass eine literaturwissenschaftliche Analyse im deutschsprachigen 
Urte Stobbe, Ulrike Kruse, Maren Ermisch

Bereich unter umwelthistorischen Aspekten noch immer nicht zu den stabil etablierten kulturwissenschaftlichen Analysemethoden gezählt werden kann (vgl. Schößler 2006), scheint symptomatisch und wurde bereits von Goodbody (1998, S. 12) und anderen wiederholt moniert.

In der umwelthistorischen Ausbildung wiederum sollten kulturwissenschaftliche Aspekte verstärkt einbezogen und Analysen literarischer Texte in Hinblick auf die in ihnen verhandelten Konzepte von Natur, Kultur, Umwelt usf. berücksichtigt werden, zumal sie auf die Gestaltung der naturalen Umwelt rückwirken können (u. a. Böhme 2000, S. 7). Bereits 1999 haben Rolf Peter Sieferle und Helga Breuninger dazu den breit angelegten Sammelband Natur-Bilder: Wabrnehmungen von Natur und Umwelt in der Geschichte vorgelegt, das Thema „Nachhaltigkeit“ ist jüngst umfassend von Ulrich Grober (2010) dargestellt worden. Insgesamt wären über die Literaturwissenschaft hinaus auch stärker die kunstwissenschaftliche Bildanalyse ebenso wie die Filmwissenschaft zu integrieren (Goodbody 1998, S. 29).

Das Ziel der Göttinger Tagung, den praktischen Dialog zwischen Literaturwissenschaft und Umweltgeschichte zu fördern, hat sie gewiss erfüllt - wovon der vorliegende Sammelband beredt Zeugnis ablegt. Besonders vor dem Hintergrund der zunehmenden Etablierung des relativ jungen Ecocriticism als eines theoretischen Zugangs einerseits zur Literatur und andererseits zur Umweltgeschichte als einem ebenfalls jungen interdisziplinären Arbeitsfeld konnte eine Fülle von Themen in Literatur und Geschichte ausgebreitet werden. Ausgehend von einer theoretischen Einführung in den Ecocriticism von Alexander Starre reichen die Beiträge zeitlich von der römischen Antike über die Frühe Neuzeit bis zur neuesten Gegenwart und räumlich von den Weiten des Alls über die alpine Maienwiese bis zur Tiefsee.

So breit auch die Themen aufgefächert sind, so schnell ergeben sich doch Gemeinsamkeiten in Modellbildungen, in theoretischen Zugängen, in Untersuchungsfragen und -ergebnissen. Als eines der wichtigsten Werke der „Nature Literature" sowohl in theoretisch reflektierender wie in narrativer Perspektive hat sich Walden von Henry David Thoreaus etabliert, um dessen Einfluss auf Umweltgeschichte und Ecocriticism die Beiträge und die Diskussionen immer wieder kreisen, z. B. bei Alexander Starre, der sich dem Ecocriticism theoretisch nähert, bei Frank Kelleter, der über Thoreaus Schreibstrategien spricht, und Heinrich Detering, der Wilhelm Lehmann als einen deutschen Thoreau-Adepten liest. Alexander Starre eröffnet für Literaturwissenschaftler wie Umwelthistoriker den Zugang zum Ecocriticism, indem er gemeinsame Wurzeln der beiden Disziplinen nicht zu Unrecht in der Umweltbewegung des 20. Jh. verortet. Er sieht z. B. ähnliche Zugänge, gleiche Referenztexte - wie etwa Walden - und den bei beiden anzutreffenden Versuch der Rekonstruktion gegenseitiger Einwirkungen von Natur und Kultur, wobei nicht aus den Augen verloren werden darf, wie mannigfaltig und unabgeschlossen die theoretische Reflexion des summarisch als „Ecocriticism“ Bezeichneten sich noch immer darstellt. 
Frank Kelleter macht darauf aufmerksam, dass das Sprechen über Naturräume national und ideologisch geprägt sei, ein Aspekt seines Beitrags über Thoreaus Walden, den er als einen Klassiker des Sprechens über Natur und der ökologischen Imagination sieht. Thoreau wolle für die Natur sprechen, stehe aber vor dem Problem, dass die Natur als „Wildnis“ als erhabenes Anderes gedeutet werde, dem man sich schwer nähern könne. Kelleter arbeitet heraus, dass das ursprüngliche ziellose Aufgehen in der Natur in das Ziel der Nation umgemünzt wird. So wird die Natur im Amerika des 19. Jh. zum Ersatz für fehlende gemeinsame kulturelle Traditionen. Damit wird ein bestimmtes Bild von der Gesellschaft, von der Welt, entworfen.

$\mathrm{Zu}$ den Weltentwürfen in den Texten kommt die Herstellung von Welt in literarischen Texten mittels Natur. Die Beiträge von Stefanie Schuh, Ulrike Kruse und Bernd Herrmann kommen auf unterschiedlichen Wegen zu ähnlichen Ergebnissen. Stefanie Schuh verweist auf die strukturelle Ähnlichkeit von Text-Welt und Um-Welt. Laut ihrer Analyse bestehen beide aus ähnlichen Einheiten, Buchstaben bzw. Atomen - in der antiken Vorstellung die kleinsten und unteilbaren Einheiten in der Welt -, die in einer regelhaften Matrix - hier Syntax, da Ordnung der Natur - ein Ganzes ergeben. Diese Ordnung der Natur, die in der von Ulrike Kruse untersuchten Hausväterliteratur (16. - 18. Jh.) eine gottgegebene ist, bestimmt die Ordnung des Textes, der mit dieser wiederum eine Welt herstellt - hier die Welt des Landgutes mit seinen klar umrissenen Bereichen wie der Landwirtschaft und der Haushaltung, deren naturkundliche Hintergründe und ökonomischen Regeln rückgebunden werden an die göttliche Ordnung. Ebenfalls um die Herstellung von UmWelt dreht sich der Beitrag von Bernd Herrmann über Gebrauch, Verbrauch und Konservierung von dem, was landläufig unter Natur verstanden wird. Er spricht sich gegen die Subjektivierung von Natur als handlungsmächtig aus. Diese Sicht auf die Welt beschreibt er als „doppelten naturalistischen Fehlschluss“ (Herrmann, S. 119), denn es werde weder anerkannt, dass Wahrnehmung kulturell gesteuert sei (Foucault 1988, S. 132ff), noch, dass „die Dinge in der Natur lediglich so sind, wie sie sind“ (Herrmann, S. 119), ohne den Menschen direkt betreffenden Zweck.

Dass natürliche Phänomene den Zweck der Ausrottung der Menschen verfolgen, legt der Roman Der Schwarm von Frank Schätzing nahe, anhand dessen Gabriele Dürbeck und Peter H. Feindt die Rolle der Natur als Menschenfeind in der Literatur beleuchten. Sie beschreiben die Welt solcher Texte als biozentrisch, aber die Erzählperspektive als anthropozentrisch. Als ähnlich disparat bezeichnen sie auch die Welt-Herstellung über globalen Schauplatzwechsel gegenüber der unterkomplexen Welt-Vorstellung mit scharf abgegrenzten Freund-Feind-Konstellationen. In den Werken Ringe des Saturn von W. G. Sebald und Solar von Ian McEwan, vorgestellt von Axel Goodbody, ist die Natur Vehikel, Schreibstrategie, zur Darstellung von inneren Zuständen und von Handlungsoptionen. Handlungsoptionen, mehr noch Handlungsregeln, also Regeln über gesellschaftskonformes Verhalten, werden in Kinderbüchern mittels Naturdarstellungen vermittelt, wie Julia Hoffmann anschaulich an Illustrationen aus der Kinderliteratur der letzten 
Urte Stobbe, Ulrike Kruse, Maren Ermisch

hundert Jahre zeigt. Blumen stehen darin z. B. metaphorisch für Reinheit und Unschuld und für beaufsichtigtes und geordnetes - zivilisiertes - Aufwachsen. Die gebändigte Natur in diesen Texten ist eine andere Facette neben der wilden Natur oder auch der symbolhaften Natur.

Handlungssubjekt in einem Text wird die Natur im Bukolischen Tagebuch von Wilhelm Lehmann, vorgestellt von Heinrich Detering. Landschaftsschilderungen bilden selbst die Handlung, nicht der Mensch, sondern die Natur in ihrer bloßen Existenz. Detering sieht die Forderung des russischen Avantgardisten Viktor Šklovskij nach der „Erweckung des Wortes“ in Lehmanns Naturschilderungen verwirklicht, denn Lehmann zeichnet sich durch eine hohe Aufmerksamkeit für die Wechselwirkungen zwischen dem Handeln der Menschen und seiner biologischen Mitwelt aus. Darin ist Lehmann wiederum (erklärtermaßen) Thoreaus Walden nahe.

Nicht im Sammelband erscheint Urte Stobbes Aufsatz, der sich dem Verhältnis von Literatur und gebauter Landschaft am Beispiel der Andeutungen über Landschaftsgärtnerei (1834) von Herman Fürst von Pückler-Muskau und dem von ihm selbst angelegten Park Muskau widmet. In Anknüpfung an die jüngsten Ergebnisse der Landschaftsforschung zeigt sie, dass die durch Text und Bild evozierten Vorstellungen vom Landschaftsgarten wirkmächtiger sind als die Realität selbst. Ihr Beitrag, der als Monographie 2011 im Deutschen Kunstverlag erscheint, lässt sich als Plädoyer für einen Abgleich von Texten mit den Korrelaten oder Referenzpunkten in der physischen Welt werten. Das enorme Potenzial einer ökokritischen Literaturanalyse läge darin, diese kulturellen Transformationsprozesse präzise offen zu legen.

Auf die Leitfrage, als was „Natur“ in Beiträgen des Ecocriticism jeweils verstanden und verhandelt wird, geben die Beiträge sehr unterschiedliche Antworten. Die Herausgeberinnen hoffen, dass dieser Sammelband nicht nur Fragen beantwortet, sondern sowohl Literaturwissenschaftler als auch Umwelthistoriker zu neuen Fragen anregt.

Unser besonders herzlicher Dank gilt Heinrich Detering und Bernd Herrmann für ihre Initiative und Unterstützung bei der thematischen Konzeption und Organisation des Workshops. Sie haben das Gespräch gesucht; ohne ihr Engagement und ihren fachlichen Rat wäre es nicht solch ein konstruktiver Workshop geworden, der eine Bresche in die oft so starren Fachgrenzen geschlagen hat. Dies wäre auch nicht möglich gewesen, wenn die Referentinnen und Referenten nicht freundlicherweise unserer Einladung gefolgt wären, um sich über zwei Tage der intensiven gemeinsamen Diskussion ihrer Beiträge zu stellen. Sie eröffneten uns allen Einblicke in ganz unterschiedliche Themengebiete und offenbarten überraschende Querverbindungen.

Danken möchten wir auch dem Sprecher des Graduiertenkollegs, Manfred Jakubowski-Tiessen, für seinen Eröffnungsvortrag und die freundliche Unterstützung dieses Workshops. Die teils aufwendige Dekoration zu einzelnen Vorträgen verdanken wir Michael Schwerdtfeger, Kustos des Botanischen Gartens 
der Universität Göttingen, Gert Tröster, Kustos des Zoologischen Museums der Universität Göttingen, dem Fundus des Deutschen Theaters und der Sammlung der Abteilung für Forstzoologie und Waldschutz der Forstwissenschaftlichen Fakultät. Den reibungslosen Ablauf gewährleisteten die studentischen Hilfskräfte Rabea Fischer und Martin Wiegand vom Graduiertenkolleg und Christian Volmari, Arndt Lümers und Nina Kullrich vom Seminar für Deutsche Philologie, deren Hilfe die Veranstalterinnen sehr entlastete. Dafür können wir nicht genug danken.

Finanziert wurden Workshop und Tagungsband aus Mitteln der DFG (Förderung des Graduiertenkollegs 1024 „Interdisziplinäre Umweltgeschichte“ und durch Heinrich Detering aus den Mitteln des Gottfried Wilhelm Leibniz-Preises).

Göttingen, Dezember 2010

Urte Stobbe, Ulrike Kruse \& Maren Ermisch 
Urte Stobbe, Ulrike Kruse, Maren Ermisch

\section{Literatur:}

Böhme, Hartmut (2000): Historische Natur-Konzepte, ökologisches Denken und die Idee der Gabe. In: Morris-Keitel, Peter; Niedermeier, Michael (Hgg.):

Ökologie und Literatur. New York: Peter Lang, S. 7-21.

Deterding, Klaus (2000): Eine Handvoll Erde. Organisch-ganzheitliches Denken in Wissenschaft, Dichtung und Philosophie seit 1770. Berlin: Weidler.

Detering, Heinrich (2009): „So könnte die Welt untergehen“ - Ökologie und Literatur im 18. Jahrhundert. In: Herrmann, Bernd (Hrsg.): Beiträge zum Göttinger Umwelthistorischen Kolloquium 2008-2009. Göttingen: Universitätsverlag, S. 1-16.

Detering, Heinrich (1992): Ökologische Krise und ästhetische Innovation im Werk Wilhelm Raabes. In: Jahrbuch der Raabe-Gesellschaft, S. 1-27.

Foucault, Michel (1988): Die Geburt der Klinik. Eine Archäologie des ärztlichen Blicks (Naissance de la clinique, 1973). Frankfurt am Main: Fischer.

Glotfelty, Cheryl (1996): Introduction. In: Glotfelty, Cheryl; Fromm, Harold (Hgg.): The Ecocriticism Reader: Landmarks in Literary Ecology. Athens: University of Georgia Press, S. XV-XXXVII.

Goodbody, Axel (1998) Hrsg.: Literatur und Ökologie. Amsterdam: Ropodi.

Goodbody, Axel (1998): Literatur und Ökologie: Zur Einführung. In: Goodbody, Axel (Hrsg.): Literatur und Ökologie. Amsterdam: Ropodi, S. 11-40.

Grober, Ulrich (2010): Die Entdeckung der Nachhaltigkeit. Kulturgeschichte eines Begriffs. München: Kunstmann.

Heise, Ursula (2001): Ecocriticism/Ökokritik. In: Nünning, Ansgar (Hrsg.):

Metzler Lexikon Literatur- und Kulturtheorie. Ansätze - Personen -

Grundbegriffe. 2., überarb. u. erw. Aufl. Stuttgart, Weimar: Metzler, S. 128f.

Hofer, Stefan (2007): Die Ökologie der Literatur. Eine systemtheoretische Annäherung, Mit einer Studie zu Werken Peter Handkes. Bielefeld: transcript.

Koschorke, Albrecht (1990): Die Geschichte des Horizonts. Grenze und Grenzüberschreitung in literarischen Landschaftsbildern. Frankfurt am Main: Suhrkamp.

Küster, Hansjörg (2009): Schöne Aussichten. München: Beck.

Lauer, Gerhard; Unger, Thorsten (2008) Hgg.: Das Erdbeben von Lissabon und der Katastrophendiskurs im 18. Jahrhundert. Göttingen: Wallstein.

Morris-Keitel, Peter; Niedermeier, Michael (2000) Hgg.: Ökologie und Literatur. New York: Peter Lang. 
Schößler, Franziska (2006): Literaturwissenschaft als Kulturwissenschaft. Eine Einführung. Tübingen: Francke UTB.

Sieferle, Rolf Peter; Breuninger, Helga (1999) Hgg.: Natur-Bilder. Wahrnehmungen von Natur und Umwelt in der Geschichte. Frankfurt am Main: Campus.

Stobbe, Urte (2008): Umweltwahrnehmung im Roman „Anton Reiser“ (17851790) von Karl Philipp Moritz. In: Herrmann, Bernd; Dahlke, Christine (Hgg.): Schauplätze der Umweltgeschichte. Göttingen: Universitätsverlag, S. 159-172.

Wellbery, David E. (2001) Hrsg.: Positionen der Literaturwissenschaft. Acht Modellanalysen am Beispiel von Kleists „Das Erdbeben in Chili“. 4. Aufl. München: Beck.

Winiwarter, Verena; Knoll, Martin (2007) Hgg.: Umweltgeschichte. Eine Einführung. Köln: UTB. 



\section{Always already green \\ Zur Entwicklung und den literaturtheoretischen Prämissen des amerikanischen Ecocriticism}

\section{Alexander Starre}

\section{Einleitung: Sorgen eines Ecocritics}

Zu Beginn dieses kurzen Überblicks über das sich seit den 1980er Jahren herausbildende Forschungsfeld des Ecocriticism möchte ich zunächst einen Blick auf eine erhellende Kurzgeschichte werfen, die auf einer einschlägigen Tagung spielt. Die Autorin und Universitätsdozentin Joy Williams veröffentlichte im Jahr 2009 die experimentelle Erzählung Saved in einer Ausgabe des literarischen Magazins McSweeney's, das sich in einem speziellen Themenschwerpunkt vergessenen Erzählformen und Genres widmete. Williams Beitrag zu dieser Ausgabe ist im Stile einer nivola verfasst, einer Romanform, die jegliche Art von geradliniger Handlung unterläuft. Der spanische Autor Miguel de Unamuno entwarf das Konzept der nivola in den 1910er und 20er Jahren, blieb aber weitgehend ihr einziger praktizierender Anhänger. ${ }^{1}$

Wir lernen die Protagonistin von Saved lediglich mit ihrem Alias-Namen Snow kennen. Snow ist eine „respected eco-critic“ (Williams 2009, S. 64) und Hauptrednerin der beschriebenen Ecocriticism-Konferenz. Der Leser ist durch die interne Fokalisierung stark an Snows Perspektive gebunden. Ihr Fachwissen scheint allerdings zu einem umgreifenden Zynismus in Bezug auf das eigene

\footnotetext{
1 Vgl. Unamunos Hauptwerk Niebla (1914/1967), ein Liebesroman voller metafiktionaler Elemente und existenzphilosophischer Überlegungen.
} 
Forschungsinteresse geführt zu haben. Ihre Erwartungen an die Tagung sind bereits im Vorhinein niedrig:

Tomorrow evening she would give her lecture but before that there would be a reception preceded by the papers and panels of others. Someone surely would bore them all by extolling that sanctimonious old pigeon, Thoreau, and his unimaginative trots into the Maine woods. (Ebd., S. 65)

Die Schriften Henry David Thoreaus, die konstitutiv für den US-amerikanischen Ecocriticism waren, ${ }^{2}$ werden hier auf ein triviales Niveau herabgesetzt, als Werk eines scheinheiligen alten Vogels. So ist es dann auch die Heuchelei der Konferenzteilnehmer, die Snow in die Verzweiflung treibt. Dem Gastgeber und Organisator, Prärie-Experte Chester Owen, hält die Protagonistin beispielsweise vor, dass ihm sein Interesse an den Graslandschaften des nordamerikanischen Kontinents nur deshalb erhöhtes Prestige eingebracht habe, weil das Objekt seiner Studien bereits im Verschwinden begriffen ist: „It was easier to study something eradicated, to reconstruct it not for future use or enjoyment but for knowledge, for the sake of knowledge“ (ebd.). Es passe ins Bild, so die Erzählerin, dass Owens große Leidenschaft für Pferdezucht im krassen Gegensatz zur unberührten Prärie steht, da sein Gestüt jede Wiese in kürzester Zeit zertrampeln und die kostbaren Gräser zermalmen würde. Die Umgebung ihres Hotels hinterfragt Snow fortlaufend auf Anzeichen menschlichen Eingreifens und selbst dem nachhaltig aufgeforsteten Waldstück vor ihrem Hotelzimmer kann sie nur wenig Gutes abgewinnen.

Die fiktive Konferenz macht einen wahrlich interdisziplinären Eindruck; Biologen und Geografen nehmen ebenso teil wie literaturwissenschaftlich orientierte Ecocritics und Autoren von Natur-Lyrik. Snow jedoch reagiert auf die zahlreichen Vorträge mit zunehmender Übelkeit. In einem Autoren-Workshop erreicht die Debatte einen Tiefpunkt, der Snow aus dem Raum vertreibt:

Some poet $[\ldots]$ was speaking about living in the now, about the necessity to frankly celebrate the fearful flux that is nature. [...] A member of the audience stood and was given a battery-operated microphone. ,I was peeling an orange this morning, she said, , and I noticed that the peel I was about to throw into the garbage reminded me of squamous cells, those tiny epidermal flakes that fall from our skin. I then realized without knowing it that we are all ... all sowers who spread tiny particles of skin here and there along our path. We create with our very waste. "Interesting, ' the poet said. [...] Snow raised her hands to her head and gently probed her temples. She felt like a heated stove. (Ebd., S. 71)

${ }^{2}$ Siehe unten, 3.1, sowie den Beitrag von Frank Kelleter in diesem Band. 
Der Einwurf aus dem Publikum lässt sich als parodistischer Seitenhieb auf die Tendenz zur sogenannten narrative scholarship lesen. Diese in der Frühphase des Ecocriticism recht weit verbreitete Synthese aus persönlichem Erfahrungsbericht und kritischer Analyse ist mittlerweile auch innerhalb des Feldes umstritten. ${ }^{3}$

Insgesamt ist die Protagonistin sichtlich geplagt von ihrem Fachwissen, welches die Barriere zwischen Mensch und Natur noch undurchdringlicher erscheinen lässt als für den Laien erkennbar. Es wirkt wie eine bittere Pointe, dass eine derart auf die Ökologie ausgerichtete Forscherin nur sehr wenig Freude an der pittoresken Umgebung ihres Hotels empfinden kann. Während die Tagung allseits als voller Erfolg gewertet wird, lässt die perspektivische Ausrichtung auf Snow den Leser an den ökologisch-ethischen Grundwerten der Tagungsteilnehmer zweifeln. ${ }^{4}$ Der Ecocriticism erscheint somit als wissenschaftliche Mode, die kaum gegründet bereits ihren Gegenstand aus den Augen verliert und in Grabenkämpfen zu versinken droht. Die fragmentarische und illusionsstörende Form der nivola trägt ein Übriges zum trüben Gesamtbild bei. Ein Blick in einschlägige Publikationen der letzten Jahre zeigt in der Tat einen sprunghaften Anstieg an selbstkritischen Auseinandersetzungen mit den Praktiken des eigenen Feldes. ${ }^{5}$ So behauptet Dana Phillips, der junge Ecocriticism zeichne sich längst durch eine Vielzahl von „creaky old traditions“ aus, die insgesamt einen modrigen Gestank verströmten (Phillips 2003, S. ix).

Dennoch ist es keinesfalls zu spät, sich ernsthaft mit dem Ecocriticism zu befassen. Seine Entwicklung deutet klar darauf hin - wie ich im Folgenden darstellen möchte -, dass diese junge Theorierichtung zu einem dauerhaft einflussreichen Forschungsfeld geworden ist. Die scharfe interne Kritik mag als Zeichen der Stärke gelesen werden, die nur im Angesicht einer gesicherten Existenz möglich wird. ${ }^{6}$ Das von Joy Williams in Saved beschriebene Frustrationspotenzial bei der Suche nach adäquaten fachlichen wie ethischen Werkzeugen zur Erkundung der erdachten und der empirisch vorhandenen Natur lässt sich ebenfalls eher als produktive Sorge verstehen - eine Sorge, die Ecocritics zu einem fortwährenden Zweifel und einem stets prekären ,,sowohl-als-auch“ führt. So wie die von Harold Bloom (1973) einst beschriebene Einflussangst (,anxiety of influence ${ }^{\text {) }}$ manch

\footnotetext{
${ }^{3}$ Siehe unten, 3.3 .

${ }^{4}$ Diese Kluft zwischen akademischer Beschäftigung mit der Natur und der persönlichen Lebensweise ist ein heftig diskutiertes - und somit äußerst produktives - Grundproblem innerhalb des Feldes. Lawrence Buell beschreibt die Schwierigkeit umweltorientierter Ansätze als ,the modern would-be environmentalist's dilemma of having to come to terms with actual natural environments while participating in the institutions of a technologized culture that insulates one from the natural environment and splits one's allegiances" (Buell 1995, S. 54f.).

${ }^{5}$ Hierzu exemplarisch Phillips (2003) und Cohen (2004).

6 Heise (2006) und Slovic (2010) erscheinen geradezu erleichtert, dass das Forschungsfeld endlich auch selbstkritische Stimmen hervorgebracht hat. Slovic sieht dabei die interne Kritik als wichtigen Bestandteil einer „dritten Welle“ des Ecocriticism. Die Wellen-Metapher zur Beschreibung der Evolution des Ecocriticism wird ebenfalls von Buell (2005) verwendet. Auch Glotfelty (1996, S. xxiixxiv) sprach bereits von mehreren Entwicklungsschritten, welche Sie in Analogie zum dreistufigen Entwicklungsmodell der feministischen Literatur- und Kulturkritik von Elaine Schowalter entwickelte.
} 
Literaten zu imaginativen Höchstleistungen angespornt hat, scheint hier eine starke Gesellschaftsangst die Wissenschaftler zu beflügeln. Ecocritics sehen sich beständig durch institutionelle Zwänge, gesellschaftliche Konventionen und theoretische Barrieren weg von der Natur gezogen.

Wie lässt sich also das relativ neue Forschungsfeld der Tagung von Snow beschreiben? Die Komparatistin Ursula Heise konstatiert, dass der Ecocriticism ähnlich wie die anglo-amerikanischen Cultural Studies - seine Kohäsionskraft eher aus einem gemeinsamen politischen Projekt als aus einem akzeptierten Set von theoretischen oder methodologischen Verfahrensweisen bezieht. Die Praktiken im Feld seien daher in einem fortlaufenden Prozess der Findung und Revision verfangen (Heise 2006, S. 506). ${ }^{7}$ Dementsprechend sind meine Anmerkungen zu den grundlegenden Eigenschaften dieser Forschungsrichtung sowohl als Momentaufnahme als auch als Selektion zu sehen. ${ }^{8}$ Das prozesshafte Werden und Vergehen der naturalen Umwelt, das im Ecocriticism stets betont wird, ist augenscheinlich auch im Feld selbst stark ausgeprägt.

\section{Entstehung und Institutionalisierung des Ecocriticism}

Die Geschichte der Institutionalisierung des Ecocriticism ist bereits vielfach erzählt worden, daher beschränke ich mich an dieser Stelle auf einen kursorischen Überblick. Als ein Meilenstein in der Entstehung des Ecocriticism wird immer wieder das Panel Ecocriticism: The Greening of Literary Studies genannt, das bei der im amerikanischen Kontext zentralen literaturwissenschaftlichen Jahrestagung der Modern Language Association (MLA) im Jahr 1991 abgehalten wurde. In diesen Anfangsjahren tat sich besonders Cheryll Glotfelty hervor, die sowohl bei der Organisation dieses Panels als auch bei der Gründung der Association for the Study of Literature and Environment (ASLE) mitwirkte. ASLE veranstaltet seit 1995 Tagungen im zweijährigen Turnus; sein interdisziplinäres Publikationsorgan ISLE: Interdisciplinary Studies in Literature and Environment erscheint bereits seit 1993. ${ }^{9}$ Seit 2009 wird das Journal durch die prestigeträchtige Oxford Univ. Press vertrieben, was sicherlich ein weiterer Indikator für die wachsende Relevanz und Akzeptanz des Ecocriticism ist.

Glotfelty, eine der ersten Ecocritics mit einer speziell auf Literatur und Umwelt ausgerichteten Professur an der Univ. of Nevada in Reno, zeichnete sich später zusammen mit Harold Fromm auch für den einflussreichen Sammelband The

\footnotetext{
${ }^{7}$ Diese Umschreibung findet sich in ähnlicher Form in den meisten Überblicksdarstellungen. So stellt Goodbody fest, dass „,ecocriticism neither constitutes a single coherent theory of literature or culture nor possesses a special methodology" (2007, S. 6).

8 Weiterführende, aber auch tendenziös argumentierende Überblicke des Forschungsfelds bieten Buell (2005) und Garrard (2004).

${ }^{9}$ Ein Überblicks-Reader über die in ISLE Interdisciplinary Studies in Literature and Environment publizierten Aufsätze ist Branch/Slovic (2003).
} 
Ecocriticism Reader (1996) verantwortlich. Das Buch ist immer noch das wohl meistzitierte Werk zum Thema, gerade da es in seiner Einführung eine griffige Definition des Forschungsfelds liefert:

What then is ecocriticism? Simply put, ecocriticism is the study of the relationship between literature and the physical environment. Just as feminist criticism examines language and literature from a gender-conscious perspective, and Marxist criticism brings an awareness of modes of production and economic class to its readings of texts, ecocriticism takes an earth-centered approach to literary studies. (Glotfelty 1996, S. xix)

In ihrer Analogie zur feministischen und marxistischen Literaturwissenschaft betont Glotfelty besonders den politischen Gehalt des Ecocriticism. Man sollte aber festhalten, dass diese Analogie nicht nur eine deskriptive, sondern auch eine performative Funktion erfüllt. So wie marxistisch und feministisch orientierte Ansätze einen festen Platz in der Forschungslandschaft haben, wird hier der emergente Ecocriticism als eine Disziplin verstanden, die bereits weitgehend gefestigt ist. Die zukünftige Entwicklung sei weniger unter konditionalen als unter temporalen Aspekten zu diskutieren. Glotfelty fragt also nicht, $o b$ sich der Ecocriticism zu einer festen Größe innerhalb der amerikanischen Universitätslandschaft auswachsen wird, sondern lediglich, wann dies erfolgt.

$\mathrm{Zu}$ dieser Verortung des Forschungsfeldes - die im gleichen Maße selbstbeschreibend wie selbstverstärkend wirkt - gesellt sich der Neologismus Ecocriticism. Der Begriff wurde von William Rueckert in seinem Aufsatz Literature and Ecology: An Experiment in Ecocriticism von 1978 geprägt. Rueckert wählt einen gewollt erhabenen Duktus in diesem Essay:

I have taken on the question of how reading, teaching, and writing about literature might function creatively in the biosphere, to the ends of biospheric purgation, redemption from human intrusions, and health. (Rueckert $1978 / 1996$, S. 112)

Obwohl der emphatische, geradezu erlöserische Tonfall der Überzeugungskraft seiner Thesen aus heutiger Sicht eher einen Bärendienst erweist, ist Rueckerts Ansatz, Grundlagen der naturwissenschaftlichen Ökologie auf die Literaturwissenschaft $\mathrm{zu}$ übertragen, durchaus weiter verfolgt worden. Mit ähnlichem Erkenntnisinteresse, wenn auch in grundlegend systematischerer Art und Weise stellt der Amerikanist Hubert Zapf später seine umfangreiche Theorie der Literatur als kultureller Ökologie vor. ${ }^{10}$ Rueckert hingegen hält sich trotz seiner ausgreifenden Rhetorik in Bezug auf eine Definition seines neu postulierten Ansatzes des Ecocriticism sonderbarerweise zurück. Er legt bedeutend mehr Wert auf die Feststellung, dass sein Text ein Experiment sei, und scheint sich damit bereits gegen später vorgetragene Kritik wappnen zu wollen.

${ }^{10} \mathrm{Vgl}$. Zapf (2002). 
Die einigende Kraft des Kurzbegriffs Ecocriticism sorgt bis heute für eine zuweilen trügerische Ordnung im Babel der Denominationen. Unter dem umbrella term Ecocriticism zirkulieren immer noch zahlreiche Vorstellungen von deskriptiver oder ethischer, politischer oder formalistischer Wissenschaftspraxis, die jeweils mit Begriffen wie environmental criticism, literary-environmental studies, literary ecology, literary environmentalism, oder green cultural studies beschrieben werden (Heise 2006, S. 06). ${ }^{11}$ Die deutsche Übersetzung „Ökokritik“ scheint eher unpassend, wie Stefan Hofer bemerkt (2007, S. 34), da dieser Terminus zu enge Assoziationen zur Literaturkritik hervorruft und somit keine direkte Verbindung zur Literaturwissenschaft ausdrückt. Mit Axel Goodbody könnten man dementsprechend von einer „ökologisch orientierten Literaturbetrachtung“" sprechen (1998, S. 11). Zu diesem Zeitpunkt und für den aktuellen Zweck ist es aber sicherlich sinnvoll, auf den englischen Begriff Ecocriticism zu rekurrieren, da er sich in der Forschungslandschaft durchgesetzt hat und seine ordnende Funktion hilfreich erscheint.

Wendet man sich noch einmal der Geschichte des Ecocriticism zu, mag es trotz der oben skizzierten Erfolgsstory verwundern, dass dieser Forschungszweig so spät den Weg an die amerikanischen Universitäten fand. So schreibt Heise:

[W] hat is remarkable about this burst of academic interest is that it took place at such a late date; most of the important social movements of the 1960s and 1970s left their marks on literary criticism long before environmentalism did, even though environmentalism succeeded in establishing a lasting presence in the political sphere. (Heise 2006, S. 505)

Die amerikanische Umweltschutzbewegung hatte seit Beginn des 20. Jahrhunderts eine zentrale öffentliche Rolle eingenommen. Der National Park Service wurde bereits im Jahre 1916, während der sogenannten progressive era, von Präsident Woodrow Wilson gegründet. Eine besondere Blütezeit erlebte diese Bewegung in den 1960er Jahren, als die Sorge um die toxischen Auswirkungen der amerikanischen Massengesellschaft stark anwuchs. Als Kristallisationspunkt gilt hier die wissenschaftlich fundierte Streitschrift Silent Spring von Rachel Carson aus dem Jahr 1962, die den Gebrauch und die verheerenden ökologischen Folgen des Pestizids DDT in massenwirksamer Form darlegt. Ein weiterer kanonischer Text der Umweltbewegung dieser Jahre ist Aldo Leopolds A Sand County Almanac (1949), in dem der Autor eine umfassende Umweltethik mit persönlichen Reflektionen verknüpft. In diesem Kontext scheint es tatsächlich klärungsbedürftig, warum sich die Literaturwissenschaft in diesen Jahren nicht direkt den dringenden Umweltproblemen widmete.

\footnotetext{
11 Lawrence Buell (2005, S. viii) macht aus seiner Abneigung gegen den Begriff Ecocriticism keinen Hehl und nennt einige Kritikpunkte, die ihn das Label environmental criticism bevorzugen lassen. So rufe die Bezeichnung Ecocriticism in manchen Bereichen ein überzeichnetes Bild von verblendeten nature worshippers hervor. Weiterhin lasse sich das Adjektiv environmental besser als das als das Präfix eco- auf Untersuchungen verschiedenartiger Umwelten wie z. B. den urbanen Raum anwenden.
} 
Ursula Heise schlägt eine Erklärung vor, die sich vornehmlich auf die Entwicklung der Literaturtheorie in diesen Jahren stützt (Heise 2006, S. 505f.). So sei es dem Einfluss von frankophoner poststrukturalistischer Sprachphilosophie à la Roland Barthes oder Jacques Derrida zu verdanken, dass die kritische Praxis sich zunehmend darauf verlagerte, Texte und Repräsentationen auf ihre Inkonsistenzen, Brüche und Polyvalenzen hin zu lesen. Unter solchen Voraussetzungen erschien eine Rückkopplung zwischen menschengemachten Diskursen und extratextuellen Gegebenheiten wenig plausibel. Stattdessen sieht Heise die strikte Historisierung und Kulturalisierung des Naturalen als ein zentrales Projekt der poststrukturalistisch ausgerichteten Cultural Studies.

Ein zweiter, vielleicht ebenso wichtiger Grund für die verspätete Institutionalisierung des Ecocriticism ist meiner Ansicht nach im universitären Klima der Vereinigten Staaten der 1970er bis 1990er Jahre zu sehen. In diesen Jahren manifestiert sich die Breitenwirkung der sozialen Reformen, die aus dem Civil Rights Movement hervorgingen. Mit den multikulturellen Emanzipationsbemühungen strömten nun Vertreter vormals marginalisierter ethnischer Gruppen in den öffentlichen Diskurs, die sich vehement gegen die etablierten Praktiken und Kanones der weißen, westlich orientierten Geisteswissenschaften auflehnten. Diese Jahre sahen die Ausbildung ethnisch orientierter Fachbereiche wie African American Studies, Chicanalo Studies, Asian American Studies, oder Native American Studies. Trotz der von Heise beschriebenen poststrukturalistischen Vorstellung, dass die Realität außerhalb des Textes niemals greifbar sein kann, wurde es zur akzeptierten akademischen Praxis, gewisse identitätspolitisch gefärbte Ansichten in die Forschung einzubeziehen. Dies wird in der weitverbreiteten analytischen Trias von class, gender und race deutlich, die die Beschäftigung mit der nicht-humanen Umwelt zunächst ausschließt. Lawrence Buell formuliert hier in einem trefflichen Beispiel, dass es für Ecocritics wesentlich problematischer sei, für die Natur zu sprechen, als für afro-amerikanische Forscher, als Stellvertreter ihres spezifischen ethnischen Hintergrunds aufzutreten (Buell 2005, S. 8). ${ }^{12}$

Einen vorläufigen Höhepunkt der politischen Revisionen der amerikanischen Literatur- und Kulturwissenschaft markiert die mitten in den sog. ,,culture wars“13 erschienene Heath Anthology of American Literature (Lauter 1989), die den literarischen Kanon um die bis dahin ausgelassenen Stimmen der amerikanischen Minderheiten zu ergänzen suchte. Stark überspitzt ließe sich daher sagen, dass die amerikanische Literaturwissenschaft in der zweiten Hälfte des 20. Jahrhunderts zunächst ihr Konzept von Kultur neu ordnen musste, bevor sie sich (wieder) der Natur zuwenden konnte. Aufgrund dieser Verspätung gab es für die Ecocritics der

\footnotetext{
12 Vgl. auch Phillips, der in ähnlicher Weise das Verhältnis von Ecocriticism zu ethnic scholarship thematisiert: „The plain fact is that, unlike women, ethnic minorities, and queers, texts and trees cannot represent themselves, they must be represented" (2003, S. 139).

13 Eine im Zeitkontext besonders einflussreiche Beschreibung dieses angenommenen Grundwertekonflikts zwischen traditionalistischen und progressiven Strömungen war die soziologische Schrift von Hunter (1991).
} 
1990er Jahre schließlich auch die unverhoffte Möglichkeit, einen Forschungszweig innerhalb der Amerikastudien zu entdecken, der sich bis zu diesem Zeitpunkt eher als lose Sammlung von einflussreichen Monografien zur Naturthematik ausnahm. In freundlicher Übernahme wurden Werke wie Henry Nash Smiths Virgin Land (1950), Leo Marx' The Machine and the Garden (1964) oder Roderick Frazier Nashs Wilderness and the American Mind (1967) neu gelesen. David Mazel (2001) sammelte eine veritable Ahnenreihe des Ecocriticism in seiner Anthologie A Century of Early Ecocriticism, die umweltorientierte Werke u. a. von Aldo Leopold, John Burroughs, F.O. Matthiessen und Perry Miller enthält. ${ }^{14}$

Die transatlantische Ausweitung des Ecocriticism ließ nicht lange auf sich warten. Auch in Großbritannien bildete sich in den 1990er Jahren ein Forschungsfeld heraus, das unter dem Schlagwort Green Studies ganz ähnliche Fragen erörterte wie das amerikanische Pendant. Formgebend für dieses Feld war die Publikation The Green Studies Reader von Laurence Coupe (2000), der eine kritische Ergänzung und Erweiterung zum Reader von Glotfelty/Fromm darstellt. ${ }^{15}$ Im Gegensatz zur amerikanischen Fokussierung auf das sogenannte nature writing, ist der dortige Ansatz eng an die Beschäftigung mit der britischen Romantik gebunden. Als Pionierleistung sei hier Jonathan Bates Romantic Ecology: Wordsworth and the Environmental Tradition (1991) genannt, in der der Anglist den Dichter als einen Umweltbewegten avant la lettre beschreibt und den Wert der britischen Romantik nicht nur an ihrer Ästhetik, sondern auch an ihrer intensiven Beschäftigung mit ökologischen Zusammenhängen festmacht. ${ }^{16}$ Die Institutionalisierung in Großbritannien schreitet ebenfalls voran; seit längerem organisiert man sich dort in der ASLE-UK (einem Ableger der amerikanischen Organisation), die entsprechende Fachzeitschrift nennt sich Green Letters. Inzwischen existieren insgesamt neun Schwesterorganisationen der ASLE; besonders in Fernost (z. B. in Indien, Japan, Korea, Taiwan) herrscht ein reges Interesse am Ecocriticism. Kontinentaleuropäische Forscher gründeten 2004 die European Association for the Study of Literature, Culture and the Environment (EASLCE), die in Ermangelung eines nationalen Verbandes zurzeit erster Anlaufpunkt für deutsche Interessenten ist.

\footnotetext{
${ }^{14}$ Eine besondere Rolle in dieser Vorgeschichte kommt dem Humanökologen und Komparatisten Joseph Meeker zu, der in The Comedy of Survival bereits 1974 eine ökologische Poetik entwarf. Er interpretiert die Ausdrucksformen der Tragödie und der Komödie als Aspekte menschlichen Verhaltens und Überlebens innerhalb größerer Umweltzusammenhänge. Anders als in den o.g. amerikanistischen Natur-Studien sind bei Meeker bereits zentrale Komponenten des späteren Forschungsfeldes en miniature vorhanden. Eine ausführlichere Beschäftigung mit dem Meekerschen Ansatz findet sich im Beitrag von Axel Goodbody in diesem Band.

15 Es ist tatsächlich erstaunlich, wie die Entwicklungsschritte des amerikanischen Ecocriticism in Großbritannien wiederholt werden. So findet sich auch bei britischen Überblicksdarstellungen stets der Hinweis auf das weiter zurückreichende literaturwissenschaftliche Interesse an naturalen Räumen. Als ein vielzitiertes Beispiel sei hier Williams (1973) genannt.

16 Auf wesentlich breiterer Basis stellt Jonathan Bate seinen ökologisch-interpretatorischen Ansatz im vielleicht noch wirkmächtigeren Band The Song of the Earth (2000) dar.
} 
Man sollte sich trotz dieses rapiden Bedeutungsgewinns nicht darüber hinwegtäuschen lassen, dass der Ecocriticism immer noch ein eher randständiges Phänomen ist. Mir erscheint es plausibel zu unterstellen - und das ohne bösen Willen -, dass die ostentativ rasch ablaufende Institutionalisierung auch einer gesteigerten Selbstbeobachtungsgabe auf Seiten der Akteure geschuldet ist. Als eine der jüngsten theoretischen Bewegungen sieht sich der Ecocriticism in der besonders vorteilhaften Position, retrospektiv auf die Genese anderer Schulen zurückblicken und aus deren rhetorisch-diskursiven Errungenschaften und Strategien lernen zu können. Somit ließe sich die hohe Anzahl von Überblicksdarstellungen mit der inhärenten Herausbildung eines sekundärtextlichen Kanons nicht nur als informativer, sondern auch als selbstverstärkender Faktor deuten.

\section{Prämissen und Verfahren des Ecocriticism}

Aufgrund der äußerst heterogenen Fragestellungen innerhalb des Ecocriticism ist es nicht leicht, einen Einblick in dessen zentrale Prämissen zu bekommen. Es bietet sich an, auf die sehr basale Einordnung des Ecocriticism in das Spannungsfeld der Literatur- und Kulturtheorie von Peter Barry zurückzugreifen:

Perhaps the most fundamental point to make here is that ecocritics reject the notion $[\ldots]$ that everything is socially and/or linguistically constructed $[\ldots]$. For the ecocritic, nature really exists, out there beyond ourselves, not needing to be ironized as a concept by enclosure within knowing inverted commas, but actually present as an entity which affects us, and which we can affect, perhaps fatally, if we mistreat it. Nature then isn't reducible to a concept which we conceive as part of our cultural practice [...]. Theory in general tends to see our external world as socially and linguistically constructed, as ,always already ${ }^{6}$ textualised into ,discourse'. (Barry 2002, S. 252)

In einem gewissen Sinne versucht der Ecocriticism also, den verbreitet konstruktivistischen Gebrauch der Formulierung always already zu invertieren. Dies verkehrt dann auch die Herangehensweise an literarische Darstellungen. Statt zu postulieren, dass die externe Welt stets dem Primat der Sprache oder der Vertextlichung unterliegt, wird hier angenommen, dass sich die Literatur und ihre Autoren einer bewussten wie unbewussten Beherrschung durch ihre Umwelt niemals erwehren können. Das Literarische wird somit always already green, wie ich es in meinem Titel bereits andeute. ${ }^{17}$ In den folgenden Unterpunkten möchte ich

\footnotetext{
17 Ähnlich auch Glotfelty: „Despite the broad scope of inquiry and disparate levels of sophistication, all ecological criticism shares the fundamental premise that human culture is connected to the physical world, affecting it and affected by it. Ecocriticism takes as its subject the interconnections between nature and culture, specifically the cultural artifacts of language and literature. As a critical stance, it has one foot in literature and the other on land; as a theoretical discourse, it negotiates between the human and the nonhuman." (1996, S. xix) Robert Kern drückt diesen Gedanken in seiner Hypothese aus ,that all texts are at least potentially environmental (and therefore susceptible to
} 
Alexander Starre

basierend auf diesem Grundgedanken einzelne wiederkehrende Muster und analytische Verfahrensweisen des Ecocriticism diskutieren sowie einige aktuelle Entwicklungstendenzen skizzieren.

\subsection{Naturerlebnis und Nature Writing}

Eine rhetorisch sehr interessante Auswirkung der fundamentalen Prämisse always already green sind die naturbezogenen Proto-Erweckungserlebnisse, die oft zur narrativen Selbstinszenierung eines Ecocritics gehören. Dana Phillips (2003, S. 5) hat dieses Ritual umfassend beschrieben. In seiner Literaturgeschichte des nature writing schreibt beispielsweise Frank Stewart (1995):

On a morning several summers ago, as I glanced up from researching the postmodern poets and critics, through the narrow window above my head I saw that the brightening dawn had made my reading lamp unnecessary. A pale mist hung like a veil over the deep meadow outside, and the violet morning colors were tinting the ends of the long grasses. (zit. nach Phillips 2003, S. 4)

Diese Beobachtung mündet in die Epiphanie, dass Geisteswissenschaftler die Natur konsequent aussperren, während sie sich in geschlossenen Räumen in Bücher vertiefen. ${ }^{18}$ Auch Lawrence Buell beschreibt in seinem meistzitierten Hauptwerk The Environmental Imagination einen bedeutungsschwangeren Blick aus dem Fenster:

$[\mathrm{T}]$ he grove of second-growth white pines that sway at this moment of writing, with their blue-yellow-green five-needle clusters above spiky circles of atrophied lower limbs, along a brown needle-strewn ridge of shale forty feet from my computer screen - this grove can be found in the pages of American literature also, but it is not the woods imagined by American criticism. (Buell 1995, S. 10).

Die amerikanische Literatur, die laut Buell ebenjene aus seinem Arbeitszimmer sichtbaren Kiefern enthält, darf nicht verwechselt werden mit dem kanonischen Querschnitt, den wir aus gängigen Anthologien kennen. ${ }^{19}$

ecocriticism or ecologically informed reading) in the sense that all texts are literally or imaginatively situated in a place, and in the sense that their authors, consciously or not, inscribe within them a certain relation to their place" (Kern 2003, S. 259).

18 Phillips zitiert ähnliche Passagen aus den Werken von Patrick Murphy (2000) und SueEllen Campbell (1996/1989). Für Campbell liegt die Lösung der universitären Abschottung gegen die freie Natur in einem gleichgewichteten Pensum von Lektüre und Wandern in den Rocky Mountains. Phillips resümiert, dass dieser Typus von Epiphanie-Beschreibungen ein Struktur- und Gattungsmerkmal von Texten des Ecocriticism sei: „,[M] uch that calls itself ecocriticism may strike outsiders as having more in common with the personal essay than with literary and cultural criticism as currently practiced in the academy, and for the good reason that escape from academic constraints is one of ecocriticism's central themes" (Phillips 2003, S. 4).

19 Buell kritisiert ausdrücklich, dass nature writing noch nicht in die wichtigen Anthologien Eingang gefunden hat. Dieses Genre wird innerhalb des Ecocriticism verstanden als ,literary nonfiction that offers scientific scrutiny of the world (as in the older tradition of literary natural history), explores the private experience of the individual human observer of the world or reflects upon the political and 
Stattdessen entwirft Buell den neuen Begriff des environmental writing, eine weitergefasste Variante des nature writing. Die Verfasstheit eines „environmental text" kann laut Buell auf der Basis von vier wertenden Kriterien erschlossen werden. ${ }^{20}$

1.) Die nicht-menschliche Umwelt ist nicht nur als Rabmung vorhanden, sondern betont die Abhängigkeit der Menschheitsgeschichte von der Umweltgeschichte. Auf dieser Achse lässt sich das Verhältnis zwischen Handlungsort und handelnden Figuren bewerten.

2.) Das menschliche Interesse wird nicht als das einzig legitime Interesse verstanden. Hier sind besonders emphatische Zuwendung zu nicht-menschlichen Lebewesen bzw. Wertvorstellungen, die die Erzählperspektive übersteigen, von Interesse.

3.) Die menschliche Verantwortung für die Umwelt ist Teil der ethischen Orientierung des Textes. Diese Kategorie zielt auf ein Reflexionsniveau, das besonders auch menschliche Fehler im Umgang mit der Natur berücksichtigt.

4.) Ein Verständnis der Umwelt als Prozess anstatt als Konstante oder Gegebenheit wird im Text zumindest impliziert. Statische Beschreibungen von Panoramen sowie Momentaufnahmen einzelner Settings sind hiernach weniger umweltgetreu als Texte, die das Werden und Vergehen von naturalen Räumen verfolgen und ein vielseitiges Bild der Mensch-Natur-Interaktionen zeichnen.

In Anbetracht dieser vier Grundpfeiler - Buell selbst nennt sie bescheiden eine „rough checklist“" (Buell 1995, S. 7) - verwundert es kaum, dass auf fast jeder Ebene fiktionale Texte von nicht-fiktionalen im Grade ihrer Umweltbezogenheit überflügelt werden. Als letztgültigen Maßstab der Analyse legt Buell die Idee des „Ökozentrismus“ an, einen bio-ethischen Grundgedanken der amerikanischen Umweltbewegung.

Die ideale Erfüllung aller dieser Wegmarken findet Buell in den Werken des neuenglischen Transzendentalisten Henry David Thoreau, besonders in dessen Walden (1854). Diese Wahl verwundert wenig, ist Buell als Experte der amerikanischen Romantik doch bestens ausgewiesen in diesem Bereich. Der Autor arbeitet anhand von Walden exemplarisch den Prozess der Diskursivierung von Naturerlebnissen heraus, wie er aus Thoreaus umfangreichen Tagebüchern und den daraus destillierten Essays sichtbar wird. Der später oft vorgebrachte Vorwurf, Buell arbeite mit seinem Buch eher im Bereich der Hagiografie, lässt sich allerdings bei genauer Lektüre kaum halten. Er benutzt zwar den Begriff „environmental saint“, um Thoreau zu beschreiben, dies geschieht jedoch vollständig im Angesicht der Tatsache, dass Walden längst zum meist-kanonisierten Werk der amerikanischen Literatur des 19. Jahrhunderts geworden ist. Die Bezeichnung „Heiliger“ ist bei Buell weniger dazu gedacht, Thoreau weiter zu huldigen, als dem Umstand Rechnung zu tragen, dass Walden Pond nahe Concord, Massachusetts heute zu einer Art Mekka der

philosophical implications of the relationships among human beings and the larger planet" (Slovic zit. nach Buell 2005, S. 144).

${ }^{20}$ Vgl. Buell (1995), S. 7f. 
Umweltbewegung geworden ist und die Rekonstruktion von Thoreaus Hütte vielen Pilgern als Schrein dient. ${ }^{21}$

Für Buells interpretatorische Praxis ist die Unterscheidung zwischen fiktionalem und nicht-fiktionalem Schreiben erkenntnisleitend. So sieht er besonders nichtfiktionales Schreiben einer doppelten Verantwortung („dual accountability“) unterworfen. Environmental writing ist Buell zufolge sowohl textlichen als auch faktischen Umständen gegenüber verpflichtet. Eine zentrale Rolle im Ecocriticism à la Buell spielen dann auch close readings von Passagen, in denen der enge referentielle Bezug von Zeichen zu Dingen offenbar wird. ${ }^{22}$ Mit einer solch textsemiotisch geradezu naiv anmutenden Grundhaltung öffnet er seinen späteren Kritikern erwartungsgemäß Tür und Tor. Dana Phillips etwa belächelt sein Insistieren auf den Grundwerten der Mimesis: „I think it is obvious that trees can never be, as Buell insists they are, in literature, and least of all in a novel, however much they may be ,in“ it figuratively.“ (2003, S. 9) An dieser Stelle entbrannte im Ecocriticism zum ersten Mal eine wahre Kontroverse. ${ }^{23}$ Buell widersprach Phillips in seinem späteren Band The Future of Environmental Criticism und verteidigte sein Beharren auf dem Konzept der Mimesis:

Yet it is equally clear that the subject of a text's representation of its environmental ground matters - matters aesthetically, conceptually, ideologically. Language never replicates extratextual landscapes but it can be bent toward or away from them. (2005, S. 33)

Es ist leicht sich in dieser Kontroverse hinter Phillips einzureihen und die vielen Ungereimtheiten in Buells interpretatorischer Praxis als Grund zur Abkehr zu sehen. Schließlich ist aber doch die Produktivität seines revisionistischen Programms erstaunlich, denn immerhin gelingt ihm eine fundamentale Re-Interpretation des Naturerlebnisses als formgebenden Moment sowohl für Thoreau als auch für eine große Anzahl weiterer amerikanischer nature writers, wie Wendell Berry, John Muir, Leslie Silko und Mary Austin. ${ }^{24}$

\footnotetext{
21 Auch in Deutschland ist der Einfluss von Thoreaus Walden gegenwärtig, wie man im Jahr 2002 in Berlin unweit des Potsdamer Platzes beobachten konnte. Hier errichtete der Künstler Tobias Hauser eine Nachbildung ebenjener Hütte, was im örtlichen Kontext des aufstrebenden Berlin-Mitte eine ganz eigene Bedeutungskraft entfaltete. Vgl. Funken (2002).

22 Buell wendet seinen zunächst am nature writing erprobten Ansatz später vermehrt auch an kanonischen Texten der amerikanischen Literatur an. Vgl. Buell (2001).

${ }^{23}$ Vgl. auch Heise (2006), S. 54-56. Eine weitere auf Buells Ansatz bezogene Debatte begann der bereits oben erwähnte Leo Marx, indem er die ökozentrische Denkweise als doktrinären Puritanismus geißelte. Marx sieht in Thoreaus Walden stattdessen eine pastorale Ausdrucksform, die Natur lediglich in ihrer Wirkung auf das menschliche Subjekt darstellt und ihr somit keinen eigenen Wert zugesteht (Marx 1999). Hier erwehrt sich ein angeblicher Pionier des Ecocriticism offensichtlich der Vereinnahmung durch die neuere Forschung.

${ }^{24}$ Einen umfangreichen Kanon des amerikanischen nature writing seit Thoreau schlägt McKibbens Anthologie American Earth (2008) vor. Weitere einflussreiche Anthologien sind Elder/Finch (1990), mit ausschließlich amerikanischen Autoren, und Murphy (1998), der sich an der herkulischen Aufgabe einer globalen Sammlung von naturbezogenen Schriften versucht.
} 


\subsection{Dialog mit den Naturwissenschaften}

Eine weitere Auswirkung der grundsätzlichen Einsicht in die Verknüpfung von Umwelt und Text innerhalb des Ecocriticism ist der oft geforderte Dialog mit den Naturwissenschaften. Einige Vertreter, wie z. B. Glen Love oder Joseph Carroll setzen sich vehement dafür ein, naturwissenschaftliche Erkenntnisse zur Basis literaturwissenschaftlicher Untersuchungen zu machen. Mit dem Ansatz, fiktionale Texte als evolutionärbiologische Notwendigkeiten zu beleuchten, stehen sie allerdings eher an einem extremen Pol. Im Mainstream der Bewegung verankert ist dagegen der Rekurs auf die Ökologie, die aufgrund ihrer holistischen Ausrichtung einen besonderen Platz in der Umweltbewegung fand. ${ }^{25}$ Schon in Rueckerts Aufsatz werden vermeintlich gesicherte ökologische Prinzipien referiert und metaphorisch auf die Poesie angewendet. Rueckert importiert wenig scharf konturierte Begriffe wie Biosphäre, Ökosystem oder Population aus Grundlagenwerken der amerikanischen Ökologie ${ }^{26}$ und legt als übergreifende Prämisse den Sinnspruch „Everything is connected to everything else“ (1978/1996, S. 112) an. Auch Cheryll Glotfelty nutzt in ihrer Einführung eine ähnliche Begründung für das eco in Ecocriticism: „Eco- [...] implies interdependent communities, integrated systems, and strong connections among constituent parts“ (1996, S. xx). Wie sehr sich die Ökologie jedoch bereits in den 1990er Jahren von Konzepten der Harmonie und des Gleichgewichts verabschiedet hat, lässt sich gut an Daniel Botkins provokanter Schrift Discordant Harmonies (1990) ablesen, nach der sich der Leitgedanke einer harmonischen Natur im Angesicht von unvorhersehbaren naturalen Prozessen und offensichtlichen Ungleichgewichten kaum halten lässt. An dieser Stelle sind Umwelthistoriker und Ecocritics einem ähnlichen Dilemma ausgesetzt, da eine gewisse Vorstellung von Ökologie auch vielen naturhistorischen Untersuchungen zugrundeliegt. Besonders wenn gefragt wird, wie menschliche Interventionen die natürliche Ausgeglichenheit eines bestimmten Ökosystems negativ beeinflussen, schwingt stets ein besonderes Verständnis von Ökologie mit. ${ }^{27}$ Solchen Analysen hält der Skeptiker Philipps entgegen: „,We want ecology to simplify things for us, and that is something it really cannot do." (2003, S. 46) Dennoch bleibt festzuhalten, dass die Rezeption ökologischer Erkenntnisse im

\footnotetext{
25 Vgl. Heise (2006): „Ecology, for many environmentalists a countermodel against normal analytical science, has opened the way for a holistic understanding of how natural systems work as vast interconnected webs that, if left to themselves, tend toward stability, harmony, and self-regeneration". Eine kritische Diskussion der Verbindungslinie zwischen Ecocriticism und Ökologie findet sich bei Hofer (2007), besonders S. 55-81.

${ }^{26}$ Vor allem aus dem Band Ecology von Eugene Odum (1963).

27 Vgl. Richard White: „Environmental historians once thought that they had a firm basis for their morality and causality. Historians read the science of ecology as both detailing basic natural processes and yielding certain moral verities: complexity is good, simplicity is bad; natural systems seek equilibrium and battle disruption; there is an ideal balance in nature that, once achieved, will maintain itself. Those verities gave historians standards against which to measure and evaluate the repercussions of human action" (1990, S. 49). Der Umwelthistoriker aus Stanford hält weiterhin fest, dass sich manches naturwissenschaftlich hergeleitete ökologische Prinzip ironischerweise gerade auf Basis historischer Studien als falsifizierbar erweist.
} 
Ecocriticism dazu beigetragen hat, die simplifizierende Dichotomie von Natur/ Kultur zu hinterfragen und den Blick eher auf Interdependenzen und gegenseitige Abhängigkeiten zu lenken. Weiterhin weist die Ökologie dem menschlichen Subjekt nur mehr eine Nebenrolle in größeren systemischen Zusammenhängen zu, was im Angesicht globaler Umweltkrisen eine ernüchternde, aber notwendige Sichtweise sein kann.

Generell lässt sich die Beziehung des Ecocriticism zu den Naturwissenschaften als prekär aber offen bezeichnen. Ein oft rezipierter ${ }^{28}$ Ansatz stammt von der Chemikerin und Literaturwissenschaftlerin N. Katherine Hayles, die auf der Schnittstelle zwischen den beiden Wissenschaftskulturen eine Praxis des constrained constructivism etablieren möchte. Hayles postuliert, dass jede objektivistische Einsicht der Naturwissenschaften der Wahrnehmung von Subjekten untergeordnet ist und somit konstruktivistisch hinterfragt werden kann. Demgegenüber sind aber auch konstruktivistische Lesarten nicht ohne Einschränkungen zu haben, und genau diese Einschränkungen sieht Hayles in der äußeren Realität:

Constrained constructivism points to the interplay between representation and constraints. Neither cut free from reality nor existing independent of human perception, the world as constrained constructivism sees it is the result of complex and active engagements between the unmediated flux and human beings. (Hayles 1995, S. 53f.)

Obwohl der „unmediated flux“, wie Hayles die äußere Realität nennt, niemals direkt greifbar sein wird, lenkt dessen Präsenz jeglichen menschlichen Beobachter, und somit auch den Wissenschaftler, in seinen Schlüssen.

\subsection{Soziales Engagement und Naturnähe}

Als einen letzten Aspekt neben der Beschäftigung mit nature writing und dem Dialog mit ökologischen Konzepten möchte ich auf die aktivistische Ausrichtung der amerikanischen Vertreter des Ecocriticism aufmerksam machen. Bereits in den grundlegenden Definitionen wird meist der Hinweis gegeben, dass gesellschaftliches Engagement neben der Forschung ein konstitutiver Bestandteil des Feldes ist. So schreibt Buell von einem ,spirit of commitment to environmentalist praxis“" (1995, S. 430, Anm. 20) und Cohen sieht den Antrieb zum Handeln in der „perceived disjunction between business as usual in the Univ. and the environmental crisis“ (2004, S. 37). ${ }^{29}$ Die Begründung solch aktivistischer Tendenzen wird denn

\footnotetext{
${ }^{28}$ Beispielsweise bei Buell (2005, S. 110f.); Heise (2006, S. 512); Hofer (2007, S. 95-97).

${ }^{29}$ Vgl. auch William Howarths (1995) eminent politische Definition eines Ecocritics: ,a person who judges the merits and faults of writings that depict the effects of culture upon nature, with a view toward celebrating nature, berating its despoilers, and reversing their harm through political action" (S. 69). Hieraus wird ersichtlich, mit welcher Unschuld in dieser frühen Phase mit später heftig umkämpften Konzepten und Termini umgegangen wurde.
} 
auch häufig in polemischer Abgrenzung von urbanen Lebensweisen formuliert. Für Buell ist die Metropole die Grundwurzel des Übels der Ausblendung von Naturthemen in der Literaturwissenschaft:

These are characteristic results of a metropolitan-based enterprise of academic criticism for which it easily becomes second nature to read literature about nature for its structural or ideological properties rather than for its experiential or referential aspects. (1995, S. 36)

Gegen solch eine Philosophie inszenieren sich Ecocritics nicht selten als besonders naturnah. Der geforderte Aktivismus wird dann vornehmlich auf zwei Arten realisiert. Erstens wird ganz im Sinne des Thoreauschen Projekts der Selbstverbesserung die Führung eines verantwortungsbewussten und naturnahen Lebens im Schreiben reflektiert. Das Genre der narrative scholarship ist hierfür das geeignete Vehikel. Um einen kurzen Einblick in diesen idiosynkratischen Schreibstil zu gewähren, zitiere ich eine Passage aus einem aktuellen Band von Scott Slovic, einem der einflussreichsten Ecocritics:

[1] seems to me that ecocritics are particularly given to this sort of [bodily] activity, and that our actual work is enhanced and deepened by getting outside and testing our strength and frailty against the physical features of the landscape. [...] I recall, for instance, several days of hectic meetings at Boston Univ. during ASLE's fifth biennial conference in 2003, followed by a climb of Mount Monadnock in New Hampshire with more than a dozen colleagues on the last day of the academic meeting, intellectuals continuing their conversations while huffing up the trail in a chilly June rain. (Slovic 2008, S. 18)

Diese Selbstinszenierung eines activist intellectual ist in der deutschen Wissenschaftspraxis weniger wahrscheinlich. Dennoch ist dieser Aspekt des Ecocriticism in seiner amerikanischen Ausformung so bedeutsam, dass nicht schamhaft über ihn hinweggegangen werden sollte.

Der zweite bedeutende Weg, auf dem soziales Engagement gezielt eingesetzt wird, ist die umweltorientierte Didaktik. In diesen Bereich gibt die kürzlich veröffentlichte Sammlung Teaching North American Environmental Literature (Christensen et al. 2008) einen Einblick. Ein Großteil der darin vorgestellten Unterrichtsentwürfe zielt darauf $\mathrm{ab}$, literarische Texte nicht nur im Kursraum zu erkunden, sondern gezielt durch Exkursionen zu ergänzen. Die zentrale Rolle, die die Hochschuldidaktik in den Vereinigten Staaten auch und besonders zur Etablierung junger Forschungsrichtungen spielt, wird hier augenscheinlich. Zahlreiche Ecocritics wie beispielsweise John Elder (1999) setzen sich für die Entwicklung einer strategischen Pädagogik ein, die gezielt auf folgende Generationen als mögliche Multiplikatoren einwirken soll. Die Literatur ist für den Ecocriticism demnach selten nur Forschungsgegenstand, sondern oft auch zielführendes Werkzeug. 
Alexander Starre

\subsection{Aktuelle Entwicklungen}

Abschließend seien noch einige aktuelle Entwicklungen des Ecocriticism referiert, die die gegenwärtigen Debatten bestimmen. Seit seiner Gründung ist der Ecocriticism in einem Prozess der Erweiterung und Expansion begriffen. Typische Publikationen, die eine solche Erweiterung einfordern, sind Beyond Nature Writing: Exploring the Boundaries of Ecocriticism (Armbruster u. Wallace 2001) oder Farther Afield in the Study of Nature-Oriented Literature (Murphy 2000). Es steht zu vermuten, dass weiterhin eine Fülle von Ausweitungsrufen erschallen wird. Die anfangs dominante Fokussierung auf Naturbilder und Wildnisdarstellungen in nicht-fiktionalen Texten wird zunehmend aufgeweicht. Stattdessen wird die Kategorie „Umwelt“ verstärkt auf urbane Räume angewandt (Bennett u. Teague 1999, Brandt et al. 2010). Damit einher geht die theoretische Hinterfragung des Naturbegriffs, so dass sich der Ecocriticism vermehrt vom simplifizierenden Natur/KulturSchema entfernt. ${ }^{30}$ Ebenso wird die etablierte Fragestellung nach Räumlichkeit erweitert um ein größeres Interesse für das Tierische, was bereits zur Ausformung sogenannter animal studies führte (Wolfe 2009).

Der Ecofeminism hatte sich bereits in der Anfangsphase des Ecocriticism als eigenständiges Interessengebiet herauskristallisiert. Besonders einflussreich waren die Studien von Kolodny (1975) und Westling (1996) mit ihrer Einsicht, dass die diskursive Gleichsetzung des domicilium vacuum des amerikanischen Kontinents mit dem Femininen - wie im metaphorischen virgin land - zu einem besonders problematischen, aber auch besonders engen Verhältnis zwischen den Kategorien Weiblichkeit und Natur geführt hat. Dieser Bereich profitiert bis heute von der Schnittstelle der feministischen Theorie mit dem Ecocriticism, so dass hier ein umfangreiches Instrumentarium zur gesellschaftskritischen Analyse von hierarchischen Dualismen erarbeitet wurde. ${ }^{31}$

Aufgrund der zunehmenden Internationalisierung wird vermehrt eine komparatistische Perspektive auf die Umweltorientierung verschiedener nationaler Literaturen gefordert (Murphy 2000). Ebenfalls heftig diskutiert wird gegenwärtig das Verhältnis zwischen der grundsätzlich eher lokalen Ausrichtung des Ecocriticism und der globalen Umweltproblematik. Sowohl Lawrence Buell als auch Ursula Heise versuchen in neueren Veröffentlichungen, die etablierten Prämissen des place attachment und des bioregionalism

\footnotetext{
30 Vgl. hierzu Phillips (2003), insbes. S. 3-41. Interessant ist in diesem Zusammenhang auch Lawrence Buells Abkehr von seinem zunächst rein naturbezogenen Erkenntnisinteresse: „I found myself agreeing with those who thought the concentration on ,environment ${ }^{\text {a }}$ as ,nature ${ }^{\text {s }}$ and on nature writing as the most representative environmental genre were too restrictive, and that a mature environmental aesthetics - or ethics, or politics - must take into account the interpenetration of metropolis and outback, of anthropocentric as well as biocentric concerns." (2005, S. 22f.) Buell sieht diese generelle Entwicklung als ein Beispiel für Neuorientierungen, die er lose zu einer ,second wave" des Ecocriticism gruppiert. Für weitere Anmerkungen zur Unterscheidung Natur/Kultur siehe auch den Aufsatz von Bernd Herrmann in diesem Band.

${ }^{31}$ Für eine Zusammenschau ökofeministischer Perspektiven siehe Plumwood (1993) sowie GreweVolpp (2004), S. 43-80 und passim.
} 
mit einer globalen Perspektive zu verbinden. Bei Buell heißt die neue Form einer transnational funktionalen Sensibilität „ecoglobalist affect“ (Buell 2007). Er analysiert unter diesem Schlagwort die Verbindung von individuellen, lokalen Naturerlebnissen mit einer Einsicht in globale Umweltzusammenhänge. Mit ähnlichem Gestus re-interpretiert Heise (2008) das negativ besetzte Konzept der Deterritorialisierung und bringt dieses Phänomen als Bestandteil eines neu zu denkenden eco-cosmopolitanism in Anschlag.

Auch in Deutschland gibt es mittlerweile einige Studien, die sich explizit im Kontext des Ecocriticism verorten. Hier haben sich besonders Zapf (2002), Grewe-Volpp (2004) und Hofer (2007) um eine kritische Aufarbeitung und Weiterentwicklung der anglo-amerikanischen Ansätze bemüht. Ein erster deutscher Sammelband liegt mit Gersdorf/Mayer (2005) vor. Die weitergehende Rezeption des Ecocriticism in der Germanistik steht zurzeit noch aus; die deutschen Beiträge situieren sich überwiegend im Forschungsgebiet der Amerikanistik oder Anglistik und versuchen, den Anschluss an den wissenschaftlichen Diskurs ihrer jeweiligen Zielländer herzustellen.

\section{Ausblick: Ecocriticism und Umweltgeschichte}

Wie lassen sich nun Ecocriticism und Umweltgeschichte zusammendenken? Zunächst einmal sind zahlreiche Gemeinsamkeiten zwischen den jeweiligen Akteuren zu erkennen. So hält Michael Cohen in Environmental History, dem einflussreichsten Periodikum der amerikanischen Umwelthistoriker fest:

Environmental historians and ecocritics [...] share common roots. Many writers who later would call themselves environmental historians or ecocritics began by reading a few books after World War II that opened both of these traditions of inquiry. (Cohen 2004, S. 9)

Cohen spricht von den bereits erwähnten Werken der Autoren Perry Miller, Henry Nash Smith oder Leo Marx, die nicht nur grundlegend für die Ausformung der Nordamerikastudien waren, sondern auch Umwelthistorikern wie John Opie als Inspiration dienten.

Als ein Beispiel richtungsweisender umwelthistorischer Forschung sei William Cronons Studie Changes in the Land (1983/2003) genannt, in der der Autor den ökologischen Transformationen Neuenglands in der Kolonialzeit nachgeht. Der besondere Vorzug von Cronons Methode ist, dass er seinen Textkorpus (frühe Reiseberichte, Naturbeschreibungen und Dokumente aus Stadtarchiven) rigoros mit naturwissenschaftlich erhobenen Daten abgleicht. So bezieht seine Studie Analysen von Jahresringen, von sedimentierten Pollen in Bohrkernen, sowie von archäologischen Ausgrabungen mit ein. Bei Cronon entsteht auf Basis dieser Quellen ein nuanciertes Bild kolonialer Natur- und Kulturräume. Für Ecocritics enthält Cronons Buch einen Fundus an kontextuellen Informationen, der beispiels- 
weise für Interpretationen der Wildnis-Metaphern in frühen amerikanischen Texten wie Predigten oder captivity narratives herangezogen werden kann. ${ }^{32}$ Die Umweltgeschichte könnte somit ein Faktor werden, der dem Ecocriticism über seine oft einseitige zeitgenössische Textauswahl hinweghilft. Michael Branch hat wiederholt darauf hingewiesen, dass prä-romantische Texte aufgrund ihrer divergenten Wertemuster kein Tabu für den Ecocriticism sein dürfen. ${ }^{33}$

Da Werkimmanenz längst kein exklusives interpretatorisches Gütekriterium mehr ist, kann eine kulturwissenschaftlich orientierte Literaturwissenschaft von der Erweiterung des Kontextbegriffs auf nicht-menschliche Zusammenhänge nur profitieren. Es darf nun sicherlich nicht darum gehen, literarische Umweltdarstellungen auf ihre Akkuratesse im Bezug auf „wahre“ ökologisch-historische Konstellationen zu testen. Stattdessen sollten ureigene literaturwissenschaftliche Zugänge beispielsweise zur Symbolik und Metaphorik von Naturbildern oder zur narratologischen Analyse von fiktionalen Raumdarstellungen mit umweltbezogenen Kontexten zusammengedacht werden. Insgesamt könnte daraus ein Projekt entstehen, dass nicht nur die Dekonstruktion von gesellschaftlichen Ideologien und Mythen über die Natur anstrebt, sondern die Rekonstruktion der Interaktionsprozesse zwischen Subjekt und Umwelt, die solche Repräsentationen erst ermöglichen. Greg Garrard beschreibt die Herausforderung des Ecocriticism als „to keep one eye on the ways in which ,nature' is always in some ways culturally constructed and the other on the fact that nature really exists" (Garrard 2004, S. 10). Selbst wenn die Literaturwissenschaft weiterhin besser mit dem ersten Auge sieht und die Umweltgeschichte mit dem letzteren, so sollte aus der Zusammenschau beider Perspektiven am Ende dennoch ein schärferes Bild unserer Beziehungen zur nicht-menschlichen Umwelt sowohl in ihrer Historizität als auch in ihrer Textualität entstehen.

\footnotetext{
32 Siehe hierzu ausführlicher Starre (2010).

${ }^{33}$ Siehe z. B. Branch (2001).
} 


\section{Literatur}

Armbruster, Karla; Wallace, Kathleen R. (2001) Hgg.: Beyond Nature Writing. Exploring the Boundaries of Ecocriticism. Charlottesville: Univ. of Virginia Press.

Barry, Peter (2002): Beginning Theory. 2nd ed. Manchester: Manchester Univ. Press.

Bate, Jonathan (1991): Romantic Ecology. Wordsworth and the Environmental Tradition. London: Routledge.

Bate, Jonathan (2000): The Song of the Earth. London: Picador.

Bennett, Michael; Teague, David W. (1999) Hgg.: The Nature of Cities.

Ecocriticism and Urban Environments. Tucson: Univ. of Arizona Press.

Bloom, Harold (1973): The Anxiety of Influence. A Theory of Poetry. New York: Oxford Univ. Press.

Botkin, Daniel B. (1990): Discordant Harmonies. A New Ecology for the TwentyFirst Century. New York: Oxford Univ. Press.

Branch, Michael P. (2001): Before Nature Writing. Discourses of Colonial American Natural History. In: Armbruster, Karla; Wallace, Kathleen R. (Hgg.): Beyond Nature Writing. Exploring the Boundaries of Ecocriticism. Charlottesville: Univ. of Virginia Press, S. 91-107.

Branch, Michael P.; Slovic, Scott (2003) Hgg.: The ISLE Reader. Ecocriticism 1993-2003. Athens: Univ. of Georgia Press.

Brandt, Stefan L.; Fluck, Winfried; Mehring, Frank (2010) Hgg.: Transcultural Spaces. Challenges of Urbanity, Ecology, and the Environment. Tübingen: Narr (= Yearbook of Research in English and American Literature; 26).

Buell, Lawrence (1995): The Environmental Imagination. Thoreau, Nature Writing, and the Formation of American Culture. Cambridge: Harvard Univ. Press.

Buell, Lawrence (2001): Writing for an Endangered World. Literature, Culture, and Environment in the U.S. and Beyond. Cambridge: Harvard Univ. Press.

Buell, Lawrence (2005): The Future of Environmental Criticism. Malden: Blackwell.

Buell, Lawrence (2007): Ecoglobalist Affects. The Emergence of U.S. Environmental Imagination on a Planetary Scale. In: Dimock, Wai Chee; Buell, Lawrence (Hgg.): Shades of the Planet. American Literature as World Literature. Princeton: Princeton Univ. Press, S. 227-248.

Campbell, Sue Ellen (1996): The Land and Language of Desire; Where Deep Ecology and Post-Structuralism Meet (1989). In: Glotfelty, Cheryl; Fromm, Harold (Hgg.): The Ecocriticism Reader. Landmarks in Literary Ecology. Athens: Univ. of Georgia Press, S. 124-136. 
Carson, Rachel (1962): Silent Spring. Boston: Houghton.

Christensen, Laird; Long, Mark C.; Waage, Fred (2008) Hgg.: Teaching North American Environmental Literature. New York: Modern Language Association of America.

Cohen, Michael P. (2004): Blues in the Green. Ecocriticism under Critique. In: Environmental History 9, S. 9-36.

Coupe, Laurence (2000) Hrsg.: The Green Studies Reader. From Romanticism to Ecocriticism. London: Routledge.

Cronon, William (2003): Changes in the Land. Indians, Colonists, and the Ecology of New England (1983). Revised ed. New York: Hill-Farrar.

Elder, John (1999): The Poetry of Experience. In: New Literary History 30 (3), S. 649-659.

Finch, Robert; Elder, John (1990) Hgg.: The Norton Book of Nature Writing. New York: Norton.

Funken, Peter (2002): Tobias Hauser, „Walden“. Rezension. In: Kunstforum International 162, S. 288.

Garrard, Greg (2004): Ecocriticism. London: Routledge.

Gersdorf, Catrin; Mayer, Sylvia (2005) Hgg.: Natur, Kultur, Text. Beiträge zu

Ökologie und Literaturwissenschaft. Heidelberg: Winter.

Glotfelty, Cheryl (1996): Introduction. In: Glotfelty, Cheryl; Fromm, Harold

(Hgg.): The Ecocriticism Reader. Landmarks in Literary Ecology. Athens:

Univ. of Georgia Press, S. xv-xxxvii

Glotfelty, Cheryl; Fromm, Harold (1996) Hgg.: The Ecocriticism Reader.

Landmarks in Literary Ecology. Athens: Univ. of Georgia Press.

Goodbody, Axel (1998): Literatur und Ökologie. Zur Einführung. In: Goodbody, Axel (Hrsg.): Literatur und Ökologie. Amsterdam: Rodopi, S. 11-40.

Goodbody, Axel (2007): Nature, Technology, and Cultural Change in Twentieth-

Century German Literature. The Challenge of Ecocriticism. Basingstoke:

Palgrave Macmillan.

Grewe-Volpp, Christa (2004): „Natural spaces mapped by human minds“.

Ökokritische und ökofeministische Analysen zeitgenössischer amerikanischer

Romane. Tübingen: Narr.

Hayles, N. Katherine (1995): Searching for Common Ground. In: Soulé, Michael

E.; Lease, Gary (Hgg.): Reinventing Nature. Responses to Postmodern

Reconstruction. Washington D.C.: Island Press, S. 47-63. 
Heise, Ursula K. (2006): The Hitchhiker's Guide to Ecocriticism. In: PMLA 121 (2), S. 503-516.

Heise, Ursula K. (2008): Sense of Place and Sense of Planet. The Environmental Imagination of the Global. New York: Oxford Univ. Press.

Hofer, Stefan (2007): Die Ökologie der Literatur. Eine systemtheoretische Annäherung, mit einer Studie zu Werken Peter Handkes. Bielefeld: Transcript.

Howarth, William (1996): Some Principles of Ecocriticism. In: Glotfelty, Cheryl; Fromm, Harold (Hgg.): The Ecocriticism Reader. Landmarks in Literary Ecology. Athens: Univ. of Georgia Press, S. 69-91.

Hunter, James Davison (1991): Culture Wars. The Struggle to Define America. New York: Basic.

Kern, Robert (2003): Ecocriticism. What is It Good For? In: Branch, Michael P.; Slovic Scott (2003) Hgg.: The ISLE Reader. Ecocriticism 1993-2003. Athens: Univ. of Georgia Press, S. 258-281.

Kolodny, Annette (1975): The Lay of the Land. Metaphor as History and Experience in American Life and Letters. Chapel Hill: Univ. of North Carolina Press.

Lauter, Paul (1989) Hrsg.: The Heath Anthology of American Literature. Lexington, MA: Heath.

Leopold, Aldo (1987): A Sand County Almanac and Sketches Here and There (1949). New York: Oxford Univ. Press.

Marx, Leo (1964): The Machine in the Garden. Technology and the Pastoral Ideal in America. New York: Oxford Univ. Press.

Marx, Leo (1999): The Struggle Over Thoreau. In: New York Review of Books 46 (11), S. 60-64.

Mazel, David (2001) Hrsg.: A Century of Early Ecocriticism. Athens: Univ. of Georgia Press.

McKibben, Bill (2008) Hrsg.: American Earth. Environmental Writing Since Thoreau. New York: Library of America.

Meeker, Joseph W. (1974): The Comedy of Survival. Studies in Literary Ecology. New York: Scribner.

Murphy, Patrick D. (2000): Farther Afield in the Study of Nature-Oriented Literature. Charlottesville: Univ. of Virginia Press.

Murphy, Patrick D. (1998) Hrsg.: Literature of Nature. An International Sourcebook. Chicago: Fitzroy Dearborn. 
Nash, Roderick Frazier (2001): Wilderness and the American Mind (1967). New Haven: Yale-Nota Bene (4th ed.).

Odum, Eugene (1963): Ecology. New York: Holt.

Philipps, Dana (2003): The Truth of Ecology: Nature, Culture, and Literature in America. Oxford: Oxford Univ. Press.

Plumwood, Val (1993): Feminism and the Mastery of Nature. London: Routledge.

Rueckert, William (1996): Literature and Ecology. An Experiment in Ecocriticism (1978). In: Glotfelty, Cheryl; Fromm, Harold (Hgg.): The Ecocriticism Reader. Landmarks in Literary Ecology. Athens: Univ. of Georgia Press, S. 105-111.

Slovic, Scott (2008): Going Away to Think. Engagement, Retreat, and Ecocritical Responsibility. Reno: Univ. of Nevada Press.

Slovic, Scott (2010): The Third Wave of Ecocriticism. North American Reflections on the Current Phase of the Discipline. In: Ecozon@1.1, S. 4-10.

Smith, Henry Nash (1950): Virgin Land. The American West as Symbol and Myth. Cambridge: Harvard Univ. Press.

Starre, Alexander (2010): Wilderness Woes. Negotiating Discourse and Environment in Early American Captivity Narratives. In: Brandt, Stefan L.; Fluck, Winfried; Mehring, Frank (Hgg.): Transcultural Spaces. Challenges of Urbanity, Ecology, and the Environment. Tübingen: Narr, S. 273-293.

Stewart, Frank (1995): A Natural History of Nature Writing. Washington: Island Press.

Thoreau, Henry David (1893): Walden, or: Life in the Woods (1854). Boston: Houghton Mifflin.

Unamuno, Miguel de (1967): Niebla. Nivola (1914). Madrid: Taurus.

Westling, Louise H. (1996): The Green Breast of the New World. Landscape, Gender, and American Fiction. Athens: Univ. of Georgia Press.

White, Richard (1990) Environmental History, Ecology, and Meaning. In: The Journal of American History 76 (4), S. 1111-1116.

Williams, Joy (2009): Saved. In: McSweeney's 31, S. 63-72.

Williams, Raymond (1973): The Country and the City. London: Chatto \& Windus.

Wolfe, Cary (2009): Human All Too Human. „Animal Studies“ and the Humanities. In: Publications of the Modern Language Association of America. 124 (2), S. 564-675.

Zapf, Hubert (2002): Literatur als kulturelle Ökologie. Zur kulturellen Funktion imaginativer Texte an Beispielen des amerikanischen Romans. Tübingen: Niemeyer. 


\title{
Blumenkinder
}

\section{Kinder- und Jugendliteratur ökokritisch betrachtet}

\author{
Julia Hoffmann
}

\section{1 Ökokritik und Kinderbuch}

Die Interaktion des Kindes mit der Natur und der Umwelt ist seit den Anfängen der Kinder- und Jugendliteratur eines ihrer zentralen Themen. Kinderbücher offenbaren die Ansichten Erwachsener darüber, wie Kinder ihre Umwelt erleben und vermitteln damit bestimmte Kindheits- und Umweltbilder. Zudem zeigen Kinder- und Jugendbücher den jungen Lesern, wie sie Natur erleben und mit ihr umgehen können. Somit ist der Einfluss von Kinderliteratur auf unseren Bezug zur Natur und unser Verständnis von Natur immens. Es bietet sich daher an, Kinderund Jugendliteratur ökokritisch zu untersuchen, Natur und Umwelt zu einer analytischen Kategorie zu machen. Die Möglichkeiten ökokritischen Arbeitens sind äußerst vielfältig. Grundsätzlich sollte es jedoch darum gehen, den ontologischen Status der Natur (der Umwelt und der Erde) in einem Text herauszuarbeiten und kritisch zu analysieren. Ökokritiker bemühen sich ferner, den konstruierten Charakter von Natur deutlich zu machen. ${ }^{1}$ Mögliche Fragestellungen wären beispielsweise:

${ }^{1}$ Vgl. Coupe (2000), S. 2; Glotfelty/Fromm (1996). 
- Wie wird Natur repräsentiert?

(im Text und im Vergleich zur außertextuellen Wirklichkeit)

- Wie wird Natur bewertet (ästhetisch und moralisch)?

- Welche Wirkung hat die Naturdarstellung auf den Leser?

- Wie wird Natur symbolisch aufgeladen (Garten Eden, Apokalypse etc.)?

- Steht die Symbolhaftigkeit der Natur in einer längeren literarischen Tradition oder wendet sie sich beispielsweise direkt gegen eine solche Tradition?

- Welches Verhältnis besteht zwischen Natur und Mensch bzw. Natur und Kultur?

- Welches Verhältnis besteht zwischen Kind und Natur?

- Auf welche Art und Weise soll Natur Kindern näher gebracht werden?

- Fungiert die Natur als Ordnungssystem?

- Wie wird Kritik an der Naturzerstörung geübt?

Im Folgenden kann ich nicht auf jeden dieser Aspekte erschöpfend eingehen. Es geht mir vielmehr darum zu zeigen, dass ein ökokritischer Ansatz im Bereich der Kinder- und Jugendliteratur auf fruchtbaren Boden fallen kann. Die deutschsprachige Kinder- und Jugendliteraturforschung hat bislang kaum ökokritisch gearbeitet. Dennoch gibt es einige Publikationen, die sich vor allem mit Umweltpädagogik und offensichtlich ökokritischer bzw. ökologischer Kinder- und Jugendliteratur beschäftigen, ${ }^{2}$ zu der beispielsweise Alle Jahre wieder saust der Presslufthammer nieder oder die Veränderung der Landschaft (1973/2007) von Jörg Müller, Die Wolke (1987/1997) von Gudrun Pausewang oder Hilfe! Ein Monster! (1986) von Ali Mitgutsch und Dirk-Holger Teichmann (vgl. Abb. 1) zählen. Solche Publikationen sind Die angekündigte Katastrophe oder: KJL und Umweltschutz (Knobloch 2009), der von Ulrich Nassen (1995) herausgegebene Sammelband Naturkind, Landkind, Stadtkind. Literarische Bilderwelten kindlicher Umwelt oder die Veröffentlichungen von Dagmar Lindenpütz (1999, 2000 und 2002). Lindenpütz hat eine Systematik für ökologische Kinder- und Jugendliteratur entwickelt, in der sie zwischen Texten zur ökologischen Aufklärung, Texten zur ethischen Fundierung umweltschonenden Verhaltens und radikal skeptischen Texten, die das Scheitern der bisherigen Lösungsversuche bereits kritisch mitreflektieren, unterscheidet (Lindenpütz 2000).

Es fehlen jedoch weitgehend ökokritische Analysen von Kinderliteratur, die nicht zu der von Lindenpütz benannten ökologischen Kinder- und Jugendliteratur zählen. Ähnlich wie dies unter anderem in den feminist studies in Bezug auf gender bereits geschehen ist, könnte man literarische Texte ökokritisch lesen, indem man die Natur in den Mittelpunkt der Analyse rückt und den Umgang mit ihr kritisch reflektiert.

\footnotetext{
2 Die sogenannte ökologische Kinder- und Jugendliteratur ist laut Lindenpütz (1999, 2000 und 2002) seit den 1970er Jahren als Genre innerhalb der Kinder- und Jugendliteratur hervorgetreten.
} 


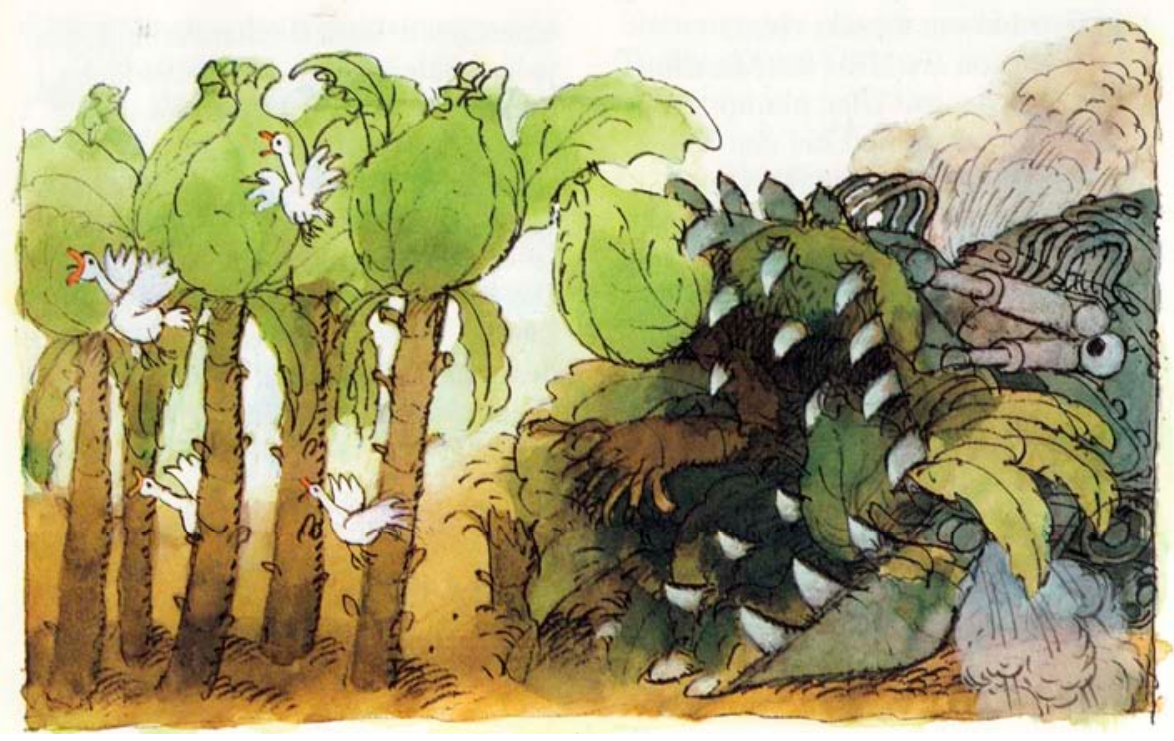

Abb. 1: Ali Mitgutsch/Dirk-Holger Teichmann (1986): Hilfe! Ein Monster! Illustration: Ali Mitgutsch

Ferner wurde die Kinder- und Jugendliteratur, die vor der zweiten Hälfte des 20. Jahrhunderts geschrieben wurde, in Hinblick auf ökokritische und ökopädagogische Potentiale überwiegend außer Acht gelassen. Daher möchte ich hier versuchen, vor allem diese frühere Kinder- und Jugendliteratur aus ökokritischer Perspektive zu betrachten.

Bezüglich der Kinder- und Jugendliteratur scheint es mir hinsichtlich dieser Thematik sinnvoll und ergiebig, die Verbindungen von Kind und Natur, Kinderliteratur und Umwelt in Augenschein zu nehmen, da das „,natürliche Kind“ eines der hartnäckigsten Kindheitsbilder überhaupt ist. Kinder werden häufig als naturnah beschrieben und, wie Dieter Richter (1987) in Das fremde Kind ausführt, sogar mit Natur gleichgesetzt. Es gibt die Vorstellung, dass Kindheit Natürlichkeit bedeutet, was mit der Auffassung einher geht, dass Kinder noch nicht von der Zivilisation verdorben seien und einen stärkeren Zugang zur Natur hätten. Besonders in der Zeit der Romantik und des Biedermeier wurden Natur und Kindheit idyllisiert und sentimentalisiert, und diese Bilder wirken teilweise bis in die heutige Zeit hinein, wie die Werke von Ida Bohatta-Morpungo (Abb. 2) oder auch die aktuellen Darstellungen von Prinzessin Lillifee zeigen. 


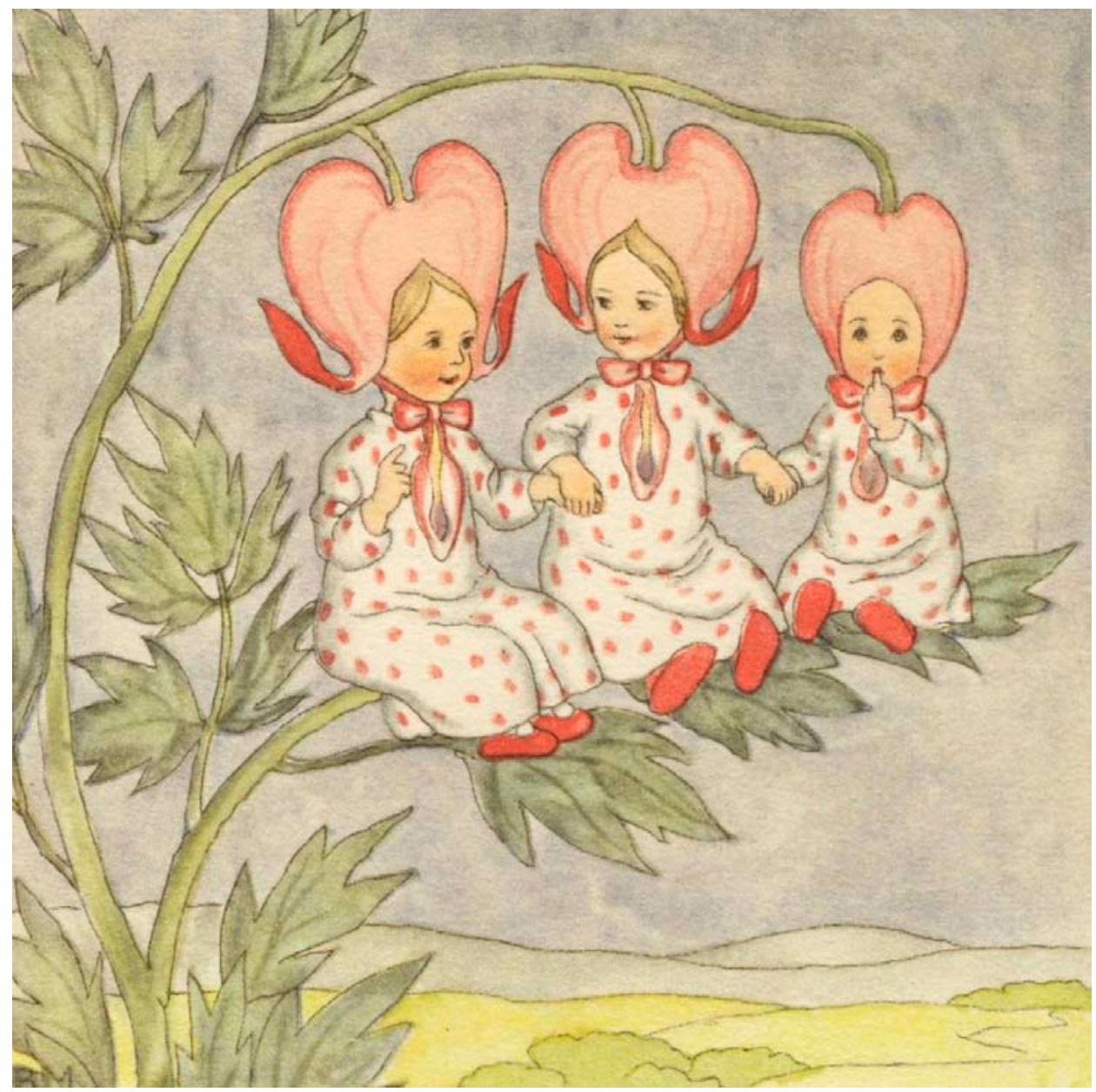

Abb. 2: Ida Bohatta-Morpungo (1935): Mein Gärtlein. Illustration: Ida Bohatta-Morpungo

\section{Blumenkinder und Kindergärten}

Wie Parallelkonstruktionen von Kind und Natur in der Kinderliteratur aussehen können, möchte ich nun anhand der traditionsreichen Verbindung von Blumen und Kindern verfolgen. Ich habe hier mit Blumen ein bewusst drastisches Beispiel gewählt, um zu zeigen, dass es problematisch ist, für etwas oder jemanden zu sprechen, der selbst keine Stimme hat.

Auch in der ,Erwachsenen'- bzw. ,Allgemein'-Literatur ist solch ein Bündnis zu finden - so beschreibt, um ein Beispiel zu geben, Novalis in Heinrich von Ofterdingen (1800) Blumen als „die Ebenbilder der Kinder“. Diese „Blumenkinder“ sind laut Wangerin „seit der Romantik zu einem wiederkehrenden Topos 
geworden, vor allem in den Massenproduktionen der Gründerzeit, aber auch im künstlerischen Bilderbuch" (Wangerin 1992, S. 18). Die beiden Bilderbücher Blumen-Märchen (1898/2000) oder Gartentraum (1911/1976) von Ernst Kreidolf (vgl. Abb. 3) bzw. die seiner Nachfolger, wie etwa Blumen-Kinder (ca. 1923) von Erica von Karger, sind dafür ein gutes Beispiel.

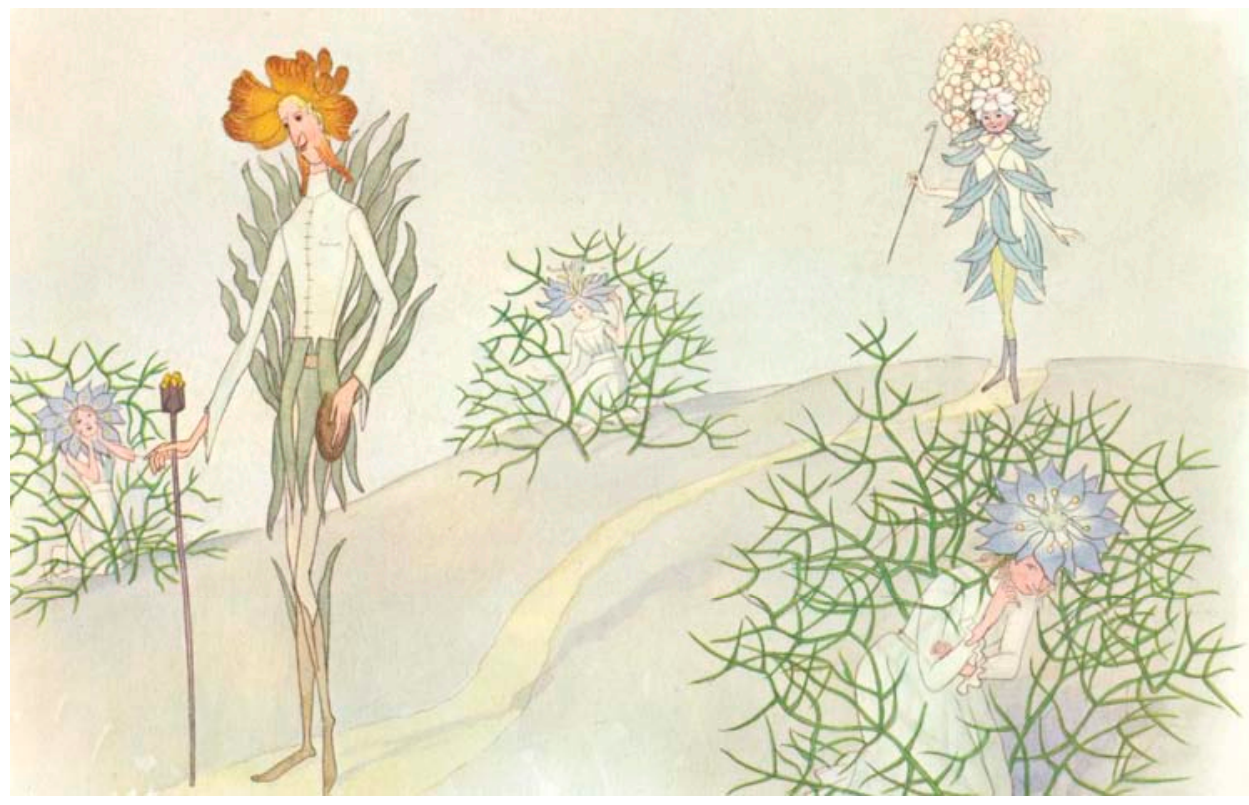

Abb. 3: Ernst Kreidolf (1911/1976):

Der Traumgarten. Märchen von Blumen und Sommervögeln.

Illustration: Ernst Kreidolf

Im Folgenden möchte ich versuchen, die Funktionen, die den Blumen in diesen Kinderbüchern zukommen, herauszustellen. Bei meinem Gang durch den Garten der Kinderliteratur werde ich drei Genres besondere Aufmerksamkeit widmen: der Mädchenliteratur, dem Bilderbuch und dem Märchen, da hier Blumen am häufigsten eine tragende Rolle spielen. Ich möchte aber auch darauf hinweisen, dass die Verbindung von Natur und Kind wie auch die spezifische Verknüpfung von Blumen und Kindern in allen kinderliterarischen Genres - angefangen bei den ABC-Büchern - zu finden ist.

Die starke Verbindung von Pflanzen, insbesondere von Blumen und Kindern wird besonders augenfällig, wenn man bedenkt, dass von Blumen und Kindern häufig im selben sprachlichen Kontext die Rede ist; beispielsweise spricht man im Zusammenhang von Kindern und Blumen häufig vom ,Wachsen und Gedeihen'. Bezeichnend ist auch der Begriff ,Kindergarten', der in viele andere Sprachen als Germanismus eingegangen ist. Dieser Begriff zeigt bereits, dass Kinder ähnlich wie Pflanzen von erwachsenen Menschen aufgezogen und beschnitten werden sollen. 
Das Heranwachsen des Kindes soll unter Aufsicht und Einflussnahme von Erwachsenen geschehen. Das Kind soll wachsen, aber eben nicht in jedwede Richtung, nicht wie ein struppiger Hagebuttenstrauch am Waldesrand, sondern wie eine gepflegte Rose im heimischen Garten.

Somit wird nicht die Natur an sich als positiv und erstrebenswert herausgestellt, sondern „eine in spezifischer Weise gestutzte Natur: die edle, gepflegte Natur" (Richter 1987, S. 259). Um Kinder in Reih und Glied wachsen und gedeihen zu lassen, werden Analogien zur Pflanzenwelt hergestellt, wobei Gartenpflanzen häufig wohlerzogene Kinder versinnbildlichen. Mädchen werden vielfach mit Blumen, Jungen seltener mit Bäumen oder Früchten in einen semantischen Kontext gesetzt, was bereits durch einschlägige Buchtitel wie Mädchengarten, Eine Festgabe für deutsche Töchter (1910) von Ottilie Pichler, Blüthenjabre, Novellen für die reifere Jugend (1856) von Julie Hirschmann, Der Knaben Lustwald (1821-22/1884a) von Heinrich Dittmar oder Blumen und Früchte, Erzäblungen für Mädchen von 6-9 Jabren (1890) von Frida Schanz erkennbar wird. ${ }^{3}$

In diesen Texten fungieren Blumen wiederholt als erzieherische Anschauungsobjekte bzw. „Erziehungskulisse“ (Ulrich 1995) und ihnen werden bestimmte menschliche Eigenschaften zugeschrieben. Dies gilt in besonderem Maße hinsichtlich der Mädchenliteratur.

\section{3 „Es ist sehr natürlich, die blühende Rose und das unschuldige Mädchen miteinander zu vergleichen“"}

Insbesondere in der Mädchenliteratur des Biedermeier und der Romantik sind Blumen und Gärten zentrale Motive und werden häufig als Illustrationsbehelfe zur Vermittlung moralischer Werte benutzt. Blumen gelten als typisch weibliches Attribut und so haben Mädchen oft Blumennamen wie z. B. Iris, Flora, Daisy, Erika, Lily oder Dalia. Umgekehrt werden auch Blumen häufig nach Mädchen oder Frauen benannt. ${ }^{4}$ Zudem repräsentieren sie vielfach den Kreislauf des Lebens und, wie Susanne Barth (1997) ausführt, Blumen und Blumennamen dienen auch zur Strukturierung von Texten.

Erwähnenswert ist außerdem, dass viele Texte, insbesondere Märchen, von Metamorphosen eines Mädchens in eine Blume handeln, wie z. B. Ludwig Bechsteins Die Rosenkönigin (1847), Clemens von Brentanos Das Märchen von dem Myrtenfräulein (1846) oder Die Nelke (1843) der Brüder Grimm. Auch hier

\footnotetext{
3 In der englischsprachigen Kinder- und Jugendliteratur gibt es außerdem die Tradition verwunschener bzw. verzauberter Gärten. Zu diesen zählen Klassiker wie Edith Nesbits The wonderful Garden (1959), Frances Hodgson Burnetts The Secret Garden (1911) und Philippa Pearces Tom's Midnight Garden (1958).

${ }_{4}^{4}$ Viele Rosen wurden auch nach prominenten Frauen und weiblichen Figuren der Literatur benannt, wie z. B. Antigone, Schneewittchen, Cleopatra, Elizabeth Taylor, Florence Nightingale, Irene von Dänemark, Lady Di und Maria Callas.
} 
geht es also um Verwandlungen bzw. Umwandlungen, was auch ein Hinweis darauf ist, dass es in kinderliterarischen Texten, in denen Blumen eine zentrale Rolle spielen, oft im Kern um Kindesentwicklung geht.

In dem Gedicht Das Mädchen und die Blumen (1830) von G. C. W. Gläser erfüllen sie eine ähnliche Funktion. Hier kann sich ein Mädchen nicht entscheiden, welche Blume es auswählen soll, woraufhin sich ihm verschiedene Blumen anpreisen. Jede Blume verkörpert ein bestimmtes Lebensstadium und so repräsentiert beispielsweise die Lilie die Kindheit:

Wähle mich; mit reinem Kleide

Schmückte mich der Mutter Hand;

Unschuld wurde mein Geschmeide,

Und - so bin ich dir verwandt. (Gläser 1830, S. 1)

Dem Mädchen wird also für jeden Lebensabschnitt eine Blume an die Hand gegeben, die die Schönheit dieses Lebensalters personifiziert. Gleichzeitig wird auch hier darauf hingewiesen, welchen Tugenden in einem Lebensabschnitt besondere Bedeutung zugemessen wird. Beispielsweise ist in der Kindheit die herausragende Tugend die Unschuld. ${ }^{5}$

In Heinrich Dittmars Gedichtsammlung mit dem bezeichnenden Titel Der Mägdlein Lustgarten (1822-23/1984b) findet man das Gedicht Die drei Blümelein von Ernst Moritz Arndt, in dem von drei Tugendblumen die Rede ist: der Bescheidenheit, der Demut und der Unschuld. Diese werden als Mädchenideal propagiert und so soll das angesprochene „Mägdlein“ diese Tugenden wie teure Blumen hegen und pflegen: „Denn wer sie wahret, wird nimmer alt, er trägt die himmlische Wohlgestalt." (ebd., S. 93) Bezeichnend ist hierbei, dass für sittliche Tugenden geworben und als Lohn die Schönheit versprochen wird.

Die den Blumen zugesprochenen Eigenschaften sollen Ideale der potentiell lesenden Mädchen sein. Die Lesende soll sich an den „Tugendblumen“ ein Beispiel nehmen, wobei es vornehmlich Tugenden wie Unschuld und Bescheidenheit sind, die in der frühen Mädchenliteratur vermittelt werden sollen, wie auch die Illustration aus Im wilden Garten, Eine Jungmädchengeschichte (1928) von Berta Wegner-Zell zeigt (Abb. 4). Es wird suggeriert, dass die Blumen ihre Schönheit als Lohn für ihre Tugendhaftigkeit erhalten haben und dass aus musterhaften Mädchen attraktive Frauen würden. Die Blumen sind für den Menschen schön anzusehen, doch ihr Dasein in der Literatur bleibt meist auf diesen Zweck beschränkt. Die Parallelisierung von Mädchen und Blumen reduziert beide gleichsam auf ihre Schutzbedürftigkeit und gezähmte Schönheit. Beide Gruppen sollen gewissermaßen kultiviert und ansehnlich sein und es wird ihnen unterstellt, dass sie genau danach strebten.

\footnotetext{
${ }^{5}$ Der Ausdruck ,in der Blüte seines Lebens stehen' weist darauf hin, dass solch eine symbolische Verwendung von Blumen gängig ist.
} 


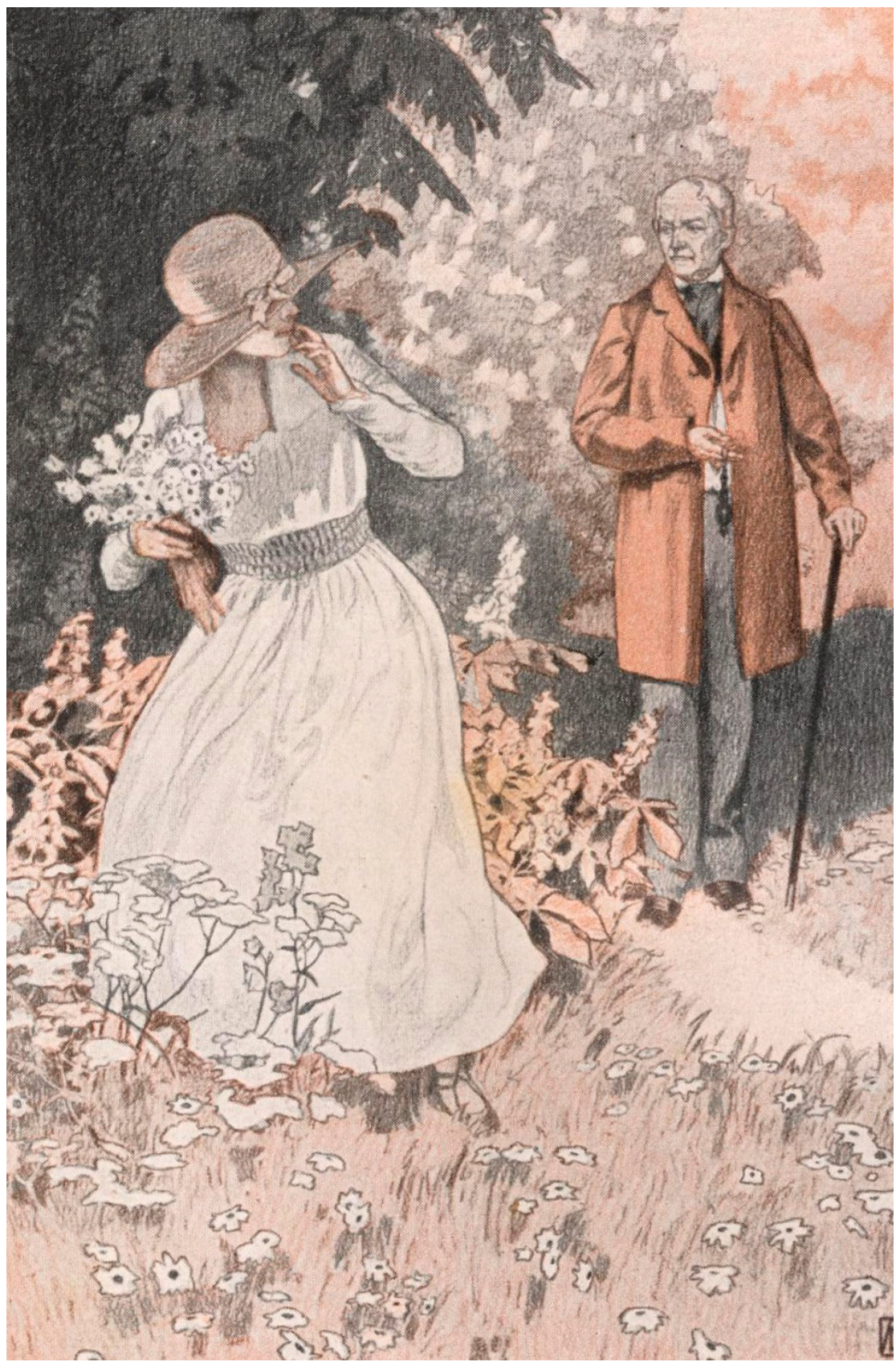

Abb. 4: Berta Wegner-Zell (1928): Im wilden Garten. Eine Jungmädchengeschichte. Illustration: Mila von Luttich 


\section{4 „Die Blumen, Dolmetscher der zartesten Empfindungen“}

Blumen werden mit bestimmten Gefühlsregungen und Eigenschaften assoziiert und so ist es beispielsweise allgemein bekannt, dass rote Rosen für die Liebe stehen. Es gibt daher auch die Konvention mit Blumen seine Gefühle auszudrücken, die sogenannte ,Blumensprache‘. Charlotte de Latour schreibt in ihrem kleinen Lexikon der Blumensprache beispielsweise: die Blumen seien die

[...] Dolmetscher der zartesten Empfindungen, leihen selbst der Liebe Reize, jener reinen und keuschen Liebe, die Plato eine göttliche Eingebung nennt. Der Ausdruck einer so zarten Leidenschaft muß daher auch zartsinnig seyn, und deshalb hat man die sinnreiche Blumensprache erfunden. Sie schmiegt sich, besser als die Schrift, allen Täuschungen eines zartfühlenden Herzens und einer lebhaften und feurigen Einbildungskraft an. (Latour 1820, S. VIIf.)

Die Blumensymbolik bzw. Blumensprache hat also hauptsächlich in der Liebe eine große Bedeutung. Nonverbal kann man durch die Blumen einen anderen Menschen wissen lassen, was man für ihn fühlt. Dies spielt auch in der Mädchenliteratur eine Rolle, da man hier häufig von Sexualität und Liebe sprichwörtlich ,durch die Blume' bzw. ,verblümt' redet. In den frühen pädagogik-dominierten Mädchenbüchern soll mithilfe von Blumen vor den Schmerzen der Liebe und den Gefahren des Geschlechtsverkehrs gewarnt werden, ohne dass dies explizit thematisiert wird. So heißt es etwa im Vermaechtniss an Helene von ibrem Vater (1794) von G.F. Niemeyer:

Die schöne Rose, die in der Stille unter dem Schutze eines sorgsamen Gärtners erzogen wurde, kann zerstört werden, wenn sie in Stürme versetzt wird, die sie in der Knospenzeit nicht kannte, ihre Blätter können zerrissen werden von dem vorüber gehenden Muthwilligen, wenn der Gärtner sie nicht mehr bewacht, alle Dornen, womit die Natur sie ausgerüstet hat, um ihre Blüthen zu verteidigen, können zerstört werden - Sollte es nicht eben so mit einem blühenden Mädchen seyn? Wahrlich! Es ist sehr natürlich, die blühende Rose und das unschuldige Mädchen miteinander zu vergleichen. (Niemeyer 1794, S. 3)

Der Gärtner wird hier also mit dem Vater gleichgesetzt und unter seiner Aufsicht und Mühe soll die Tochter zur Schönheit heranreifen, ohne vorher zerstört zu werden. Seine Daseinsberechtigung erhält der Vater-Gärtner dadurch, dass Blumen und Mädchen als fragil und schutzbedürftig dargestellt werden. Als Schutzbedürftige brauchen sie einen Beschützer. Der Gärtner und Vater ist der Zivilisator, unter dessen ,Schutz' Blumen und Mädchen nach seinem Willen geformt werden. Es ist jedoch fraglich, ob die Rose es vorzieht, im Garten beschnitten zu werden, statt ein Gepflücktwerden in der Natur zu riskieren; genauso wie zu fragen bleibt, ob das junge Mädchen vor dem ,vorüber gehenden Muthwilligen“ geschützt werden möchte. Das Oppositionspaar Vater = Gärtner versus Mädchen = Blume hat folglich den Zweck, die Machtposition der ersten 
Gruppe herauszustellen. Die Blume ist dabei eine Projektionsfläche, mit Hilfe derer die Abhängigkeit der Tochter vom Vater beschönigend untermauert werden soll.

Der Vergleich weiblicher Schönheit mit der Schönheit von Blumen ist also ein sehr beständiger. In den meisten Texten werden den Blumen dabei menschliche Eigenschaften zugesprochen und sie werden aus menschlicher Perspektive heraus beschrieben, nicht so jedoch in Lewis Carrolls Through the Looking-Glass (1871/2003), dem zweiten Teil von Alice in Wonderland.

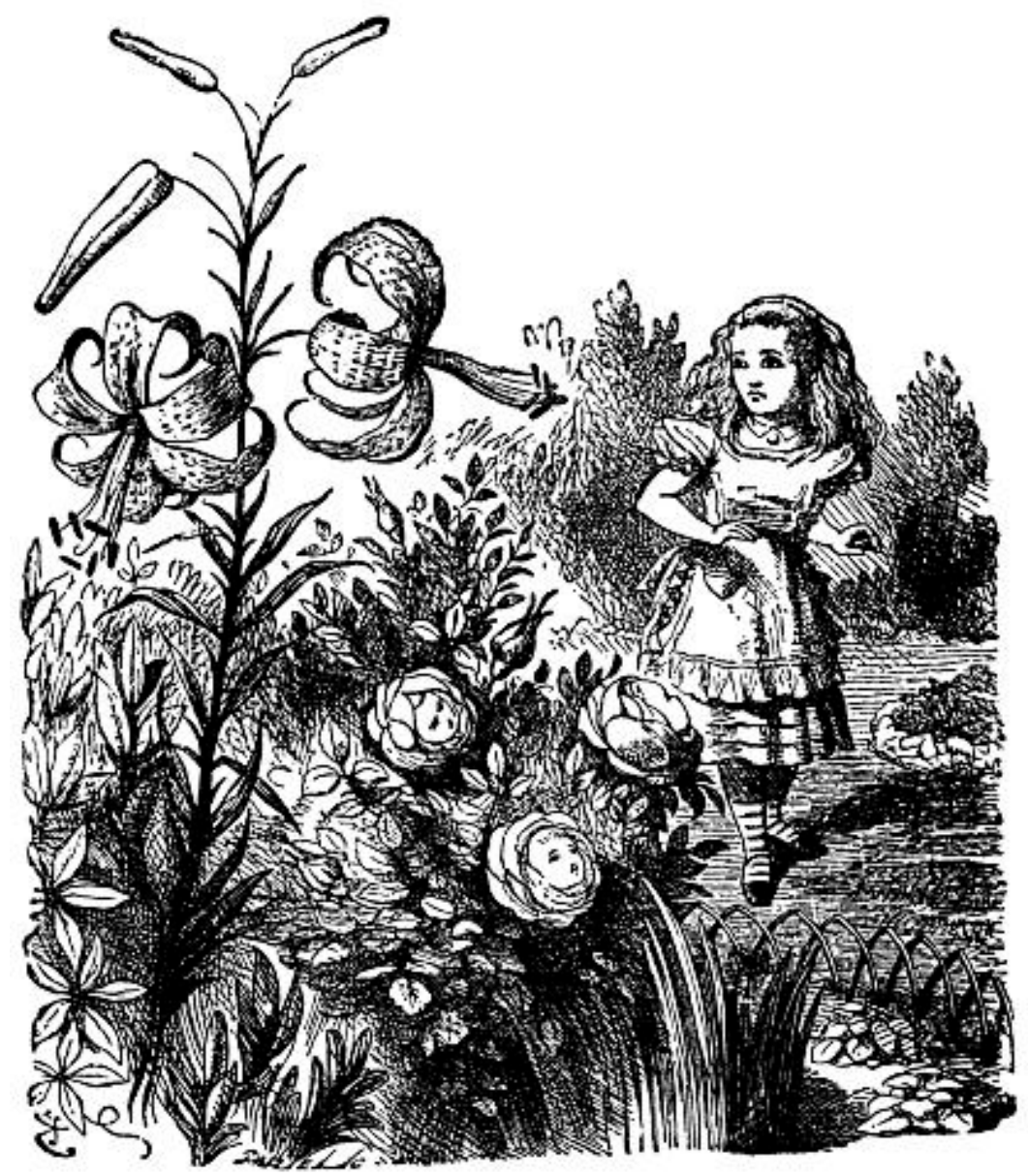

Abb. 5: Lewis Carroll (1871/2003): Through the Looking-Glass.

Illustration: John Tenniel 


\section{5 „There's one other flower in the garden that can move about like you ${ }^{66}$}

Wie auch im übrigen Text von Through the Looking-Glass wird im Kapitel The Garden of live flowers mit Konventionen der Kinder- und Jugendliteratur gespielt und den pädagogisch dominierten Kinderbüchern ein Text gegenübergestellt, der die Phantasie des Kindes in den Mittelpunkt rückt. Alice, die sich im Garten des Spiegelhauses verlaufen hat, trifft auf einige sprechende Blumen (Abb. 5). Doch diese Pflanzen werden nicht aus menschlicher Perspektive geschildert, sondern beschreiben umgekehrt Alice aus ihrer eigenen Sicht heraus, wenn etwa die Lilie spricht: „I don't care about the colour, the Tigerlily remarked. ,If only her petals curled up a little more, she'd be all right."“ (Carroll 1871/2003, S. 139).

Es wirkt obskur, dass die Lilie das Schönheitsideal ihrer Spezies zum Vorbild nimmt und es auf den Menschen überträgt, womit implizit kritisiert wird, dass Menschen Blumen nach ihren Schönheitsmaßstäben bewerten. Auch dieser Text handelt also von der Schönheit der Blumen, doch hier geht die Schönheit nicht mit Tugendhaftigkeit, sondern mit Arroganz einher. Die Lilie und auch die Rose sind nicht lieblich, zurückhaltend rein und unschuldig, sondern ganz im Gegenteil vorlaut, anmaßend und furchtlos. So erklärt wenig später letztere: „There's one other flower in the garden that can move about like you [...] but she's more bushy than you are." (Ebd., S. 140)

Die für den Menschen gewöhnliche Eigenschaft laufen zu können, wird hier als Besonderheit dargestellt und so wird auch deutlich, dass die Pflanze von sich selbst als dem Normalen ausgeht und Alice bzw. die Menschen als das Andere bezeichnet. Durch die Perspektive der Pflanzen wirkt der Mensch seltsam verfremdet und wird somit ,geothert'. Die Blumen zeigen sich überheblich und charakterisieren Alice als dumm, weil sie ihre Perspektive nicht teilt. Sie haben kein Interesse daran, sich mit Menschen zu unterhalten, und glauben von sich selbst, dem Menschen überlegen zu sein. Als die erstaunte Alice sie fragt, ob alle Blumen sprechen, antworten ihr die Rose und die Lilie in einer überheblichen Art und Weise:

„As well as you can,“ said the Tiger-lily. „And a great deal louder.“

„It isn't manners for us to begin, you know,“ said the Rose, ,and I really was wondering when you'd speak! Said I to myself, ,Her face has got some sense in it, though it's not a clever one!' Still, you're the right colour, and that goes a long way." (Ebd., S. 139)

Nach Auffassung dieser beiden Blumen bedürfen sie keinerlei menschlichen Schutzes, da der Baum für ihre Sicherheit sorgt. Als Alice sich wundert, wie ein Baum sie beschützen könne, erklärt die Rose: „It could bark“ (ebd., S. 139), und das Gänseblümchen führt weiter aus: „It says ,Bough-wough! [...] that's why its branches are called boughs!“ (Ebd., S. 139) 
Somit präsentiert der Text hier eine Sicht, die derjenigen der zuvor behandelten Texte diametral entgegengesetzt ist. Alles, was man in diesen Texten über Blumen erfährt, wird umgekehrt, wodurch der Text gleichzeitig eine befremdliche und komische Wirkung erzielt. Dies zeigt auch, wie willkürlich die charakterlichen Zuschreibungen von Blumen eigentlich sind, und so offenbart sich in einem Nonsense-Dialog, wie wenig Sinn die üblichen Blumenvergleiche ergeben. In Through the Looking-Glass wird somit dem Menschen tatsächlich ein Spiegel vorgehalten, und der Text zeigt, wie geringschätzig wir uns den Pflanzen gegenüber verhalten. Bei Carroll wird deutlich, dass Blumen häufig aus anthropozentrischer Sicht beschrieben werden.

\section{Tod und Tulpe}

Ein weiterer traditionsreicher Symbolisierungszusammenhang ist die Verbindung bestimmter Blumen mit dem Tod. Zu den Pflanzen, die beständig mit dem Tod assoziiert werden, zählen z. B. Efeu und Immergrün, die Treue und Ewigkeit verkörpern, Mohn symbolisiert den sanften Tod, Zypressen stehen für Trauer und Stechpalmen für Leid und Schmerz. All diese Blumen und Bäume sind in unzähligen bebilderten Kinderbüchern in ihrer symbolischen Bedeutung zu finden, wie beispielsweise in Orangen für Opa (2008) von Natali Fortier, Die Blumen der Engel (2001) von Maria Balezjovsky und Wie Niklas ins Herz der Welt geriet (2008) von Gerd Scobel. In letzterem repräsentiert der Mohn den ,sanften Tod' (Abb. 6). Kinderbücher helfen somit, die etablierten Assoziationen und die Blumensprache an die nächste Generation weiter zu geben.

Blumen spielen in zahlreichen Büchern häufig allein wegen ihres Symbolgehalts eine Rolle, wie sich auch schon bei der frühen erzieherischen Mädchenliteratur gezeigt hat. Auch in diesen Texten werden sie eng mit dem Tod verknüpft. Der Sprecher in Gläsers Blumentod (1830, S. 73) wird beispielsweise durch das Betrachten verwelkter Blumen zum Philosophieren über den Tod angeregt. Er glaubt, nach dem Tod in Gottes Garten zu gelangen, wo es ihm besser ergehe als auf der Erde, wodurch bereits deutlich wird, dass es Gläser hauptsächlich um die Vermittlung des christlichen Glaubens geht. Erneut sind die Blumen allein Projektionsfläche, „Erziehungskulisse“ und symbolische Konstrukte. 


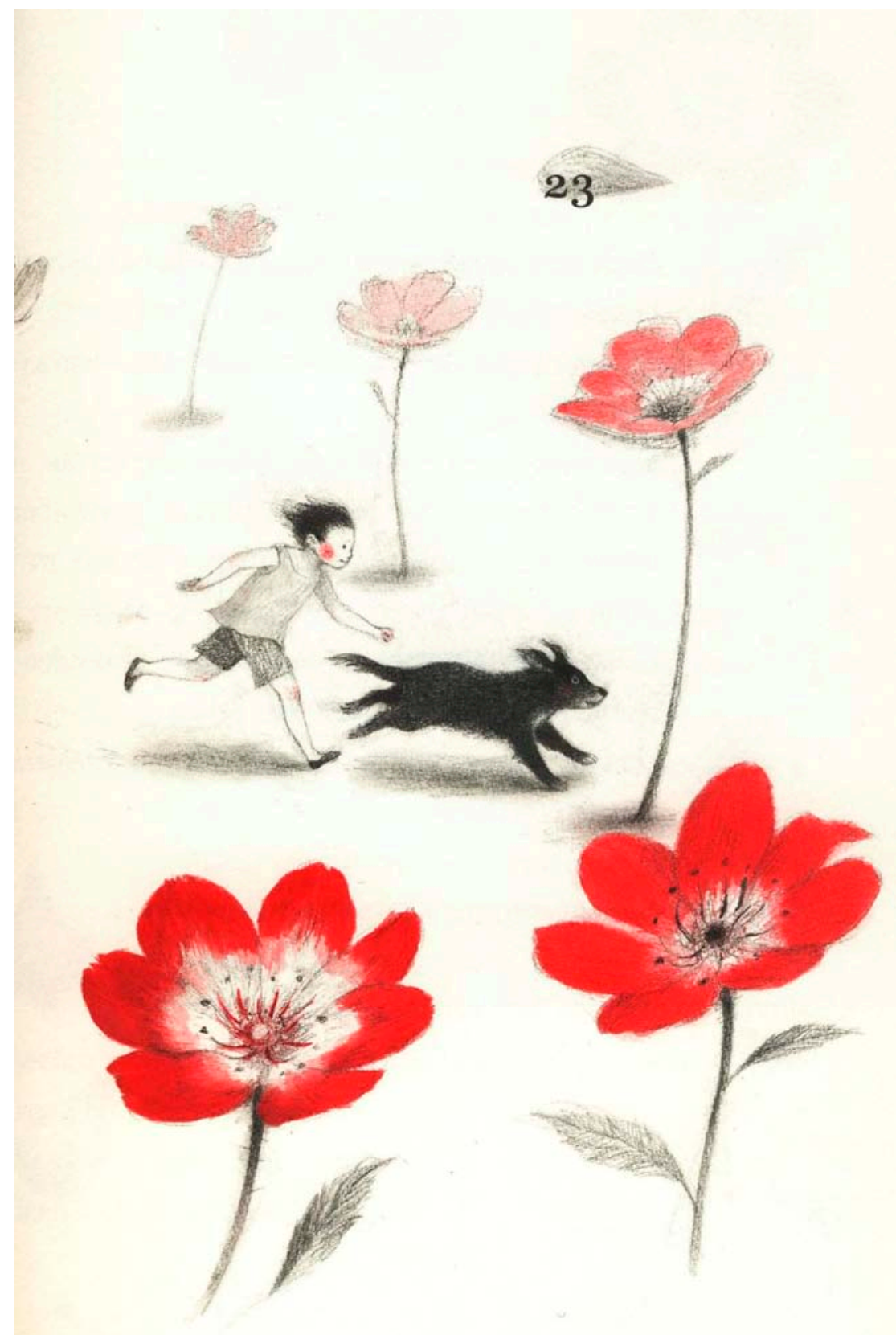

Abb. 6: Gerd Scobel (2008): Wie Niklas ins Herz der Welt geriet.

Illustration: Ayano Imai 
Die Verbindung von Tod und Blumen ist auch häufig in den Blumenmärchen Hans Christian Andersens zu finden. Beispielsweise handelt Die Blumen der kleinen Ida (dt. 1839/1996a) von einem kleinen Mädchen, das traurig über ihre verwelkten Blumen ist: „Meine armen Blumen sind ganz tot!“ beklagt sie sich und drängt einen befreundeten Studenten, ihr dies zu erklären. Anstatt aber auf rationale Weise das Verwelken zu erläutern, erzählt dieser der traurigen Ida, dass die Blumen sich die ganze Nacht auf einem Ball amüsiert hätten, deshalb etwas derangiert seien und sich ausruhen müssten:

Dann kommen all die hübschesten Blumen, und dann ist großer Ball, die blauen Veilchen sind kleine Seekadetten, die tanzen mit Hyazinthen und Krokussen, die sie mit Fräulein anreden! Die Tulpen und die großen, gelben Lilien, das sind alte Damen, die passen auf, daß fein getanzt wird und daß es vornehm zugeht! (Andersen dt. 1839/1996a, S. 32)

Am Ende begräbt Ida die verwelkten Blumen in der Hoffnung, dass sie im Sommer umso schöner blühen werden. Dieses Märchen ist unter anderem deshalb interessant, weil es zwei unterschiedliche Kinder-Blumen-Motive der Kinderliteratur miteinander vereint: die anthropomorphisierte Blume und das JenseitsMotiv. Zudem geht es auch auf den Kreislauf der Natur ein, ohne ihn jedoch zu erklären, wodurch der Tod tabuisiert wird.

Auch in einem Märchen Anni Geiger-Hofs geht es um den Tod einer Blume. In Vom Gänseblümelein (1931) findet die Protagonistin - ein einfaches Gänseblümchen - im Tod Erfüllung, da sie so in den Blumenstrauß eines Mädchens gelangt. Als das Mädchen es pflückt, „[...] wußte es, daß es sterben müsse. Da nahm es sich vor, vorher noch einmal recht zu blühen." (Geiger-Hof 1931, S. 33) Die Blume geht beschwingt in den Tod, um dem Kind eine Freude zu machen, was verdeutlicht, dass sie den Kindern ergeben ist und sich sogar für sie opfert. Genauer betrachtet stirbt ein Gänseblümchen in der außertextuellen Welt jedoch nicht, indem man ihm die Blüte abbricht, was erneut ein Beleg dafür ist, dass der Mensch nur die Nützlichkeit der Pflanze betrachtet, denn es interessiert den Menschen allein die Blüte des Gänseblümchens. Die Blume wird wieder auf ihren Zweck für die Menschen reduziert, auch wenn durch das Buch die Perspektive des Gänseblümchens mehr in den Mittelpunkt gerückt wird.

Hans-Christian Andersens Die Gänseblume (dt. 1845 als Das Marienblümchen/1996b) erzählt ebenfalls aus der Perspektive einer Blume und auch dieses Gänseblümchen ist gewillt, sein Leben zu opfern, jedoch nicht für einen Menschen, sondern für eine Lerche, die ihr als einziges Lebewesen Beachtung und Freude geschenkt hatte (Abb. 7). Wie auch in Geiger-Hofs Text wird das Gänseblümchen hier stereotyp als einfach und bescheiden beschrieben, denn wie die Mädchenbuchautorin Ottilie Wildermuth ausführt, steht das Gänseblümchen in der Blumensprache für „Sanftmuth, gemessene Freude, Demuth, Bescheidenheit, Liebes-Gram, Achtung aus reinem Triebe“ (Wildermuth 1876, S. 61). 


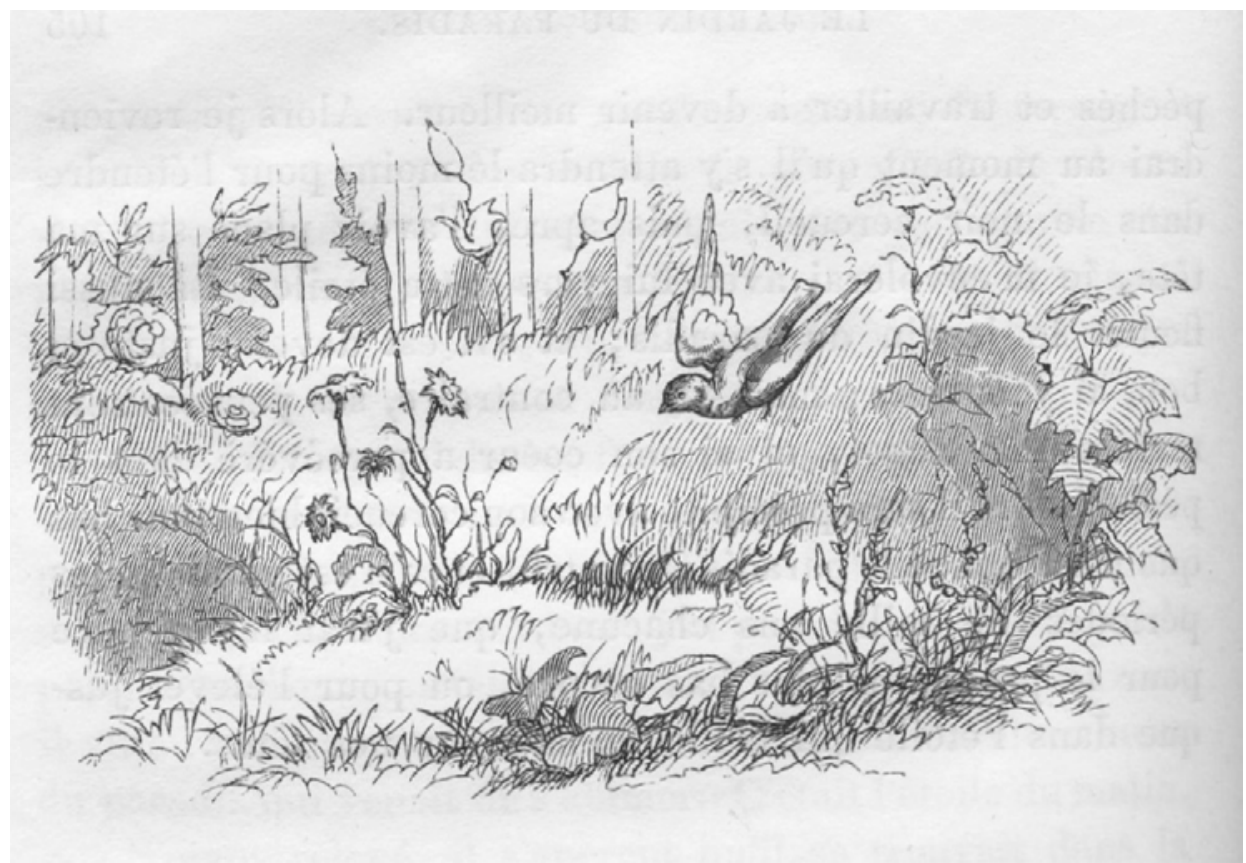

Abb. 7: Hans Christian Andersen:

Die Gänseblume (dt. 1845 als Das Marienblümchen).

Illustration: Lorenz Frølich

Anders als Geiger-Hofs Gänseblume fürchtet sich das zarte Pflänzchen aber davor, von Kindern abgeschnitten oder ausgerupft zu werden: „[...] das Gänseblümchen zitterte ordentlich vor Angst, denn abgerissen zu werden hieß ja das Leben einzubüßen“. Dadurch wird evident, dass der Pflanze durch die Kinder Schaden zugefügt wird, obwohl dies hier dramatisiert wird. Außerdem macht der Text deutlich, wie wenig die Kinder die Pflanze wertschätzen, da sie das tote Gänseblümchen am Ende in den Staub der Landstraße werfen.

Kinder, die in der menschlichen Gesellschaft am schwächsten sind, sind zumindest diesen Lebewesen überlegen, bringen ihnen aber selten Achtung entgegen und so leiden die Blumen oft unter den Kindern. Dies zeigt auch Sophie Reinheimers Im Blumenhimmel (1929), ein Märchen, das deutliche Kritik am unnachsichtigen Umgang mit Blumen übt. Im Blumenhimmel beschweren sich verschiedenste Blumen darüber, wie ein Kind sie misshandelt und getötet hat, so klagt die Rose:

Man schnitt mich ab vom Rosenstock, weil allzu schön mein rosa Rock.

Daß ich zwei kleine Schwestern hab, die mir der Herrgott zum Hüten gab, das war ganz einerlei.

Man schnitt uns alle drei. (Reinheimer 1929) 
Dementsprechend wird die so oft gepriesene Schönheit der Rose zu ihrem Verhängnis. Ähnlich ergeht es auch dem Gänseblümchen, dessen Blätter durch ein Orakelspiel entfernt wurden, und das fleißige Lieschen hat sein Dasein auf der Erde beendet, ohne jemals das Freie gesehen zu haben. Einige Blumen werden zu Kränzen gebunden, mit anderen wird in der Puppenstube gespielt. Den Kaktus hat man aus dem warmen Heimatsand in einen kalten, feuchten Topf verpflanzt:

Die Menschen sind doch Toren!

Verpflanzen mich aus fernem Land

Aus glühend heißem Wüstensand, wo man kein Wasser kennt, wo nur die Sonne brennt, in einen feuchten Topf.

Dann macht der Heinz, der Tropf ach, Engel, staunet nur mit mir die Badekur!

Kalt Wasser - nicht zu sagen!

Es stieg mir bis zum Kragen.

Ich kann's doch nicht vertragen!

Es schlägt mir auf den Magen.

So mußte ich ersaufen

und in den Himmel laufen. (Reinheimer 1929)

Nach ihrem Tod kommen die Pflanzen in den Blumenhimmel, wo sie von den Engeln gepflegt und umsorgt werden und schließlich neu erblühen. Um zu zeigen, dass den Blumen Leid zugefügt wurde, hat die Illustratorin wie auch die Textautorin die Pflanzen anthropomorphisiert dargestellt. In den Illustrationen von Else Wenz-Vietör wird beispielsweise der Kaktus weinend und an Krücken gehend verbildlicht (Abb. 8). Auf der einen Seite wird so ein Hineinversetzen in die Pflanze möglich und dies kann zu mehr Achtung und Respekt führen. Auf der anderen Seite werden den Pflanzen erneut menschliche Gefühle zugeschrieben.

Man weiß jedoch nicht, ob und wie eine Pflanze fühlt und was das Abreißen ihrer Blüte für sie bedeutet. Blumen haben kein Gesicht und auch keine Stimme. Dies zeigt schon, dass es prinzipiell unmöglich scheint, eine Pflanze in einem literarischen Text im engen Sinne, ökokritisch vorbildhaft ${ }^{`}$ zu repräsentieren. Man kann sich einer korrekten Darstellung nur annähern und sich bewusst machen, wie die Pflanze vom Menschen benutzt wird. 


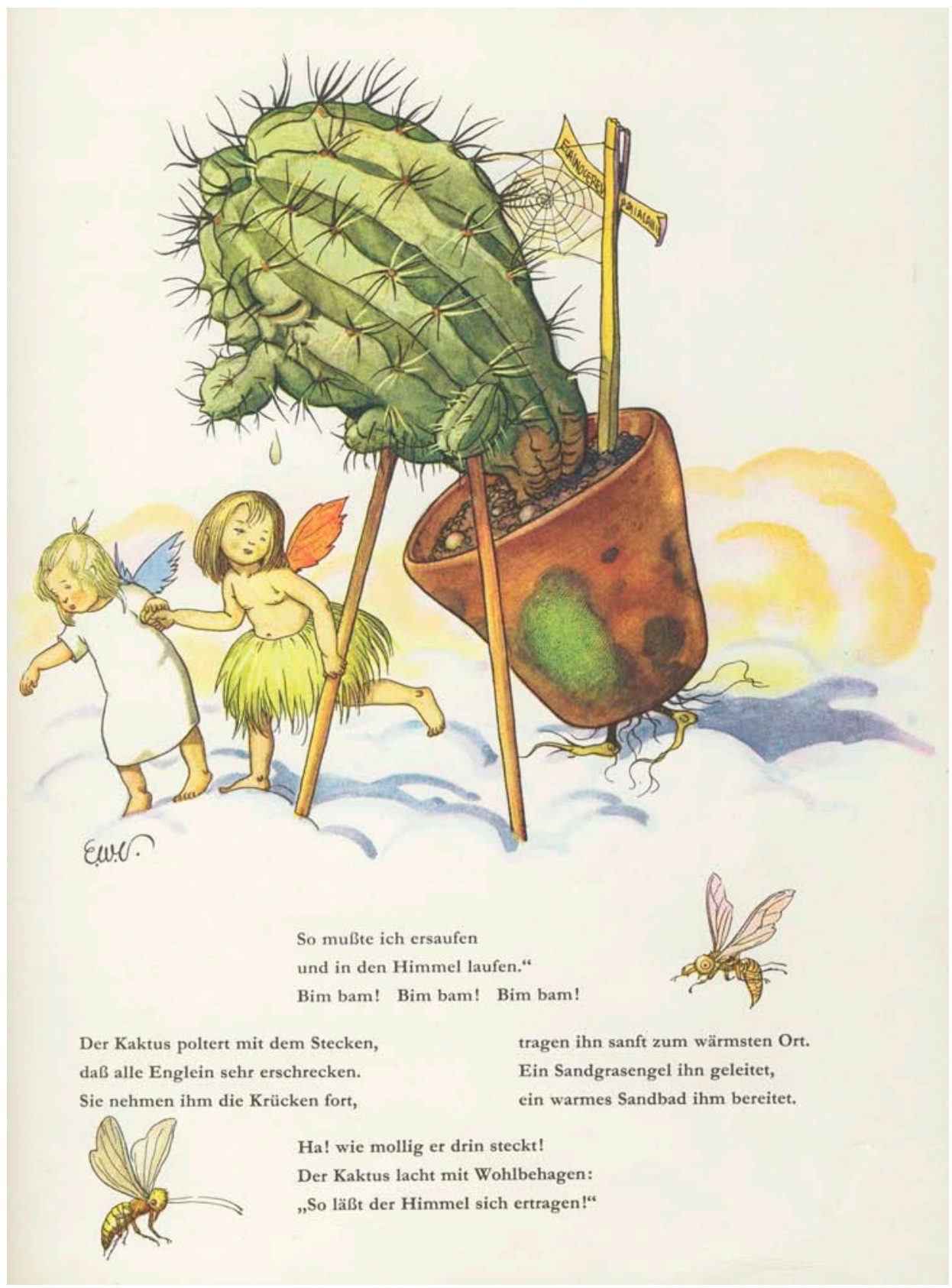

Abb. 8: Sophie Reinheimer (1929): Im Blumenhimmel. Illustration: Else Wenz-Viëtor 
In dieser Hinsicht kann man Im Blumenhimmel immerhin als einen Text mit ökokritischem Potential bezeichnen, in dem die Pflanze in den Vordergrund gerückt wird. Aus der Perspektive der Pflanzen wird geschildert, wie sie von den Menschenkindern vernachlässigt und gequält wurden, aber auch, wie es ihnen gut geht (Abb. 9). Umweltbewusstsein oder zumindest Bewusstsein für das eigene Verhalten Pflanzen gegenüber soll hier dadurch erzielt werden, dass den Kindern die Folgen ihres Handelns verdeutlicht werden sollen: Wenn ich den Kaktus zu stark gieße, stirbt er. So lernt das Kind verantwortungsvoll ökologisch zu handeln. Der Text weist außerdem darauf hin, dass die Kinder die Pflanzen aus Unwissenheit verkommen lassen und klärt darüber auf, was sie falsch gemacht haben. Diese Prinzipien werden auch von der späteren ökologischen Kinderund Jugendliteratur, die in Deutschland seit den 1970er Jahren stark vertreten ist, häufig verwendet.

Gleichzeitig wird auch das Kind nicht idealisiert und entmachtet, sondern als handelndes, aber auch zu negativen Taten fähiges Wesen dargestellt. Diese Negativbesetzung von Kindern wird durch Wenz-Viëtors Bilder entlastet, da sie die mitfühlenden Traumengel ebenfalls als Kinder darstellt. Bilder und Text stehen somit - wie so oft - in einem ambivalenten Verhältnis. Die gezeichneten Englein vermitteln ein engelhaftes, braves Kindheitsbild, in dem sich christliche Vorstellungen mit denen von guten Blumenfeen vermischen. Im Kontrast dazu zeigt der Text das ,böse“ Kind, das anderen Schaden zufügt. Anders aber als in Warngeschichten werden die Kinder für ihre Missetaten nicht bestraft, denn das Pflücken oder Vernachlässigen einer Pflanze ist - im Gegensatz zur Misshandlung eines Tieres - kein Tabu und nicht sanktionswürdig. ${ }^{6}$

\section{7 „Lasst Blumen sprechen“6}

Damit unsere Erde auch für die folgenden Generationen ein lebenswerter Ort sein kann, müssen wir lernen, uns Menschen als Teil eines ökologischen Gefüges zu begreifen, in dem unsere Handlungen weitreichende Folgen haben. Es gibt Texte, die ein solches ökologisches Denken anregen können, wie beispielsweise Sophie Reinheimers Im Blumenhimmel, oder die uns, wie Lewis Carrolls Through the Looking-Glass, zeigen können, wie wir Natur aus unserer überheblichen, menschlichen Perspektive betrachten. Andere Kinder- und Jugendbücher vermitteln dies nicht, doch man kann auch durch eine ökokritische Interpretation solcher Texte

\footnotetext{
${ }^{6}$ Auch in Reinheimers Das erste Veilchen (1923) bangt die Blume um ihr Leben, da ein Kind sie pflücken und dem Vater zeigen will. Dies kann jedoch abgewendet werden, da der Vater die Blume lieber im Garten sehen will. Man muss eine Blume nicht pflücken, um sich an ihr zu erfreuen. Der Text macht auch deutlich, dass die Pflanzen vom guten Willen der Menschen abhängig sind, weil sie sich gegen menschliche Grausamkeit nicht wehren können. Obwohl eine Armee von Grashalmsoldaten das Veilchen schützen soll, sind die Pflanzen gegen die Hand des Menschen schließlich machtlos. Ausgehend davon, dass die Pflanzen hier die Natur an sich repräsentieren sollen, ermahnt der Text zum Nachdenken über und zum bewussten Umgang mit der Natur.
} 
das Bewusstsein für ökologische Zusammenhänge stärken. Allerdings sollte man dabei politische Zielsetzungen und realpolitische Verknüpfungen nicht zur Priorität literaturwissenschaftlicher Analysen machen.

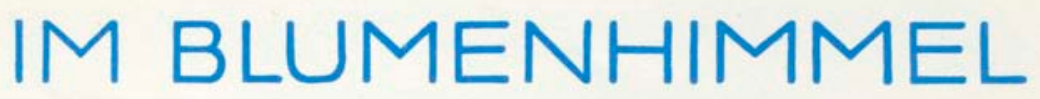

VON SOPHIE REINHEIMER

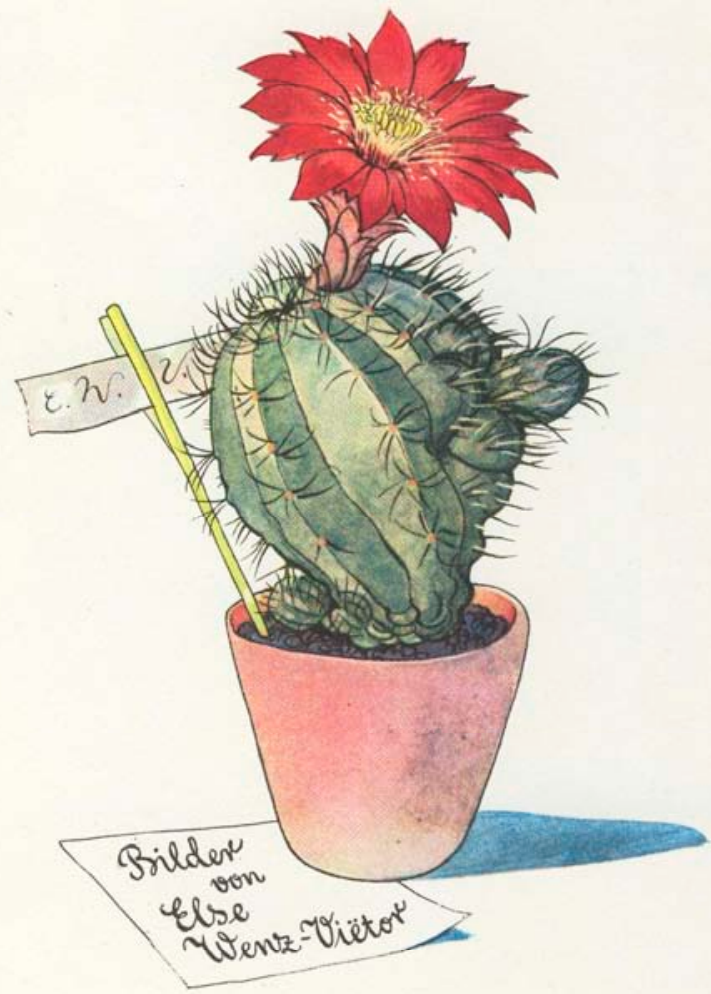

Abb. 9: Sophie Reinheimer (1929): Im Blumenhimmel.

Illustration: Else Wenz-Viëtor 
Es hat sich gezeigt, dass es schwierig ist, Blumen in literarischen Texten aus ökokritischer Sicht angemessen zu repräsentieren. Der Auffassung von Deep Ecologists ${ }^{7}$, also früheren, radikalen Ökokritikern, zufolge kann Natur überhaupt nicht repräsentiert werden, sollte daher für sich selbst sprechen und nicht in Beziehung zum Menschen gesetzt werden. Ferner fordern sie eine radikale Umstellung der Lebensweise. Ein Deep Ecologist würde wahrscheinlich bemängeln, dass all diese Texte auf die eine oder andere Art anthropozentrisch sind. Texte kritisch zu betrachten sollte jedoch nicht gleichbedeutend mit deren Abwertung sein. Ich bezweifele, dass man die menschliche Perspektive ablegen und sich in einen Baum hineinfühlen kann und denke wie auch Jonathan Bate, dass „,nature can never be perceived by itself, but only in its effects on the perceiver." (Bate 1991, S. 73). Ferner bin ich der Meinung, dass der Ansatz der Deep Ecology derart radikal ist, dass solche Arbeiten nur ein sehr kleines Publikum erreichen. So wird kein ökologisches Bewusstsein in der Bevölkerung hervorgerufen und folglich kann die ökologische Krise mit Hilfe solcher Interpretationen auch nicht überwunden werden. Gelingt jedoch eine fundierte literaturwissenschaftliche Analyse, in der die Natur im Mittelpunkt steht, so hoffe ich, dass sich auf diese Weise das Umweltbewusstsein des Lesers vergrößert. Aus diesen Gründen ist die neuere ökokritische Forschung von Ansätzen der Deep Ecology abgekommen, doch leider hängt dieser Ruf den Ökokritikern insgesamt nach.

Mit einem ökokritischen Ansatz lässt sich Nachdenken über Natur fördern und bewirken, so dass man sich fragt, warum die Natur - oder in diesem Fall die Blumen - auf diese Weise dargestellt werden. Es ist interessant und lehrreich zu sehen, welche Aspekte von Natur und Umwelt in der Literatur thematisiert (oder nicht thematisiert) werden und wie deren Darstellungen erfolgen. So lässt sich viel über unseren Umgang mit und unseren Zugang zur Natur erfahren.

Für das Beispiel Blumen bleibt festzuhalten, dass diese Pflanzen häufig anthropomorphisiert und Kinder gleichzeitig vermehrt wie Blumen beschrieben werden. Damit werden beide meist eng verbunden gezeigt, was dem Kindheitsbild des ,natürlichen Kindes“ entspricht. Ferner gibt es viele Texte, in denen sie eine reine Projektionsfläche und „Erziehungskulisse“ sind. Versteckt bzw. ,durch die Blume ${ }^{6}$ oder ,verblümt ${ }^{6}$ sollen erzieherische Absichten oder tabuisierte Sachverhalte wie Liebe, Sex und Tod einem jüngeren Publikum möglichst schonend und implizit vermittelt werden.

Natur und Kind werden häufig als das Schöne, Unschuldige und Schwache konstruiert und der Erwachsenwelt sowie der Kultur gegenübergestellt. Diese zieht sie als ,Gärtner' auf, formt sie und übt damit Macht über sie aus. Dementsprechend wird die Natur in vielen Fällen instrumentalisiert. Blumen sind meist positiv besetzt und ihre Funktion ist häufig die eines Symbols. Die Texte und

\footnotetext{
${ }^{7}$ Deep Ecologists sehen Menschen anderen Lebewesen gegenüber als gleichwertig an. Es geht ihnen um die tieferen Belange der Umwelt. Bill Devall und George Sessions (1985, S. 110) gelten als Begründer der Deep Ecology; ihr gleichnamiges Buch ist eine der einflussreichsten Veröffentlichungen in diesem Bereich.
} 
Bilder zeigen, welchen Stellenwert wir der Natur in unserem Leben einräumen, und so ist es auch bezeichnend, dass Natur in vielen Büchern nur beiläufig vorkommt und in vielen Illustrationen als reines Ornamentwerk fungiert.

Zusammenfassend kann gesagt werden, dass Blumen und Kinder in der Kinderliteratur häufig in einen Sinnzusammenhang gebracht werden und die Konstruktionen von Kindheit und Natur häufig ineinander greifen. Es bietet sich daher an, Kindheitsforschung und Ökokritik zu kombinieren, da das, was wir unter Kindheit verstehen, genau wie das, was wir unter Natur verstehen, Produkte kultureller Diskurse sind, in denen wir Menschen Natur von Kultur und Kindheit von Erwachsenenalter abgrenzen. 


\section{Literatur}

Andersen, Hans Christian (1996a): Die Blumen der kleinen Ida (dt. 1839). In: Andersen, Hans Christian: Sämtliche Märchen in zwei Bänden. Bd. 1. Mit Nachwort, Anmerk. u. Zeittafel hrsg. v. Heinrich Detering. Düsseldorf [u.a.]: Artemis \& Winkler, S. 31-39.

Andersen, Hans Christian (1996b): Die Gänseblume (dt. 1845 als Das Marienblümchen). In: Andersen, Hans Christian: Sämtliche Märchen in zwei Bänden. Bd. 1. Mit Nachwort, Anmerk. u. Zeittafel hrsg. v. Heinrich Detering. Düsseldorf [u.a.]: Artemis \& Winkler, S. 149-153.

Arndt, Ernst Moritz: Die drei Blümelein. In: Ewers, Hans-Heino (Hrsg.): Kinderund Jugendliteratur der Romantik. Eine Textsammlung. Stuttgart: Reclam, S. 93.

Balezjovsky, Maria (2001): Die Blumen der Engel. Illustrationen von Jutta Treiber. Wien: Annette Betz/Carl Überreuter.

Barth, Susanne (1997): Marie, Aurelie, Elmine und ihre Freundinnen. Geschlechterspezifische Erziehung in der Literatur für kleine Mädchen zwischen 1800 und 1840. In: Grenz, Dagmar; Wilkending, Gisela (Hrsg.): Geschichte der Mädchenlektüre. Mädchenliteratur und die gesellschaftliche Situation der Frauen vom 18. Jahrhundert bis in die Gegenwart. Weinheim, München: Juventa, S. 73-90.

Bate, Jonathan (1991): Romantic Ecology. Wordsworth and the Environmental Tradition. New York, London: Routledge.

Bechstein, Ludwig (1847): Die Rosenkönigin. In: Deutsches Märchenbuch. Leipzig: Georg Wigand, S. 35-39.

Bohatta-Morpungo, Ida (1935): Mein Gärtlein. München: Josef Müller.

Brentano, Clemens (1846): Das Märchen von dem Myrtenfräulein. In: Görres, Guido (Hrsg.): Die Märchen des Clemens Brentano. Zum Besten d. Armen u. d. letzten Willen d. Verfassers. Bd. 1. Stuttgart, Tübingen: Cotta, S. 476-495.

Burnett, Frances Hodgson (1911): The Secret Garden. London: Heinemann.

Carroll, Lewis (2003): Alice in Wonderland and Through the Looking-Glass (1871). Ill. v. John Tenniel. Hrsg. v. Hugh Haughton. London: Penguin Classics.

Coupe, Laurence (2000) Hrsg.: The Green Studies Reader. From Romanticism to Ecocriticism. London, New York: Routledge.

Devall, Bill; Sessions, George (1985): Deep Ecology: Living as if Earth really mattered. Layton: Gibbs Smith.

Dittmar, Heinrich (1984a): Der Knaben Lustwald (1821-22). In: Ewers, Hans-Heino (Hrsg.): Kinder- und Jugendliteratur der Romantik. Stuttgart: Reclam, S. 79-89. 
Dittmar, Heinrich (1984b): Der Mägdlein Lustgarten. Erlangen (1822-23). In: Ewers, HansHeino (Hrsg.): Kinder- und Jugendliteratur der Romantik. Stuttgart: Reclam, S. 90-94.

Fortier, Natali (2008): Orangen für Opa. Ill. von Francoise Legendre. Düsseldorf: Sauerländer.

Geiger-Hof, Anni (1931): Vom Gänseblümlein. In: Himmelsschlüssel. Ein

Märchenbuch für kleine und große Kinder. Stuttgart: Gundert, S. 25-34.

Gläser, G. C. W. (1830): Blumen und Früchte für die Kindheit und das erste Jugendalter: Zur Bildung des sittlichen Gefühles und zur Übung im freien seelenvollen Vortrage. Hannover: Hahn.

Glotfelty, Cheryll; Fromm, Harold (1996): The Ecocriticism Reader. Landmarks in Literary Ecology. Athen, London: The Univ. of Georgia Press.

Grimm, Jacob und Wilhelm (1843): Die Nelke. In: Kinder- und Hausmärchen. Große Ausgabe. Bd. 1. Göttingen: Dieterichsche Buchhandlung, S. 452-458.

Hirschmann, Julie (1856): Blüthenjahre. Novellen für die reifere Jugend. Mit 8 colorirten Bildern. Berlin: Winkelmann \& Söhne.

von Karger, Erica [ca. 1923]: Blumen-Kinder ein neues Bilderbuch von Garten, Wiese, Wald und Feld. Stuttgart: Loewes.

Knobloch, Jörg (2009) Hrsg.: Die angekündigte Katastrophe oder: KJL und Umweltschutz. kjl \& m. 09.4., Jg. 61. München: Kopaed.

Kreidolf, Ernst (1976): Der Traumgarten. Märchen von Blumen und Sommervögeln (Gartentraum, 1911). Zürich: Rotapfel.

Kreidolf, Ernst (2000): Blumenmärchen (Blumen-Märchen, 1898). München: Ars Edition.

Latour, Charlotte de (1820): Die Blumensprache oder Symbolik des Pflanzenreiches. Nach d. Franz. D. Frau Charlotte de Latour v. Karl Müchler. Berlin: Stuhr.

Lindenpütz, Dagmar (1999): Das Kinderbuch als Medium ökologischer Bildung. Untersuchungen zur Konzeption von Natur und Umwelt in der erzählenden Kinderliteratur seit 1970. Essen: Die Blaue Eule.

Lindenpütz, Dagmar (2000): Natur und Umwelt als Thema der Kinder- und Jugendliteratur. In: Lange, Günter (Hrsg.): Taschenbuch der Kinder- und Jugendliteratur. Baltmannsweiler: Schneider, S. 727-745.

Lindenpütz, Dagmar (2002): Children's Literature as a Medium of Environmental Education. In: Goodbody, Axel (Hrsg.): The Culture Of German Environmentalism. Anxieties, Visions, Realities. New York, Oxford: Berghahn Books.

Mitgutsch, Ali; Teichmann, Dirk-Holger (1986): Hilfe! Ein Monster! Ravensburg: Otto Maier. Müller, Jörg (2007): Alle Jahre wieder saust der Presslufthammer nieder oder die Veränderung der Landschaft (1973). Düsseldorf: Patmos. 
Nassen, UIrich (1995) Hrsg.: Naturkind, Landkind, Stadtkind. Literarische Bilderwelten kindlicher Umwelt. München: Wilhelm Fink.

Nesbit, Edith (1959): The wonderful Garden. London: E. Benn.

Niemeyer, G. F. (1794): Vermaechtniss an Helene von ihrem Vater. V. d. Verfasser d. Greises an d. Jüngling mit e. Vorrede v. Adolph Freyhern Knigge. Bremen: Friedrich Wilmans.

Novalis (2007): Heinrich von Ofterdingen (1800). Frankfurt am Main: Suhrkamp.

Pausewang, Gudrun (1997): Die Wolke (1987). Ravensburg: Ravensburger Buchverlag (11. Aufl.).

Pearce, Philippa (1958): Tom's Midnight Garden. Oxford: Oxford Univ. Press.

Pichler, Ottilie (1910): Mädchengarten. Eine Festgabe für deutsche Töchter. Mit feinen Chromobildern. Potsdam, Leipzig: Bonneß \& Hachfeld.

Reinheimer, Sophie (1929): Im Blumenhimmel. Bilder von Else Wenz-Viëtor. Oldenburg: Gerhard Stalling.

Reinheimer, Sophie (1923): Das erste Veilchen. In: Bunte Blumen. Ill. v. C. A. Brendel und Erich Schütz. Berlin: Franz Schneider, S. 12-14.

Richter, Dieter (1987): Das fremde Kind. Zur Entstehung der Kindheitsbilder des bürgerlichen Zeitalters. Frankfurt am Main: Fischer.

Schanz, Frida [ca. 1890]: Blumen und Früchte. Erzählungen für Mädchen von 6-9 Jahren. Mit Farbdruckbildern nach Aquarellen von Paul Wagner. Stuttgart: Weise.

Scobel, Gerd (2008): Wie Niklas ins Herz der Welt geriet. Ayano Imai (Ill.). Berlin: Bloomsbury/Berlin Verlag.

Ulrich, Anna Katharina (1995): Natur als Erziehungskulisse: Mutterbilder im Vaterwort. Psychoanalytische Deutungsversuche zu zwei Schweizer Kinderbuchklassikern. In: Nassen, Ulrich (Hrsg.): Naturkind, Landkind, Stadtkind. München: Fink 1995, S. 9-24.

Wildermuth, Ottilie (1876): Vollständige Blumensprache mit eingestreuten Poesien für Liebende. Hamburg: Gustav Elkan (6. verm. u. verb. Aufl.)

Wangerin, Wolfgang (1992): Die Natur im Käfig. Kindheitsbilder in alten Kinderbüchern. In: Ders.: Pfui ruft da ein jeder! Alte Kinderbücher aus der Vordemann-Sammlung der Universität Göttingen. Ausstellungskatalog. München: Heinrich Hugendubel, S. 13-18.

Wegner-Zell, Berta (1928): Im wilden Garten. Eine Jungmädchengeschichte. Ill. v. Mila v. Luttich. Reutlingen: Enßlin \& Laiblin. 


\section{Die fleißige und nützliche Biene \\ Natur als Gegenstand und Metapher in der Hausväterliteratur}

\section{Ulrike Kruse}

Die literarische Repräsentation eines besonderen Tieres - der Biene - als Teil der naturalen Umwelt im Genre der Hausväterliteratur ist das Thema dieses Aufsatzes. Der Biene werden verschiedene Attribute zugeordnet: Sie gilt als fleißig, als reinlich, als rachsüchtig, als vorbildlich und beispielhaft. Die metaphorischen Zuschreibungen sind so wirkmächtig, dass sie zu einem Topos geronnen sind. Gleichzeitig liefert die Biene Rohstoffe, wodurch sie ökonomisch nützlich ist. Ihr Leben als Insekt birgt Geheimnisse, die sich nur schwer entschlüsseln lassen.

Diese drei Zugänge zur Biene - metaphorisch, ökonomisch und naturkundlich -, die sich in der Hausväterliteratur wiederfinden, deuten die These des Aufsatzes an: Die Natur ist in der Hausväterliteratur Gegenstand und Metapher zugleich. Sie bildet den Gegenstand naturkundlichen Erkenntnisstrebens und ökonomischen Handelns und dient als Metapher zur Welterklärung.

Über den Topos Biene als Teil der Natur wird immer wieder auf die gleiche Weise gesprochen, bei ihr wird immer auf die gleiche Vorläuferliteratur zurückgegriffen und sie wird besonders oft metaphorisch zur Welterklärung verwendet. Die Hausväterliteratur verweist beim Sprechen über die Biene gleichzeitig auf klassische Texte wie auf zeitgenössische Fach- und Sachliteratur, so dass Veränderungen des Blicks auf Natur beobachtet werden können.

Das Ziel der Betrachtung der Biene in der Hausväterliteratur ist es herauszukristallisieren, ob Gegenstand und Metapher als bipolare Argumentationsstruktur in den Texten anzusehen sind oder ob die Repräsentationsformen korrelieren. 
Dafür werden zunächst die verwendeten Quellentexte vorgestellt. Danach wird die Textsorte Hausväterliteratur in das Genre der Sachliteratur eingeordnet. Mittels Ansätzen aus der Topikforschung wird ein theoretischer Zugang zum Umgang mit Wissen in den Texten erklärt. Folgend wird gezeigt, wie Natur als Handlungsgegenstand beschrieben wird und gleichzeitig als Metapher dient. Am Ende werden die Repräsentationsformen zur Klärung ihrer Funktion ins Verhältnis gesetzt.

\section{Quellentexte}

Die verwendeten Texte sind der Kalender (1591) und die Oeconomia (1593-1606/1680) von Johannes Coler, das Adeliche Land- und Feldleben von Wolf Helmhardt Freiherr von Hohberg (1682/1695), das anonym veröffentlichte Kurtz abgefasste schlesische Wirthschaffts-Buch (4 Aufl. 1700 - 1746 ) sowie der Hausvater in systematischer Ordnung (1783-1786) von Christian Friedrich Germershausen.

Johann Köhler (folgend Coler, 1566-1639), lebte als evangelischer Pastor in Parchim/Kurmark Brandenburg. Er gab 1591 zunächst einen immerwährenden Landwirtschaftskalender Calendarium oeconomicum $\mathcal{E}$ perpetuum heraus. Daran anschließend veröffentlichte er in sechs Bänden die Oeconomia ruralis et domestica, welches die land- und hauswirtschaftlichen Regeln des Kalenders thematisch geordnet ausführlich behandelt. Beide Texte wurden bis zum Beginn des 18. Jahrhunderts oft neu aufgelegt und erweitert und mindestens bis zum Ende des 18 . Jahrhunderts rezipiert und zitiert. Für die Untersuchung werden der Kalender in der Ausgabe 1591 und das Hausbuch in der erweitert herausgegebenen Fassung von 1680 verwendet. Coler gilt als erster echter Hausvater.

Wolf Helmhardt Freiherr von Hohberg (1612-1688) war ein aus Schlesien stammender österreichischer protestantischer Adliger, der in der Zeit der Rekatholisierung Österreichs in die multikonfessionelle freie Reichsstadt Regensburg emigrierte. Dort veröffentlichte er 1682 das Adeliche Land- und Feldleben, das sich reich ausgestattet thematisch an den begüterten Adligen richtet. Er war als „der Sinnreiche“" Mitglied der Fruchtbringenden Gesellschaft. ${ }^{1}$ Sein besonders gelehrtes Werk fand verschiedene Wiederauflagen. Es wird auf die zweibändige Ausgabe Georgica Curiosa Aucta von 1695 zurückgegriffen.

\footnotetext{
${ }_{1}^{1}$ Die Fruchtbringende Gesellschaft wurde 1617/1622 gegründet. Ihre Mitglieder stammten vorrangig aus dem Adel, doch wurden bürgerliche Gelehrte zugelassen, so sie die Ansprüche der Gesellschaft erfüllten: Es sollten ,humanistische sowie schon moderne, auf Anwendung, Gegenwartsbezug und Praxis bezogene Bildungsinhalte und Sozialisationsmuster, eigene höfische Bildungseinrichtungen und -verfahren wie Ritterakademien, Hofschulen, auch Labore, Observatorien, Natur- und Kunstkabinette, Bibliotheken, Kavalierstouren usw. die Szene“ prägen. (Herz 2009, S. 173f.) Ihre Aktivitäten beschränkten sich nicht auf Sprache und Literatur, wie in der älteren Forschung angenommen, sondern „politische, diplomatische, militärische [...] Thematiken kommen zur Sprache“ (ebd., S. 189). Ihr Motto „Alles zu Nutzen“ hält die universale Gesellschaftsethik der Fruchtbringenden Gesellschaft fest, die sich nicht auf die Sprache als Gegenstand der Aktivitäten der Gellschaft reduzieren lässt.
} 
Das Kurz abgefasste Schlesische Wirthschaffts-Buch, erstmals 1700 anonym veröffentlicht, richtet sich kleinformatig und ohne Textillustrationen ausgestattet an den niederen Landadel und den Gutsverwalter, um ganz praktische Regeln zu vermitteln. Drei weitere Auflagen erschienen 1712, 1725 und 1746, jeweils inhaltlich erweitert. Die Ausgaben wurden verglichen und es wird die Essenz mit den anderen Hausvätertexten in Beziehung gesetzt.

Der letzte echte Text der Hausväterliteratur ist der fünfbändige Hausvater in systematischer Ordnung von Christian Friedrich Germershausen (1725-1810), einem protestantischen Pastor aus Schlalach bei Treuenbrietzen, südlich von Berlin. Als Mitglied verschiedener ökonomischer Gesellschaften sah er sich als moderner Volksaufklärer, der die Landwirtschaft zum Nutzen des Staates und zur Verbesserung der Lage der Landbevölkerung effektivieren wollte. Sein Werk richtet sich an die Gutsbesitzer und Pastoren, die als Wissensmultiplikatoren neue landwirtschaftliche Techniken bekannt machen sollten.

\section{Hausväterliteratur als Sachliteratur}

Landwirtschaftliche Literatur, wie die antiken römischen Texte und auch die Hausväterliteratur, werden in Kindlers Literaturlexikon (2009) unter der Rubrik Sachliteratur geführt. Gero von Wilpert schreibt über Sachliteratur, sie stelle einen ,bestimmten Tatsachengehalt aus Natur- und Geisteswelt [...] in zugleich belehrender und unterhaltender Form übersichtlich, leichtverständlich und geschickt aufgemacht" dar. (Wilpert 2001, S. 712) Harald Riebe beschreibt die Sachliteratur als nicht-fiktional über Tatsachen und Erkenntnisse berichtend, wobei sie sowohl Information als auch Orientierung und kritische Aufklärung biete. (Riebe 1973, S. 114) Das entspricht dem Anspruch der Hausväterliteratur, in der sittliche Belehrung mit Wissensvermittlung einhergeht. Die volksaufklärerische Literatur trägt den Aufklärungsimpetus im Namen.

Nach Stephan Porombka spricht die Sachliteratur über zu ihrer Entstehungszeit je gegenwärtiges Wissen, das als Regelwissen, Weltwissen und Orientierungswissen vermittelt wird. (Porombka 2005, S. 11; Porombka 2007, S. 157) Regelwissen ist das Wissen, das sich in der Praxis nach bestimmten Regeln anwenden lässt. Für die Frühe Neuzeit, die ihr Wissen aus der antiken und christlichen Tradition schöpft, bedeutet das entsprechend der Theorie vom Mikro- und MakroKosmos, dass jede Regel im Kleinen im Zusammenhang mit dem großen Ganzen der Welt steht, die wiederum nach bestimmten - z. B. göttlichen Regeln funktioniert. Weltwissen ist Wissen über die Welt, über Ereignisse, Entdeckungen und Erfindungen genauso wie über Phänomene der Natur. Das Weltwissen ist mit dem Regelwissen zum Orientierungswissen verknüpft, das als Gleichnis oder Beispiel ermöglicht zu verstehen, warum im großen Weltzusammenhang welche Regel gilt - oder wie Porombka es ausdrückt: „Sachliteratur integriert die Informationen, mit denen sich die Kultur über sich selbst informiert, um sie sinnvoll erscheinen zu lassen." (Porombka 2005, S. 15) Sie wird 
nicht deshalb gelesen, weil man mit ihrer Hilfe etwas substantielles über neue wissenschaftliche Erkenntnisse lernen kann, sondern weil man sie als Lektürematerial zur Weiterverarbeitung der Selbst- und Weltwahrnehmung nutzen will. (Porombka 2007, S. 158)

In der Sachliteratur wird einerseits neues Wissen vermittelt, indem auf aktuelle Veröffentlichungen verwiesen wird. Andererseits wird auf das Wissen des Lesers rekuriert, indem Standardwerke zitiert oder genannt werden, die der Leser kennt oder von denen er zumindest schon gehört haben könnte.

Auch die Hausväterliteratur rekuriert auf das Wissen der Leser und vermittelt gleichzeitig neues Wissen, indem sie sowohl auf antike Landwirtschaftsautoren als auch auf zeitgenössische naturkundliche Schriften zu speziellen Themen, wie Texte über Gartenbau und naturkundliche Enzyklopädien, verweist. Parallel dazu werden Bibelzitate und Sinnsprüche über die göttliche Ordnung der Welt aus theologischen Quellen und der Bibel verwendet, so dass Regel- und Weltwissen vor der Folie christlicher Welterklärung zu Orientierungswissen werden kann.

\subsection{Forschungsgeschichte und Definition}

1864 prägte Carl Fraas erstmals den Begriff Hausväterliteratur. (Fraas 1864, S. 76) Wilhelm Roscher definierte ihn 1874 als auf den Erfahrungen des Autors und seiner Korrespondenzpartner beruhend, auf die Unterweisung in ökonomischen und landwirtschaftlichen Fragen und Problemen der Haushaltung zielend, die christlichsittliche Belehrung bezweckend und (oft) ein Kalendarium beinhaltend. (Roscher 1874, S. 137 u. S. 304) Mitte des 20. Jahrhunderts erklärte Otto Brunner die Hausväterliteratur zur normativen Literatur über das Konzept des Ganzen Hauses. Seine Definition im Handwörterbuch der Sozialwissenschaften legte den zeitlichen Rahmen vom 16. bis zum 18. Jahrhundert und die inhaltliche Ausrichtung fest als

Ökonomik im älteren Sinne und [sie] enthält daher eine Fülle ethischen, soziologischen, pädagogischen, medizinischen, agrartechnischen Stoffes, der durch [...] das ordnende Prinzip des Hauses und der ihm maßgebenden leitenden Funktion des Hausherrn (Hausvater) zusammengehalten wird. (Brunner 1956, S. 93)

Ihm folgend fasste Gertrud Schröder-Lembke Inhalt und Funktion der Hausväterliteratur zusammen als die Darstellung der „Gesamtheit des landwirtschaftlichen Betriebes“ und ,als eine erweiterte Haushaltung [...], die unter der Leitung des Hausvaters und der Hausmutter steht und die Versorgung der zu ihr gehörigen Menschengemeinschaft [...] als Arbeitsziel hat.“ (Schröder-Lembke 1953, S. 109)2

\footnotetext{
${ }^{2}$ An dieser Stelle könnte mehr Forschungsliteratur aufgezählt und auf neuere Ergebnisse eingegangen werden, z. B. Hoffmann (1959); Brunner (1956/1966); Kuhn (1980); Stein (1980); Keil (1982); Richarz (1991); Brunner (1993); Brandes (1999); Sieglerschmidt (1999); Haage u. Wegner (2007); Schmidt-Voges (2008).
} 


\subsection{Struktur}

Strukturell ist die Hausväterliteratur ein Gemisch aus Fachprosatexten, mathematischen Gleichungen, astronomischen und astrologischen Tafeln, enzyklopädischen Einträgen (z. B. über einzelne Pflanzen), schöngeistiger Beispielargumentation, Rezepten, Sprüchen und Versen, Bibelzitaten und Zitaten aus Vorläuferliteratur, Listen, Bauanleitungen usw.

Ihr Aufbau orientiert sich streng an den Regeln der Rhetorik. Ein Sachverhalt - in der Hausväterliteratur die Oeconomia - wird anhand verschiedener Themen (Topoi $\left.{ }^{3}\right)$ erläutert, die regelhaft in einer durch die Tradition der Vorläuferliteratur bestimmten Reihenfolge behandelt werden. Es wird in das ganze Buch allgemein eingeleitet, die Herkunft des Sachverhaltes Oeconomia geklärt, Auctoritas angeführt ${ }^{4}$ und im weiteren Verlauf werden katalogartig die einzelnen zum Sachverhalt gehörigen Themen in eigenen Büchern oder Teilen abgearbeitet. Dabei wird immer vom Allgemeinen zum Besonderen und vom Abstrakten zum Konkreten übergegangen. Auf die gleiche Art sind die einzelnen Bücher/Teile mit den jeweiligen Topoi aufgebaut: Einleitung und Grundlegung, Beschreibung und Bearbeitung der untergeordneten Topoi in einzelnen Kapiteln.

Da die Landwirtschaft zu den artes profanes gehört, darf nach den Regeln der Angemessenheit (aptum) nur in schlichtem Stil (genus humile) über sie geschrieben werden. Diese Regel kollidiert jedoch sowohl mit der Regel der variatio als auch mit der Selbstpräsentation der Autoren. Exkurse werden eingeflochten, in denen metaphorisch über das eigentliche Thema gesprochen wird, so dass das profane landwirtschaftliche Thema als Aufhänger dient zur Diskussion theologischer oder philosophischer Fragen, denen der gehobene Stil (genus grave) gebührt. So wird der Forderung nach sprachlicher Variation Rechnung getragen und werden die literarischen Fertigkeiten des Autors herausgestellt. ${ }^{5}$

Der Paratext der Bücher ist stets sehr umfangreich, unabhängig vom Umfang des eigentlichen Textes: Es gibt paratextuelle Elemente, die der Präsentation des Werkes dienen. Z. B. sind manche Bücher reich illustriert, manche haben nur ein Titelbild oder kommen ohne Bilder aus. Sie haben stets thematische und rhematische Titel. Der thematische Titel zeigt an, worum es hauptsächlich im Text gehen wird, z. B. „Land- und Feld-Leben“. Der rhematische Titel bietet bisher unbekannte Zusatzinformationen darüber, ob das Buch illustriert ist und wie es strukturiert ist,: „Auf alle in Teutschland übliche Land- und Haus-Wirthschafften gerichtet/ hin und wieder mit ... einer mercklichen Anzahl schöner Kupffer

\footnotetext{
3 Vgl. die Topos-Definition im Kapitel 3: „Topikforschung“ in diesem Text.

4 Aristoteles (1952, 105b, 12-18), vor allem: „Ferner muß man, was in allen oder den meisten Fällen gilt, ansetzen als Ausgangspunkt und anerkannte Meinung. Denn das nehmen die Leute hin, die nicht übersehen können, in welchen Fällen es nicht so ist. Auch die veröffentlichten Schriften muß man bei der Auswahl heranziehen."

${ }^{5}$ An dieser Praxis zeigt sich deutlich die Orientierung an antiken Texten, bei denen Deinlein (1975, S. 16) die gleiche Schreibstrategie aufgedeckt hat.
} 
gezieret/ und in Zweyen absonderlichen Theilen/ deren jeder in Sechs Büchern bestehet". Die Bücher werden entweder wichtigen Persönlichkeiten und/oder Freunden gewidmet und enthalten eine Vorrede an den Leser. Zur Erschließung des Inhaltes und zur Ordnung des Textes sind Inhaltsverzeichnisse, Kolumnentitel, Marginalien oder Kapitelüberschriften und Register enthalten.

\subsection{Inhalt}

Hausväterliteratur fußt auf antiker griechischer und römischer sowie mittelalterlicher Vorläuferliteratur. Diese Vorläufer geben die Topoi selbst und die Struktur der Behandlung der Topoi vor. Gleichzeitig aktualisiert die Hausväterliteratur mittels der je gegenwärtigen Fachliteratur ihre Inhalte, ohne dabei ihre Topoi zu stark zu erneuern oder auszuweiten. Sie bedient sich botanischer Abhandlungen, Traktaten über Bodenkunde, zoologischer Untersuchungen und agrarwissenschaftlicher Texte genauso wie landwirtschaftlicher Ratgeber und anderer zeitgleicher Hausvätertexte. Eine stets sprudelnde Quelle für die Hausväterliteratur ist die Bibel, die als Grundlage das christliche Weltbild für Erklärungen über Phänomene der naturalen Umwelt (manifestiert im Weltwissen) und für Regeln der Haushaltung und der Landwirtschaft (Regelwissen) liefert und so Orientierungswissen über die Welt generiert.

Die Erziehung des Lesers zur Gottesfurcht und die Bestätigung und Festigung seines christlichen Weltbildes ist Anspruch und genuiner Bestandteil der Hausväterliteratur. Konkrete ethische Regeln werden meist im Teil über Haushaltung behandelt. Gottes Gnade und die göttliche Ordnung schwingen bei jedem Thema als Welterklärungsmuster Orientierung bietend mit. (Hoffmann 1959) Weitere Themen sind: Boden und Düngung, Aussaat und Ernte, Saatgut und Vorratshaltung, Schädlingsbekämpfung, Viehhaltung und Wiesenwirtschaft, Holznutzung und Gartenbau, Fischzucht und Bienenhaltung. Dazu kommen Ökonomie und Personalfragen, technische Anforderungen, Jagd, Kräuter- und Arzneikunde sowie hauswirtschaftliche Belange, z. B. Lichtziehen und Wäschewaschen, Bierbrauen und Brotbacken, Kindererziehung und Verhalten gegenüber Gesinde und Familie.

Kurz gesagt, Hausväterliteratur ist normative Sachliteratur über Haus- und Landwirtschaft für adlige Haus- und Gutsbesitzer, die dem Leser pragmatisch und handlungsanleitend einen Orientierungsrahmen bezüglich seiner eigenen adligen Lebenswelt bietet. (Schmidt-Voges 2008, S. 405) Sachliteratur ist sie, weil sie sowohl Information als auch Orientierung und kritische Aufklärung verschafft (Riebe 1973, S. 114) und in ihr sittliche Belehrung und Wissensvermittlung Hand in Hand gehen. Ihr Ziel ist dreifach: dem Leser Unterweisung (= Information = Regelwissen), Belehrung (= kritische Aufklärung $=$ Weltwissen) und Erbauung (= Orientierungswissen) zu geben. 


\section{Topikforschung}

Der Begriff des Topos (topoß) stammt aus der klassischen Rhetorik und bedeutet zunächst Ort, Gemeinplatz. Weitergehend bedeutet er u. a. stereotype Redewendung, vorgeprägtes Bild, Beispiel oder auch Motiv. Mittels Topoi wird in der Rhetorik über Sachverhalte argumentiert. (Aristoteles 1999, 1358a, 21f.) SchmidtBiggemann und Hallacker definieren Topos als:

ein Klischee, eine Sehgewohnheit, ein Bild- oder Handlungsmotiv, ein intellektueller Habitus, ein Leitbegriff, ein Klassifizierungsvorschlag, ein Sprichwort, ein Zitat, eine Illusion, eine Geschichte, kurz das, was sozusagen zum gebildeten Fundus gehört. (Schmidt-Biggemann u. Hallacker 2007, S. 17)

Dieser Fundus gerinnt zum Weltbild, das sinnstiftend wirkt. Dafür ,kondensiert [es] die Selbstauffassung des Menschen in einem [...] Narrativ [einer Geschichte]“. Damit wird „dem prinzipiell nicht erfahrbaren Weltganzen eine ,Anschauungsform“ [unterlegt]“. (Friedrich 2009, S. 196) Etwas Abstraktes wird so zu etwas Greifbarem - eben einem Topos. Topoi „verwalten Wissensfülle, um sie argumentativ anwendbar zu machen." (Schmidt-Biggemann u. Hallacker 2007, S. 17) Sie formen enzyklopädische Metaphernfelder, also ein

Inhaltsuniversum, das bereits in Netze von Interpretanten organisiert ist, die (semiotisch) über die Ähnlichkeiten und Unterschiede von Eigenschaften entscheiden. [...] Jedenfalls hat man zu lange geglaubt, daß es notwendig sei, den Code (oder die Enzyklopädie) zu kennen, um Metaphern zu verstehen: in Wahrheit ist die Metapher das Werkzeug, das es uns erlaubt, die Enzyklopädie zu verstehen. (Eco 1985, S. 189)

Auf diese Weise kanonisieren die Topoi mittels enzyklopädischer Metaphernfelder Wissen. Sie formen Ordnungsschemata, deren Aufgabe die „Verwaltung und Verfügbarkeit von Erfahrungsschemata“ (Schmidt-Biggemann 2008, S. 20) ist. Ordnungsschemata sind Erfahrungsschemata zweiter Ordnung, „die die tragende Struktur von Verhaltensformen und komplexen Objekten ausmachen“" (SchmidtBiggemann 2008, S. 21) und ihnen auf diese Wiese eine Anschauungsform geben. Als solche Ordnungsschemata und Anschauungsformen stellen Topoi Verlässlichkeit her. Sie sichern und tradieren Verhaltensformen, indem sie Handlungsmöglichkeiten anbieten - auch in einer sich verändernden Welt:

Verlässlichkeit bezieht sich auf die Beschreibung der Vergangenheit als vergangener Erfahrung. Erfahrungswissen erzeugt und stützt sich auf topische Strukturen, die identifizierbar sind und sich als wandelbare Schemata zeigen. Sie bleiben aber in ihrem Wandel als sie selbst erkennbar. (Schmidt-Biggemann 2008, S. 28) 
Die Wandelbarkeit des Topos lässt ihn über seine Funktion der Wissenskanonisierung hinaus wissensgenerierend wirken. ${ }^{6}$

Sowohl die Kanonisierung vorhandenen Wissens als auch die Generierung neuen Wissens geschehen gleichzeitig in einem Text - zumal in Sachtexten: Das über Topoi vermittelte Erfahrungswissen führt zu Regelwissen und Weltwissen, das sich in Orientierungswissen vereint. Das wiederum bildet die Funktion von Sachliteratur ab, nämlich die Belehrung über naturkundliche Phänomene, Unterweisung über ökonomisches Handeln auf der Grundlage naturkundlicher Erkenntnisse und Erbauung, indem die Natur als Metapher zur Beantwortung gesellschaftlicher und religiöser Fragen verwendet wird.

Deshalb werden in dieser Arbeit derartige Themen - Topoi - untersucht, über die auf die gleiche Weise gesprochen wird, bei denen auf die gleiche Vorläuferliteratur zurückgegriffen wird und die besonders oft metaphorisch zur Welterklärung verwendet werden, bei denen gleichzeitig auf zeitgenössische Fach- und Sachliteratur rekuriert wird und an denen man Veränderungen des Blicks auf Natur beobachten kann.

Es gibt in der Hausväterliteratur auch Themen, über die nicht metaphorisch gesprochen wird und die nicht topisch verwendet werden. So spielen in der antiken Vorläuferliteratur Fischzucht bzw. Teichwirtschaft keine Rolle. Erst Petrus de Crescentiis, ein italienischer Autor um 1300, führt die Fischerei in die Landwirtschaftsliteratur ein. (Schröder-Lembke 1978b, S. 76ff.) 7 Und obwohl es naheliegt wegen der Apostel, von denen einige von Beruf Fischer waren, und wegen Jesus, der auch als Menschenfischer bezeichnet wird -, werden Fische und Christentum in den landwirtschaftlichen Texten nicht metaphorisch verbunden. Fischzucht bzw. Teichwirtschaft wird nur gegenständlich betrachtet. Ökonomisch sind Fische leicht zu erlangende Nahrung und gewinnträchtige Handelsware. Die Anlage von Fischteichen verspricht die Verbesserung der wirtschaftlichen Lage, besonders wenn Ackerflächen gewählt werden, die wenig Ertrag bringen. Das naturkundliche Wissen über Fische ist so umfangreich, dass ihre Zucht gelingt und die besten Haltungsmethoden aus den Ansprüchen der Fische an Lebensbedingungen abgeleitet werden können. Doch „Fische“ sind kein Topos im engeren Sinne, da sie ausschließlich gegenständlich betrachtet werden. Sie sind zwar Gegenstand der Belehrung und Unterweisung, nicht aber der Erbauung.

\footnotetext{
6 Schmidt-Biggemann u. Hallacker (2007, S. 23) zum Prozess des Wissenswandels und der Wissensgenerierung durch Topoi: „Der [...] topisch strukturierte Prozess des Wissenswandels führt zu neuen, bisweilen auch nicht intendierten oder vorhersehbaren Erkenntnissen, das heißt er erzeugt unerwartetes Wissen. In der entscheidenden Phase der krisenhaften Umstrukturierung unter dem Druck der pragmatischen Anpassung an die funktionalen Erfordernisse des neuen Kontextes bewirkt der Prozess der Fragmentierung und Neuordnung von traditionellen Wissensbeständen zugleich auch die Generierung von neuem Wissen.“.

${ }^{7}$ Crescentiis „Opus ruralium commodorum“ wurde 1471 zum ersten Mal gedruckt und in Teilen und im Ganzen bis zum Beginn des 17. Jahrhunderts mehrfach aufgelegt.
} 


\section{Bienen als Gegenstand und Metapher}

Von Hesiod über Aristoteles zu den römischen Landwirtschaftsautoren fliegt die Biene durch die antiken Texte, um bei den Kirchenvätern genauso aufzutauchen wie in naturkundlichen Texten des Mittelalters. ${ }^{8}$ Der früheste Hausvater Coler nennt allein 16 Autoren, die über Bienen schreiben, bspw. Aristoteles, Virgilius, Plinius, Columella, Varro, Petrus de Crenscendiis, Constantinus (Africanus), Palladius, Dioscorides, Matthioli, Heresbach, Thomas Brabantinus, Basilius und Ambrosius. ${ }^{9}$ Auch zeitgenössische Autoren werden zitiert, z. B. Nicolaus Jacobi: Die rechte Bienenkunst von 1568. Spätere Autoren verweisen gern auf den Nützlichen Bericht von den Bienen (1611) von Johannes Coler selbst. Dazu kommen Werke zeitgenössischer Autoren, die nicht auf Deutsch oder Latein veröffentlichten. ${ }^{10}$ Auch Gartenbücher mit einem Teil über Bienen lagen früh vor.

Bienen werden in den untersuchten Texten einerseits objekthaft, andererseits metaphorisch verwendet. Objekte sind sie auf zweierlei Weise: Einerseits sind sie ökonomische Objekte unter dem Aspekt des Nutzens. Andererseits werden sie als naturkundliche Objekte betrachtet. Diese beiden Betrachtungsweisen finden sich in allen untersuchten Hausvätertexten.

\subsection{Bienen metaphorisch}

Nur zwei der untersuchten Werke gehen explizit auf die Bienenstaatsmetapher ein: das Hausbuch von Coler in der Ausgabe 1680 und das Adeliche Land-und Feld-Leben von Hohberg (Ausgabe 1695). Doch selbst in diesen Werken nimmt sie nur geringen Raum ein: Das Hausbuch widmet sich der Bienenstaatsmetapher auf etwa vier Seiten, obwohl das Kapitel über Bienen insgesamt 40 Seiten umfasst. Ähnlich ist es bei Hohberg. Die Bienenstaatsmetapher bedenkt er mit fünf Seiten, aber die naturkundlichen und ökonomischen Ausführungen umfassen 49 Seiten (insgesamt 54 Seiten). Trotzdem schwingt die Bienenstaatsmetapher in den Texten, in denen sie nicht ausgebreitet wird, im Hintergrund mit, wenn z. B. das Wort Weisel für das Oberhaupt des Bienenstaats in der grammatisch männlichen Form verwendet wird. Als Sachliteraten konzentrieren sich die Hausväter in erster Linie auf den praktischen und ökonomischen Nutzen der Bienenhaltung. Die politisch und gesellschaftlich relevante und vielleicht auch brisante Staatsmetaphorik der Bienen beansprucht bei den Hausvätern mit knapp 10 Prozent der Ausführungen nur geringen oder sogar keinen Platz, so bei Rist (1650), dem Schlesischen WirthschafftsBuch (in allen Ausgaben) und Germershausen (Bd. 5, 1786).

\footnotetext{
8 Vgl. allgemein Engels u. Nicolaye (2008) und darin besonders Olbertz (2008) über die Metaphorik und Nicolaye (2008) über naturkundliches Wissen über die Bienen in der Antike, außerdem Peil (1983). Kurz und prägnant ist Johach (2007).

9 Z. B. Thomas Brabantinus: Bonum universale de Apibus (Dit is der bien boeck, 1488).

10 Z. B. Olivier de Serres: Le Théâtre d'Agriculture et Mesnage des champs, 1600/1603, der von Hohberg zitiert wird.
} 
Die Staatenbildung und das Sozialverhalten der Biene dienen als Gesellschaftsmetapher. In einem dialektischen Verhältnis ist einerseits der Bienenstaat Vorbild für die menschliche Gesellschaft, andererseits wird die Konstruktion vom Staat soziomorph auf die Bienen übertragen. Im Gegensatz zu einer technomorphen Übertragung, bezeichnet soziomorph nach Ernst Topitsch:

Einzelne Phänomene, ihre Zusammenhänge und schließlich das ganze Universum erschienen als Vorgänge, Objekte und Produkte künstlerischhandwerklicher Tätigkeit oder als soziale Strukturen und Sinnzusammenhänge wie Familie, Sippe und Staat, wie Brauch, Sitte und Recht, wie Lohn, Rache und Strafe. Die [erste] Gruppe von Analogien kann man als technomorph bezeichnen, wenn man den antiken Sinn von Techne als Kunstfertigkeit und nicht den modernen der Maschinentechnik zugrunde legt, die zweite als soziomorph. (Topitsch 1958, S. 18f.)

Dietmar Peil überträgt das Konzept der soziomorphen Metapher: „Das Bild vom Bienenvolk als Staat ergibt sich aus einer soziomorphen Interpretation der Natur.“ (Peil 1983, S. 181) Soziomorph ist die Betrachtung der Biene bei Coler, wenn er von der „Bienen Policey-Ordnung“ spricht, in der er das Verhalten der Bienen dem Hauswirt als Vorbild anbietet:

Diese edle Creatur der lieben Bienichen/ soll ein jeder frommer Haußwirth haben/ nicht allein/ daß sie uns mit ihrem lieblichen Honig und Wachs viel dienen in Speisen/ Träncken/ Arztneyen/ sondern auch wegen ihrer grossen Geschicklichkeit/ und wohlbestellten Regiment/ daß sie uns in vielen Sachen gute Exempel und instruction geben/ wie wir uns im gemeinen bürgerlichen Leben und in unserer Haußhaltung verhalten sollen/ wann wir nur ihrem Exempel/ Thun und Wesen recht nachdencken und nachfolgen wollen. (Coler 1680, Oecon., S. 545)

Besonders wichtig sowohl bei den Bienen als auch in der feudalen Gesellschaft ist die Führung durch einen König: „Ihr Regiment ist nicht eine democratia, nicht eine aristocratia, sondern eine monarchia, dann sie haben nur einen König und dem sind die andern alle unterworffen." (Coler 1680, Oecon., S. 546) Coler untermauert seine Ausführungen über den Bienenstaat als Musterstaat mit einer Etymologie des Wortes Biene als vom gotischen Wort für König herkommend:

Ich halte daß vom Lateinischen Apis das teutsche Wort Biene herkommet. Apis eine Biene. In der alte Gotischen Sprache heißt es ein König. Dann in der Regierung muß ein König den Stachel der Gerechtigkeit in der Hand haben/ und straffen was zu straffen ist/ er muß aber mit dem Honig der Gnaden vermischet seyn/ daß er nicht zum Tyrannen werde. (Coler 1680, Oecon., S. 527)

Soziomorpher Analogie folgt auch die Beschreibung des Bienenstocks, wenn die Bienen als „Bürger in einer Stadt“ (Coler 1680, Oecon., S. 527) bezeichnet werden, die arbeitsteilig geregelten Tätigkeiten nachgehen wie Wasser holen, Waben bauen oder als Soldaten den Stock bewachen: 
Etliche sind Kriegsleute, darunter/ die kommen bißweilen herausser/ und lassen sich vor dem Stocke sehen/ und wann die Raubbienen kommen/ und wollen den andern/ die geflogen kommen/ und tragen/ das Wachs oder Honig nehmen/ so stossen sie flugs auff sie zu/ und treiben sie weg. (Coler 1680, S. 27)

Einige sind Architekten, die

aus Wachs [...] längliche Häußlein/ erstlich oben auff ein sonderlichs ihrem Könige/ darnach an den Seiten herunter andere/ darinnen die andern Bienen seyn und wohnen können (Coler 1680, Oecon., S. 257).

Oder sie „richten das Essen zu/ daß sie alle miteinander essen/ wanns Essenszeit ist.“ (Coler 1680, Oecon., S. 542). Bienen sind nicht nur gesellig in der Arbeit, sondern bilden eine Gemeinschaft, die sich um den Tisch des Hausherrn versammelt. In ihrem Haus ,wohnen sie alle miteinander/ arbeiten einander alle zum besten/ geniessen auch ihrer Arbeit allesambt in gemein" (Coler 1680, Oecon., S. 544) Sie handeln selbstlos und gemeinnützig - ein Beispiel für eine ideale Gesellschaft.

Besonders im Kapitel über den „Weiser und Bienenkönig“" mischen sich bei Coler Gleichnis und Beschreibung. So ist der Weiser ,ihre von Gott verordnete Obrigkeit" (Coler 1680, Oecon., S. 545), der mit einem Stachel als Waffe (im übertragenen Sinne) ausgestattet ist:

[Die Weiser] haben keine Haar/ und keine Stacheln: Doch sagen etliche/ daß sie Stacheln haben/ brauchen sie aber nicht/ und thun niemand kein Leyd damit oder ja selten. Dann eine Obrigkeit soll eine Wehr an der Seite tragen/ aber niemand privatim damit beleidigen. (Coler 1680, Oecon., S. 544)

Die naturkundlich interessante Frage danach, ob der Weisel einen Stachel habe, wird nicht experimentell überprüft, sondern metaphorisch gedeutet: Der Bienenkönig muss einen Stachel haben zur Durchsetzung seiner Macht - so wie jeder Menschenkönig über Soldaten und Waffen verfügt. Und wie jeder gute König im Menschenreich darf auch der Weiser seine Macht nicht missbrauchen:

Er hat wohl einen Stachel/ aber er brauchet ihn nicht leichtlich. Dann ob er wol als ein König über sein Volck ein volle Macht und Gewalt hat/ und von Gott eben so wol mit einem Stachel gewappnet/ als ein Kaiser/ König/ Fürst/ oder ander Herr: So ist er doch gleichwohl kein Tyrann/ thut niemand Gewalt/ sticht und beist sein Volck nicht/ stöst sie auch nicht unbarmherzig mit den Füssen von sich/ als die Hunde/ sondern erhält einen jedern Bienen gleich und in treuen Schutz/ und ist daneben gegen seinen Unterthanen gütig und gnädig/ und brauchet seine Stachel wider sie durchaus nicht. (Coler 1680, Oecon., S. 545)

Das Exempel wird konkret übertragen auf die Gesellschaft, wenn Coler schreibt:

Diß hat GOTT in die Natur nicht umsonst und vergebens hinein geordnet und gepflanzet/ sondern er will/ daß ihnen alle Obrigkeiten ein Exempel und Beyspiel [...] nehmen sollen/ daß sie mit ihren frommen und gehorsamen Unterthanen auch sollen Geduld tragen/ und sie wieder alle Billigkeit nicht 
verletzen noch beschweren/ sondern vielmehr bey gleich und bey recht schützen/ und handhaben: Wie auch der Bienenkönig [...] im Nothfall selbst mit Heerskraft außzeucht/ und wider seine Feinde mit einem gantzen heilen Haufen/ und wolbestelten Regiment streitet. (Coler 1680, Oecon., S. 545)

Ein guter König ist ein milder König, der seine Untertanen juristisch nach innen genauso beschützt, wie militärisch nach außen. Diesen Schutz und die weise Staatsführung danken die Bienen - wie die Menschen es sollten - ihrem König durch Gehorsam. Sie „tragen alles ein, was ihnen der König befihlet ein zu schaffen“ (Coler 1680, S. 527f.), und sind ihrem König treu ergeben:

Diesen haben die Bienen in grosser Acht/ bauen ihm ein sonderlich Wohnung oder Schloß/ hoch empor/ darinnen er allein sitze und seyn/ als ein König/ den haben sie lieb und werth/ und bleiben todt oder lebendig bei ihm. (Coler 1680, Oecon., S. 544)

Die Treue der Bienen geht so weit, dass sie um ihren Weiser trauern, wenn er stirbt und nicht mehr arbeiten, „sondern sitzen mit grosser Traurigkeit bey ihrem verstorbenen König/ ihn alle ferner Sorg der Nahrung/ und arbeiten gar nichts" (Coler 1680, Oecon., S. 544)

Am intensivsten verwendet der gelehrte Hohberg (Ende des 17. Jahrhunderts wie die untersuchte Coler-Ausgabe) die Bienen metaphorisch. Sein Einstieg in das Thema ist ein gutes Beispiel, dass und wie die Hausväterliteratur nach den Regeln der klassischen Rhetorik aufgebaut ist und wie die Hausväter mit rhetorischen Mitteln argumentieren: ${ }^{11}$ Hohberg beginnt den Teil über „Bienen-Hütten“ mit einem Prooimion (theoretisierende Einleitung) - nicht nur einer einfachen propositio thematis ${ }^{12}$ -, in welchem Hohberg das Thema topisch in gehobenem Stil (genus grave) ausbreitet. Mit den Gegensatzpaaren „unbeachtet“" vs. „hochgelobt" und „Ungeziefer“" vs. „Nutztier" lenkt Hohberg die Aufmerksamkeit des Lesers hin zu seinem Thema:

Ich werde in diesem Buch von unachtbaren/geringschätzigen/ mehr unter die Insecta und Ungeziefer/ als unter die Thier gerechneten/ doch überaus nützlichen und guten Thierlein zu handeln haben; die zwar vor allen Augen verächtlich/ von allen Vögeln gefressen/ von allen Füssen zertreten/ nichts destoweniger bey allen Verständigen ihr wohlverdientes Lob/ in allen Wirthschafften einen herrlichen Nutzen/ und bey allen Hausvättern ihre billichte Verpflegung und Obsicht verdienen. (Hohberg 1695, Bd. 2, S. 413)

Ganz nach den Regeln der klassischen Rhetorik werden in einem Vergleich (comparatio) zwei mal je drei bipolare Begriffe bzw. Wortgruppen verwendet, die sich aufeinander folgend überbieten (Tab. 1). Die rhetorische Figur ist die Steigerung (incrementum):

\footnotetext{
11 Vgl. Kapitel 2: „Hausväterliteratur als Sachliteratur“, darin den Abschnitt 2.2: „Struktur.“, S. 63.

12 Die propositio thematis wäre die einem Fachtext angemessene Einleitung in das zu behandelnde Thema. In niederer Stilhöhe wird darin das folgende Thema benannt und definiert. In einem prooimion dagegen wird das Thema gehoben und theoretisch - fast exkursorisch - eingeleitet.
} 


\begin{tabular}{|c|c|c|}
\hline & Negativ & Positiv \\
\hline \multirow[t]{3}{*}{ a) } & Unachtbar & Nützlich \\
\hline & Geringschätzig & Gut \\
\hline & unter die $[. .$.$] Ungeziefer gerechnet$ & Thierlein \\
\hline \multirow[t]{3}{*}{ b) } & vor allen Augen verächtlich & $\begin{array}{l}\text { bey allen Verständigen ihr } \\
\text { wohlverdientes Lob }\end{array}$ \\
\hline & von allen Vögeln gefressen & $\begin{array}{l}\text { in allen Wirthschafften einen } \\
\text { herrlichen Nutzen }\end{array}$ \\
\hline & von allen Füssen zertreten & $\begin{array}{l}\text { bey allen Hausvättern ihre billichte } \\
\text { Verpflegung und Obsicht }\end{array}$ \\
\hline
\end{tabular}

Tab. 1: Rhetorische Paarungen zur Illustration des Gegensatzes der Unscheinbarkeit der Biene gegenüber ihrem Nutzen.

Damit nicht genug, steigert sich der Text weiter zu einem hymnischen Lob:

Ich [könnte] unser Bienlein zu einem Beyspiel der arbeitsamen Jugend auf das Theatrum führen/ das nicht allein ihm/ seinen König und Mit-Bürgern/ sondern auch dem Menschen zu guten/ seine Mühewaltung so löblich und emsig anstellet/ daß man wol billig ausruffen kann: Sic vos, non vobis mellificatis Apes. (Hohberg 1695, Bd. 2, S. 414)

„So macht ihr nicht für euch selbst den Honig, ihr Bienen“, zitiert Hohberg einen Vergil zugeschriebenen Ausspruch. Diese Sentenz verweist auf die Uneigennützigkeit als Handlungsantrieb der Bienen, so dass diese nun metaphorisch für diese Eigenschaft stehen. Ihr Altruismus schlägt sich in der Staatsführung der Bienen nieder:

Ich halte nicht/ daß einige in der Welt Innbegriff sich befindende Policey und gemeines Wesen unter den Menschen anzutreffen sey/ darinnen eine bessere und lobwürdige Politica geführt/ einem jeden das seine so billichmässig zugetheilt/ die Obrigkeit so herzlich und treulich geehret und geliebet/ die Unterthanen mit so unverdrossenem und stets wirckendem Fleiß in ihrer Arbeit geübet/ die Aemter mit so tüchtigen Subjecten versehen/ mit so artlicher Geradigkeit verrichtet/ mit so löblicher Ordnung anbefohlen und geschlichtet/ und das gemeine Wesen so treulich betrachtet/ aller eigene Nutzen/ Vortheilhaftigkeit und Untreu aber vermieden bleibe/ als eben bei den holdseligen und weisen Bienlein. (Hohberg 1695, Bd. 2, S. 415)

An dieser Stelle verwendet Hohberg als Redefigur die Häufung (congerius). Argumente der gleichen Art werden zur Unterstreichung der Aussage aneinandergereiht: Gerechtigkeit, Treue, Fleiß, Tüchtigkeit, Ordnung, Gemeinnutz und Altruismus. Diese positiven Eigenschaften der Bienen beruhen auf der weisen und gerechten Herrschaft ihres Bienenkönigs: 
Der König hat die Schönheit/ Majestät und Weisheit/ an statt der Waffen/ die Unterthanen nicht mit dem Stachel der Tyranney/ sondern mit Lieb und Vorsorge zu regieren/ alle seine Mandata und Befehl sind eitel Honig/ die mit affection befohlen/ und mit Lust verrichtet werden. (Hohberg 1695, Bd. 2, S. 415)

Sowohl bei Coler als auch bei Hohberg wird explizit die Milde und Gerechtigkeit des Königs als Ursache für die Liebe seiner Untertanen herausgestellt. Beide Hausväter sprechen sich gegen die Tyrannis aus - ein klassischer Topos aus der antiken Literatur-, sowohl gegenüber den Untertanen als auch (hier geht Hohberg weiter als Coler) bezüglich der Legitimation des Königs:

Bey den Bienen aber mag man wol sagen/ daß es ein angebornes ErbKönigreich sey/ dann der König wird nicht erwählt/ sondern gebohren/ er reisst die Herrschaft weder durch List/ noch durch Verrätherei oder Gewalt zu sich/ sondern die Natur hat ihn/ von seiner Geburt an/ zu einen König erkohren/ er bringet Scepter und Kron mit sich auf die Welt/ und allen seinen untergebenen Bienlein ist von Natur die Ehrerbietung und der Gehorsam gegen ihrem Oberhaupt so fest eingepflantzet/ daß sie weiter keiner Huldigung bedörffen. (Hohberg 1695, Bd. 2, S. 419)

Damit ist Hohberg dem Staatstheoretiker Hobbes nahe, der 1654 dem König als Staatssouverän unbeschränkte Machtvollkommenheit zuspricht. Dieser ist als verkörpertes Gesetz das öffentliche Gewissen des Volkes: „Das Volk ist eine Einheit mit einem Willen und ist einer Handlung fähig [...]; in der Monarchie [ist] der König [...] das Volk.“ (Hobbes 1654/1918, S. 206, Hervorhebgn. im Original)

Deshalb kann das einheitlich handelnde Bienenvolk die Monarchie symbolisieren, in der der „König/ Weisel und Heerführer [...] seinem Amt und Stand gemäßer Vorzug gegönnet wird" (Hohberg 1695, Bd. 2, S. 414). Noch ausführlicher schreibt Hohberg dazu:

Es ist kein Stock oder Schwarm [...]/ der nicht seinen eigenen Weisel und König habe/ den alle Bienen mit solchem Ernst und Eifer/ ehren und lieben/ $\mathrm{daß}$ sie/ als gehorsame Unterthanen/ ihm/ wohin der sich begibt/ folgen/ Tribut/ Nahrung und Unterhalt abstatten/ ihn bewahren/ begleiten und beschützen/ auch in aller Gefahr/ als treue Leib-Trabanten/ in ihre Mitte nehmen/ und treulich anhangen. (Hohberg 1695, Bd. 2, S. 417)

Neben der Staatsform werden weitere gesellschaftliche Organisationsformen sowie menschliche Fähigkeiten und Fertigkeiten soziomorph auf die Bienen übertragen und dann als Vorbild angeführt: Ihre Behausungen sind beispielhaft für das Wirken der Hausfrau im Haus, wo die „emsigen Hausmütter/ ihre Speiß-Gewölbe/ und Vorraths-Kammer darnaben haben und anfüllen können“, ihre Stöcke sind wie Städte, deren „die Gassen also beederseits mit aneinander benachbarten und angräntzenden Häusern versehen/ [...] so sauber und reinlich erhalten " sind (Hohberg 1695, Bd. 2, S. 414). Ihre ganze Gesellschaft ist so eingerichtet wie die menschliche: 
Und wie ein jedes Königreich ihre Könige und Unterthanen/ Räthe und Beamten/ Handwerksleute und Bauren/ Officire und Soldaten/ gesetzte Statuten/ und Ordnungen habe [...]; Also findet sich dieses alles bey den Bienlein/ die in ihren Bienstöcken gleichsam ihre Wohnstätte und ausgezeigten Häuser/ ihr Proviant/ und Königliche Burg halten; ihre Handwerksleute/ die diß alles bereiten/ ihre Soldaten/ die für das Vatterland fechten [...]/ ihre Bauren/ die Speis und Tranck hinein verschaffen/ ihre Räthe/ die dem König beystehen/ ihre Fourier/ Wächter/ Köche/ Hausknechte und Tagwercker/ ihre gewissen Statuten und Ordnungen. (Hohberg 1695, 2. Bd., S. 417)

Bei den Bienen treffen sich - ganz wohleingerichteter Staat - die positivsten Eigenschaften der Untertanen wie die des Königs: ${ }^{13}$

In Summe/ sie haben alle weltliche politische Tugenden/ die Vorsichtigkeit das Gewitter zu prognostizieren/ und sich dafür zu hüten; die Weisheit/ sich der Gelegenheit zu gebrauchen; den Fleiß/ ihre Wirthschafft und VorrathsKammer aufs beste zu versehen; die Einträchtigkeit/ nach ihres Königs Willen den Frieden zu erhalten; und die Tapferkeit/ sich auf Anführung ihres Printzen/ den Feinden zu widersetzen. (Hohberg 1695, Bd. 2, S. 418)

Ihre Tugenden sind die bevorzugten Tugenden im idealen Staat: vorausschauendes und weises Handeln, Fleiß, Eintracht nach innen und Wehrhaftigkeit nach außen.

So wird die Bienenstaatsmetapher bei Coler und Hohberg - den einzigen Autoren der untersuchten Hausvätertexte, die den metaphorischen Gehalt der Bienen thematisieren - für Anmerkungen allgemeiner und gesellschaftlicher Natur verwendet. Auf diese Weise wird kanonisiertes Wissen über komplexe Gesellschaftsvorstellungen vermittelt, das den Lesern Orientierung in ihrer adligen Lebenswelt bietet und die Gottgefälligkeit der bestehenden Ordnung unterstreicht.

Doch Bienen eignen sich nicht nur als Beispiel für einen wohleingerichteten Staat, sondern auch als Analogie für menschliche Eigenschaften und Handlungsweisen. So ist die Biene zwar klein, doch nützlich, was biblisch rückgebunden wird (Coler zitiert Sirach 11, 2-3):

Du solt niemand rühmen umb seines grossen ansehens willen/ noch niemand verachten umb seines geringen Ansehens willen/ dann die Biene ist ein kleines Vöglein, und gibt doch die allersüsseste Frucht. (Coler 1680, Oecon., S. 527)

Anders ausgedrückt: Größe und Schönheit sind keine Qualitätsmerkmale und wer besonders groß oder schön ist, ist nicht gleich besonders nützlich oder gut. Und doch gilt beim Aussortieren der Bienenweisel das Aussehen als Kriterium:

\footnotetext{
13 Vgl. zur Deutungsreichweite der Bienenstaatsmetapher Peil (1983, besonders S. 4). Die politisch gedeuteten Eigenschaften der Bienen, a) Das Bienenvolk sowie b) Der Bienenkönig, Exkurs: Das Problem der Deutungsreichweite (ebd., S. 195-251).
} 
Dann wie ein feiner ehrbarer gerader Leib eine Anzeigung eines ehrlichen redlichen Gemüths/ aber ein ungestallter Leib eine Anzeigung eines unehrbaren Gemüths ist/ daher man auch sage: Man soll sich vor denen hüten/ die die Natur gezeichnet hat. (Coler 1680, Oecon., S. 544)

Denn die Schönheit der äußeren Form ist das äußere Anzeichen für die Qualität der Materie und folglich für die guten inneren Eigenschaften, die in dieser Form stecken. Einfach ausgedrückt: Ein guter Charakter steckt in einem schönen Körper, entsprechend dem antiken Prinzip der Einheit von Wahrem, Gutem und Schönem - Kalokagathia. ${ }^{14}$ Platon sieht „Schönheit als Harmonie und Proportion der Teile“. (de Michele 2006, S. 48) D. h., was nicht wohlproportioniert ist, ist auch nicht schön und gut. ${ }^{15}$

Ein besonderes Kapitel ist die ungeschlechtliche Fortpflanzung der Bienen. Die angenommene Ungeschlechtlichkeit lässt die Bienen besonders rein erscheinen mit einem „züchtigen/ jüngferlichen unbefleckten Leib“ (Coler 1680, Oecon, S. 527). Diese Reinheit schlägt sich nach Meinung der Landwirtschaftsautoren auch auf ihr Verhalten nieder. So mögen sie keinen Lärm, keine unangenehmen Gerüche, keine verdorbenen Speisen und keine Störungen. Bienen sind ein „zornig und rachgierig Insect" (Coler 1680, Oecon., S. 528), das sich bei mutwilliger Störung wehrt. Stattdessen lieben sie Süßes, angenehmen Duft und Musik. Sie sind ein „sauber und rein Insect“ (Coler 1680, Oecon, S. 528), das nur Reines und Sauberes um sich duldet. Das heißt, der Imker muss selbst leise, sauber und duftend sein, wenn er zu den Bienen geht: „Wer umb sie seyn/ und mit ihnen umbgehen will/ der muß sich sauber und rein halten/ daß er nur nicht stincke/ sondern wol rieche.“ (Coler 1680, Oecon, S. 528)

Eine weitere Eigenschaft der Bienen ist ihre Treue gegenüber ihrem Imker. Sie lassen sich von ihm beruhigen:

Wann sie aber also erzürnet seyn/ so muß der Bienenmann/ der stetigs mit ihnen umgehet/ kommen/ und sie zu frieden stellen/ dann den kennen sie gar eigentlich/ und haben ihn lieb. (Coler 1680, Oecon., S. 528)

Sie lieben ihn laut Coler so sehr, dass sie sterben, wenn er stirbt, weshalb man kein Bienenvolk kaufen soll, dessen Imker kurz vorher gestorben ist. Imker und Weisel werden gleichgesetzt in ihrer Funktion als paternales Oberhaupt des Bienenvolkes. Nicht ohne Grund werden Weisel und Imker beide Bienenväter genannt. Denn so, wie die Bienen ihren Weisel lieben und bei seinem Tod um ihn trauern, so lieben sie ihren Imker und betrauern seinen Tod. Wie sie nach dem Tod ihres Weisels kopflos und ohne Führung sind und ohne Anweisungen keine Arbeiten mehr

\footnotetext{
14 Vgl. Megara (1859, I, 18): über kalón (Schönheit) „Nur was schön ist, ist beliebt, was unschön ist, ist auch beliebt nicht." Siehe auch de Michele (2006, S. 48).

15 Siehe ähnlich Thomas von Aquin, ,für den Schönheit neben der richtigen Proportion und der Leuchtkraft oder Klarheit integritas, Vollständigkeit, verlangt - weshalb eine Sache alle Eigenschaften aufweisen muss, die die Form der Materie gegeben hat." (Eco 2007, S. 15.)
} 
durchführen können, so geht es ihnen auch beim Tod ihres Imkers. Übertragen illustriert diese Vorstellung die Position des Bienenvaters als Hausvater, dessen umsichtiger Führung Haus und Gut dringend bedürfen.

Die Hausväterliteratur benutzt diese und andere metaphorisch zugeschriebene Eigenschaften der Bienen zur Erklärung für Regeln der Bienenhaltung. Das metaphorische Potential wird also nicht nur zur Kanonisierung von Orientierungswissen genutzt, sondern auch zur Etablierung von Regelwissen. So kann aus der metaphorischen Treue der Bienen zu ihrem König ganz praktisch abgeleitet werden, dass es so, wie es nur einen Hausvater und weitergehend nur ein Staatsoberhaupt bei den Menschen geben sollte, pro Bienenstock auch nur ein Weisel sein soll, denn „ein jeder hat seinen Anhang/ seyn wider einander/ das hindert sie in ihrer Arbeit gar sehr." (Coler 1680, Oecon, S. 544) Daraus leitet Coler die Regel ab, dass entweder die Schwärme getrennt oder aber Weisel getötet werden müssen, um die Bienen produktiv zu halten:

Wann zween wunderliche rumorische Könige zugleich in einem Stock seyn/ die sich miteinander nicht vertragen können/ einer will regiren/ so will der ander auch regiren/ einer will diß/ der ander das haben/ einer wils also/ der ander wils anders haben. [...] so nehme man den schlimmsten unter diesen beyden Königen/ der auffrührisch ist/ und keinen Frieden haben will/ und würge ihn todt. (Coler 1680, Oecon., S. 547)

Die beobachteten Handlungen der Bienen werden gleichnishaft für die Handlungen der Menschen verwendet. Das Verhalten der Biene wird genauso soziomorph übertragen, wie der gesamte Bienenstaat eine soziomorphe Übertragung ist. Diese soziomorphe Übertragung wiederum ist eine metaphorische Beschreibung dessen, was Bienen in einem Bienenstock tun: Sie bauen Waben, versorgen die Brut und die Weisel, sammeln Nektar, stellen Wachs und Honig her, regulieren die Temperatur, sammeln Wasser und beschützen den Stock.

Wenn Bienen von den Hausvätern metaphorisch behandelt werden, dient dies der Etablierung und Kanonisierung von Orientierungswissen. Die soziomorphe Übertragung hat allenfalls erläuternden, vertiefenden Charakter oder dient der Zurschaustellung der Gelehrtheit der Autoren. Politische Positionen oder gar Kritik lassen sich nicht aus der Hausväterliteratur ablesen, wie es beispielsweise bei Mandeville (1714) der Fall ist. Der Verweis auf die Staatsmetapher nimmt sehr wenig (knapp 10 Prozent) oder gar keinen Raum ein. Weder das praktische Schlesische Wirthschaffts-Buch (ab 1700) noch der moderne Germershausen (1786) sprechen über die Bienen metaphorisch oder diskutieren naturkundlich das Geschlecht der Weiseln. Für sie sind Bienen nützliche Objekte der Ökonomie. 


\subsection{Bienen naturkundlich}

Objekt naturkundlichen Wissens ist die Biene nicht in allen untersuchten Texten, und auch diesem Thema wird weniger Platz eingeräumt als ökonomischen Fragen. Wie bei der metaphorischen Betrachtung der Biene sind es nur etwa 10 Prozent. Trotzdem wird detailliert über die Eigenschaften und Krankheiten der Bienen gesprochen. Ebenso ausführlich geht es darum, welche Kräuter und Blumen als Bienenweide dienen, was den Bienen schaden kann und welche Feinde sie haben.

Coler beschreibt über diese klassischen Fragen hinaus Beobachtungen des Verhaltens der Bienen sehr anschaulich, z. B. den Bienenflug:

Wann sie aus dem Stock wieder außfliechen/ so schiessen sie auch schnell dahin/ wie ein Pfeil. Aber in den Städten/ da sie mit den Ringmauren und viel Häusern umbgeben sind/ fliegen sie erstlich einmal oder etlichs/ gleich als in einem Circkel herumb/ aber doch also/ daß sie immer höher kommen/ als dann schiessen sie schnell/ wie ein klein Pfeilichen davon. (Coler 1680, Oecon., S. 527)

Die genaue Beschreibung scheint auf Beobachtungen zu beruhen, doch zoologische Kenntnisse über Bienen gehen bis zur Mitte des 17. Jahrhunderts (und außerhalb der Naturforschung bis zur Mitte des 18. Jahrhunderts) kaum über die Tierkunde von Aristoteles ${ }^{16}$ hinaus. So werden z. B. die Pollenpakete an den Beinen der Bienen als Wachspakete interpretiert, die die Bienen zum Wabenbau sammeln. Auch andere Berichte über die Bienen sind bei Coler weniger genau und tragen sowohl Züge von Behauptungen als auch von Beobachtungen, wie sich an der Beschreibung der Bienenbrut zeigt:

brüten ein weißes Würmlein auß/ das innerhalb vierzig Tagen eine Biene wird: Daher mans dann auch den Brüt nennt/ daß die Bienen auf der Brüt/ und sie/ wie die Vögel ihre Jungen außbrüten. Sie seynd aber erstlich todt/ wie des Löwen Jungen auch todt seyn/ wann sie jung werden. Aber wie darnach der Löw seine jungen mit dem Geschrey aufferweckt/ und lebendig machet; Also machen die Bienen ihre Junge lebendig mit ihrem Geräusch und Getöhne/ daß sie mit den Flügeln machen. Dann dadurch wehen sie ihnen die Wärme und das Leben zu. (Coler 1680, Oecon., S. 542)

Längst ist bekannt, dass die Biene ein Larvenstadium als Made durchlebt und sich nach einer bestimmten Zeit zu einer Biene entwickelt. ${ }^{17}$ Ins Reich der Legenden gehört die Geschichte über die Erweckung der Brut durch Geräusche wie beim Löwen, die eine Schöpfungserzählung ist. Der Löwe haucht per animam (mittels seines Atems) seinen Jungen Leben (Seele, ebenfalls lat. anima) ein. Die Bienen fächeln ihrer Brut Luft und damit Leben zu. Ihr durch Flügelschlagen erzeugtes

\footnotetext{
16 An folgenden Stellen wird in der Historia animalium (4.Jh. BCE) über Bienen gesprochen: I, 1, 478b/488a (Aristoteles 1957, S. 51f.): die Biene als zwon politik on, staatenbildend wie der Mensch; IV, 7 (S. $170 \mathrm{ff}$ ): Gestalt; V, 21 (S. 227f.): Entstehung; V, 22 (S. 228-232): Arten; IX, 40 (S. 420-433): Verhalten.

17 Siehe z. B. Ovid Metamorphosen: „Siehest du nicht das Geschlecht der Seim eintragenden Bienen, / Die sechseckiges Wachs umschließet, der Glieder entbehren / Bei der Geburt und spät erst Füße bekommen und Flügel?" (Ovid o.J., S. 147)
} 
Summen wird als orales Geräusch gedeutet, so dass das Verhalten der Bienen mit dem des Löwen verglichen werden kann. Nach dieser Vorstellung erwecken beide ihre Nachkommen im schöpferischen Akt des Leben-Einhauchens (per animam vitae). ${ }^{18}$ Die Beschreibung des Zufächelns von Luft vereint folglich der Zeit geschuldete Vorstellungen und Beobachtungen: Einerseits gehen Wärme und Leben in der Säftelehre ${ }^{19}$ Hand in Hand und gelangen die Geschöpfe per animam vitae. Andererseits nutzen Bienen Flügelschlagen und Muskelzittern zur Regulierung der Temperatur im Bienenstock (Ruttner 2003, S. 190-194), was Coler nicht erklären, aber beschreiben kann.

Genauso kann Coler bereits in seinem Kalender (1591/1988) beschreiben, dass Bienen ihren Ausflugsreiz durch die Sonne erhalten, so dass sie an klaren Wintertagen zum Ausflug gebracht werden können, weil „die Biene ein Vogel ist, der sich sehr nach der Sonnen richt" (Coler 1591/1988, B 2v). Deshalb seien für die Bienen klare Wintertage mit Schnee gefährlich. Sie fliegen ob des grellen Lichtes aus, „der Schnee verblendet ihnen die Augen/ und die Kälte bezwinget sie“ (Coler 1591/1988, B 3r). ${ }^{20}$ Die Biene als Vogel zu bezeichnen beruht nicht auf einer zoologischen, sondern auf einer eigenschaftsorientierten Zuordnung: Bienen können fliegen, sind also Tiere der Lüfte, mithin Vögel. ${ }^{21}$

Nachgedacht wird auch über die Entstehung und die Fortpflanzung der Bienen. Die antiken Autoren spekulieren, die Bienen entstünden aus Rinderkadavern, weshalb sie im Lateinischen apis heißen - wie der ägyptische Stier Apis:

Die Gelehrten sind der Meinung/ wie dann auch Plutarch, Virgilius und petrus de Crescentiis, daß von todten verfaulten Ochsen sollen bienen werden/ auß todten Pferden/ Hurnißen/ auß todten Eseln/ Roßteffer/ auß todten Menschen/ Schlangen. (Coler 1680, Oecon., S. 535) 22

Aber Coler hält diese Geschichte für unwahrscheinlich: „es glaube es wer da will/ [...] wollen davon nicht weiter disputieren“ (Coler 1680, Oecon., S. 535), sondern erkennt einen anderen Zusammenhang zwischen Aas und Insekten:

\footnotetext{
18 In diesem schöpferischen Akt schwingt ebenso mit, dass die Eltern ihre Kinder erst formen, wie Ovid das für die Bären beschreibt: „Nicht ist ein Junges sogleich, was eben geboren die Bärin, / Nur halblebendes Fleisch; durch Lecken gestaltet die Mutter / Glieder daraus und bildet die Form, die selber sie einnimmt.“ (Ovid o.J., S. 147f.)

19 Siehe ausführlicher zur Säftelehre Kruse (2010, S. 182).

${ }^{20}$ Bienen haben Temperaturfühler, die eigentlich das Ausfliegen bei zu niedrigen Temperaturen verhindern. Trotzdem kommt es gelegentlich zu tödlichen winterlichen Ausflügen einzelner Bienen. (Ruttner 2003, S. 194)

21 Sie gelten in der Antike auch als Vögel der Musen. Vgl. z. B. Thompson (2007), der auf Aristophanes „Ecclesiazusae“ [Die Weibervolksversammlung] und Varro „Rerum rusticarum libri tres" verweist. Dieser Aspekt wird in der Hausväterliteratur gar nicht besprochen.

22 Vgl. z. B. Ovid: „Siehest du nicht, wie jeglicher Leib, den erweichende Wärme / Auflöst oder die Zeit, in kleines Getier sich verwandelt? / Geh und geschlachteten Stier von erlesener Güte verscharre: / Wie die Erfahrung lehrt, gehn blumenbenaschende Bienen / Bald aus dem Aase hervor, die emsig nach Sitte des Zeugers / Schaffen im Feld und fördern das Werk und sich mühen in Hoffnung." (Ovid o.J., 15,361-67)
} 
Judic. 14 findet Simson einen Bienenschwarm im Aaß deß Löwen/ aber es will drum nicht balde folgen, daß auß dem todten $A a ß$ Bienen worden seynd. Die insecta setzen sich sonsten gerne auff todte Asß/ und sonderlich kriechen die Bienen gern in hohle Löcher. (Coler 1680, Oecon., S. 535)

Für Coler entstehen die Bienen in den Löchern des Wachses der Bienenwaben:

Auch haben sie einen feinen/ züchtigen/ jüngferlichen unbefleckten Laib, dann sie ihre Jungen nit zeugen per libidum, wie andere Thier oder Geflügel/ sondern formieren dieselbigen auf ihre sonderliche Art und Weise in den Löchern des Wachses. (Coler 1680, Oecon, S. 527)

Sie stammen seiner Meinung nach aus „süssen Safft auß den Blättern und Kräutern“, den die Bienen ,in die sechseckigen Löchlein/ in cellulas hexagenas des Rohsts" bringen, auf die sie sich setzen, um „ein weisses Würmlein“ auszubrüten. (Coler 1680, Oecon, S. 542) Dieser Gedanke beruht auf zwei Beobachtungen: Erstens tragen die Bienen Substanzen in den Bienenstock, die sie in die Waben platzieren. Zweitens durchleben die Bienen in den Waben ihr Larvenstadium, sprengen nach der Verpuppung die Deckel der Wabenzelle und kommen als vollentwickelte Biene heraus. Wenn nun der Beobachter mangels anderer Optionen eine auf räumliche Nähe beruhende Kausalität aufstellt, so kann er schließen, dass die Bienen ihre Brut als Substanz von den Pflanzen sammeln und im Bienenstock durch das Wirken der göttlichen Ordnung aus unbelebter Materie belebte Materie wird. So ähnlich beschreibt auch Hohberg zunächst die Bienenvermehrung:

Was ihre Ankunfft und Geburt anbetrifft/ wollen die wenigsten/ daß sie ex concubitu coniugali, wie andere Thiere erzeugt/ sondern im Frühling aus den Blumen und Kräutern gesogen/ [...] in ihre Hütlein eingelegt/ und hernach von ihnen ausgebrutet werden; wie man denn nie sehen solle/ daß die Bienen/ wie andere Fliegen/ Kefer und Insecta einander besteigen/ und also die Generation verrichten/ sondern man siehet im Auswärts/ daß sie erstgesagte weißlichte Brut von dem Feld einführen/ werden auch allzeit die Brut noch/ ehe sie anfangen ihr Honig-Arbeit zu beginnen/ vorher eintragen. (Hohberg 1695, Bd. 2, S. 415)

Mangels sichtbarer Paarung der Bienen wird ungeschlechtliche Vermehrung angenommen und die Entstehung lebender Materie aus unbelebter. Aber Hohberg sieht darin ein Problem und hält eine geschlechtliche Vermehrung nicht für abwegig:

Die Verständigsten halten dafür/ ihre Vermehrung geschehe modo naturae in generatione ordinario, und daß Gottes Befehl-Wort/ crescite $\mathcal{E}$ multiplicamini, die Bienen eben so wol/ als alle ander Creaturen angehe/ daß also die Bienen untereinander junge Bienen/ der Weisel aber mit Bienen/ auf dies Weis und Maß/ wie ihnen von Natur eingepflanzt worden/ Weisel und Thronen zeugen/ ob mans schon (weil sie meistentheils in ihren Stöcken sich verhehlen) so offentlich nicht kan 
wahrnehmen/ so kan doch wol seyn/ daß die natürlich ihnen eingepflanzte Schamhaftigkeit/ wie an mehr Thieren zu sehen/ sie dißfalls darzu anleite/ ne verecundiae leges videantur contemnere, das Brut wie ein weisses Würmlein wird in den Wesel (das ist/ in die Häuslein ihres Rostes) eingelegt/ und/ zu seiner Zeit/ in eine Biene transformirt/ wie man/ wann man nachsehen will/ bey den grösser Würmen/ Kopff/ Füsse/ Leib und Flügel erkennen/ und also über Gottes Weisheit sich verwundern und bedancken kann. (Hohberg 1695, Bd. 2, S. 415f.)

Eine geschlechtliche Vermehrung will Hohberg nicht deshalb ausschließen, weil keine Paarung beobachtet wurde. Denn seiner Meinung nach gilt auch für die Bienen das Bibelwort: „Seid fruchtbar und mehret euch!“" (Gen 1,28), das Hohberg nur in der geschlechtlichen Vermehrung als der natürlichen Ordnung entsprechend erfüllt sieht. Deshalb spricht er den Bienen Schamhaftigkeit zu und glaubt, sie vollzögen die Paarung an geschützten Orten.

Doch sicher ist er sich nicht über die Vermehrung der Bienen, denn im Kapitel 18 Von den Threnen referiert er verschiedene Ansichten über die Natur der Drohnen, ihre Aufgabe im Stock und ihre Herkunft. Exemplarisch steht die letzte von Hohberg vorgeschlagene Herkunftsgeschichte für seine Unsicherheit:

Die Threnen wären allein diejenigen Bienen/ welche/ wann sie einen Menschen oder Viehe hecken und beissen/ ihre Stachel verlohren haben; und weil alle geschnittene Thiere besser wüchsen und grösser würden/ (wie an Stieren und Ochsen mercklich zu sehen) also würden auch die castrirt Bienen stärcker von Leib/ als die gemeinen Bienen. Nachdem nun solche entstachelte Bienen zum Ausflug nicht tauglich/ würden sie von dem Weisel der Brut vorgesetzt/ und nach Verrichtung derselben/ als unnütze Gäste/ ins Exilium verwiesen/ oder gar erwürget. (Hohberg 1695, Bd. 2, S. 428f.)

Mit dem Problem der Vermehrung im Zusammenhang steht die Unkenntnis über das Geschlecht der Weisel. Obwohl Charles Butler (1560 - 1647) im Jahre 1609 aufdeckt, dass es sich beim sogenannten König um eine Biene weiblichen Geschlechts handelt (Butler 1609), wird dieses Wissen in der Zeit narkotisiert, ${ }^{23}$ um die Staatsmetapher (siehe den vorherigen Abschnitt) aufrechterhalten zu können.

23 Eigenschaften von Objekten werden vom Betrachter entsprechend seiner eigenen Weltanschauungsweise entweder als wichtig hervorgehoben oder als nichtig narkotisiert, also als irrelevant verdrängt. Deutlich geschieht dies, wenn die Eigenschaften die Weltvorstellung des Betrachters entweder besonders stützen (= Hervorhebung) oder besonders in Frage stellen (= Narkotisierung). (Eco 1989, S. 220f.) 
Noch hundert Jahre später schreibt der englische Arzt Joseph Warder (1688 1718) in seinem Werk Webr-und wabrbafte Amazonen, oder die Monarchie der Bienen (1712/dt. 1718) gegen die Meinung an, das Geschlecht der Weisel sei männlich. Der niederländische Zoologe und Naturforscher Jan Swammerdam (1637 - 1680), der Ende des 17. Jahrhunderts das Geschlecht der Weisel experimentell nachweist, verwirft in seiner Bibel der Natur (niederl. u. latein $1737 /$ dt. 1752) die Idee vom Bienenstaat vollständig und nennt die Arterhaltung die einzige Motivation der Bienen:

Daß die ganze Beywohnung der Bienen von nichts anders herrührt, und auf nichts anders abzielet, als auf die nothwendige Fortpflanzung und Auferziehung, und das im übrigen bey ihnen keine Regierung, keine Regenten-Wahl, keine bürgerliche, keine häusliche Einrichtung, Zucht und Tugend im geringsten nicht zu bemerken sind. (Swammerdam 1752, S. 159)

Die Bienen handeln nach den Regeln der Natur „so unvermeidlich, als die Folge des Winters auf den Sommer unvermeidlich ist." (Swammerdam 1752, S. 174.) Swammerdams Vorstellungen sind konträr zur vorherrschenden Betrachtung der Bienen als bewusst handelnde Wesen und werden erst in der zweiten Hälfte des 18. Jahrhunderts anerkannt. So bezeichnet Schirach 1770 die Weisel ausdrücklich als Bienenkönigin, so im Titel seiner Ausfuebrliche[n] Erlaeuterung der unschaetzbaren Kunst, junge Bienenschwaerme, oder Ableger zu erzielen. Nebst einer natuerlichen Geschichte der Bienenkoenigin. Auch Krünitz spricht $1774 \mathrm{im}$ Lemma Biene von einer Königin:

Gewöhnlicher Weise ist in jedem Stocke oder Korbe nur Ein Weibchen, dem man sonst den Nahmen des Weisers oder Bienenköniges gab, das man aber eher, wegen seines Geschlechtes, die Königinn nennen sollte. (Biene 1774, S. 169f.)

Damit ist die Frage nach der Vermehrung der Bienen und dem Geschlecht der Weisel geklärt und wird in der Fachliteratur nicht mehr diskutiert. Die Erkenntnis, dass die Weisel weiblich ist, setzt sich aber in der Sachliteratur nur sehr schwer durch und wird noch 1738 von Friedrich Christian Lesser in seiner InsectoTheologia problematisiert. Er sichert die Übertragbarkeit des Bienenstaatsmodells, indem er auf europäische Königinnen und deren kluge Staatsführung verweist:

Betrachtet man insonderheit die Weiber-Monarchie derer Bienen, so muß man sich über derselben kluge Verfassung ihres Regiments so sehr verwundern, als man sich ehemals über das Regiment der Königin Christinae in Schweden, der Königin Annae in England, und der jetzigen Groß-Zaarin von Rußland gleiches Nahmens verwundert. (Lesser 1738/1740, S. 227f.)

Nichtsdestotrotz seien diese klugen Königinnen vereinzelte Ausnahmen und es lasse sich keinesfalls eine Regel daraus ableiten. 
Coler diskutiert naturkundliches Wissen neben dem Problem der Vermehrung der Bienen auch anhand der Frage, woraus die Bienen Honig herstellen. Bei ihm fällt der Honig nicht vom Himmel, ${ }^{24}$ sondern stammt aus Blüten: „Etliche saugen eine süßen/ subtielen/ lautern/ reinen/ und gar gesunden Saft aus den Blumen/ nemlich den Honig.“ (Coler 1680, Oecon., S. 527) Es ist nicht klar, ob Coler über Beobachtungen spricht, oder aus anderen Texten über Bienen zitiert, denn auch Aristoteles, obwohl er zunächst den Honig als Himmelsgabe bezeichnet, lässt die Bienen Honig „mit einem zungenähnlichen Werkzeug“ saugen aus „allen Blumen [...], die in einem Kelch blühen". 25

Hohberg schreibt Plinius die Ansicht zu, Honig sei eine Himmelsgabe, die mit dem Tau an Frühlingstagen auf die Pflanzen fällt, so wie das Manna. Die Bienen sammelten diese himmlische Substanz und fertigten daraus ihren Honig. Doch Hohberg bestreitet dies und argumentiert, Bienen flögen viel lieber, wenn es trocken sei und sammelten dann von den Blumen den Honig. Dieser Honig habe sogar die Eigenschaften der Blumen, von denen er stamme, ,daher man in Sardinia bitters Hönig findet/ wegen des Wermuths/ der häuffig darinnen wächset“ (Hohberg 1695, Bd. 2, S. 459). ${ }^{26}$ Doch Hohberg weiß nicht sicher, woraus die Bienen den Honig herstellen und stellt klar:

daß einem Verständigen weit besser anstehet/ seine Unwissenheit bekennen/ als mit übelfundierten und nur eingebildeten Vermuthungen etwas gewisses behaupten wollen/ wo man die rechte eigentliche Ursach unfehlbar nicht wissen kan/ weil Gottes Verordnung viel Wundersachen seiner Weißheit allein vorbehalten/ und dem menschlichen Fürwitz nur in einem Nebel gezeigt hat [...] Das fernere Spintisiren wollen wir bleiben lassen/ und Gott um diese seine/ wie auch um alle andere Wohlthaten danken. (Hohberg 1695, Bd. 2, S. 459)

Der Verweis auf die Unergründlichkeit der göttlichen Ordnung bei Unsicherheit über die Ursache eines Phänomens aus der naturalen Umwelt rettet die Expertise des Autors. Außerdem bietet er eine probate Möglichkeit, eine auf theoretischen Überlegungen basierende, aber durch theoretische Überlegungen nicht zu beantwortende Frage als unentscheidbar stehen zu lassen. Der Topos der Unergründlichkeit der gottgeschaffenen Welt ist für das Erkenntnisverständnis der Autoren von erbaulichen Sachtexten grundlegend. Das Gleiche gilt für die Autoren von naturkundlichen Fachtexten, die ihre Beschreibungen der Natur in der Schöpfungsgeschichte verankern. So ist Gott in allen Fragen der zentrale Bezugs-

\footnotetext{
24 Aristoteles sagt, Honig falle vom Himmel: „Die Wabe entsteht aus den Blüten, den Wachsüberzug tragen sie aus dem Harz der Bäume herbei, der Honig, den sie bringen, fällt aus der Luft, besonders um die Anfangszeit gewisser Sternbilder und wenn ein Regenbogen sich über die Erde gespannt hat.“ (Aristoteles 1957, V, 22, $553 \mathrm{~b}$ )

25 Aristoteles (1957, V, 22, 553 b).

26 Siehe z. B. Ovids Amores, wo Wachs und Honig erwähnt werden, die von korsischen (nicht sardischen) Bienen aus Schierling (nicht Wehrmut) hergestellt wurde: „Fort, unseliges Wachs, das nur ,ich kann nicht' enthält. Dich hat gewiss eine korsische Biene von ragender Schierlingsblüte gesammelt und dann giftig zum Honig gesellt.“ (Ovid 1880, 1,11): Die Antwort; vgl. auch Olbertz (2008, besonders S. 107). Krünitz nennt in seinem Lemma Mayblumenbusch als Garanten für bitteren Honig Dioscorides, Plinius, Xenophon und Diodorus von Sicilien (Mayblumenbusch 1802).
} 
punkt. (Friedrich 2009, S. 195) Auf diese Weise erhält der Leser Orientierung in einer undurchschaubaren Welt, über die in den Texten kein neues und erhellendes Weltwissen vermittelt werden kann.

Neben Spekulationen über die Herkunft der Bienen und des Honigs sowie das Geschlecht der Weiseln werden in den Texten auch anatomische Kenntnisse über die Bienen transportiert:

Den Honig [...] bringens im Leibe in einem sonderlichen Bläßlein in die Stöcke/ damit erfüllen sie die Löcher des Wachses/ und verschmierens obe fein artig wieder mit einem subtilen Wachs/ daß es nicht wieder wegfließen kann. (Coler 1680, Oecon., S. 527)

Und etwas später: „Wann man die Biene anatomirt/ oder entzwey reisset/ so findet man in ihrem Leibe ein klein zart Bläßlein voll subtil Honig.“ (Coler 1680, Oecon., S. 533.) Dieses „Bläßlein“ ist die Honigblase, in die der Nektar aus den Blüten eingesaugt im Stock wieder erbrochen wird. Aus diesem Nektar entsteht am Ende der Honig. Es ist nicht klar, ob Coler aus eigener Anschauung schreibt oder sich auf vorhandenes Wissen stützt. ${ }^{27}$ Hohberg zitiert zum gleichen Thema die Regulae Oeconomicae von Achatius Sturm (1680):

Artlich ist/ was Herr Achaz Sturm in seinen Regulis Oeconomicis fol. 229. schreibet/ in seiner 511. Regul: Wann man eine Biene voneinander zerreißet/ so wird man in der Mitte ein Bläslein finden/ darinnen das Honig ist/ etliche als ein Erbse/ etliche als ein Hirsekorn/ darnach viel oder wenig Nutzung zu finden ist. (Hohberg 1695, Bd. 2, S. 416)

Durch den Verweis auf eine Autorität legitimiert Hohberg seine Aussage und greift auf vorhandenes Weltwissen über die Anatomie der Biene zurück. Dieses Wissen ist neues Wissen - neu insofern, als es nicht aus der Antike stammt, und als Erfahrungswissen experimentell generiert wurde. Aus diesem generierten Wissen wird Regelwissen abgeleitet: Die Größe der Honigblase im Inneren der Biene ist Ausdruck ihrer ökonomischen Leistungsfähigkeit.

Das Schlesische Wirthschaffts-Buch, das sich an anderer Stelle oft auf Hohberg beruft, geht in der Bienenkunde andere Wege. Z. B. begründet es auf ganz eigene Weise, warum Bienenstöcke schattig stehen sollten:

Die Stöcke soll man setzen/ daß die Flug-Löcher gegen Mittag gewendet werden/ doch daß auch Bäume davor stehen/ damit im Sommer die Hitze nicht immerzu auf den Stöcken liegen kan/ der honig möchte wegen allzu

\footnotetext{
27 Auch Höffler (1614, S. 21) schreibt nach Nikolaus Jacob (sein Buch über Bienen erschien 1568 in Görlitz) über die Honigblase: „Das Honig tragen sie im Leibe in einem kleinen Bläßlein/ daß etwann eines Hanffkörnleins gros/ das Wachs aber an ihren Beinen." Da der ursprüngliche Text von Nikolaus Jacob (bei Coler Jakob Nickel genannt) bereits 1568 in Görlitz erschienen ist, liegt nahe, dass Coler den Text kannte. Seine Familie lebte von 1566 bis 1574 in Schlesien, sein Vater Jacob Coler beschäftigte sich in dieser Zeit mit Landwirtschaft und trug erste Gedanken zum später von Johann Coler herausgegebenen Hausbuch zusammen. Vgl. Schröder-Lembke (1978a), besonders S. 94.
} 
großer Hitze flüßig werden/ und schmelzen/ darinnen die Bienen leicht ersauffen und umkommen. (Schlesisches Wirthschaffts-Buch 1700, S. 298)

Die Vorgänge im Bienenstock sind dem anonymen Autor nicht geläufig, doch er stellt Vermutungen an, die mit Erfahrung unterfüttert werden, was sich als Gedankenspiel folgendermaßen darstellen könnte: 1) Kristallisierter Honig wird flüssig, wenn man ihn erwärmt. 2) Insekten - also auch Bienen - ertrinken in süßen Flüssigkeiten. 3) Bienen ertrinken in durch Sonnenwärme verflüssigtem Honig. Daraus folgt, dass Bienenstöcke im Schatten stehen sollen.

Der in der Hausväterliteratur vermittelte Wissensstand über die Biene als naturkundliches Objekt läuft den in der Fachliteratur diskutierten Erkenntnissen deutlich nach. Das liegt in der Natur der Textsorte, da Sachliteratur zwar neues Wissen vermitteln will, doch muss dieses neue Wissen bereits in der Fachliteratur kanonisiert sein und darf nicht mehr diskutiert werden. Denn die Sachliteratur will den Lesern Orientierung bieten in einer unübersichtlichen Welt - und Fachdiskussionen sind für Laien unübersichtlich. Außerdem sollten aus dem vermittelten Wissen Regeln abgeleitet werden können, die in einer unübersichtlichen Welt handlungssichernd wirken. Das geht nur anhand kanonisierten Weltwissens, das schon in ein Orientierungssystem eingeordnet ist.

\subsection{Bienen ökonomisch}

Sowenig wie die Herkunft des Honigs oder die Vorgänge im Bienenstock bekannt sind, genauso wenig wissen die Landwirtschaftsautoren über die Bestäubung der Blüten durch die Bienen. Dieser Umstand wird erst 1793 von Christian Konrad Sprengel (1750-1816) entdeckt und in Dem entdeckten Geheimniss der Natur im Bau und in der Befruchtung der Blumen beschrieben. ${ }^{28}$ Und weil die Autoren nichts über die Bestäubungsleistung wissen, wird auch in der ökonomischen Betrachtung der Bienen dieser Punkt nicht erwähnt. Sie sind nützliche Tiere, die Honig und Wachs als wichtige Grundstoffe produzieren: Honig ist das einzige lokal verfügbare Süßungsmittel bis zur Erfindung der Herstellung von Zucker aus der Zuckerrübe im 19. Jahrhundert. Außerdem ist er ein wichtiges Konservierungsmittel und wird in der Heilkunst verwendet. Wachs ist Lichtspender und wird fast universal eingesetzt. Insofern haben die Bienen als Rohstofflieferanten einen ökonomischen Zweck, der die Beschäftigung mit ihnen sinnvoll macht. Coler schreibt, Bienen sind:

einem Haußwirth in seiner Narung auch sehr nützlich und gut/ dann man kann davon seinen Honig und Wachs haben/ und darff einer das gantze Jahr nichts drauff wenden/ wann er nur recht mit ihnen umgehen will. (Coler 1680, Oecon., S. 526)

Etwas später wird die Nützlichkeit der Bienen nochmals betont: „Wem die Bienen wol schwärmen/ der darff sich nicht härmen." (Coler 1680, Oecon., S. 527)

${ }^{28}$ Sprengel (1793), dessen Erkenntnisse zu Lebzeiten keine Beachtung fanden (Wunschmann 1893). 
Diese große ökonomische Bedeutung der Bienen schlägt sich im Umfang der Betrachtungen nieder. Die Hausväter widmen etwa 80 Prozent des Raumes, den die Bienen in den Ökonomiken einnehmen, der Frage nach den Regeln der Bienenhaltung. Diese Regeln werden aus dem naturkundlichen Weltwissen generiert und als Regelwissen kanonisiert. Einige Regeln werden auch aus dem metaphorisch ermittelten Orientierungswissen gezogen, das mit Weltwissen kombiniert wird. Das Regelwissen bietet dem Landwirt Handlungssicherheit bezüglich der Bienenhaltung auf seinem Gut.

Bienen sollen, da sie ökonomisch wertvoll sind, nicht von Angestellten versorgt werden, müssen wohltemperiert gehalten und beim Schwärmen wieder in die eigenen Stöcke gelenkt werden. Außerdem gibt es Anleitungen über den Bau und die Aufstellung von Bienenkörben bzw. -stöcken, wie man beim Schwärmen neue Bienenvölker abteilt, worauf man beim Kauf von Bienen achten muss und wie Bienen insgesamt gehalten werden. ${ }^{29}$

Auch bei Hohberg gibt die Biene sorgfältige Pflege mit Zins zurück:

Die Bienen pflegen uns das kleine Oertlein/ darauf sie stehen/ die geringe Herberge/ die wir ihnen vergönnen/ den wenigen Fleiß/ den wir darauf wenden/ mit so reichem Wucher und überschüssiger Verzinsung abzuzahlen/ daß sie wohl mehr als dreifachen Zehenden darfür reichen. (Hohberg 1695, Bd. 2, S. 414) (10 $^{30}$

Diesen Fleiß soll der Hausvater belohnen, indem er die Bienenstöcke in den Kräutergarten und in die Nähe der Obstbäume setzt. Er soll für Frischwasser sorgen, sie vor kalten Winden und Störungen schützen, vor Schaden durch Fraßschädlinge bewahren und sie - im Gegensatz zu Coler - von erfahrenen Wärtern betreuen lassen.

Im Schlesischen Wirthschaffts-Buch, das sich an den weniger begüterten Landadligen wendet, sind die Bienen das Steckenpferd des Hausvaters und in ihrem Nutzen nicht zu überschätzen. Deshalb soll der Hausvater die Arbeit mit

\footnotetext{
${ }^{29}$ Eine Besonderheit im Brandenburgischen wird am Rande erwähnt: die Wald- und Heidezeidlerei, die von professionellen Zeidlern betrieben wurde. Die Zeidler hielten ihre Bienenvölker in ausgehöhlten Bäumen, vor allem in Kiefern (Coler 1680, S. 562). Diese Wirtschaftsweise wird territorial gebunden an: „Fürstenwalde/ Stockau/ Cöpenigk/ Beskow und da umbher“ (Coler 1680, Oecon., S. 561). Es wird angegeben, dass die Zeidler jährlich 4 Tonnen Honig oder 36 Taler abzuliefern hätten. „Tonne“ bezieht sich laut Brockhaus (2006) auf eine alte deutsche Volumeneinheit (Fässer, Tonnen als Frachtbehälter). 1 Tonne $=6$ Stechkannen $\triangleq 108$ Kilogramm. Die brandenburgischen Zeidler mussten also im 17. Jahrhundert umgerechnet 432 Kilogramm Honig pro Jahr an ihren König abliefern.

Da die Zeidlerei nicht zur Hauswirtschaft gehört, sondern ein eigenes Gewerk ist, wird diese Wirtschaftsform hier nicht bearbeitet. Außer Coler geht keiner der untersuchten Autoren selbständig auf die Zeidlerei ein, es sei denn, es wird Coler zitiert. Siehe über Zeidlerer und Waldbienenhaltung Biene (1774), Schirach (1774) und über die Rechtsfragen des Zeidelns Lühn-Irriger (1999), besonders V.2.: Zeidelwesen.

${ }^{30}$ Der ökonomische Nutzen der Bienen wird von Varro (116 BCE - 27 BCE) in der römischen Antike beziffert. So habe der Besitzer eines kleinen Hofes jährlich 10.000 Sesterzen durch Honigverkauf eingenommen (Varro, rust. 3,016,010f.). Zum Vergleich: ein halber Liter Wein kostete ungefähr einen halben Sesterz (vgl. Kampmann 2004).
} 
den Bienen auch nicht dem Gesinde überlassen, schon gar nicht die Wachsherstellung: „Derowegen diese Arbeit dem unachtsamen Gesinde nicht zu vertrauen ist/ sondern ein jeder Hauswirth soll es lieber selber thun. “31

Für Germershausen dagegen soll Bienenhaltung nicht Liebhaberei betuchter Gutsherren sein, sondern nutzbringender Landwirtschaftszweig. Bienenhaltung als kostenintensives Steckenpferd dient als negatives Beispiel:

[Man] errichtete nun bey vielen Edel- und Amtleuten, statt der Hütten der Armuth, fast Bienenpaläste, (ich habe einst im Vorbeyreisen ein Bienenhaus, welches an die 800 Thlr. gekostet, und wobey sich der Herr an dem einen Flügel ein eignes Bienenobservatorium mit anbauen lassen,) die $[\ldots]$ nach Verlauf von etwa 10 Jahren [...] abgebrochen wurden. (Germershausen 1786, Bd. 5, S. 512.)

Von diesen „Bienenkünsteleyen“ will er hin zu einfacher Bienenwirtschaft, basierend auf der Haltung in Bienenkörben und in der Größe an die vorhandenen Bienenweiden angepasst. Germershausen thematisiert als erster (und auch letzter, da mit ihm das Genre stirbt) in der Hausväterliteratur die Endlichkeit natürlicher Ressourcen. War bis dahin die Fruchtbarkeit der Natur gottgegeben, ${ }^{32}$ so kann sie nun aufgebraucht werden:

Die gewöhnlichen Feld- und Wiesenblumen an und vor sich allein wollen es selten ausmachen, weil sie nicht alle von Bienen besucht werden, oder als Honigblumen angesehen sind. Die nicht große Menge der Feld- und Wiesenblumen muß ferner gar nicht so angesehen werden, als ob sie unerschöpflich sey. (Germershausen 1786, Bd. 5, S. 513.)

Das beschreibt Germershausen mit einem Beispiel, das er aus der Beobachtung schöpft:

Wer Beobachter seyn will, bemerke sich z. B. des Frühjahrs in seinem Blumengarten eine einfache Hyazinthe oder Primel, die des Morgens vor seinen Augen von einer Biene besuchet worden. Kommen nach der ersten Biene auf solche Blume andere nachgeflogen, so werden sie schnell wieder abfliegen, zum Beweise, daß die Blume von der ersten Biene bereits erschöpfet worden. (Germershausen 1786, Bd. 5, S. 513f.)

Germershausen generiert mit diesem Beispiel neues Orientierungswissen: Die Natur ist nicht unerschöpflich, obwohl sie von Gott wohleingerichtet dem Menschen zum Nutzen übergeben wurde. Diesen Umstand bindet er an naturkundliches Weltwissen und leitet daraus Regelwissen ab: Der Mensch muss sich an die natürlichen Gegebenheiten anpassen - in diesem Fall bezüglich der Bienenhaltung. Es muss die der Bienenvölker beschränkt werden, Felder als Bienenweiden angelegt werden und Bienen als „Wanderbienen“ (Germershausen 1786, Bd.5, S. 517) je nach Jahreszeit und Nahrungsangebot in ein

31 Dieser Satz findet sich identisch in allen vier Ausgaben von 1700 bis 1746, z. B. Kurtz abgefaßtes schlesisches Wirthschaffts-Buch (1700, S. 331) bzw. Schlesisches Wirthschaffts-Buch (1712, S. 349).

32 Siehe dazu vor allem den Abschnitt über die Bodenfruchtbarkeit. 
anderes Gebiet versetzt werden. Diese Bienenwirtschaftsform propagiert in der Antike bereits Columella ( $\rightarrow 70 \mathrm{CE})^{33}$, aber erst Germershausen führt diesen Vorschlag in die frühneuzeitliche Hausväterliteratur ein. ${ }^{34}$

Germershausen bestätigt anhand von Zahlen den Nutzen der Bienen und erläutert, wie viel Wachs, Honig und neue Bienenschwärme (zur Erneuerung des eigenen Bestandes wie auch als Handelsgut), erzeugt werden können:

In schlechten Jahren [...] hat man von 30 Körben weiter nichts, als etwa 20 Pfund

Wachs. In mittelmäßigen Jahren, und deren sind immer 2 und 3 gegen ein schlechtes, giebt es von 30 Körben schon mehr Wachs, noch einige gute Schwärme, und zu 30 bis 80 Kannen Ausbeute an Honig. Eben diese 30 Körbe können einen halben Zentner Wachs in guten Jahren haben. Die guten Schwärme kommen eben so hoch, als der alte Stamm gewesen ist, und man kann dazu etlichen 100 Kannen Honigvorrath anlangen. (Germershausen 1786, S. 539f.)

Übertragen bedeutet dies: Der Imker kann in schlechten Jahren 20 Pfund, also etwa 10 Kilogramm $(9,34 \mathrm{~kg}$ ) Wachs ernten (das Berlinische Pfund hat etwa 467 Gramm). In guten Jahren sollte ein halber Zenter $(25,7 \mathrm{~kg})$ möglich sein $(1$ Zenter $=110$ Pfund). 30 Kannen Honig (in einem schlechten Jahr) entsprechen $540 \mathrm{~kg}$ Honig $\left(1 \mathrm{Kanne} \bumpeq 18 \mathrm{~kg}^{35}\right)$. In guten Jahren können Imker von 30 Bienenkörben $1800 \mathrm{~kg}$ Honig ernten.

Angesichts dieser Zahlen liegt auf der Hand, dass die Bienenhaltung ein wichtiger wirtschaftlicher Faktor für die Gutsbesitzer ist. Erfolgreiche Honig- und Wachsproduktion sowie die von Bienenvölkern sichert die Eigenversorgung genauso wie die Möglichkeit handelbarer Überschüsse durch den Verkauf der Rohstoffe und überzähliger Bienenvölker. Die Kenntnis praktikabler und probater Regeln über die Bienenhaltung ist vor diesem Hintergrund für die Landwirte unerlässlich. Deshalb legen die Autoren der Hausväterliteratur mehr Wert auf das Vermitteln von Regelwissen, als darauf, die Leser mit neuem naturkundlichem Weltwissen bekannt zu machen oder ihre eigene Gelehrtheit mittels kanonisiertem Orientierungswissen zu demonstrieren. Solches Wissen wird vor allen dann vermittelt, wenn sich daraus Regeln für die Bienenhaltung ableiten lassen bzw. wenn die Zielgruppe als gelehrt und an theoretischen Überlegungen interessiert angesehen werden kann. Das trifft vor allem auf die begüterten Adligen zu, die von Hohberg angesprochen werden und die auch das bevorzugte Klientel der ColerAusgabe von $1680 \mathrm{zu}$ sein scheinen.

\footnotetext{
33 Columella (1472, 9, 14, 19f.), vgl. Thompson (2007).

34 Z. B. schreibt Julius Bernhard von Rohr in der Einleitung zu der allgemeinen Land- und FeldWirthschaffts-Kunst weder über Wanderbienenhaltung noch über Waldzeidlerei (Rohr 1720, S. 300325). Krünitz (Biene 1774) kennt die Wanderbienenhaltung, wie Germershausen sie beschreibt, nicht. Er beschreibt stattdessen ausführlich die Wald- und Heidezeidlerei, wobei er sich z. B. auf Coler (1611) und Schirach (1774) bezieht.

35 Vgl. Fußnote 35.
} 


\section{Schlussbetrachtungen}

Die Biene ist in ihrer Klugheit, ihrem Fleiß und ihrer Kunstfertigkeit ein leuchtendes Vorbild für den Menschen, gleichzeitig ökonomisch nützlich in ihrem Werk und ein Beweis für die Güte Gottes, wie Coler schreibt:

Item [...] unter allen Thieren sey die Biene das klügste und kunstreichste/ und habe schier eine Seele und einen Verstand wie ein Mensch/ und ihr Werck sey ein Göttlich Werck/ und dem Menschen sehr nützlich. (Coler 1680, Oecon., S. 546.)

Ähnlich hymnisch formuliert Hohberg:

Daraus wir absonderlich des grossen Weltschöpffers gütige Vorsorg erkennen und preisen sollen/ daß er aus so kleinen und unachtbaren Thierlein dennoch dem

Menschen so grosse und danckwürdige Wolthaten erweisen/ und so vortreffliche Vorspiel und Meisterstücke vorstellen kann. (Hohberg 1695, Bd. 2, S. 414.)

Ihre Vorbildlichkeit und ihr ökonomischer Nutzen prädestinieren die Bienen als Topos in der Hausväterliteratur, die als Sachliteratur nicht nur Regel- sondern auch Weltwissen vermitteln will, und dem Leser Orientierung in einer undurchschaubaren Welt bietet.

Orientierungswissen wird dem Leser anhand der Bienen über Metaphern nahe gebracht. Einerseits gibt es die Bienenstaatsmetapher, in der der Bienenstaat für den monarchisch geführten Staat steht, in dem ein weiser König die arbeitsteilige Beschäftigung seiner ihm unbedingt gehorchenden Untertanen überwacht. Um diese Metapher aufrecht zu erhalten, wird naturkundliches Wissen über das Geschlecht der Weisel narkotisiert. Aber nicht nur der Bienenstaat wird soziomorph übertragen, sondern es werden auch Eigenschaften der Bienen wie ihr Fleiß, ihre Klugheit und ihre Umsicht als Vorbild benutzt. Aber die Autoren der Hausväterliteratur benutzen diese Metapher nicht zur politischen Kritik, sondern beschränken sich auf das Weitererzählen kanonisierter Narrative; sie wiederholen Gemeinplätze.

Diese Übertragung bleibt nicht beim Orientierungswissen stehen, sondern bietet die Möglichkeit zu beschreiben, was in einem Bienenstock geschieht: Bienen bauen Waben, versorgen die Brut, sammeln Nektar, beschützen den Stock usw.

Das in den Texten referierte naturkundliche Wissen über Bienen erreicht kaum den Stand des je gegenwärtigen Wissensstandes, der in der Fachliteratur diskutiert wird. Trotzdem wird sehr erfolgreich Bienenwirtschaft betrieben - auch ohne Kenntnis der genauen Abläufe in einem Bienenstock. Dass erfolgreiche Bienenwirtschaft betrieben wird, ist von existentieller Bedeutung. Schließlich dient die Biene in erster Linie der Produktion von Überschüssen, d. h. sie ist ein Objekt mit hohem ökonomischen Nutzen.

Als solches wird die Biene als besonders gewinnträchtig erachtet, da sie wenig Pflege benötigt, aber großen Ertrag an Honig und Wachs bringt. Die Kenntnis und Anwendung probater Regeln über die Bienenhaltung ist deshalb für die Landwirte unerlässlich, weshalb diesem Teil der Unterweisungen in der Hausväterliteratur 
besonders viel Raum gegeben wird. In den Texten, die naturkundlich und/oder metaphorisch über die Bienen sprechen, macht dieser Teil rund 80 Prozent aus, bei den anderen Autoren 95 bis 100 Prozent.

Die drei Betrachtungsweisen sind voneinander abhängig. Naturkundliche Fragen, die auf die Mehrung von Weltwissen abzielen, werden vor dem Hintergrund des ökonomischen Nutzens gestellt und generieren im Zusammenhang mit ökonomischen Fragen Regelwissen. Metaphorische Beschreibungen, die Orientierungswissen transportieren, nehmen Naturkunde auf und übertragen sie genauso, wie umgekehrt die Naturkunde sich auf Metaphern stützt. Die Betrachtungsweisen bedingen sich gedanklich und vermischen sich textuell, indem innerhalb weniger Sätze zwischen ihnen gewechselt wird. Auf diese Weise gehen Belehrung über Weltwissen, Unterweisung über Regelwissen und Erbauung (Orientierung in der Welt) die Grundanliegen jedes Sachtextes - Hand in Hand.

Welches Naturbild ergibt sich am Beispiel der Bienen? Zum Einen ist die Natur Vorbild für die Menschen, hier in Form des Bienengleichnisses. Zum Anderen ist sie nützlich als Lieferant von Rohstoffen. Zum Dritten muss sie gelenkt werden, z. B. bei der Trennung von Bienenvölkern oder der Auslese der besten Weisel. Viertens ist Natur als Schöpfung Gottes undurchschaubar (z. B. bei der Frage, woher der Honig stammt), aber mit den richtigen Mitteln beherrschbar, weil Gott dem Menschen die Herrschaft über sie gegeben hat (Gen. 1, 28f.).

Die Natur erhält in den Texten drei Kardinalattribute: Sie ist nützlich, beherrschbar und vorbildhaft, wenn auch undurchschaubar. Diese drei Attribute korrelieren mit den Sachliteraturzielen der Information, Belehrung und Erbauung, also der Versorgung des Lesers mit Regelwissen über ökonomisches Handeln (Information), mit Weltwissen über naturkundliche Vorgänge (Belehrung) und mit Orientierungswissen zur Welterklärung (Erbauung). Es ist dabei unentscheidbar, ob der jeweilige Gegenstand der Betrachtung Anlass zur Welterklärung und Wissensvermittlung ist oder andererseits bekannte Welterklärungsmuster zur Erläuterung des Gegenstandes dienen. Beides steht in einem dialektischen Verhältnis.

Die drei Kardinalattribute des Gegenstandes ändern sich nicht, obwohl sich die Methoden der Wissensautorisierung bezüglich des Gegenstandes ändern. So wird im Laufe von 200 Jahren der Fokus von der Kanonisierung des Wissens mittels Vorläuferliteratur zur Generierung von Wissen mittels Erfahrung und Experiment verschoben. Diese Verschiebung erfolgt für die untersuchten Sachtexte aber nicht linear oder entsprechend der Verschiebung dieser Methoden in der Fachliteratur am Ende des 17. und in der ersten Hälfte des 18. Jahrhunderts, sondern zeitlich versetzt und komprimiert in der zweiten Hälfte des 18. Jahrhunderts. 


\section{Literatur}

Aristoteles (1952): Topik. Paderborn: Schöningh. (= Gohlke, Paul: Die Lehrschriften; II: Logik).

Aristoteles (1957): Tierkunde. 2. Aufl. Paderborn: Schöningh. (= Gohlke, Paul: Die Lehrschriften; 8,1).

Aristoteles (1999): Rhetorik. Stuttgart: Reclam.

Artikel „Biene“ (1774): In: Krünitz, Johann Georg (Hrsg.): Oeconomische Encyclopädie oder Allgemeines System der Land-, Haus- und StaatsWirthschaft in alphabetischer Ordnung. Bd. 4. Berlin: Pauli, S. 417-805.

Brandes, Helga (1999): Frühneuzeitliche Ökonomieliteratur. In: Meier, Albert; Grimminger, Rolf und Pfister, Manfred (Hgg.): Die Literatur des 17. Jahrhunderts. München/Wien: Hanser, S. 470-484. (= Hansers Sozialgeschichte der dt. Literatur v. 16. Jh. b. z. Gegenwart ; 2).

Brabantinus, Thomas Cantipratanus (1510): Bonum universale de Apibus (Dit is der bien boeck. Swolle: Os, 15.I.1488). [Paris]: Venalis habetur in vico sancti Jacobi apud sanctum Benedictum ad signum Georgii [Wolfgang Hopyl].

Brunner, Horst (1993) Hrsg.: Wissensliteratur im Mittelalter und in der Frühen Neuzeit. Bedingungen, Typen, Publikum, Sprache. Wiesbaden: Reichert. (=Wissensliteratur im Mittelalter; 13).

Brunner, Otto (1956): Hausväterliteratur. In: von Beckerath, Erwin (Hrsg.): Handwörterbuch der Sozialwissenschaften. Bd. 5. Göttingen: Vandenhoeck \& Ruprecht, S. 92-93.

Brunner, Otto (1966): Das „Ganze Haus“ und die alteuropäische „Ökonomik“ (1956). In: Oeter, Ferdinand (Hrsg.): Familie und Gesellschaft. Tübingen: Mohr, S. 23-56. (= Civitas gentium).

Butler, Charles (1609): The feminine monarchie or a treatise concerning bees, and the due ordering of them wherein the truth, found out by experience and diligent observation, discovereth the idle and fondd conceipts, which many haue written anent this subiect. At Oxford: Printed by Ioseph Barnes.

Coler, Johann (1611): Nützlicher Bericht von den Bienen oder Imen Welche einem hausswirt in seiner Narung nützlichen vnd gut davvon man Honig vnd Wachs haben kan/ Ob man ihnen wol des Jahrs keinen sonderlichen Hirten wie dern andern Vieh halten darff so mus doch der Haussherr derer Eigentschafft vnd Tugend erlernen die Schwarmzeit in acht haben .... Wittenberg: Hellwig.

Coler, Johann (1680): Oeconomia ruralis et domestica. Darin das gantz Ampt aller trewer Hauß-Vätter und Hauß-Mütter/ beständiges und allgemeines HaußBuch/ vom Haußhalten/ Wein-Acker-Gärten-Blumen- und Feld-Bau 
begriffen/ auch Wild- und Vögelfang/ Weid-Werk/ Fischereyen/Viehezucht/ Holzfällung ... Hiebevor von Joanne Colero beschrieben/ Jetzo aber/ auff ein Neues in vielen Büchern mercklich corrigiert, vermehrt und verbessert (1593). Franckfurt am Mayn: In Verlegung J.B. Schönwetters sel. Erben.

Coler, Johann (1988): Calendarium oeconomicum \& [et] perpetuum. Vor d. Haußwirt, Ackerleut, Apotecker und andere gemeine Handwercksleut, Kauffleut, Wanderßleut, Weinherrn, Gertner und alle diejenige so mit Wirtschafft umbgehen ... (1591). Neudr. der Erstausg. Wittenberg 1591, 1. Aufl. Leipzig: Edition Leipzig.

Columella, Lucius Iunius Moderatus (1472): De re rustica. In: Merula, Georgius (Hrsg.): Scriptores rei rusticae. Venedig: Nicolas Jenson.

Deinlein, Baptist (1975): Das römische Sachbuch. Dissertation. Erlangen-Nürnberg. Eco, Umberto (1985): Semiotik und Philosophie der Sprache. München: Fink.

Eco, Umberto (1989): Die Rolle des Lesers. In: Franz, Michael; Richter, Stefan (Hgg.): Umberto Eco. Im Labyrinth der Vernunft. Texte über Kunst und Zeichen. 3. Aufl. Leipzig: Reclam, S. 190-245.

Eco, Umberto (2007) Hrsg.: Die Geschichte der Hässlichkeit. München: Hanser.

Engels, David; Nicolaye, Carla (2008) Hrsg.: Ille operum custos.

Kulturgeschichtliche Beiträge zur antiken Bienensymbolik und ihrer Rezeption. Hildesheim: Olms. (= Spudasmata; 118).

Fraas, Carl (1864): Geschichte der Landbau- und Forstwissenschaft. München: Oldenbourg. (= Geschichte der Wissenschaften in Deutschland; 3).

Friedrich, Udo (2009): Weltmetaphorik und Wissensordnung in der Frühen Neuzeit. In: Schierbaum, Martin (Hrsg.): Enzyklopädistik 1550 - 1650. Typen und Transformationen von Wissensspeichern und Medialisierungen des Wissens. Berlin: Lit, S. 193-248. (= Pluralisierung \& Autorität; 18).

Germershausen, Christian Friedrich (1786): Der Hausvater in systematischer Ordnung. Vom Verfasser der Hausmutter. Bd. 5. Leipzig: Junius.

Haage, Bernhard Dietrich; Wegner, Wolfgang (2007): Deutsche Fachliteratur der Artes in Mittelalter und Früher Neuzeit. Unter Mitarb. von Gundolf Keil und Helga Haage-Naber. Berlin: Schmidt (= Grundlagen der Germanistik; 43).

Herz, Andreas (2009): Der edle Palmenbaum und die kritische Mühle. Die Fruchtbringende Gesellschaft als Netzwerk höfisch-adeliger Wissenskultur der frühen Neuzeit. In: Denkströme. Journal der Sächsischen Akademie der Wissenschaften. 2, S. 152-191. 
Hobbes, Thomas (1918): Grundzüge der Philosophie. Zweiter und dritter Teil: Lehre vom Menschen und Bürger (1654). Dt. hrsg. v. Max Frischeisen-Köhler. Leipzig: Felix Meiner. (= Philosophische Bibliothek; 158).

Höffler, Caspar (1614): Die rechte Bienen-Kunst: Aus bewehrter Erfahrung zusammen geschrieben. Daraus ein fleissiger Haußhalter gründlich erlernen kan, wie er eine Bienenzucht zulegen/ solcher in der Person ersprießlichen warten/ und fruchtbarlich geniessen könne. Weyland, zum Theil für 46 Jahrn von Nicolao Jacob publicirt: Jetzo ... trewl. an Tag geben durch Caspar Höflern/ Meißnern (Nikolaus Jacob, 1568). Leipzig: In Henning Grossen des Eltern Druckerey und auff seinen Verlag verfertiget.

Hoffmann, Julius (1959): Die „Hausväterliteratur“ und die „Predigten über den christlichen Hausstand“. Lehre vom Hause und Bildung für das häusliche Leben im 16., 17. u. 18. Jhdt. Weinheim: Beltz (= Göttinger Studien zur Pädagogik; 37).

von Hohberg, Wolf Helmhardt (1695): Georgica Curiosa Aucta, Das ist:

Umständlicher Bericht und klarer Unterricht Von dem Adelichen Land- und Feld-Leben. Auf alle in Teutschland übliche Land- und Haus-Wirthschafften gerichtet (1682). Nürnberg: Endter.

Johach, Eva (2007): Der Bienenstaat. Geschichte eines politisch-moralischen Exempels. In: Heiden, Anne von der (Hrsg.): Politische Zoologie. 1. Aufl. Zürich: Diaphanes, S. 219-235. (= [Sequenzia]).

Kampmann, Ursula (2004): Die Münzen der römischen Kaiserzeit. Regenstauf: Gietl.

Keil, Gundolf (1982) Hrsg.: Fachprosa-Studien. Beiträge zur mittelalterlichen Wissenschafts- und Geistesgeschichte. Berlin: Schmidt.

Kindlers Literatur-Lexikon. (2009): Hrsg. v. Arnold, Heinz Ludwig. Stuttgart: Metzler.

Kruse, Ulrike (2010): Zum Beispiel die Melone. In: Herrmann, Bernd; Kruse, Ulrike (Hgg.): Schauplätze und Themen der Umweltgeschichte. Umwelthistorische Miszellen aus dem Graduiertenkolleg. Göttingen: Univ.-Verl., S. 181-203.

Kuhn, Hugo (1980): Entwürfe zu einer Literatursystematik des Spätmittelalters. Tübingen: Niemeyer.

Kurtz abgefaßtes schlesisches Wirthschaffts-Buch (1700): worinnen gründlich gezeiget wird/ Wie dieselbe fortzustellen/ und was dabey in acht zu nehmen/ damit ein guter Nutzen daraus erfolge ... versehen von T. Breßlau und Liegnitz: In Verlegung Michael Rohrlachs Seel. Wittib und Erben.

Lesser, Friedrich Christian (1740): Insecto-Theologia, oder Vernunfft= und schrifftmäßiger Versuch, wie ein Mensch durch aufmercksame Betrachtung derer sonst wenig geachteten Insecten zu lebendiger Erkänntniß und Bewunderung der Allmacht ... Gottes gelangen könne (1738). 2., vermehr. Aufl. Frankfurt: Blochberger. 
Lühn-Irriger, Susanne (1999): Die Biene im deutschen Recht von den Anfängen bis zur Gegenwart. Münster: Lit. (= Juristische Schriftenreihe; 129).

de Mandeville, Bernard (1714): The fable of the bees: or, private vices publick benefits. Containing, several discourses, to demonstrate, that human frailties, during the degeneracy of Mankind, may be turn'd to the advantage of the civil society, and made to supply the Place of Moral Virtues. London.

Artikel „Mayblumenbusch“ (1802): In: Krünitz, Johann Georg (Hrsg.):

Oeconomische Encyclopädie oder Allgemeines System der Land-, Haus- und Staats-Wirthschaft in alphabetischer Ordnung. Bd. 86. Berlin: Pauli, S. 227.

von Megara, Theognis (1859): Die Elegien des Theognis (Elegi). Deutsch im Versmaße der Urschriften von Wilhelm Binder. Stuttgart: Krais \& Hoffmann.

de Michele, Giromalo (2006): Das ästhetische Ideal Griechenlands. In: Eco, Umberto (Hrsg.): Die Geschichte der Schönheit. München: Hanser, S. 36-51.

Neu vermehrtes Schlesisches Wirthschaffts-Buch (1712): worinnen gründlich gezeiget wird/ was durchs gantze Jahr dabey in acht zu nehmen; damit ein guter Nutzen daraus erfolge. Bestehend in zweyen Theilen .... Breßlau und Liegnitz: in Verlegung Michael Rohrlachs seel. Wittib und Erben.

Neu-vermehrtes Schlesisches Hauss- und Wirthschaffts-Buch (1725): worinne zu finden, was durchs gantze Jahr, sowol in Wirthschaffts-Rechnungen, als auch im Hauß-Wesen, Ackerbau, Viehzucht, Gaertnerey und andern œconomischen Sachen, in Acht zu nehmen und zu verrichten sey, damit ein guter Nutzen daraus erfolge. Bresslau und Lignitz: bey Michael Rohrlach [jun.].

Neuvermehrtes Schlesisches Haus- und Wirthschafts-Buch (1746): Welches durchs gantze Jahr zeiget, Was so wohl in Wirthschafts-Rechnungen, Als auch im Haus-Wesen, Acker-Bau, Vieh-Zucht, Gärtnerey und anderen Oeconomischen Sachen ... bey dieser neuen Auflage Mit einem wohl eingerichteten Koch- und Trenchier-Büchlein Und mit Dem wohl unterwiesenen Brandtewein-Brenner und Destilirer, auch einer Anweisung von Confect-Backen vermehret. Breßlau und Leipzig: Verlegts Daniel Pietsch, Buchhändler.

Nicolaye, Carla (2008): ,Sed inter omnia ea principatus apibus“. Wissen und Metaphorik der Bienenbeschreibungen in den antiken Naturkunden als Grundlage der politischen Metapher vom Bienenstaat. In: Engels, David; Nicolaye, Carla (Hgg.): Ille operum custos. Kulturgeschichtliche Beiträge zur antiken Bienensymbolik und ihrer Rezeption. Hildesheim: Olms, S. 114-137. (= Spudasmata; 118).

Olbertz, Thomas (2008): „Illum admirantur et omnes“. Apis in der klassischen römischen Literatur. In: Engels, David; Nicolaye, Carla (Hgg.): Ille operum custos. Kulturgeschichtliche Beiträge zur antiken Bienensymbolik und ihrer Rezeption. Hildesheim: Olms, S. 95-113. (= Spudasmata; 118). 
Ovid (1880): Elegien der Liebe (Amores). Leipzig: Teubner.

Ovid (o.J.): Ovids Werke. Deutsch in den Versweisen der Urschrift. Bd. 3: Metamorphosen nebst geographischem Register. 7. Aufl. Berlin:

Langenscheidtsche Verlagsbuchhandlung.

Peil, Dietmar (1983): Untersuchungen zur Staats- und Herrschaftsmetaphorik in literarischen Zeugnissen von der Antike bis zur Gegenwart. München: Fink. (= Münstersche Mittelalter-Schriften; 50).

Porombka, Stephan (2005): Regelwissen und Weltwissen für die Jetztzeit. Die Funktionsleistungen der Sachliteratur. Arbeitsblätter für die Sachbuchforschung; 2. Berlin. $<$ http://www2.hu-berlin.de/sachbuchforschung/MEDIA/abfdsbf/ Arbeitsblaetter_Sachbuchforschung_02.pdf> (letzter Besuch: 26.05.2010).

Porombka, Stephan (2007): Sachbücher und -texte. In: Anz, Thomas (Hrsg.): Handbuch Literaturwissenschaft. Bd. 2: Methoden und Theorien. Darmstadt: Wiss. Buchges., S. 155-160.

Richarz, Irmintraut (1991): Oikos, Haus und Haushalt. Ursprung und Geschichte der Haushaltsökonomik. Göttingen: Vandenhoeck \& Ruprecht.

Riebe, Harald (1973): Literatur der Tatsachen. In: Die Literatur. Wege zum Verständnis der Literatur. Autor, Gattungen, Sprache, Schrift, Buch, Theater. Freiburg im Breisgau: Herder, S. 78-114. (= Wissen im Überblick).

von Rohr, Julius Bernhard (1720): Einleitung zu der allgemeinen Land- und FeldWirthschaffts-Kunst derer Teutschen. Drinnen die allgemeinen Regeln und Anmerckungen die so wohl bey der Land und Feld-Oeconomie überhaupt als insonderheit bey dem Ackerbau, der Viehzucht, Gärtnerey, Wäldern, Jägereyen, Teichen und Fischereyen. Leipzig: Johann Christian Martini.

Roscher, Wilhelm (1874): Geschichte der Wissenschaften in Deutschland. Neuere Zeit. Bd. 14: Geschichte der Nationalökonomik in Deutschland. München: Oldenbourg.

Ruttner, Friedrich (2003): Naturgeschichte der Honigbienen. Biologie, Sozialleben, Arten und Verbreitung. 2. Aufl. Stuttgart: Kosmos.

Schirach, Adam Gottlob (1770): Ausfuehrliche Erlaeuterung der unschaetzbaren Kunst, junge Bienenschwaerme, oder Ableger zu erzielen. Nebst einer natuerlichen Geschichte der Bienenkoenigin, oder Weyselerzeugung, und deren wichtigen Einflusse in die Oekonomie der Bienen; nach neuen genauen Beobachtungen und physikalischen Erfahrungen. Budißin [Bautzen]: Drachstedt.

Schirach, Adam Gottlob (1774): Adam Gottlob Schirachs Wald-Bienenzucht, nach ihren großen Vortheilen, leichten Anlegung und Abwartung, mit Kupfern herausgegeben und mit einer Vorrede, nebst des Herrn Verfassers Lebensbeschreibung begleitet von Johann George Vogel. Breßlau: Korn. 
Schmidt-Biggemann, Wilhelm (2008): Was macht Wissen verlässlich? Überlegungen zum Verhältnis von Wissenschafts- und Wissensgeschichte. In: Dickhut, Wolfgang; Manns, Stefan; Winkler, Norbert (Hgg.): Muster im Wandel. Zur Dynamik topischer Wissensordnungen im Spätmittelalter und Früher Neuzeit. Göttingen: V \& R Unipress, S. 1329. (= Berliner Mittelalter- und Frühneuzeitforschung; 5).

Schmidt-Biggemann, Wilhelm; Hallacker, Anja (2007): Topik: Tradition und Erneuerung. In: Frank, Thomas; Ursula, Kocher; Tarnow, Ulrike (Hgg.): Topik und Tradition. Prozesse der Neuordnung von Wissensüberlieferungen des 13. bis 17. Jahrhunderts. Göttingen: V \& R Unipress, S. 15-27. (= Berliner Mittelalter- und Frühneuzeitforschung; 1).

Schmidt-Voges, Inken (2008): Oiko-nomia. In: Düselder, Heike; Weckenbrock, Olga; Westphal, Siegrid (Hgg.): Adel und Umwelt. Horizonte adeliger Existenz in der Frühen Neuzeit. Köln: Böhlau, S. 402-427.

Schröder-Lembke, Gertrud (1953): Die Hausväterliteratur als agrargeschichtliche Quelle. In: Zeitschrift für Agrargeschichte und Agrarsoziologie. 1/2, S. 109-119.

Schröder-Lembke, Gertrud (1978a): Die Genesis des Colerschen Hausbuches und die Frage seines Quellenwertes (ZAA 3/1967: 121-129). In: Schröder-Lembke, Gertrud (Hrsg.): Studien zur Agrargeschichte. Stuttgart: Fischer, S. 93-101. (= Quellen und Forschungen zur Agrargeschichte; 31).

Schröder-Lembke, Gertrud (1978b): Petrus de Crescentiis und sein Einfluss auf d. frühe dt. Sachliteratur. In: Schröder-Lembke, Gertrud (Hrsg.): Studien zur Agrargeschichte. Stuttgart: Fischer, S. 75-91. (= Quellen u. Forschungen z. Agrargeschichte; 31).

de Serres, Olivier (1603): Le Théâtre d'Agriculture et Mesnage des champs (1600). 2. Aufl. Paris: Saugrain.

Sieglerschmidt, Jörn (1999): Die virtuelle Landwirtschaft der Hausväterliteratur. In: Sieferle, Rolf Peter; Breuninger, Helga (Hgg.): Natur-Bilder. Wahrnehmungen von Natur und Umwelt in der Geschichte. Frankfurt am Main: Campus, S. 223-254.

Sprengel, Christian Konrad (1793): Das entdeckte Geheimniss der Natur im Bau und in der Befruchtung der Blumen. Mit 25 Kupfertafeln. Berlin: Vieweg.

Stein, Peter K. (1980) Hrsg.: Sprache, Text, Geschichte. Beiträge zur Mediävistik und germanistischen Sprachwissenschaft aus dem Kreis der Mitarbeiter 1964 1979 des Instituts für Germanistik an der Universität Salzburg. Göppingen: Kümmerle. (= Göppinger Arbeiten zur Germanistik; 304).

Sturm, Achatius (1680): Regulae Oeconomicae Oder nützliche HaußhaltungsRegeln. Durch langer Jahre Erfahrenheit und Versuchung bewähret un[d] heilsamlich erfunden. Leipzig: Christian Michael.

Swammerdam, Jan (1752): Der Arzneykunst Doctor von Amsterdam, Bibel der Natur. Worinnen die Insekten in gewisse Classen vertheilt, sorgfältig 
beschrieben, zergliedert, ..., mit vielen Anmerkungen über die Seltenheiten der Natur erleutert, und zum Beweis der Allmacht und Weisheit des Schöpfers angewendet werden. Leipzig: Gleditsch.

Thompson, J. S. (2007): Bienenzucht. In: Der Neue Pauly. Bd. 2: Geschichte der antiken Texte. Darmstadt: Wiss. Buchges., S. 650-652.

Topitsch, Ernst (1958): Vom Ursprung und Ende der Metaphysik. Eine Studie zur Weltanschauungskritik. Wien: Springer.

Varro, Marcus Terentius (2002): Gespräche über die Landwirtschaft. Buch 3. Hrsg., übers. und erl. von Dieter Flach. Darmstadt: Wiss. Buchges. (= Texte zur Forschung; 67).

Warder, Joseph (1718): Wehr- und wahrhafte Amazonen, oder die Monarchie der Bienen (The true amazons: or, the monarchy of bees. London, 1712). Hannover: Förster.

von Wilpert, Gero (2001): Sachbuch. In: von Wilpert, Gero (Hrsg.):

Sachwörterbuch der Literatur. 8. verb. u. erw. Aufl. Stuttgart: Kröner, S. 712.

Wunschmann, E. (1893): Sprengel, Christian Konrad. In: Allgemeine Deutsche Biographie (ADB). 35, S. 293-296. <http://www.deutsche-

biographie.de/artikelADB_pnd119151871.html> (letzter Besuch: 26.08.20). 


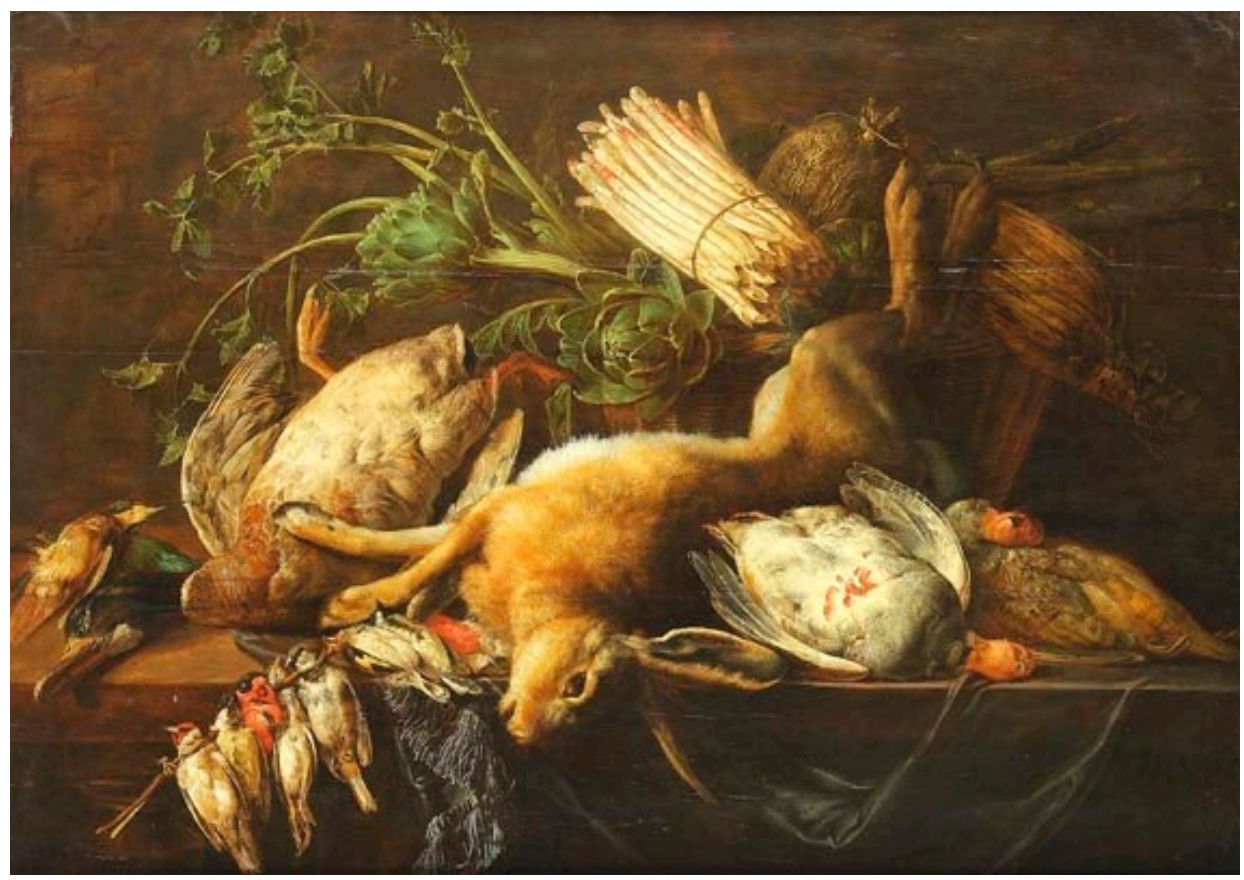

Abb. 1: Adriaen van Utrecht (1599-1652) Küchenstillleben mit erlegtem Wild und Gemüse. Zweite Hälfte 1640er Jahre. Öl auf Holz. Privatbesitz

Die Zutaten sind beisammen. Verbunden sind Vorfreude und Melancholie. Raffiniert spielt der Maler mit den Andeutungsebenen: Dem Aristotelischen Diktum vom ,animal triste“, das vorher den „kleinen Tod“ gestorben ist, der in Wahrheit das Leben unterhält, wird hier mit den toten Tieren die Tristesse des großen Todes gegenübergestellt. Auch sie sind, als Nahrung, ein notwendiger Beitrag zum Leben. Die Zusammenstellung der Objekte ist keine wirkliche Küchenszene, denn der unter den Singvögeln zweimal vertretene Stieglitz ist ein Zugvogel. Er ist zwar zur Spargelernte wieder in Mitteleuropa, dann ist hier aber die Artischocke nicht erntereif, und Hasen und Enten stünden, sofern geschützt, ebenfalls nicht zum Fang bzw. Abschuss. Weil es sich nicht um eine wirkliche Küchensituation handeln kann, ist nach einer anderen Bedeutung zu suchen. Die erwiesenen, vermuteten oder sympathetischen Eigenschaften der Nahrungsmittel liefern den weiterführenden Deutungsschlüssel: Artischocken und Spargel, damals absolute Luxusartikel, bilden zusammen mit Hase (oder Kaninchen) und Enten das Versprechen eines Mahls mit erotischer Konnotation an einer sozial gehobenen Tafel. Unter den einschlägig scheinbar unverdächtigen Singvögeln hängt, prominent unmittelbar vor der Tischkante, ein Sperlingshahn, das Symbol für Unkeuschheit und sexuelle Hyperaktivität schlechthin, schwerlich durch die Symbolik des Stieglitz (rechter Nachbar) gedämpft, der eben nur mit einer seiner Bedeutungen eine theologische Sinnzuschreibung erfährt, in der anderen aber für Beharrlichkeit und Fruchtbarkeit steht. Während der unmittelbare Nachbar links neben dem Sperling nicht zu identifizieren ist (Sperlingshenne?), sind die nächsten wieder bestimmbar: Dompfaffhahn, Sperlingshahn, Stieglitz. Der Dompfaff, auch Gimpel genannt, repräsentiert Tölpelhaftigkeit, Dummheit, Ungeschicklichkeit. Bringt er einen kritisch-ironischen Unterton in die Szene? Denn so leuchtend rot ist sein Federkleid nur während der Balz im Frühjahr, nicht aber in den übrigen Jahreszeiten. 


\section{Natura morte im Delikatessenladen oder Wie viele Divisionen hat die Natur?}

Bernd Herrmann

Als die Frankfurter und die niederländischen Stillebenmaler ihre enigmatisch codierten, artifiziellen Arrangements alltäglicher Gegenstände, raffinierter Leckereien, exotischer Delikatessen und wundersamer Naturdinge zu atemberaubender Kunstfertigkeit führten, war allen klar: hier betrachtete man calvinistisches Selbstbewusstsein und gekonnte Vanitasroutinen. Opulenter Naturgebrauch war nach dem göttlichen Verfügungsauftrag selbstverständlich und bedurfte keiner weiteren Rechtfertigung. ${ }^{1}$

\footnotetext{
1 Abgestellt wurde auf Genesis 1,28: ,Seid fruchtbar und mehrt euch und füllt die Erde und macht sie euch untertan und herrscht über die Fische im Meer und über die Vögel unter dem Himmel und über alles Getier, das auf Erden kriecht.“ Es ist der folgenschwere Imperativ, der als „dominium terrae“ wirkungsgeschichtlich auf Naturkonzepte des Abendlandes Einfluss nahm. Eigentlich müsste auffallen, dass aus diesem Auftrag alle Pflanzen ausgenommen sind. Der Begriff des „Getiers“ ist zudem eine ungeeignete Kategorie, weil er keine Differenzierung erlaubt und im Wortsinne nur die für menschliche Ohren lärmigen Tiere bezeichnet. In einem wörtlichen Sinne funktionierte der Auftrag auch deshalb nicht, weil die hier ausgenommene Kontrolle über Pflanzen als Primärproduzenten gleichzeitig die Kontrolle über die Lebensgrundlage aller Nahrungsketten darstellte. Kein Sophist der Nachaufklärung hätte je diesen Widerspruch aufgedeckt und damit z. B. Lynn Whites Argumente noch vor ihrer Formulierung (White, 1967) ad absurdum geführt. Selbstverständlich geht es aber in dieser Passage um das vorweggenommene Faktum, dass Menschen - gleichgültig welchem Überzeugungssystem sie anhängen - in der Lage sind, der Erde ihren Willen aufzuzwingen. Von den kritischen Exegeten wird dabei vergessen, dass auch „die Gräser“, „die Saurier“ oder „die Korallen“ zu ihrer Zeit planetare Wirkungen erzielten, ganz zu schweigen von den Organismen, welche die Photosynthese erfanden und damit lang-fristig letztlich alle Lebewesen töteten, die in einer Sauerstoff-
} 


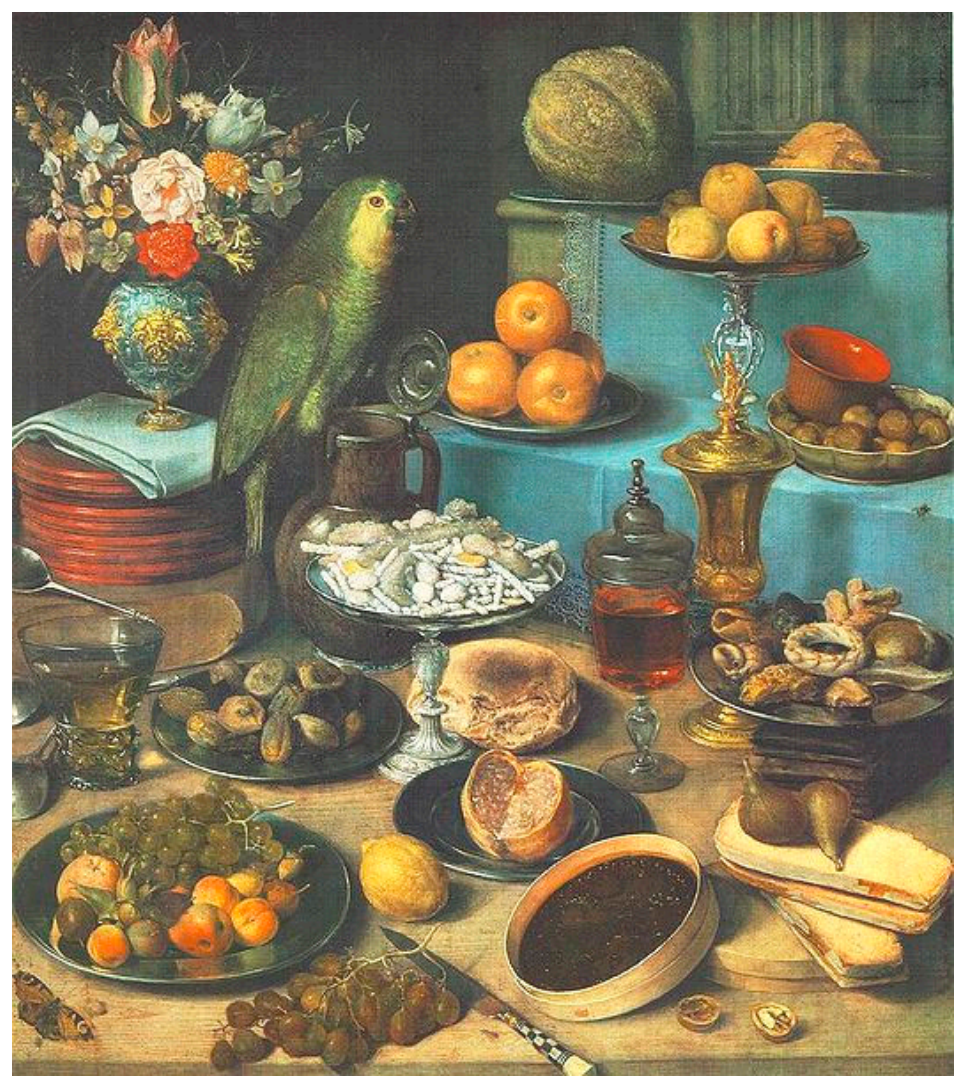

Abb. 2: Georg Flegel (1566-1638) Großes Schauessen mit Papagei. (o.J., Öl auf Kupfer. Alte Pinakothek, München.)

Köstliche exotische Früchte, exquisites Naschwerk und erlesene Genussmittel präsentieren sich in dieser Auslage, der als Blickfang eine südamerikanische Blaustirnamazone hinzugefügt wurde. Die Tulpenblüten seltener Färbung im Blumenstrauß unterstreichen die erlesene Kostbarkeit der einzelnen Gegenstände und den im Abgebildeten repräsentierten Wohlstand (vgl. Wettengl 1993; hierzu weiter in einem Nachtrag am Ende des Aufsatzes)

atmosphäre nicht überleben konnten. Aber das war noch zu den menschenfreien geologischen Zeiten der Erde, die so in der Bibel nicht vorkommen. Diese Gedankenführung ist erkennbar albern, weil sie Einsichten der Naturwissenschaft mit Postulatenethik verbindet und damit das Feld der naturalistischen Fehlschlüsse betritt. - Die Passage in Genesis 2,15 „Und Gott der Herr nahm den Menschen und setzte ihn in den Garten Eden, dass er ihn baute und bewahrte.“ [Hervorhebung B.H.] wird offenbar im Allgemeinen wo nicht absichtlich übersehen - auf die Zeit vor der Vertreibung aus dem Paradies bezogen und damit offenbar als obsolet für den postparadiesischen Menschen angesehen. - Will man nicht auf „christliche“ Begründungsrhetoriken zurückgreifen, genügt allein schon der Hinweis auf die platonische Weltsicht, wonach die Welt so eingerichtet sei, dass sie dem Menschen nütze. Skrupelloser Naturgebrauch hat also zumindest im Abendland eine lange geistige Tradition, da bei Lichte besehen die angeblichen Mahnungen selbst der griechischen Philosophen seit Platon keinen naturbewahrenden Gestus, sondern politische Gesellschaftskritik enthalten. 
Im Gegenteil, statt einer Rechtfertigung enthielt der Naturgebrauch, sofern er mit wirtschaftlichem Erfolg gepaart war oder sich diesem verdankte, die auf göttliches Wohlgefallen gegründete Selbstbestätigung. Es war zu derselben Zeit, in der sich noch die Bestimmung der Natur durch menschliche Nutzung vollendete, etwa als Vollendung der Bestimmung eines seltenen Fisches in einem herrschaftlichen Festbankett, wenn er nur rechtzeitig in der Küche von Françoise Vatel eintraf. ${ }^{2}$ Es ist die Zeit, in der sich die Frage des existentiellen Sinns vom Vertrauen auf die Heilserwartungen im Jenseits löst und auf das Diesseits und seine Ersatzbefriedigungen umzustellen beginnt.

Deswegen bereichern noch bizarre oder geschmackswidrige Gliederfüßer die abgebildete Tafel oder die Kredenz um ihre physikotheologischen Botschaften und gemahnen, den Genuss nicht zu sehr vom demütigen Gotteslob zu trennen, sofern sie denn ikonologisch dazu taugten und nicht einfach nur noch pflichtschuldig die ständige Bedrohung durch den altbösen Versucher abarbeiteten und im übrigen eine ästhetisch brauchbare Arabeske im Motiv darstellen. Im Beispiel (Abb. 2) besorgen diese Verbindungen das Tagpfauenauge links vorn als Symbol für die gefährdete menschliche Seele und die Fliege am rechten mittleren Bildrand, die nicht nur vom Duft angezogen wird, sondern auch als Metapher unterweltlicher Macht auftritt. Einen ähnlich subtilen Hinweis gibt die Walnuss im Vordergrund, die gleichzeitig den Menschen und Christus repräsentiert. Alle drei Bildelemente sind auch kompositorisch als Farbtupfer und dekorative Struktur platziert. ${ }^{3}$ Natur tritt in diesem Stillleben dem Betrachter vielgestaltig, köstlich und kostbar entgegen, versehen mit kleinen Warnungen. ${ }^{4}$

Der Naturgebrauch, wie ihn das Stillleben vorführt, steckt nicht allein deshalb voller Raffinesse, weil er sich auf den Genuss ihrer bloßen Voraussetzungen konzentriert, also etwa des mühsam Gesammelten, des von weit Hergeschafften, des Seltenen oder des sozial Monopolisierten konzentrierte, sondern weil er sich zusätzlich darauf konzentriert, was durch menschlichen Einfallsreichtum veredelt und raffiniert, was mit höchstem Einfallsreichtum und größter Kunstfertigkeit zubereitet wurde oder wird (deshalb steht das Naschwerk in Abb. 2 in der Mitte). Nicht das bloße Naturgut, sondern seine gesellschaftliche oder handwerkliche Veredelung macht die Delikatesse. Wenn Francis Bacon (1623/1783) die Natur durch eine Dreiteilung ,in die Historie der Zeugungen, der Miss-Zeugungen und der Künste" ordnet, ${ }^{5}$ dann steckt darin auch die selbstbewusste Einsicht, dass die

\footnotetext{
2 Meisterkoch am Hofe des Prinzen von Condé auf Schloss Chantilly, der sich wegen einer verspäteten Fischlieferung für ein Festbankett 1671 das Leben genommen haben soll.

3 Auf die Bedeutung der Stilllebenmalerei für die minutiöse Naturbeobachtung, die schließlich in die moderne Naturwissenschaft führt, wird hier nicht weiter eingegangen. Der Hinweis auf das Standardwerk von Alpers (1998) mag genügen.

4 So, wie es sich Flegels wohlhabende Auftraggeber wohl gewünscht haben werden.

5 „Die Einteilung der menschlichen Historie wollen wir nach dem Zustand und der Beschaffenheit der Natur selbst unternehmen, als die in dreifachen Zustand gesetzt erfunden wird und gleichsam eine dreifache Regierung eingeht. Denn entweder ist die Natur frei und erklärt sich durch ihren gewöhnlichen Lauf, wie an den himmlischen Körpern, den Tieren, den Pflanzen und dem ganzen
} 
menschlichen Künste Dinge eigener Qualität hervor zu bringen vermögen. Zwar auf der Grundlage der „freien Natur", aber nun gemäß den Vorgaben und Ansprüchen des Menschen, der der Natur „Bande“ auferlegt, ihr also vorschreibt, wie und wohin sie sich zu entwickeln oder was aus ihr zu entstehen hätte. Die Delikatesse repräsentiert den durch menschliche Kunstfertigkeit veredelten Gebrauch und Verbrauch von Natur auf der Stufe des höchsten sinnlichen Genusses, der dadurch noch verstärkt wird, dass die Sinnessensationen, die der so Privilegierte erlebt, von nur wenigen oder gar niemandem geteilt werden können.

In der Eitelkeit des weltlichen Genusses und im Vertrauen auf die göttliche Vor- und Fürsorge tauchte der Gedanke an eine endliche Welt im Sinne einer Endlichkeit der Ressourcen oder der sie hervorbringenden naturalen Prozesse noch nicht auf. Dass menschliche Nutzung Ressourcen erschöpfen könnte, widersprach absolut der Idee der besten aller Welten. Noch bedeutete ,ausrotten“ wie bei Luther lediglich das vollständige Entfernen von einer konkreten Parzelle (DWB) nicht aber die Entfernung aus der Kette der Wesen. Noch fehlen Verlusterfahrungen aus mangelnder Verfügbarkeit; 6 die Natur erscheint seit 1500, seit dem Beginn des globalisierten Handels und der Entstehung der ersten modernen Ökonomie, ${ }^{7}$ als Warenhaus, ${ }^{8}$ aus dem man sich grenzenlos bedienen kann. Erst das 18. Jahrhundert wird beginnen, über die Endlichkeit von Ressourcen nachzudenken. Aber das sind Gedanken vereinzelter philosophischer Köpfe, Voltaire etwa, ${ }^{9}$ und für die betuchte Kundschaft sind jene Delikatessen, welche das Warenhaus der Natur nach wie vor bereithält, einladend ausgebreitet (Abb. 1 u. 2).

\footnotetext{
Vorrat der Natur; oder sie wird durch bösartige Ungewöhnlichkeiten eines unbändigen Stoffes und durch die Gewalt der Hindernisse außer ihren Zustand gestoßen, wie in Missgeburten; oder sie wird endlich von der menschlichen Kunst und Arbeit gebunden, gestaltet und gleichsam erneuert, wie an den Kunstsachen zu sehen. Also teilt sich die natürliche Historie in die Historie der Zeugungen, der Miss-Zeugungen und der Künste, welche letztere man auch Mechanik und die Erfahrende Naturlehre zu nennen gewohnt ist. Die erste behandelt die Freiheit der Natur, die zweite die Fehler, die dritte die Bande." (Bacon 1623/1783, S. 173).

${ }^{6}$ Selbstverständlich ist hier nicht vom Mangel bei Armut die Rede, sondern davon, dass Wünsche selbst bei Reichtum unerfüllbar bleiben, wenn die Objekte der Begierde nicht mehr existieren. Ich übersehe nicht, dass sogen. Naturkatastrophen durchaus „Verlusterfahrungen“ bedeuten und dem Menschen um 1600 als Hochwasser, Ernteausfälle, Erdbeben, als Epidemien usw. durchaus bekannt waren. Die Rede ist hier vielmehr von Verlusten, die auf irreversiblen Naturverbrauch gegründet sind.

Die ersten anthropogenen Ausrottungen werden in Europa erst im 18. Jahrhundert „bekannt“. Sie werden bestenfalls unter Spezialisten (s. u.) diskutiert, obwohl sie historisch mindestens bereits in der Europäischen Antike eingesetzt haben und nicht allein in Europa, wenn nicht in Nord-Amerika sogar bereits am Ende der Eiszeit.

7 Gemeint sind die Niederlande und die Ostindien-Kompanie VOC (gegr. 1602) sowie die Westindien-Kompanie WIC (gegr. 1621); hierzu de Vries \& van de Woude 1997.

${ }^{8}$ Eine Formulierung von Günter Bayerl, 2001, die sich ihm aus der Lektüre von Johann Beckmann, Anfangsgründe der Naturhistorie, Göttingen 1767, ergab. Ich danke Günter Bayerl, Cottbus, für seine Erläuterung.

9 In der Debatte über die Scala naturae hat Voltaire (1770), Questions sur l'éncyclopédie par des amateurs Vol 3, p. 284-287, auf die allgemeine Feststellung hin, dass es nach den Prinzipien der Scala naturae und dem der Fülle kein Aussterben von Arten geben könne, eingewandt, dass seit der Entstehung der Welt Tiere schon ausgestorben seien, bzw. der Mensch in der Lage wäre, Arten auszurotten (zit. nach Wagenitz 1997, S. 187).
} 


\section{$1 \quad$ Im Delikatessenladen}

Ein Delikatessenladen ist ein verdinglichtes Stillleben. Er verspricht die Erreichbarkeit höchster Genussmittel, die Käuflichkeit des sublimsten Gaumenkitzels, dessen sich ein Jean Floressas Des Esseintes ${ }^{10}$ je hätte rühmen können, und zwar für denjenigen, der es sich leisten kann. Das Geheimnis der Delikatesse ist ihre für die meisten unerreichbare Exotik, ist ihre in Geld gegründete Exklusivität, ist der Nimbus, der sich allererst ihrer Seltenheit verdankt, ist die Distinktion, mit der sie ausschließt oder zurechnet.

Eine Frau betritt das Delikatessengeschäft von Ernst Jandl und trägt ihre Wünsche vor. ${ }^{11}$ Alles, was folgend geschlossen wird, bemisst sich an „Bedeutung und Interesse [von] Kunst einzig für den, der die kulturelle Kompetenz, d. h. den angemessenen Code besitzt" ${ }^{12}$ Mit dem beabsichtigten Einkauf bereitet sie nicht etwa ein exquisites Abendessen vor. Wie selbstverständlich verlangt sie nach ein, zwei ungewöhnlichen Dingen. Der Ort, die Situation, das Verlangte, es ist diese Kombination, die sofort unsere Vorstellungskraft übersteigt. Die Dame sucht nach den Ingredienzien für einen kulinarischen Höhepunkt eigener Art, bei dem das Gekaufte nicht mit dem Munde, sondern mit den Augen verschlungen werden soll: Hier finden offenkundig Vorbereitungen für einen gehobenen Augenschmaus statt, oder vielleicht doch nicht?

Man hört den Gesprächspart der Käuferin, der sich nach anfänglich energischer Bestimmtheit nachdenklich verzögert, weil sie unerwartet umdisponieren muss und an die Stelle des ursprünglich geplanten genießenden Betrachtens dann offenbar doch das genießende Verzehren treten soll:

\footnotetext{
${ }^{10}$ Protagonist in Joris-Karl Huysmans Roman „Gegen den Strich“ (1884/1981).

11 Meine nachstehende Deutung weicht, z. T. ganz erheblich, von derjenigen ab, die Ernst Jandl 1974 selbst gegeben hat (siehe Anhang). Fast fünfzig Jahre nach Entstehung des Gedichts, in denen u. a. der Naturverbrauch und die Konsequenzen menschlicher Handlung für das Weltklima als prekär erkannt wurden, sehe ich Jandls Gedicht in einem ganz anderen Kontext als er selbst.

12 Die vorstehende Fußnote erklärt sich aus und findet ihre Berechtigung in der allgemeinen Position, die Pierre Bourdieu (1982/2010) für die Bedeutung von abbildender Kunst formulierte, an die hier angeschlossen wird und die bereits an den eingangs gezeigten Stillleben demonstriert wurde: „Die Fähigkeit des Sehens bemisst sich am Wissen oder, wenn man möchte, an den Begriffen, an den Wörtern mithin, über die man zur Bezeichnung der sichtbaren Dinge verfügt und die gleichsam Wahrnehmungsprogramme erstellen. Von Bedeutung und Interesse ist Kunst einzig für den, der die kulturelle Kompetenz, d. h. den angemessenen Code besitzt" (S. 19, Hervorhebung im Original). Die Essenz der Einsichten Bourdieus ist nicht neu und bereits mutatis mutandis in der 100 Jahre älteren und 600 Seiten kürzeren Abhandlung von Veblen 1899/2007 zu lesen. Der Unterschied besteht lediglich darin, dass für Veblen das soziologische Phänomen der „feinen Leute“ rational in ökonomischen Ursachen gesehen wird, für Bourdieu hingegen scheint der Distinktionsgewinn einem narzistischen Selbstzweck zu folgen. Und selbstverständlich ist auch dem soziologischen Klassiker Simmel, der den Umwelthistorikern wegen seines Beitrags zur Landschaftsästhetik (vgl. Smuda 1986) bekannt ist, vieles Grundsätzliche zur Distinktionsfrage zu entnehmen, z. B. dem Aufsatz über „Die Mode“ (1911).
} 


\section{Ernst Jandl (1962) \\ im delikatessenladen}

bitte geben sie mir eine maiwiesenkonserve etwas höher gelegen aber nicht zu abschüssig so, daß man darauf noch sitzen kann.

nun, dann vielleicht eine schneehalde, tiefgekühlt ohne wintersportler. eine fichte schön beschneit kann dabeisein.

auch nicht. bliebe noch - hasen sehe ich haben sie da hängen. zwei drei werden genügen. und natürlich einen jäger. wo hängen denn die jäger?

Wird es nun, wo die Menüfolge offenkundig eine Änderung erfahren muss, doch bloß Gespickten Hasen und etwa Jägerschnitzel geben?
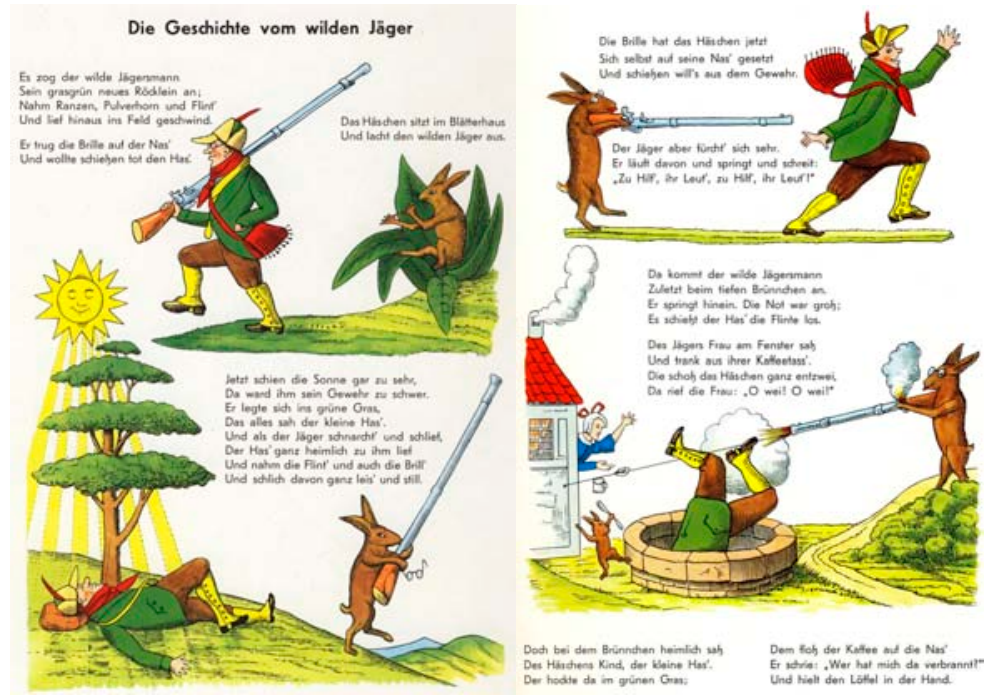

Abb. 3: Heinrich Hoffmann, Die Geschichte vom wilden Jäger.

Jandls Schabernack bereitet vordergründiges Vergnügen. Der Leser begreift sofort, dass die Person, die den Einkauf besorgt, nur eine Frau sein kann. Kein Mann wäre in der Lage, sich so umstandslos flexibel dem kulinarischen Defizit anzupassen und dabei noch so scheinbar arglos nach den Jägern zu fragen. Ur-Rolle und Geschlechterkampf, gut abgehangen als amuse gueule. Der Spaß, eigentlich die Schadenfreude, die sich zum mitfühlenden Bedauern über die toten 
Hasen gesellt, denkt die Geschichte jenes Meister Lampe aus Dr. Hoffmanns lustigen Geschichten und drolligen Bildern endlich einmal bis zu ihrem angemessenen Ende (siehe Abb. 3). ${ }^{13}$

Der Gott des Gemetzels entpuppt sich in dem Gedicht als Verwandter des Saturn, der nun selbst verschlungen wird von dem, was er verschlingt. Deshalb hängt der Täter neben seinem Opfer - freilich nur als Prinzip Hoffnung, denn dem Wunsch der Käuferin wird die Bedienung, obwohl das Gedicht hier abbricht, nicht entsprechen.

Jandls Beschreibung der Begebenheit im Delikatessenladen bürstet augenscheinlich allen Vorstellungswillen gegen den Strich. Aber nur, weil eine Maienwiese, vielleicht sogar die Szenerie um Heidis und Peters Maiensäß, nicht in eine Konservendose zu passen scheint, ist die Begebenheit keinesfalls völlig absurd, nicht nur, weil gemäß René Magritte eine Maienwiese eben nicht immer eine Maienwiese ist. ${ }^{14}$ Vielmehr werden im Gedicht zwei zutiefst problematische Dinge mit einem Mal auf den Punkt gebracht, den wir heute anders als zur Zeit Jandls dechiffrieren: Es geht um Naturverbrauch, bei dem die Güter aus dem "Warenhaus der Natur" geholt werden, und es geht um Konservierung von Naturparzellen. Und noch ein Drittes gesellt sich dazu, angedeutet in der fragenden Suche nach den abhängenden Jägern.

\subsection{Die Naturkonserve}

Was scheinbar so fröhlich daherkommt, endet in einer bitteren Einsicht, allerdings erst in einem zweiten Anlauf. Vorderhand erscheint der Schmaus, zu dem hier die Zutaten eingekauft werden sollen, als einer, bei dem die Dinge nicht wirklich verzehrt werden und nicht verschwinden und der die Welt scheinbar um keinen Sekundenbruchteil ihrem Ende näher bringen wird. An der Tafel des Augenschmauses haben viele Gäste Platz, nichts wird tranchiert, nichts wird durch bloße Betrachtung verändert, es gibt keinen Verbrauch. Ob zwei Menschen oder einhundert in „freier genießender Anschauung" ${ }^{\prime 15}$ auf den Sonnenuntergang schauen, macht keinen Unterschied. Mit der Sprache der Ökonomen kommt es nicht zum „rivalisierenden Konsum“, wie etwa beim Tafelspitz-Essen, wo das Stück Rind, das ein Gast verzehrt, den anderen Gästen unumkehrbar vorenthalten bleiben wird.

Die bloße Betrachtung ist eine Seite, eine zweite aber der Naturverbrauch durch Besitz, der anderen den Zugang vorenthält oder späteren Anschlussnutzen für Dritte durch Störung wie Zerstörung des Ist-Zustandes erschwert oder gar ausschließt.

\footnotetext{
13 Hoffmann [ab 1847].

14 In der Folge von Magrittes La trabison des images (Ceci n'est pas un pipe, 1929) kann eine Maienwiesenkonserve ebenso wenig eine Maienwiese sein, wie die Abbildung einer Pfeife eine Pfeife sein kann.

15 Ritter (1974/1989, S. 151).
} 
Wer eine Maienwiese schätzt, wird sich vermutlich gern auf ihr niederlassen. Dass man Maienwiesen (oder Schneehänge) kaufen kann, wird jeder Immobilienhändler gern bestätigen. Dass sie hier im Delikatessenladen gesucht werden, erscheint als untauglicher Versuch lediglich wegen des nur scheinbar irrigen Ortes, denn tatsächlich wird „Landschaft“, wo sie nicht wirtschaftlich genutzt oder ausgebeutet wird, längst so konsumiert, wie andere Genussmittel konsumiert werden. ${ }^{16}$ Landschaftliches Pathos ist ein Hauptmotor der Tourismusbranche und ein Imponierinstrument in der Konversation bestimmter Nachmittags- oder Abendgesellschaften.

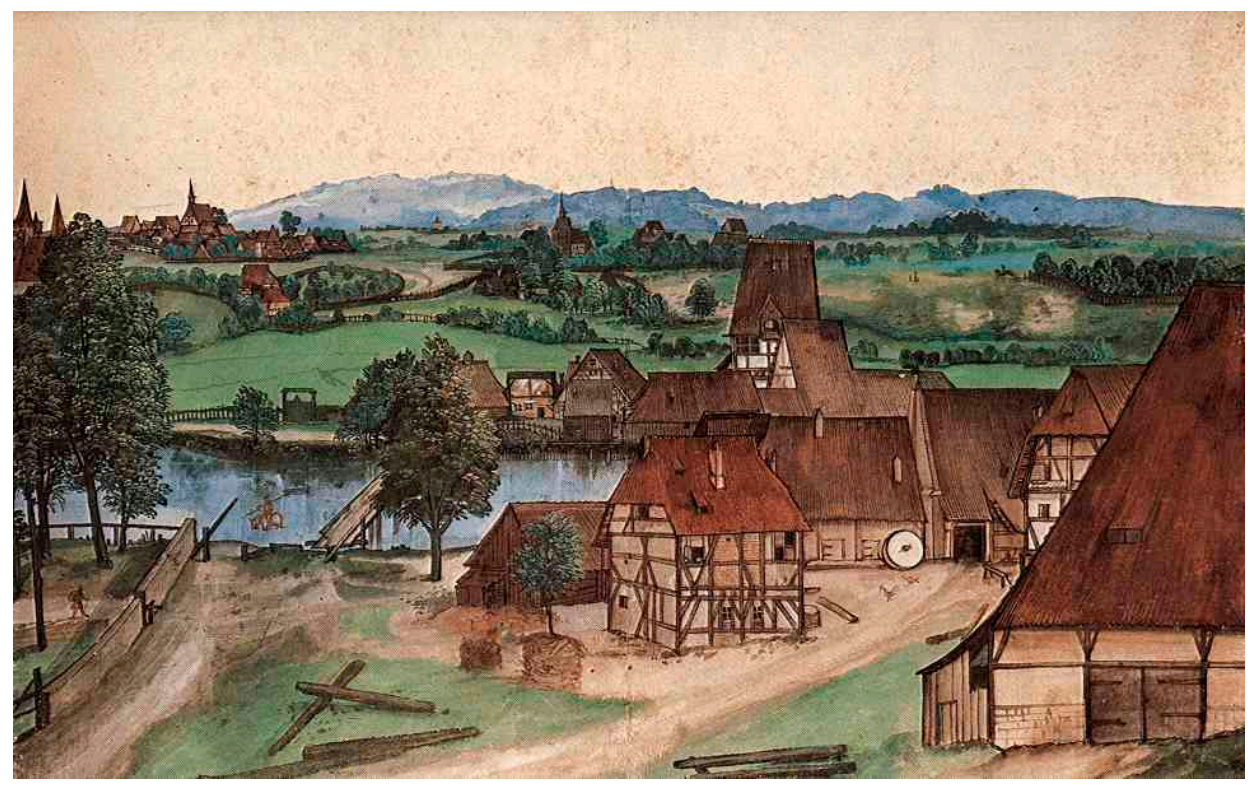

Abb. 4: Albrecht Dürer (1471-1528) Die Drahtziehmühle (an der Pegnitz). (um 1494; Aquarell und Deckfarben, Kupferstichkabinett Berlin)

Eine der ersten mitteleuropäischen Landschaftskonserven. Es handelt sich um einen Kulturlandschaftstyp, der infolge fehlender Flurbereinigungen bis heute im benachbarten lieblichen Taubertal erhalten blieb.

Für den Unabkömmlichen oder den relativ Unbetuchten bietet der Delikatessenhandel Ausweichmöglichkeiten auf Surrogate für den anderweitig nicht erreichbaren Naturgenuss. Längst hat der technische Fortschritt Möglichkeiten bereitgestellt, Landschaften in Konserven zu füllen, nachdem die ersten Versuche von Albrecht Dürer, Claude Lorrain, Nicolas Poussin und Salvator Rosa ihren Weg auf

\footnotetext{
16 „Landschaft“" steht hier auch stellvertretend für „Natur“ - und es müsste diese Subtextbedeutung mehr oder weniger durchgängig mitgelesen werden. Im konkreten Zusammenhang ist keine Diagnose wahrer als die Folgende: „Natur wird dadurch, dass der gesellschaftliche Herrschaftsmechanismus sie als heilsamen Gegensatz zur Gesellschaft erfasst, in die unheilbare gerade hineingezogen und verschachert.“ (Horkheimer \& Adorno 1969/2009, S. 157).
} 
das Papier, die Tafel und die Leinwand fanden. Nach der Malerei war die technische Konserve der Landschaft die Fotografie, ${ }^{17}$ heute ist es der Film, ist es die DVD. ${ }^{18}$ Der Genuss einer schönen Landschaft wird damit überall verfügbar. ${ }^{19}$

Selbstverständlich wird niemand von der Landschaftskonserve ähnlich beeindruckt, wie es noch eine gute Kopie eines Kunstwerks vermag. Hierin weicht das konservierte „Naturschöne“ vom konservierten „Kunstschönen“ grundsätzlich ab. ${ }^{20}$ Der Konservenlandschaft fehlt die sinnliche Erfahrung, welche eine bewegte Luft auf der Haut hinterlässt, fehlt der Geruch der Pflanzen, die Geräusche der Tiere, womöglich das Gemurmel einer Quelle, die wechselnde Lichtintensität, fehlt der Nieselregen. Die Konserve vermittelt mir die Vorstellung der Wirklichkeit, vermittelt aber nicht die Wirklichkeit selbst. ${ }^{21}$ Ähnlich dem entscheidenden Unterschied, den Walter Benjamin für „Das Kunstwerk im Zeitalter seiner technischen Reproduzierbarkeit“ mit dem Mangel an „Aura“ benannte, die in Authentizität und Tradition verborgen wären, fehlt der Landschaftskonserve die aus der Erfahrung des in ihr anwesenden Menschen resultierende gesamtsinnliche Authentizität. Auch diese ist über die kollektive Schulung der Augen und anderer Sinne an den Naturdingen in einem Konstrukt der Konvention mit der Tradition verbunden. ${ }^{22}$

Anders als das vervielfältigte Kunstschöne, dem praktisch alle materiellen Eigenschaften des Originals zu eigen sind und bleiben, rangiert das konservierte Naturschöne von vornherein hoffnungslos hinter seiner Vorlage. Aber die Naturkonserve hat mit dem Datum ihres Entstehens der Vorlage gegenüber immer voraus, dass sie bewahrt und am Tage ihrer „Öffnung“ im Vergleich mit dem heutigen Zustand des Originals das Ausmaß zwischenzeitlich unweigerlich ein-

17 In großartiger Meisterschaft ehedem vorgeführt von Georg Gerster. Neuerdings finden die Luftaufnahmen von Alex S. MacLean viel Beifall, ohne die älteren Aufnahmen Gersters oder die von Ansel Adams zu übertreffen, der allerdings keine Luftbildaufnahmen wie die beiden erstgenannten anfertigte.

18 Z. B. die Weltseller „Die Erde von oben“ oder „Home“ des Fotografen Yann Arthus-Bertrand.

19 Letztlich ist auch das Sonnenstudio (ugs. „Münzmalle“: als Mallorca-Ersatz) eine kleinstmögliche Variante des Landschaftssurrogats. Die Palette dieser inhaltlich und hinsichtlich der an sie gerichteten Ansprüche extrem reduzierten Ersatzlandschaften wird hier nicht weiter verfolgt.

20 Siehe weiter unten.

21 „Das Bild bildet die Wirklichkeit ab, indem es eine Möglichkeit des Bestehens und Nichtbestehens von Sachverhalten darstellt“ (Satz 2.201) und „Aus dem Bild allein ist nicht zu erkennen, ob es wahr oder falsch ist.“" (Satz 2.224), Wittgenstein (1922/2003).

22 „Die Landschaft trägt [...] nicht nur eine ,von Menschen gestaltete Physiognomie،, wir sehen sie auch ,mit durch die Kunst erzogenen Augen'. Malerei und Literatur haben die Landschaft für uns so eingerichtet, dass wir sie nach deren Bildern wahrnehmen. Das ging bereits dem jungen Friedrich Hebbel so: ,Ich glaube oft, schon etwas gesehen zu haben, was ich erweislich zum erstenmal sehe, namentlich Landschaften.' - Man kann dieselbe Beobachtung erstmals in der Breite im 18. Jahrhundert, dem großen Jahrhundert der Reisen, in England und auf dem Kontinent machen. Wohin die Reise auch ging, stets sprang den Landschaftsenthusiasten das Bild eines Meisters aus der Natur entgegen - eine ,schöne', ,reizende', ,malerische', ,erhabene', ,pittoreske 6 oder ,romantische ${ }^{6}$ Landschaft, wie sie ein Lorrain, Poussin oder Salvator Rosa gemalt hatten. Die Namen dieses Dreigestirns waren Chiffren für drei Landschaftstypen und die durch sie erzeugten Stimmungen. Claude Lorrain stand für ,zarte Schönheit und das ,Heiter-Ideale‘, Nicolas Poussin für ,erhabene Größe und das ,Klassisch-Heroische', Salvator Rosa für ,gebannten Schrecken“ und das ,Wild-Romantische“". (Fischer 1997, S. 88). 
getretener Veränderung dokumentiert. Die mediale Konserve ist, anders als das reproduzierte Kunstwerk, das sich vom Original auch nach langer Zeit kaum unterscheiden wird, die einzige Möglichkeit einer wenigstens teilweise beobachtbaren und von mehreren Menschen teilbaren Erinnerung an einen ehemaligen Naturzustand.

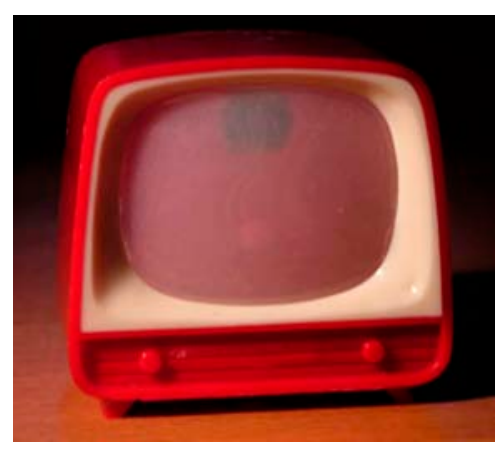

Abb. 5: Eine „Naturkonserve“ eigener Art bilden Guckkästen mit Landschaftsaufnahmen, die der Käufer so oder ähnlich anstelle von Postkarten wohl noch immer im Andenkenhandel erwerben kann. Im Innern befindet sich eine Scheibe mit 8 transparenten Landschaftsminiaturen. (Objektbasis: $5 \mathrm{~cm}$ )

Darin besteht ihr Wert, der sich auch unter dem wiederholten „Öffnen“ der Konserve in Form der wiederholten Vorführung ihres Inhalts nicht abnutzt. Der Augenschmaus wird zwar auf ein zweidimensionales Erlebnis reduziert, vielleicht ergänzt um eine Tonaufnahme, dem aber mindestens drei sinnliche, ${ }^{23}$ sowie eine räumliche und eine zeitliche Qualität fehlen. Aber selbst dieser folienhafte Abzug der Wirklichkeit ist wertvoller als die bloßen Erzählungen sich unsicher Erinnernder.

Vor jedem Landschaftsverbrauch aus menschlicher Ursache führt der ewige Wechsel der Jahreszeiten in ökologischer Zeit zum Verlust von Maienwiesen und Schneehalden. Es ist der ewige Kreislauf der Jahreszeiten, der aus Maienwiesen Schneehalden macht und aus Schneehalden manchmal Maienwiesen. Am Ende, wenn aus der ökologischen Zeit die geologische geworden ist, wird es keine Maienwiese mehr geben, vielleicht auch keine Schneehalde mehr. Das Beständige in der Natur ist der Wandel. Nicht nur, weil unsere Wahrnehmung nicht über unsere Lebensspanne hinausreicht, macht sich unsere Zukunftsvorstellung notwendig am Vergangenen fest. Die Wahrnehmung blendet in der Regel die Ungewissheit der Zukunft aus und beharrt auf der Konstanz des Gegenwärtigen. Auch „Natur" solle sich als konstant erweisen, etwa unter der „Linde am Brunnen vor dem Tore“, die ein deutsches Volkslied beschwört, ohne zur Kenntnis zu nehmen, dass Brunnen und Linde längst dem Parkplatz des Baumarktes im Weichgürtel der Zwischenstadt zum Opfer fielen. Das Beharren auf dem biedermeierlichen Topos bezieht sich letztlich auf eine spezifische Ästhetik, die in unserer Kultur aus der belehrten wie gelehrten Betrachtung von „Landschaft" und den diversen physikotheo-

${ }^{23}$ Es fehlen die geruchlichen, geschmacklichen und getasteten Eindrücke. 
logischen Zugängen ${ }^{24}$ zum populären Konstrukt des „Naturschönen“ führte: „Schön ist an der Natur, was als mehr erscheint, denn was es buchstäblich an Ort und Stelle ist." (Adorno 1973/2003, S. 111) Diese Bedeutung der Naturbetrachtung, ihre katalytische Rolle für die Ich-Erfahrung, für emotionale Selbststabilisierung und als Anknüpfungspunkt für Rückgriffe auf transzendente Mächte ist in unserer Kultur zutiefst verankert. Sie führt letztlich auch in die naive Vorstellung, dass der Besitz von Naturschönem, ${ }^{25}$ und sei es aus dem Delikatessenladen, existentielle Sicherung bedeutet.

\subsection{Die konservierte Natur}

Ob Maienwiese oder Schneehalde, beide sind ephemere, jährlich wiederkehrende Zustandsbilder naturaler Abläufe. Sie zu konservieren, kann ganz unterschiedliche Gründe haben. Wer sich biographisch immer weiter aus dem rhythmischen Wechsel saisonaler Erscheinungen in der Natur entfernt, weil die Kunstwelt der gerontologischen Aufbewahrungsanstalten einen klimatischen Dauerzustand in den Farben Beige und Graubraun erschafft, kann sich über die Betrachtung einer Winterlandschaft vielleicht noch daran erinnern, dass es „draußen“ Temperaturschwankungen gibt, dass die Maienwiese eben nur im Mai blüht und im Juni dort andere Blumen erscheinen, während sich die aus Seide gefertigten Mohnblüten im Aufenthaltsraum jahrelang und unverändert in ihrer immergleichen, verlogenen Vitalität präsentieren.

Im allgemeinen Bewusstsein kommt diese Konservennutzung nicht vor. Möglich, dass sie überhaupt nicht vorkommt. Die öffentliche Handlungsoption kreist vielmehr um die Idee einer Natur, die mit ihrer eigenen Konserve identisch ist und auf diese Weise zum Gegenstand der Verfügung wird. Die Bemühungen, „Natur“ zu erhalten, führen in vielfältiger Weise zu einem im wahrsten Sinne konservierenden, ja konservativen Naturverständnis. Da erhält

\footnotetext{
24 Michel (2008).

25 Die Verbindung von Naturschönem und seiner transzendenten Bedeutung für den Betrachter hat Adorno gleich eingangs seines „Verdiktes über das Naturschöne“ betont (S. 98): „Der Begriff des Naturschönen rührt an eine Wunde, und wenig fehlt, dass man sie mit der Gewalt zusammendenkt, die das Kunstwerk, reines Artefakt, dem Naturschönen schlägt. Ganz und gar vom Menschen gemacht, steht es seinem Anschein nach nicht Gemachtem, der Natur, gegenüber. Als pure Antithesen aber sind beide aufeinander verwiesen: Natur auf die Erfahrung einer vermittelten, vergegenständlichten Welt, das Kunstwerk auf Natur, den vermittelten Statthalter von Unmittelbarkeit. Darum ist die Besinnung über das Naturschöne der Kunsttheorie unabdingbar. Während paradox genug Betrachtungen darüber, beinahe die Thematik an sich, zopfig, ledern, antiquiert wirken, versperrt große Kunst samt ihrer Auslegung, indem sie sich einverleibt, was die ältere Ästhetik der Natur zusprach, die Besinnung auf das, was jenseits der ästhetischen Immanenz seine Stätte hat und gleichwohl in diese als ibre Bedingung fällt." (Hervorhebung B.H.) Gemeint sind hier vermutlich Rezeptionsverständnisse nach physikotheologischen, nach panpsychistischen oder idolatrischen Grundmustern. Werden solche Rezeptionsweisen aus der Naturbetrachtung entfernt, wechselt diese aus der ästhetischen Sphäre in den Bereich der bloßen positivistischen Existenzerfahrung und -beschreibung. „Die Natur“" würde damit reduziert auf Dinge der Umgebung, die außer der Tatsache ihrer Existenz keine weitere Bedeutung haben. - Damit würde auch der Erwerb einer Maienwiese ein sinnfreies Unterfangen.
} 
die schutzwürdige Parzelle den Auftrag, sich nicht zu verändern, stille zu stehen, die Abläufe des Normal-Prozesshaften einzustellen. So, wie die Großmutter die Lüneburger Heide kannte, so kennen sie die Enkel. Kein Sandkorn darf sich um der Erhaltung von Natur willen bewegen. Alles hält den Atem an, wird auf dem status quo eingefroren. Und wenn der status quo nicht dem normativen Verständnis des konservativen Naturschutzes entspricht, wird zuerst der status quo ante hergestellt. Und dann wird eingefroren. Der Vorgang heißt dann z. B. „Landschaftspflege“.

Wer eine Maienwiesenkonserve oder eine Schneehaldenkonserve um ihrer selbst willen kauft, offenbart eine konservative Vorliebe und Vorstellung von Natur nach dem Muster der Vor-Darwin-Zeit. Einer Natur, in der die Dinge scheinbar von Anbeginn so waren, wie sie vor uns liegen. Einer Natur, in der auch die Kenntnis über das Ausmaß von „Gemachtem“, von anthropogenen Anteilen, völlig fehlt. Einer Natur, in welcher der paradiesische Mythos des ewigen Gleichstandes herrschen soll.

Dies ist eine Überforderung jeglicher realen Natur, die uns als Ökosystem oder eine ihrer Komponenten entgegentritt, weil diese möglicherweise für den Zeitraum einer menschlichen Wahrnehmung „stabil“ bleiben können, aber darüber hinaus muss eine solche Stabilität durch investierte Arbeit erhalten werden. Da ist dann ständig die Schafherde über die Magerwiese zu treiben, der Wald auszulichten, die Lüneburger Heide mit Pestiziden, Maschineneinsatz und Tierproduktion auf Postkartenformat zu halten. Diese Vorstellung von konservierter Natur führt zwangsläufig in eine musealisierte Natur. Nirgends ist die Natur besser musealisiert als in der Konserve. Die heißt vielleicht „Naturschutzgebiet“26 oder „Naturkundemuseum", oder hat einen anderen Namen, in dem alle möglichen Filiationen von „Natur" auftauchen. Ein Delikatessenladen erscheint da nur als eine unwissenschaftliche, profanisierte, kulturell abgesunkene Variante für konservativen Naturgenuss, in der die Dinge zum Verkauf stehen und die damit ihr Eigeninteresse ungeniert zur Schau stellt. ${ }^{27}$ Ein „Natur“-Museum, das dagegen die Veränderung thematisierte, die doch das entscheidende Merkmal alles Lebendigen ist, würde in Widerspruch zu seinem eigenen Inhalt geraten müssen.

Jandl führt uns nach Art einer erlebten Verkennung vor Augen, dass der Delikatessenladen die konservative Bewahranstalt nicht nur jenes Keksduftes der Erinnerung ist, er ist es auch für die Erinnerung an Naturgenüsse, die wir

\footnotetext{
${ }^{26}$ Definitionsbestandteil des „Naturschutzgebietes“ im deutschsprachigen Raum ist „Schönheit“ und „Einzigartigkeit“, womit u. a. auch die Ensemblewirkung gemeint ist. Existieren etwa für die subjektiven Begriffe „Schönheit“ und „Einzigartigkeit“ normative Setzungen? Wandeln sich „Schönheit" und „Einzigartigkeit" etwa nicht in den Zeitläuften?

${ }^{27}$ Es bieten sich hier kulturtheoretische Überlegungen an, ob, wann und wo Naturgenuss die Grenze überschreitet, die gewöhnlicherweise zwischen der Freiwilligkeit und der Prostitution gezogen wird. Was zunächst wegen des dieser Diagnose zugrundeliegenden naturalistischen Fehlschlusses nicht erörterungswürdig erscheint, wird es spätestens dann, wenn unsere Vorstellung der „Natur“ einen Metagehalt zuschreibt. Dieser Gedanke, dem nachzugehen sicher lohnend wäre, wird hier nicht weiter verfolgt.
} 
aufsuchen, um uns dem Sog der natürlichen Veränderung zu entziehen, uns zu ent- schleunigen und zu erinnern. ${ }^{28}$ Wie in der antiken Tragödie entrinnt der Mensch in der Natur und als Teil dieser dem Schicksal der unaufhaltsamen Veränderung aber nicht. Die Stunde verrinnt, das Leben geht weiter, es entgleitet und lässt zurück. Der Versuch sich „biophil“ zu gebärden, zu „bewahren“, ist ein hilfloses Aufbäumen gegen die unabänderliche Tatsache der Veränderung in der irrigen Annahme, wonach das Bios beständig wäre. „Nachhaltigkeit“ erscheint da auch als Hoffnung, den gegenwärtigen Zustand durch Verstetigung dem Einfluss der unausweichlichen Veränderung zu entziehen. Dabei ist „Nachhaltigkeit“ als Konzept in der Natur unbekannt. Sie ist eine gesellschaftliche Vorstellung, wonach durch eine bestimmte Managementpraxis eine lang anhaltende Nutzung natürlicher Populationen oder anderer Ressourcen ohne deren Erschöpfung und ohne Einschränkungen auf der Nutzerseite möglich sei. Damit ist sie eine gesellschaftliche Utopie, die von unhintergehbaren Eigenschaften des betroffenen Naturgutes keine Kenntnis nimmt. ${ }^{29}$

Die Delikatessenabteilung im Warenhaus der Natur bedient in Wahrheit auch (oder ausschließlich?) Bedürfnisse des in seinem Verhältnis zur Natur mehrfach narzisstisch gekränkten neuzeitlichen Menschen (Freud), in dem Delikatessen als Kompensationsangebote vorgehalten werden, die über die Kränkungen hinwegtrösten oder hinwegmogeln sollen:

- die erste Kränkung verdanke er Kopernikus, der nachwies, dass die Erde nicht der Mittelpunkt des Weltalls ist,

- die zweite Kränkung verdanke er Darwin, der nachwies, dass der Mensch nicht das Produkt einer kreationistischen Leistung ist,

- die dritte Kränkung verdanke er der Psychoanalyse, in deren Vermögen es liege, dem Bewusstsein erwachsener Menschen die unangenehme Einsicht vermitteln zu können, dass sein Anspruch auf Geborgenheit und Versorgung, auf Zuneigung durch einen anderen Menschen, auf Halt in Einrichtungen und Institutionen, infantil und illusorisch ist.

\footnotetext{
${ }^{28}$ Herrmann \& Schutkowski (1998); Sebba (1991).

29 Die offenkundige Stabilität von Ökosystemen über sehr lange Zeiträume, z. B. die zyklische Sukzession in der afrikanische Gras-Baum-Steppe, ist als emergentes Phänomen des zufälligen Zusammenspiels vieler kleinskaliger Systemelemente zu begreifen, die auf der Skala des einzelnen Baums völlig vorhersagefrei abläuft (Gillson 2004). Aus ihnen ist nicht abzuleiten, dass „Nachhaltigkeit“ ein natürliches Prinzip wäre. Nicht einmal „Stabilität“ kann einem Ökosystem als angestrebter Zustand zugeschrieben werden, weil die naturalen Abläufe der „Natur“ (hier der organismischen Evolution) nicht zielsuchend sind (Mayr 1979) und weder Ökosysteme noch „Natur“ als selbstständig handelnde Akteure anzusehen sind.
} 
Alle drei Kränkungen lassen sich in umwelthistorische Erwägungen einbeziehen. ${ }^{30}$ Zu den Konsequenzen der dritten Kränkung gehört ein allmähliches Erschrecken darüber, dass Folgen und Nebenfolgen menschlichen Handelns den in ,prästabilierter Harmonie" begriffenen Zustand der Welt zu destabilisieren in der Lage ist. Damit wird eine vierte Kränkung ${ }^{31}$ unausweichlich:

\section{- das „Warenhaus Natur" wird sich künftig dem größeren Teil der Menschbeit verweigern.}

Eine weltweite Konsumgesellschaft auf der Basis desjenigen Naturverbrauchs, wie er der euro-amerikanischen Zivilisation zugrunde liegt, wird es nicht geben können. Die narzisstische Kränkung derjenigen, die von der Partizipation ausgeschlossen werden, weil sie ein entsprechendes Niveau noch nicht erreicht hatten, und derjenigen, denen der Abbau erreichter Konsumhöhe abverlangt wird, hat ein hohes Bedrohungspotential für gesellschaftliche Stabilität. Vladimir Majakowski konnte noch dichten:

Haselhühner schlemme, friss das Ananas, dein letzter Tag wird kommen, Bourgeois! ${ }^{32}$

und unter der Chiffre der Delikatessen gesellschaftskritischen Agitprop betreiben, in der Hoffnung auf spätere Haselhühner und Ananas für alle. Anders aber als Majakowski dachte, wurde die Erreichbarkeit der Ananas bereits mit den Konserven des kapitalistischen Unternehmens Del Monte möglich. Freilich ist diese Erreichbarkeit nicht mit derjenigen Vergesellschaftung der Ressourcen und Produktionsmittel zu verwechseln, die nicht nur den Sowjetdichtern erstrebenswert schien. Denn es werden heute nur die Folgekosten der Ananasproduktion (o. ä.) vergesellschaftet, die Gewinne hingegen bekanntermaßen privatisiert. Erst wenn die heutigen Preise durch solche ersetzt sein werden, in denen die ökologischen Kosten nicht länger externalisiert sind und auf Allgemeinheit und Nachwelt abgewälzt werden, werden sie vor dem Konzept der „Nachhaltigkeit“, das in

30 Diese Behauptung kann selbstverständlich nur für jene Menschen gelten, die von den kopernikanischen, darwinschen und freudschen Erklärungsmodellen betroffen sind, also den westlichen Kulturmenschen. Vier Jahrhunderte nach Kopernikus wird aber kaum noch jemand an dem von ihm entworfenen Weltbild verzweifeln. Hundertfünfzig Jahre nach Darwin waren dagegen zu einer allgemeinen Beruhigung nicht ganz ausreichend, wie u. a. der Blick auf den amerikanischen bible belt und dort tätige Kreationisten zeigt. In den fünfzig Jahren nach Freud selbst sind seine Hypothesen und Theorien noch nicht einmal allgemein rezipiert. In summa gilt auch den narzisstischen Kränkungen gegenüber, die Freud ausgemacht hatte, die Gnade der späten Geburt. Dagegen ist die hier so bezeichnete vierte Kränkung (weiter unten) aktuell und bestimmend, bis hinein in Entscheidungen von weltpolitischer Bedeutung.

31 Da es weitere Anwartschaften auf die Position 4 unter den Kränkungen gibt (z. B. Braungart 2008), ist meine Zählung lediglich als Fortsetzung der Reihe, nicht als Anspruch zu verstehen. Ich danke Ulrike Kruse für den Hinweis.

32 Ешь ананасы, рябчиков жуй, день твой последний приходит, буржуй (1917). Haselhühner und die im zaristischen Gewächshaus teuer erzeugte Ananas sind hier zunächst nur Chiffren einer Sozialund Gesellschaftskritik, noch nicht des Naturverbrauchs. 
Wahrheit bisher immer nur Besitzstand und die Verstetigung des herrschenden kulturellen Niveaus meint, Bestand haben. Die potenzierte Ironie des Majakowskischen Kampfrufs besteht dann allerdings darin, dass tatsächlich die Bourgeoisie untergehen wird, wenn Haselhuhn und Ananas für Alle zur Verfügung stehen sollen. Neben dem Bourgeois wird allerdings auch der Klassenkämpfer untergehen, weil eben Alle wegen der allgemeinen Ressourcenerschöpfung zugrunde gehen werden.

\section{Hase und Jäger}

Im Delikatessenladen von Ernst Jandl scheinen Jäger wie Hasen nebeneinander zu hängen. Während der Weg der Hasen in den Laden bekannt ist, kann Gleiches für die Jäger nicht behauptet werden. Ebenso, wie die Landschaftskonserven in Jandls Gedicht Metaphern für den Naturverbrauch und das Raisonnement über ihn sind, ebenso sind auch die abhängenden Jäger nur traurige Tropen. Sie sind gewendete Metaphern für den Akteur, der Unglück und Tod über die Hasen bringt. Der Jäger repräsentiert eine Ureigenschaft menschlicher Naturaneignung (sammeln, jagen) vor jeder produzierenden Ökonomie. ${ }^{33}$ Hier geht es also um ein ur-grundsätzliches Verhältnis zwischen dem Menschen und dem Hasen, hinter dem der pars-pro-toto-Gedanke erkennbar ist: der Hase repräsentiert die Natur, die unter der Gewalt des Menschen leidet.

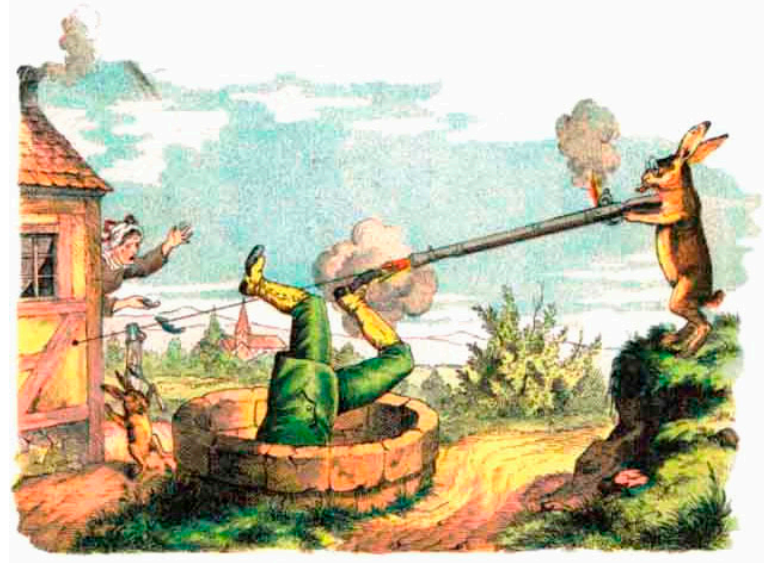

Abb. 6: Der Hase schießt auf den Jäger.

${ }^{33}$ Die Ökonomie ist das Mittel zur Befriedigung der Lebensansprüche des Menschen. Damit ist die Ökonomie die spezifischste Seite der Humanökologie. 
Die Geschichte von wilden Jäger im Struwwelpeter kehrt die Verhältnisse drastisch um: Hier wird der Jäger zum Gejagten, der Verfolgte zum Verfolger, der Starke wird schwach, der Schwache wird stark. In der Vorstellung einer verkehrten Welt wird die Wunschvorstellung der Ohnmächtigen nach Rache am Mächtigen, am Peiniger, am Ausbeuter für den Augenblick der bildlichen Vergegenwärtigung Realität. Das Opfer wendet sich gegen den Täter, wobei der Jäger im Struwewelpeter Glück hat: Der Hase schießt sicher nicht auf ihn, sondern nur in seine Richtung. Die Geschichte selbst hatte sich aus einem harmlosen Streich des übermütigen Hasen entwickelt (siehe die Eingangs-Abbildung, in welcher der Hase dem Jäger eine lange Nase dreht). Körperlichen Schaden erleidet am Ende sogar allein nur das Hasenkind, das als Nebenfolge des Geschehens eine Brandblase auf der Nasenspitze beklagt. Der Vater wird den Kleinen ziemlich trösten müssen: Übermut (des Vaters) tut selten gut (dem Kinde).

Hoffentlich hat die Geschichte einen eher anderen moralischen Hintergrund oder auch mehrere. Eine Option wäre, dass die Handlung des Hasen den Jäger zum Nachdenken über sein Waidwerk bringt. Was aber, wenn der Hase keinen pädagogischen Zeigefinger am Abzug hätte, sondern einen alttestamentarischen?

\subsection{Der Hase ist Sinnbild der „zurückschlagenden Natur“}

Die Geschichte vom Hasen und Jäger ist die Geschichte eines von vornherein und immer Unterlegenen, dem ein Augenblick der Überlegenheit geschenkt wird und der diesen Augenblick nutzt. Die im Hasen versinnbildlichte genutzte Natur beschreibt die gängige Naturwahrnehmung: sie ist Gegenstand des dominium terrae. Vermittels seiner technischen Überlegenheit, die er seinem Ingenium verdankt, kann der physisch schwache Mensch die Natur beherrschen, sie in die von ihm beabsichtigten Bahnen lenken. Der weiter oben zitierte Bacon entwarf, auf dieser Sicht aufbauend, sogar ein Bild der Natur, in dem dieser Vorwürfe gemacht werden. Statt in der ihr zugewiesenen ewigen Weise abzulaufen, würde sie zuweilen Fehler machen, wenn ,[die Natur] durch bösartige Ungewöhnlichkeiten eines unbändigen Stoffes und die Gewalt der Hindernisse außer ihren Zustand gestoßen" werde. ${ }^{34}$ Übersetzt man die Vorstellung Bacons, die wohl auch unsere eigene ist, dann hat man sich einerseits mit bestimmten naturalen Abläufen abzufinden: mit Tag und Nacht, mit Ebbe und Flut, dem Regen womöglich, der Erosion der Alpen, dem Vogelzug, dem Planetenlauf, der Schwerkraft und ähnlichem mehr. Dem steht eine von menschlicher „Kunst und Arbeit gebundene, gestaltete und gleichsam erneuerte Natur gegenüber" (Bacon, S. 173). Das ist jede Form ge-

\footnotetext{
${ }^{34}$ Vgl. Fußnote 3. Bacons Position ist bis auf den heutigen Tag ungebrochen zu finden: „Denn viele öffentliche Krisen des vergangenen Jahrzehnts - Sars, Schweinegrippe, Aschewolke - hängen damit zusammen, dass die Auswüchse der Natur, kombiniert mit dem weltumspannenden Flugverkehr, eine tödliche Gefahr bilden können." (Aus dem Kommentar von Alfons Kaiser auf der ersten Seite der Frankfurter Allgemeinen Zeitung vom 23. April 2010. Hervorhebung B. H.). Nota bene: „Auswüchse der Natur"'!
} 
nutzter Natur, vom Pflasterstein über das Flugzeug, vom Schlachtvieh und Getreide bis hin zum Mittelmeerstrand: der Rohstoff wird verbessert im Interesse menschlicher Nutzungsmöglichkeit.

Zwischen diesen beiden Naturen stehen offenbar die Fehler. Dabei ist es mindestens absurd, der einen Natur ${ }^{35}$ vorzuhalten, sie würde die in sie gesetzten Erwartungen nicht erfüllen. Wer von Fehlern spricht, hat eine Vorstellung, wie es stattdessen, wie es ,richtig“ sein müsste. Bacons Sicht beruht auf der Annahme einer absolut rational-logisch zu durchdringenden Natur. Er ahnte nicht, dass Erdbeben oder Vulkanausbrüche absolut keine Fehler der Natur waren, sondern lediglich aus mangelnder menschlicher Einsicht in die naturalen Abläufe so klassifiziert wurden. Naturerscheinungen sind feindselig dort, wo sie vom Menschen so belegt werden. Es wäre ein Fehler der Natur, ein Akt ihrer Feindseligkeit, wenn das Hochwasser eine Ernte vernichtete und nicht ein Fehler der Menschen, indem sie die naturalen Abläufe in ihrem Interessengebiet falsch einschätzten? Bis auf den heutigen Tag ist die Verblüffung darüber groß, dass sich der Fluss bei Hochwasser nicht von der menschlichen Siedlung fernhält.

Diese Wahrnehmung sieht das dominium terrae gefährdet und erträgt die Demütigung durch den „unbändigen Stoff“ zähneknirschend, wenn dem Ereignis straftheologische Botschaften abgewonnen werden, ${ }^{36}$ anderenfalls reagiert sie mit Entlastungsstrategien. Die Entlastung besteht in der Behauptung, dass Extremereignisse nicht zu kalkulieren seien. Dabei wäre es so einfach: Wer nicht in der Flussaue lebt, braucht das Hochwasser nicht zu kalkulieren, nicht zu fürchten. Er braucht dann nicht einmal zu wissen, ob das Hochwasser alle 10, alle 100 oder alle 1000 Jahre so hoch ausfällt.

\footnotetext{
35 Unübersehbar teilt hier Bacon die Natur in zwei Reiche: in die unkultivierte Natur und die kultivierte. Dazwischen befindet sich die dritte Natur, die der Fehler, wie in einem Limbus: Man weiß nicht recht, was von ihr zu halten ist.

36 Z. B. wird man nach einem zerstörenden Hochwasser selten lesen können, dass die Menschen leichtfertigerweise im Rückhaltesystem des Flusses gesiedelt hätten oder dort ihren Interessen mit einem Gefährdungsrisiko nachgingen. Es ist auch nichts zu lesen über ingenieurtechnische Fehler, sondern nur etwas über Jahrhundert- oder Jahrtausendhochwasser. Diese sind ja schließlich auch nicht vorauszusehen. Nun gilt als nicht vorhersehbar, was gängige Muster durchbricht, sich nicht an die Regeln hält, was Fehler macht: Die „Schuld“ liegt selbstverständlich bei den Fehlern der Natur, ganz so, wie schon Bacon es wusste. - Könnte man Bacon befragen, der an den Folgen des einzigen eigenhändigen Experimentes, das von ihm überliefert ist, verstarb, nachdem er Hühner durch Ausstopfen mit Schnee länger genießbar machen wollte, könnte man also Bacon befragen, wo der Fehler lag, der zu seinem Tod durch Lungenentzündung führte, wen oder was würde er angeben? Läge der Fehler beim Schnee, bei der Kälte, bei der Lunge oder würde er akzeptieren, dass der „Fehler“ in einer von ihm selbst zu verantwortenden Entscheidung lag, sich dem Gefährdungsrisiko von Witterungsunbilden auszusetzen?
} 
Manchmal scheint „der Mensch“ mit „der Natur“ „,in Einklang“ zu leben, jedenfalls dort, wo es aus Sicht „des Menschen“ keine Probleme zu geben scheint bzw. Topoi einer Rückvergoldung bedient werden. ${ }^{37}$ Der tägliche Kampf gegen das Unkraut im Garten deutet es aber schon an: „die Natur“ scheint nur zu gern bereit, sich einiges „zurückzuholen“, mitunter wendet sie sich auch ganz offensichtlich „gegen den Menschen“.

In der Summe muss sich „die Natur" offenbar vom Menschen eher einiges gefallen lassen. Jedenfalls wird gemeinhin verstanden, was die öffentliche Rede meint, wenn von „vergewaltigter“ Natur, von „Missbrauch“, „Ausbeutung“, „Zurückdrängung“ u. a. m. die Natur betreffend die Rede ist. Es stehen sich offenbar „der Mensch“ und „die Natur“ in einem Kampf gegenüber. 38

${ }^{37}$ Der „Einklang mit der Natur“ ist immer ein Kampfbegriff des politischen Streites oder der Klientelpolitik gewesen, z. B.: „Biosphärenreservat - Mensch und Natur im Einklang. Im Nordosten Niedersachsens liegt eine Landschaft mit ganz eigenem Rhythmus. Im weiten Tal der Elbe bestimmt der breite Strom das Bild, prägt mit seinen wechselnden Wasserständen den Naturraum und das Leben der Menschen. Im Herbst und Frühjahr bieten zahlreiche Zugvögel, die dem Flusslauf folgen, ein beeindruckendes Naturschauspiel. [...] Nach der deutschen Wiedervereinigung nutzten die Elbe-Anrainerländer die einmalige Chance, mit dem innerdeutschen Grenzfluss von einst ein verbindendes grünes Band zu knüpfen: Sachsen-Anhalt, Brandenburg, Niedersachsen, Mecklenburg-Vorpommern und Schleswig-Holstein beantragten bei der UNESCO die Anerkennung der Stromlandschaft der Mittelelbe als länderübergreifendes Biosphärenreservat.[...] [Der] niedersächsische Teil des Biosphärenreservats [ist] auf der seit 1998 geltenden rahmenrechtlichen Grundlage des $\ 25$ des Bundesnaturschutzgesetzes [seit November 2002] auch förmlich als Biosphärenreservat aus[gewiesen]. [...] Mit dem Biosphärenreservatsgesetz wurde der niedersächsischen Mittelelbe ein Schutz zuteil, der in dieser Weise in der Bundesrepublik Deutschland noch an keiner anderen Stelle verwirklicht worden war und der das Fundament für ein neues Miteinander von Mensch und Natur im Elbetal gelegt hat.“ (zitiert aus http://www.umwelt.niedersachsen.de/live/live.php?navigation_id=2431\&article_id=8077 \&_psmand=10, zuletzt besucht am 17.8.2010; Hervorhebung B.H.) Woraus das „Fundament für ein neues Miteinander von Mensch und Natur im Elbetal" besteht, erschließt sich weder hier noch an anderer Stelle des Textes. Vielmehr belegt dieser, dass „Mensch und Natur im Einklang" lediglich eine rhetorische und inhaltsleere Floskel ist, die auf der unreflektierten Anschauung beruht, wonach geringe menschliche Eingriffstiefe einen „Einklang“ dar- oder herstelle bzw. Menschen auf eine eigentliche, auf eine technologie- und anspruchsreduzierte Weise lebten. Diese unsinnige Randbedingung erfüllen auch die Slums in Kalkutta.

38 Unübersehbar wird in solchen Reden der Natur Subjekthaftigkeit unterstellt, woraus archaisches Denken aufscheint. In der platonischen Philosophie (Platon, Timaios; vgl. Bredekamp 1984) erhält die Erde die Seinsform eines lebendigen Wesens, was der älteren Idee der „Mutter Erde“ folgt und ihr Leibeigenschaft verleiht. Von hier leitet sich eine Vorstellung ab, die auch „der Natur“" wesenhafte, leibhafte, subjekthafte Züge zuschreibt. Diese Ideen bilden die Quelle jeder personalisierten Naturvorstellung. Die Vorstellung überlebt offensichtlich das Idolatrieverbot der christlichen Dogmatik. Zeitgenössisch werden solche Vorstellungen durch panpsychistische oder naturreligiös gefärbte Mythen wiederbelebt. Vorstellungen von Gewalt, die „,der Natur“ angetan würde, bedienen sich bei der Leibmetapher einer analogen Bildhaftigkeit, die selbst vor den Gewaltperversionen des Sexuellen nicht zurückschrecken: Die Natur wird „,vergewaltigt“, „missbraucht“. „Mutter Erde“ muss sich ausbeuterisch ihren Leib „durchwühlen“ lassen und, mit dem was in ihm steckt, menschliche Gier befriedigen (Niavis 1492-1495/1953). Wenn sie „zurückschlägt“, ist das die Verteidigung eines vergewaltigten und ausgebeuteten Wesens? Die Unangemessenheit der geübten Bildsprache ist offensichtlich. - Der Literaturwissenschaftler Dieter Hensing (2002) hat sich mit dieser Thematik am Beispiel eines Stückes von Heiner Müller befasst: „Gegen die anthropozentrische Wesensbestimmung der Geschichte bringt Sasportas [der Protagonist bei Müller, B.H.] mit der revolutionären Bestimmung der elementaren (unvernünftigen) Natur- 
Täglich scheint der Mensch erfolgreich „die Natur“ nicht nur in Schach zu halten. Die eingesetzte Terminologie lässt kaum Zweifel daran, dass die Metapher vom dominium terrae anspruchsbewusst und rabiat umgesetzt wird. ${ }^{39}$ Nur manchmal, so der Eindruck, gelingt es der Natur, sich Respekt zu verschaffen, wenn sie sich mit „Gewalt“ und kleinen Erfolgen dem menschlichen Würgegriff zeitweilig entziehen kann. Das ist gewöhnlich der Moment, in dem „die Natur zurückschlägt“. Dabei zeigt sich lediglich, bis zu welchem Grade der Mensch gelernt, vielmehr nicht gelernt hat, die naturalen Abläufe einzuschätzen. Und dass Folgen und Nebenfolgen menschlicher Handlungsweise für den Menschen selbst nachteilig sein können. ${ }^{40}$

Der Begriff der zurückschlagenden Natur verlagert nach einem simplen Entlastungs-Prinzip die Verantwortung weg von der fehleinschätzenden prognostischen Kapazität menschlicher Planungsarbeit und Bedenkenlosigkeit gegenüber den Handlungsfolgen hin auf eine anonyme Naturmacht, auf ein Täterwesen, das sich der menschlichen Regieanweisung entzieht. Die kompensatorische Erhöhung der Deichkrone ist die Antwort auf das Hochwasser, mit der demonstrativ jede Bereitschaft zur friedlichen Koexistenz ausgeschlossen wird. „Die Natur“ soll „im Kampf bezwungen“ werden, denn: Der Fluss hat gefälligst im menschengemachten Bett zu bleiben.

gewalt ein irrationales Modell der subjektlosen Körper-Revolte zur Sprache: die sich gegen ihre Verdinglichungen, Versklavungen und Verstümmelungen ,rächende', die ,zurückschlagende“ Natur-Landschaft als gedachtes Prinzip der Befreiung." (S. 312) Die Überlegung Hensings ist für den Naturdiskurs brauchbar und erhellend.

39 Während dominium terrae eine den christlichen Religionen verbundene Wortbildung ist und auch als spezifisch christlicher Umgang mit Natur angesehen wird, ist doch unübersehbar, dass alle Kulturen Naturnutzung im Rahmen ihrer technologischen Möglichkeiten praktizieren. Erreichen diese technologischen Möglichkeiten eine bestimmte Höhe, ist Naturverbrauch eine Universalie menschlicher Kultur.

${ }^{40}$ Hier genügt der Hinweis auf die anthropogenen Ursachen des globalen klimatischen Wandels. 


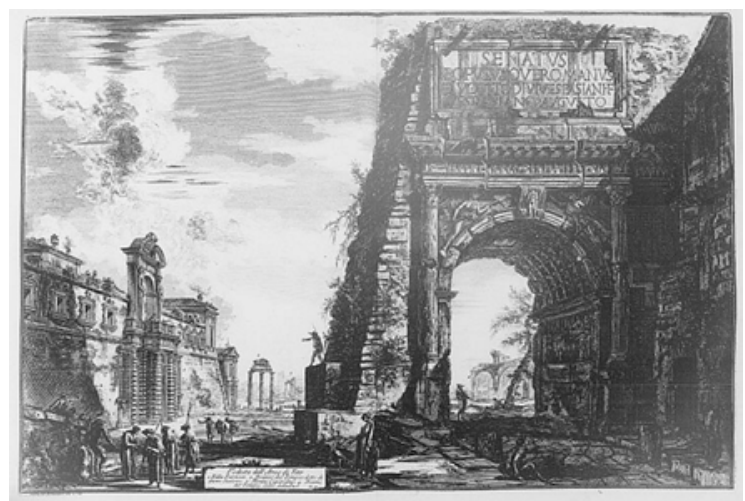

Abb. 7: Piranesis Veduten der antiken römischen Bauwerke (Titusbogen, 1748) stellen mit ihrem sichtbaren Bewuchs ein frühes Beispiel für Szenerien dar, aus denen sich der Topos der angeblich „zurückerobernden Natur““ entwickeln konnte. Eindrucksvollere Beispiele liefern mittlerweile alte, überwucherte Großbauten in Kambodscha oder Thailand oder Bauwerke mittelamerikanischer Indianerkulturen.

Abb. 8: zeigt eine von Würgefeigen überwucherte Tempelanlage in Koh Ker, Kambodscha (aus: National Geographic, April, 2008).

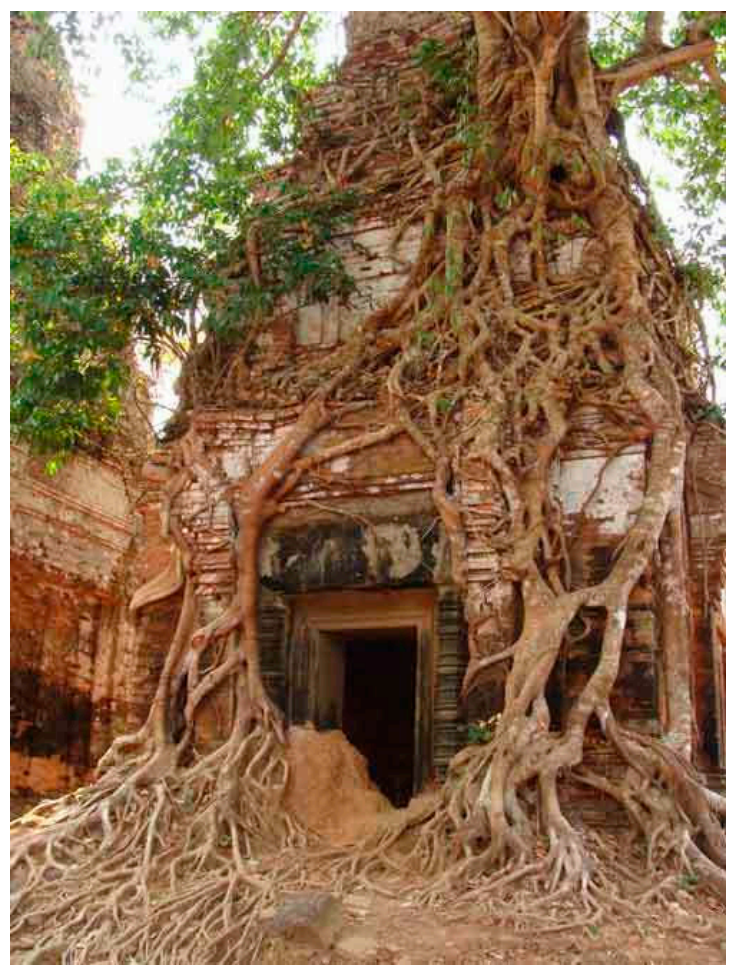


Die „zurückschlagende Natur“" wird gern dort bemüht, wo es um vermeintliche Unvorhersehbarkeit eines Elementarereignisses geht, meist um Hochwasser oder Flutereignisse. Die Printmedien haben die griffige Formel gern und schnell bei der Hand. So „,zeigte“ in der Frankfurter Allgemeinen Zeitung am 3.8.2010 (Nr. 177) mal wieder ,die Natur ihre Muskeln“ (in einem Bericht über das Elbe-Hochwasser 2002; Seite 31). An diese Vorstufe der Gewaltbereitschaft knüpft dann das brachiale „Zurückschlagen“ an.

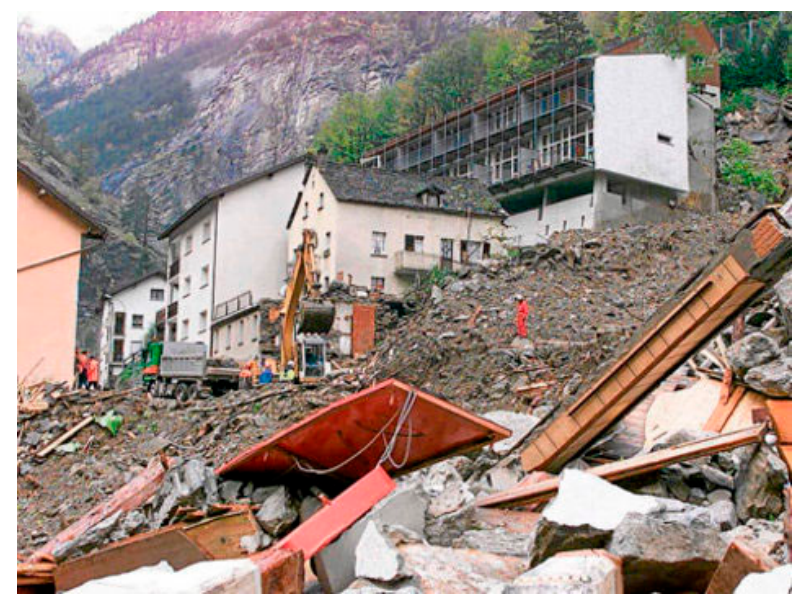

Abb. 9: „Gräber aus Stein - die Natur schlägt zurück“

14. Oktober 2000: Am Schweizer Simplonpass (an der Grenze zu Italien) geht eine Gerölllawine mit großer Geschwindigkeit ab. Die Folgen: elf Todesopfer im Dorf Gondo und zwei Verschollene. Die Mure hat ein Volumen von etlichen 10.000 Kubikmetern. Genau vier Jahre später wurde das wieder aufgebaute Dorf eingeweiht. Vor der Katastrophe lebten 120 Menschen in Gondo, 2007 nur noch 80.“ (zitiert aus www.merkur-online.de, am 26.01.2010)

Warum in diesem Ereignis die „Natur zurückschlägt“", bleibt unklar. Worin hätte denn der „Angriff“ bestanden, der „die Natur“ zum selbstverteidigenden oder rächenden „Zurückschlagen“ veranlasst haben könnte? Tatsächlich ist auch dieses Beispiel in Wahrheit nichts als ein Beispiel der Fehleinschätzung naturaler Prozesse durch Menschen: der Fehleinschätzung von Erosionsprozessen und Stabilitäten im hängenden Gebirge und der Schwerkraft.

Die bis auf den heutigen Tag wirksame Vorstellung von einer personalisierten, autonom handelnden „Natur“ ist offenkundig. Sie beruht auch auf der alltäglich vermeintlich in nämlicher Weise erfahrenen grundsätzlichen Differenz zwischen dem Bereich „der Natur“ und dem Bereich „,der Kultur“, wobei diese erfahrene Differenz nicht Ergebnis eines analytischen Prozesses ist, sondern einer bloßen, alltagsentlastenden Spontanqualifizierung (vgl. auch die andere Lesart in Fußnote 41). 


\section{2 „Natur und Mensch“}

Eine Rede von Mensch und Natur, die einander gegenüberstünden, wäre nur möglich, wenn ihr zugleich die Annahme zugrunde gelegt würde, dass „Natur“ und „Mensch“ zwei gleichartige Kategorien bildeten oder in zwei gleichartigen Kategorien verortet wären. ${ }^{41}$ Diese Annahme ist erkennbar ein klassischer Kategorienfehler i. S. von Gilbert Ryle (1969), und zwar einer, der durchaus dem Kategorienproblem „Geist und Körper“ von Descartes äquivalent ist. Ohne weiter auf dieses für die Konzeption der Umweltgeschichte eminente Problem einzugehen, genügt hier, das Begriffspaar „Mensch“ und „Natur“ als Scheinopposition zu entlarven. Während „Tag und Nacht“, „rechts und links“, „Mann und Frau“ usw. zwar kulturelle Muster sind, die aber auf überkulturellen kategorialen Vorgaben beruhen, handelt es sich bei „Mensch und Natur" um eine Bezugskonstruktion anderer Art. Selbstverständlich ist „Mensch“ enkaptisch in der Kategorie „Natur“ enthalten, und zwar in jeder nur denkbaren Weise. Selbst die Betonung der kulturellen Leistungen des Menschen kann weder die Naturbedingtheit dieser Leistungen selbst noch die Eigengesetzlichkeiten naturaler Prinzipien überwinden und damit eine logische Trennung von Natur und Mensch begründen. Den emergenten Phänomenen menschlicher Leistung, die sich scheinbar oder tatsächlich über alle Naturgesetzlichkeiten erheben können, sind mit den Möglichkeiten der materiellen Eigenschaften, denen sich jede Form menschlicher Existenz und Lebensäußerung verdankt, ihre absoluten Grenzen gesetzt. Dabei ist das logische Problem klein: „Natur“ wird ausschließlich durch Wahrnehmung erfahren. Die Grundlage ihrer Wahrnehmung ist „Kultur“, und nicht unser bloßer

\footnotetext{
${ }^{41}$ Das alltagspraktisch konstruierte „Gegenüber“ von „Natur“ und „Kultur“ ist so wirkmächtig, dass ausgeschlossen erscheint, dass beide in einem anderen als oppositionellen Verhältnis zueinander stehen. Dieser Alltagsgebrauch verdeckt, dass „Natur“ und „Kultur“ derselben Kategoriengruppe angehören und als solche nicht gleichzeitig zueinander in Opposition gesetzt werden können. Siehe weiter im Text. - Gabriele Dürbeck hat in der Diskussion die berechtigte Frage aufgeworfen, ,warum man nicht davon sprechen können sollte, dass der Mensch (auch wenn er selbst eine physische Seite hat) sich in ganz verschiedenen Weisen zu seiner Umwelt ins Verbältnis setzen kann; es ist dann i. E. zu bestimmen, was als ,Umwelt' und was davon als ,Natur ' bezeichnet wird." - Fraglos ist dies möglich und unzweifelhaft auch alltagspraktische Realität. Ich plädiere ja in nämlicher Weise für relationale Umwelt-UmgebungNatur-Benennungen. Die Differenz ergibt sich gegebenenfalls aus der wissenschaftssystematischen bzw. epistemologischen Grundlage, auf die diese Relationen bezogen sind: auf die Konstruktion einer „Natur-Kultur-Opposition“ oder auf die erkenntnismäßige Ausdifferenzierung des menschlichen Erlebnisgehaltes unter einer Wahrnehmung und davon abgeleiteter Umwelt-Systematik. Das bloße Vertrauen auf posthumanistische Standpunkte würde hier nicht ausreichen, weil der Posthumanismus ja keine Aussage zu den Kategorien macht, sondern lediglich eine herausgehobene Stellung des Menschen bestreitet. Herausgehoben-Sein oder Eingeschlossen-Sein des Menschen berührt jedoch nicht die Frage der Natur-Kultur-Dichotomie, sondern zunächst nur eine hierarchische Ebene.

Im Beitrag von Alexander Starre zu diesem Band wird dieselbe Frage ebenfalls behandelt, wobei der Ecocriticism, soweit ich verstanden habe, ebenfalls zu dem Ergebnis kommt, dass die Natur-KulturOpposition obsolet ist (vgl. das von Starre angeführte Zitat von Buell 2005, S. 22-23). Alexander Starre verdanke ich darüber hinaus den Hinweis, dass Dana Phillips (2003) den zur Zeit ergiebigsten Überblick über Naturverständnisse liefert, die im Ecocriticism favorisiert werden. Gleichzeitig ist es verblüffend, dass im anderen Standwerk des Ecocriticism, dem von Greg Garrard (2004), die Kapitelüberschriften geradezu wie einem Lehrbuch der Humanökologie oder einem der Umweltgeschichte entnommen erscheinen: pollution, wilderness, apocalypse, dwelling, animals, the earth.
} 
sensorischer Apparat. „Kultur“ ist die hinreichende Bedingung der Wahrnehmung von Natur. Als ihre Bedingung kann sie der Natur nicht als gleichwertige Kategorie gegenübergestellt werden. ${ }^{42}$

Wie immer auch: Die Rede von „Mensch und Natur“ tut so, als seien beide nach derselben Art souverän handelnde Akteure, nach der Art, wie die Menschen sich erfahren, wenn sie sich unter dem Versuch objektivierender Betrachtung beobachten. Das Grundmissverständnis der Begriffsschöpfung „Mensch und Natur“ beruht darauf, dass der sich kultürlich definierende und erfahrende Mensch glaubt, in der Natur einem „objektiv“ verfassten Subjekt gegenüberzustehen. ${ }^{43}$ Adorno (Fußnote 26) hatte bereits auf die Scheinbarkeit der Natur verwiesen, die nur ihrem Anschein nach nichts Gemachtes ist. Tatsächlich ist „Natur“ in ihrer Totalität das kultürlichste aller Produkte, weil sie alle Projektionen, alles Verständnis des Menschen und alle seine Defizite aufnimmt, diese ständig zitiert, reflektiert und permanent zu Handlungen animiert. „Nicht die Dinge selbst beunruhigen die Menschen, sondern ihre Urteile und Meinungen über sie.“ (Epiktet, Handbuch der Moral 5).

Die Rede über die Natur wird gewöhnlich auf einen doppelten naturalistischen Fehlschluss gegründet. Zum einen wird nicht anerkannt, dass die Wahrnehmungen von und Aussagen über Natur den kulturell geprägten Mustern folgen. Aus diesem Fehlschluss folgt der nächste: Die Bewertungskategorien werden als vermeintlich natural vorgegeben angesehen, wo doch die Dinge in der Natur lediglich so sind, wie sie sind, nicht aber, weil sie so sein sollen. ${ }^{44}$ Jeder aus der Natur abgeleiteten Handlungsoption liegt eine menschliche Bewertung zugrunde. Niemals spräche z. B. die Natur, die ohnehin nicht spricht, über einen Hochwasserschutz. Selbstverständlich ist es die menschliche Bewertung, die naturale Gegebenheiten prospektiv und prophylaktisch in Deichbau übersetzt und von Sachzwängen spricht. Der Sachzwang ist menschliches Interesse, das an bestimmter Stelle umgesetzt werden soll.

\footnotetext{
42 Diese Aussage benennt das logische Problem aller Kultur-Natur-Oppositionen und behauptet, dass „Natur“ letztlich in „Kultur“ eingeschlossen ist, unabhängig davon, dass sie sowohl aus objektiver materieller Wirklichkeit wie aus konstruierter Wirklichkeit besteht. Dieser Erkenntnis-Fehler ist weit verbreitet und wird selbst in Lehrbüchern der Umweltgeschichte fortgeschrieben (z. B. Winiwarter/Knoll 2007, S. 129). - Eine andere, wahrscheinlich die präziseste Lesart desselben hier vorgetragenen Gedankens ist: Der „Natur“ kommt, als einer Universalie, die ontologische Existenz zu. Ihre Wahrnehmung allerdings ist kulturell vermittelt.

43 In den nachfolgenden Passagen wird belegt, dass diese Auffassung irrig ist. Allerdings: Jede aufgeklärte Position wird ihrerseits ungültig, wenn Menschen aus einem wahrnehmungspsychologisch verständlichen Impuls in den voraufklärerischen Gestus zurückfallen und „die Natur" mit den Eigenschaften eines personalisierten, wenn auch irgendwie anonymen Täterwesens belegen. Es gilt das sozialpsychologisch grundlegende Thomas-Theorem: „If men define situations as real, they are real in their consequences." (Thomas \& Thomas 1928, S. 572).

${ }^{44}$ David Hume „There is no Ought from an Is.“
} 
Weiterhin wird in der Rede über Natur zumeist übersehen, dass im Falle von „Mensch und Natur“ vielfach und kontextabhängig der Begriff der „Natur“ synonym den Begriffen von „Umgebung“ und „Umwelt“ verwendet wird. In einem systematischen Verständnis ist „Natur“ zunächst alles, was in unserer und möglichen anderen Welten an belebten und unbelebten Dingen existiert. ${ }^{45}$ Selbstverständlich schließt dies den Menschen ein. Die Dinge der Natur, zwischen und mit denen wir uns in einem weitesten Sinne aufhalten, stellen dabei das Tableau, „die Umgebung“. Einer Entdeckung Jakob von Uexkülls zufolge bilden diejenigen Dinge der Umgebung, die Bedeutung für ein Lebewesen erhalten, seine „Umwelt".46

„Umgebung“ ist eine relationale Form von „Natur“, die sich allein dem beschreibenden Bezug zu einem bestimmten Naturelement verdankt. Es gibt demnach die Umgebung eines Steines wie die einer Pflanze oder eines Tieres. Vereinfachend können diese „Umgebungen“ als gleich gedacht werden, wenn Stein, Enzian und Murmeltier auf derselben Maienwiese vorkommen. Aber allein jene Elemente der Maienwiese, die für die Murmeltierindividuen kollektive (artliche) Bedeutung haben, bilden die „Murmeltier-Umwelt““.47

Die Rede eines Menschen über „Natur“ ist entsprechend daraufhin zu prüfen, ob sie sich in einem abstrakten, philosophischen Verständnis bemüht, allgemein über die Dinge zu sprechen und sich dabei vielleicht sogar bemüht, sich von kulturellen Bewertungen frei zu halten, was ihr selbstverständlich (natürlich) nicht wirklich gelingt. Wenn die Rede konkret Bezug nimmt, kann sie

\footnotetext{
45 Die „Totalität des Existierenden“ (Mutschler 2002).

46 Auch der neuere Versuch Mutschlers zur Systematisierung der Naturzugänge kann die alte Dichotomie der Naturvorstellungen nicht hierarchisch überwinden, sondern stellt neben das szientifische Naturbild (die „objektive“ Natur) die Pluralität konkurrierender oder kontextuell anderer Naturbilder (Naturvorstellungen im kulturellen Kontext). Am Ende wird das Heil in einer Dreifaltigkeit der Natur gesucht: Natur als Korrelat des Theoretischen, Natur als Korrelat des Technisch-Praktischen und Natur als Korrelat des Ethisch-Praktischen. - Demgegenüber scheint mir das Skalentheorem, wie ich es nennen möchte, das sich aus Uexkülls Umwelt-Begriff ergibt, ein weniger kompliziertes und von vornherein auf Scheinobjektivität verzichtendes Naturkonzept zu sein. Diesem Theorem zufolge hätte man auf der kleinsten, der subjektivsten Ebene die „Umwelt“, dann die „Umgebung“ bei abnehmender Bedeutung für das Subjekt, und schließlich die abstrakte „Totalität des Existierenden“, zu der es keine subjektiven Bezüge mehr gibt. Mit diesem Theorem ist es gleichzeitig und ohne Wechsel eines theoretischen Bezugsrahmens möglich, sowohl über Amazonien als auch über meinen kleinen Kater zu sprechen, was mit keinem anderen Systematisierungsansatz über Natur möglich erscheint. Skalenspezifität würde, bei Anerkennung skalenabhängiger Emergenzen, auch mühelos Komplexitätszunahmen innerhalb des Gesamtsystems zulassen und anerkennen.

${ }^{47}$ Der „Umwelt“-Begriff ist bei Uexküll mindestens teilweise noch ein individualistischer Begriff. Da die Biologie aber bestrebt ist, sich der strengen Gesetzlichkeit der nomothetischen Naturwissenschaften zu nähern und an die Stelle des Zufalls die Notwendigkeit zu setzen und damit Ereignis und Struktur voneinander $\mathrm{zu}$ trennen, werden anstelle von Aussagen über Individuen solche über Kollektive angestrebt, z. B. über Arten, Gattungen, Familien usw. Entsprechend spricht die Biologie etwa seit den 1940er Jahren von „,der Umwelt der Fliege“ und meint damit, dass alle FliegenUmwelten im Grundsatz gleich wären. Entscheidend für den „Umwelt“-Begriff im Verständnis Uexkülls ist der über den jeweiligen Sinnesapparat einer biologischen Art vermittelte Eindruck, der zum „Weltbild“ einer Tierart führt. Entsprechend ist die Umwelt einer Fliege, eines Hundes und eines Menschen, die im selben Zimmer leben, je und spezifisch voneinander geschieden.
} 
dies nur auf Dinge der Umgebung bzw. der Umwelt tun. Einzig in den Wahrnehmungsperspektiven von „Umgebung“ und „Umwelt“ erscheint es möglich, sich den konkreten Dingen der Natur zu nähern. Über die Pinguine der Antarktis z. B. kann ich nur abstrakt als Elemente von Natur reden. Aus eigener Anschauung oder aus einer für mich bedeutsamen Beschäftigung werden sie zu Elementen von Umgebung oder von Umwelt.

Ernst Cassirer hat die Uexküllsche Entdeckung von „Merknetz“ und „Wirknetz“ als Elemente desjenigen Funktionskreises im Tier, der die „Umwelt“ erfasst und auf sie reagiert, im Falle des Menschen um das „Symbolnetz“ bereichert. Alles, womit Menschen in ihrer Umgebung umgehen, wird von ihnen symbolisiert, wird mit Sinn und Bedeutung belegt, die Elemente der Umgebung sind nicht einfach mehr bloße Elemente der Umgebung. Sie werden zu den Elementen der „Umwelt“ und immer symbolisch belegt, so dass sie „als mehr erscheinen gleichzeitig zu dem, was sie buchstäblich an Ort und Stelle sind“" (Adorno, a. a. O.). Und deshalb ist Umweltgeschichte von Naturgeschichte zu unterscheiden und geschieden. Am Ende aber können beide zusammenfallen. Man kann die Naturgeschichte nämlich auch als eine nicht einmal besonders extreme Variante der Umweltgeschichte auffassen, wobei sich jene von dieser durch die Behauptung unterscheidet, dass man kulturfrei und zeitunabhängig über „Natur“ sprechen könne. ${ }^{48}$

\section{Wie viele Divisionen hat die Natur?}

Womit „schlüge“ denn „die Natur“ tatsächlich „zurück“, wenn sie es denn täte? Die Formulierung greift die bekannt gewordene rhetorische Frage Josef Stalins auf. ${ }^{49}$ Abgesehen davon, ist die Frage sinnvoll nur zu stellen im Hinblick darauf, was den Menschen irgendwie angeht. ${ }^{50}$ Was den Menschen irgendwie angeht, ist eben nicht mehr „die Natur“ in der „Totalität des Existierenden“, sondern es ist ein konkreter Ausschnitt aus ihr, es ist „Umwelt“. Und diese ist durch den Menschen mit Sinn und Bedeutung versehen. Menschen belegen das Geschehen in diesem Naturausschnitt, in Verkennung der Abläufe, mit den Handlungsqualitäten

\footnotetext{
$48 \mathrm{Vgl}$. Fußnote 41.

49 „Wie viele Divisionen hat der Papst?“, mit der Stalin auf der Konferenz von Jalta die Beteiligung des Vatikans an späteren Friedensverhandlungen mit Deutschland abgelehnt haben soll. Wer nicht mitschießt, kann sich hinterher nicht an der Verteilung des Bärenfells beteiligen.

50 Die unter den (deutschsprachigen) Biologen des 20. Jh.s gängige Verständnisformel für „Umwelt“ ist nach meiner Kenntnis von Friedrichs (1943) herausgearbeitet worden: Er definierte Umwelt ,für den praktischen Gebrauch“ als „Komplex der direkten und der konkret greifbaren indirekten Beziehungen zur Außenwelt." Der Unterschied gegenüber der Definition von Uexkülls besteht in der Aufnahme aller Beziehungen (Friedrichs 1943, S. 157). Eine überdachte Begriffserläuterung durch Friedrichs („,dasjenige außerhalb des Subjekts, was dieses irgendwie angeht“. 1950, S. 70) kann als für die nachfolgenden Biologen leitend bezeichnet werden, ohne dass die Autoren sich jeweils explizit auf Friedrichs bezogen hätten. Friedrichs fasste die Leitlinien des biologischen Diskurses zusammen, wie er davor bestimmend war und es im Grunde bis heute ist.
} 
einer personalisiert gedachten Natur, obwohl es sich tatsächlich um zufällige, aber mit Notwendigkeit ablaufende Vorgänge handelt oder sogar um die reinen Folgen menschlicher Fehler. Wer also schlägt zurück, wenn es gar nicht die als Personalität verkannte Natur sein kann? Mit der Behauptung einer zurückschlagenden Natur fällt der Mensch tatsächlich auf sich selbst zurück.

Die Gewaltkataloge, mit denen sich Menschen seit historischen Zeiten auseinandersetzen müssen, sind anthropogen und anthropozentrisch. ${ }^{51}$ Deshalb wird die Rede über Elementarereignisse, deren Letztursache nicht menschliche Absicht ist, vom Menschen ebenfalls anthropomorph als „Gewalt" bewertet. „Gewaltig“ sind Regenfälle, sind Stürme, Hagelschlag, Erdbeben, Hochwasser, Feuersbrünste, Heuschreckenschwärme. Diese lautstarken Extremereignisse werden mit „Gewalt“ in Verbindung gebracht, weil menschliches Interesse sie als zerstörerisch oder als die menschliche Vorstellung ,sprengend“ (sic!) erfährt. Die Dimensionen solcher Extremereignisse übersteigen am Ort ihres Auftretens die technischen Möglichkeiten menschlicher Gegenmaßnahmen. Das Ohnmachtsgefühl angesichts dieser tosenden Freisetzung ungeheurer naturaler Kräfte entspricht dem gewaltigen Ausmaß, in dem diese erfahren werden.

Die dominium-terrae-Idee wird seit der Renaissance selbstbewusst verstärkt. Die philosophische Formel wandelt sich in faber mundi und beansprucht, die Welt zwar nicht in einem kreationistischen, aber einem erkenntnis- und wahrnehmungsmäßigen Prozess hervorzubringen. ${ }^{52}$ Deshalb fällt das Entsetzen über eine als gewaltbereit dargestellte „Natur" auch jeweils groß aus (z. B. Erdbeben von Lissabon 1755), u. a. wohl auch, weil nach dem menschlichen Selbstverständnis der aufgeklärten Moderne (bomo faber) das Monopol für „Gewalt“ ausschließlich beim Staat liegt. ${ }^{53}$ Die Natur hält sich in solchen Fällen erkennbar nicht an die Regeln, die der rational-logisch funktionierende Mensch der Nachaufklärung als selbstverständlich und allen Abläufen in der Welt unterliegend annimmt.

Selbstverständlich hat die Natur keine Divisionen. Sie brauchte sie nicht einmal. Sofern man existentielle Bedrohung als eine Form von Gewalt begreift, steht der Umwelt des Menschen ein unerschöpfliches Gewaltreservoir zur Verfügung und ist auch ununterbrochen tätig. Leben in der uns bekannten Form ist ohne das

\footnotetext{
51 Selbst die Abläufe innerhalb des naturalen Prinzips von „fressen und gefressen werden“ können eine anthropologische Wende erfahren, wenn der Mensch präventiv „zu fressen“ beginnt, um nicht gefressen zu werden. Dann ist auch die Gewalt des Tigers, der einen Menschen tötet, sofern dieser Mensch keine dem Tiger angemessene Weise der Koexistenz gefunden hat, als anthropogen verursachte Gewalt zu erkennen.

52 Es ist offensichtlich, dass in dem Ausdruck faber mundi alle philosophischen Probleme zur Sortierung und Hierarchisierung der Natur angelegt sind.

53 Dass „Naturkatastrophen“ straftheologische Bedeutung haben, glaubt um 1800 eigentlich kaum noch ein gebildeter Mensch. - Hier müsste sich eine Gegenüberstellung der Konstrukte „Natur“ und „Staat" anschließen, die vermutlich direkt aufeinander aufbauen oder sich einander in gewisser Weise sogar bedingen.
} 
Risiko der existentiellen Gefährdung weder denkbar noch offenbar möglich. ${ }^{54}$ Alles kann zu Gewalt werden, aber nur, weil Menschen die Elemente der Umwelt entsprechend symbolisieren. „Der Natur“ sind wir und unsere Taten gleichgültig. „Die Natur“ ist auch sich selbst gegenüber gleichgültig. Nicht nur, weil sie kein personalisiertes Wesen ist, sondern auch, weil alles bloß so ist, wie es ist, und nicht, weil es in irgendeiner Weise so sein soll. ${ }^{5}$

Es wird damit zu einer absolut kulturabhängigen Frage, ob wir überhaupt Mitleid haben und wenn ja, Mitleid mit dem Hasen oder mit dem Jäger oder mit beiden? Der Aporien, in die der Mensch in seinem Verhältnis zu „Natur“ gerät, sind viele. Sie lassen sich mit weltlichen oder religiösen Weltbildern zwar nicht reduzieren, sie lassen sich aber zum Teil verdrängen. Der Kompromiss, dem alle folgen können sollten, ist die Praktizierung von Konvivialität. Ganz gewiss leben Hasen länger auf dieser Erde als Menschen. Wer müsste also - wenn Seniorität, wenn „Erstgeburt“ zu einer historisch akzeptablen Größe erklärt wird - allererst Verständnis dafür haben, wenn der Hase den Gabentisch des Menschen entdeckt und für sich nutzt, so wie der Mensch vor Zeiten Hasenland zu seinem Nutzen in Ackerland und Gemüsegarten verwandelte, in dem er den Hasen verdrängte? Jedes Lebewesen verhält sich opportunistisch bezogen auf das Erreichen seines ultimaten Lebensziels, von dem Biologen behaupten, es sei nichts weiter als die Fortpflanzung. Nur der Mensch beginnt mit der Sortierarbeit, die seit Noahs Arche in der Welt ist: in Tiere (Organismen), die nützlich sind, in jene, die lästig sind und solche, die schädlich sind. ${ }^{56}$ Auf der Grundlage dieser Sortierarbeit übt er das dominium terrae aus.

Dass „die Natur zurückschlägt“, ist manchmal auch einfach nur der Wunsch, dem dominium terrae möge dort ein Ende gesetzt werden, wo der angeblich vernunftbegabte und verantwortlich handelnde Mensch jene Verantwortung missen lässt, auf die er sich so viel einbildet. Deshalb ist es richtig, im Delikatessenladen (mitunter) auch nach den Jägern zu fragen.

\footnotetext{
${ }^{54}$ Biologen gehen davon aus, dass sich die Fortpflanzung, bei der Erbanlagen rekombinant neu arrangiert werden (also bei allen „höheren“ Lebewesen), einer Strategie verdankt, mit der die Lebewesen existentiellen Bedrohungen durch Pathogene ausweichen.

55 Selbstverständlich ist dies nicht die Behauptung der Aufhebung von Kausalitäten.

56 Die christliche Meistererzählung über den Tierbestand, der die Sintflut überlebte, ist eine Erzählung auch über eine Umbewertung, die Gott selbst offenbar mit seiner Schöpfung vornahm. Er veranlasst nämlich die Benachteiligung eines Teiles der Tierwelt bei ihrer Verladung auf die Arche. Wenn doch alles so richtig war, wieso reduziert Gott die Anteile der „nicht nützlichen“ (d. i. nicht zum Opfer geeigneten) Tiere? Die Archen-Erzählung sagt außerdem nichts über Pflanzen, die selbstverständlich außerhalb der Arche keine vierzigtägige Wasserbedeckung überlebt hätten. Zu den „nicht nützlichen Tieren“ gibt es mit den „Unkräutern“ ein analoges Problem für Pflanzen, über die uns die biblischen Texte jedoch nichts weiter mitteilen.
} 


\section{Nachtrag zum Stillleben Abb. 2, Flegel, Schanessen}

Der Nachtrag ergibt sich aus Platzgründen, da im unmittelbaren Anschluss an das Bild kein hierfür ausreichender Druckraum zur Verfügung steht.

In der Diskussion warf Manfred Jakubowski-Tiessen die Frage auf, ob die Bewertung des Bildes als Beispiel eines Naturgebrauchs und -verbrauchs angemessen wäre, der einem beeindruckten oder neidischen Betrachter opulentes Luxusleben vorführt. Die Lebenszeit Flegels (1566-1638) wäre eine des allgemeinen wirtschaftlichen Mangels und der klimatischen Depression gewesen. Somit könnte das Stillleben in Wahrheit auch seine eigene Verkehrung darstellen: thematisiert wären Gegenstände, die aus Gründen des Mangels tatsächlich gar nicht zur Verfügung gestanden haben könnten.

Ich habe auf diese Vermutung zurückhaltend reagiert, nicht nur, weil mir dieses Argument trotz langjährigen Interesses am Stillleben bisher weder direkt noch indirekt begegnet ist, sondern auch und gerade, weil aus der Situation Georg Flegels eine solche Deutung sehr überraschend wäre. Gewöhnlich bedient sich das Interpretationsrepertoire von Stilleben bei physikotheologischen Lesarten, bei reiner Objektsymbolik oder einer bloß dekorativen Abbildungskunst. Ein Reflex des allgemeinen Zustands der Welt zur Zeit des Malers oder die Thematisierung der allgemeinen Lebenssituation bzw. gar ihre kritische Darstellung wäre eine neuartige Interpretationsebene des spezifischen Sujets, das in aller Regel einem sehr bestimmten und begrenzten Verwendungszweck diente. Eine solche, neue Bewertung lässt sich auch nach aller Kenntnis der Kunstgeschichte, zumindest für Flegels Grosses Schauessen, nicht unterstützen, das zudem auf einer Kupfertafel gemalt ist und nicht auf Leinwand oder Holz. Frankfurt am Main, die Wirkungsstätte Flegels ab 1593, war zu seiner Zeit eine sehr prosperierende Handelsstadt, war „eine Stadt des Luxus und der Eleganz“ und keine Stadt des Mangels, bis sie 1630 in den Strudel des Dreißigjährigen Krieges geriet. Alle abgebildeten Gegenstände, reine Luxuswaren, wurden nachweislich zu Flegels Zeiten in Frankfurt gehandelt. Die Bilder bedienen Geschmack und Nachfrage einer sehr wohlhabenden bürgerlichen Oberschicht der Stadt oder von wohlhabenden Messebesuchern, die mit dem Bild zugleich den eigenen Wohlstand zur Schau stellten. - Ich danke in diesem Zusammenhang Kurt Wettengl, Dortmund, für seine freundliche Auskunft. 


\section{Literatur}

Adorno, Theodor W. (2003): Ästhetische Theorie (1970). Frankfurt am Main: Suhrkamp.

Alpers, Svetlana (1998): Kunst als Beschreibung. Köln: DuMont.

Bacon, Francis (1783): Über die Würde und den Fortgang der Wissenschaften. Pest: Weingand \& Köpf.

Bayerl, Günter (2001): Die Natur als Warenhaus. Der technisch-ökonomische Blick auf die Natur in der Frühen Neuzeit. In: Hahn, Sylvia; Reith, Reinhold (Hgg.): Umwelt-Geschichte. Arbeitsfelder, Forschungsansätze, Perspektiven. Wien/München: Oldenbourg (= Querschnitte. Einführungstexte zur Sozial-, Wirtschafts- und Kulturgeschichte, Bd. 8), S. 33-52.

Beckmann, Johann (1767): Anfangsgründe der Naturhistorie. Göttingen, Bremen: Georg Ludewig Förster.

Benjamin, Walter (2006): Das Kunstwerk im Zeitalter seiner technischen Reproduzierbarkeit (1936). Frankfurt am Main: Suhrkamp.

Bourdieu, Pierre (2010): Die feinen Unterschiede (1982). Frankfurt am Main: Suhrkamp.

Braungart, Georg (2008): „Katastrophen kennt allein der Mensch“. In: Recherche - Zeitung für Wissenschaft 2, S. 17-19.

Bredekamp, Horst (1984): Der Mensch als Mörder der Natur. Das ,Iudicium Iovis‘ von Paulus Niavis und die Leibmetaphorik. In: Reinitzer, Heimo: All Geschöpf ist Zung' und Mund. Vestigia Bibliae 6, S. 261-283.

Buell, Lawrence (2005): The Future of Environmental Criticism. Malden: Blackwell.

DWB. Das Deutsche Wörterbuch von Jacob und Wilhelm Grimm http://germazope.uni-trier.de/Projects/DWB.

Fischer, Hubertus (1997): „Nur wer den Garten bebaut, weiß, was Wildnis ist.“ Zum Wandel der Naturwahrnehmung. In: Wilhelm-Busch-Gesellschaft und Grünflächenamt der Landeshauptstadt Hannover (Hrsg.) „Zurück zur Natur“ - Ideen und Geschichte des Georgengartens in Hannover-Herrenhausen. Ausstellungskatalog. Göttingen: Wallstein, S. 83-94.

Friedrichs, Karl (1943): Über den Begriff der „Umwelt“ in der Biologie. Acta Biotheoretica 7, S. 147-162.

Friedrichs, Karl (1950): Umwelt als Stufenbegriff und als Wirklichkeit. Studium Generale 3, S. 70-74.

Garrard, Greg (2004): Ecocriticism. The new critical idiom. London/New York: Routledge. Gerster, Georg (1985): Brot und Salz. Flugbilder (1980). 4. Aufl. Basel [u. a.]:

Birkhäuser. 
Gerster, Georg (1987): Der Mensch auf seiner Erde. Eine Befragung in Flugbildern (1975). 7. Auflage. Basel [u. a.]: Birkhäuser.

Gillson, Lindsey (2004): Evidence of hierarchical patch dynamics in an East African savanna? Landscape Ecology 19, S. 883-894.

Hensing, Dieter (2002): Wenn der Stein der Geschichte zurückrollt. Über einen glücklichen und vor allem einen unglücklichen Sisyphos - über Albert Camus und Heiner Müller. In: Stillmark, Hans-Christian; Lehker, Christoph (Hgg.): Rückblicke auf die Literatur der DDR. Amsterdamer Beiträge zur neueren Germanistik Bd. 52, S. 253-305.

Herrmann, Bernd; Schutkowski, Holger (1998): Naturerfahrungsgebiete Humanökologische Prolegomena zur Sicherung der Landschaft als Erlebnisraum und zur Förderung einer natur- und landschaftsverträglichen Erholung. In: Schemel, Hans-Joachim (Bearb.): Naturerfahrungsräume. Angewandte Landschaftsökologie 19. Bonn, Bad Godesberg: Bundesamt für Naturschutz, S. 13-29.

Hoffmann, Heinrich [ab 1847]: Die Geschichte vom wilden Jäger. In: Hoffmann, Heinrich: Der Struwwelpeter. Verschiedene Ausgaben, Verlage und Verlagsorte.

Horkheimer, Max; Adorno, Theodor W. (2009): Kulturindustrie (1969). In: Dialektik der Aufklärung. Philosophische Fragmente. Frankfurt am Main: Fischer, S. 128-178.

Huysmans, Joris-Karl (1981): Gegen den Strich (1884). Zürich: Diogenes.

MacLean, Alex S. (2008): OVER: The American landscape at the tipping point. New York: Abrams.

MacLean, Alex S. (2010): zahlreiche seiner Abbildungen sind enthalten in: Valentien, Donata (Hrsg.): Wiederkehr der Landschaft. Return of landscape. Berlin: Jovis Verlag und Akademie der Künste.

Mayr, Ernst (1979): Teleologisch und teleonomisch: eine neue Analyse. In: Mayr, Ernst: Evolution und die Vielfalt des Lebendigen. Berlin [u. a.]: Springer, S. 198-229.

Michel, Paul (2008): Physikotheologie. Ursprünge, Leistung und Niedergang einer Denkform. Neujahrsblatt auf das Jahr 2008. Herausgegeben von der Gelehrten Gesellschaft in Zürich (Nachfolgerin der Gesellschaft der Gelehrten auf der Chorherrenstube am Großmünster) vormals zum Besten des Waisenhauses. 171. Stück. Als Fortsetzung der Neujahrsblätter der Chorherrenstube Nr. 229. Zürich: Editions à la Carte.

Mutschler, Hans-Dieter (2002): Naturphilosophie. Stuttgart: Kohlhammer. 
Niavis, Paulus (1953): Iudicium Iovis oder Das Gericht der Götter über den Bergbau (1492-1495). Ein literarisches Dokument über den Bergbau. übers. u. hrsg. von Paul Krenkel. Freiberger Forschungshefte, Kultur und Technik D3. Berlin: Akademie Verlag.

Phillips, Dana (2003): The truth of ecology. Nature, culture, and literature in America. Oxford [u. a.]: Oxford Univ. Press.

Ritter, Joachim (1989): Landschaft. Zur Funktion des Ästhetischen in der Gesellschaft (1974). In: Ritter, Joachim: Subjektivität. Frankfurt am Main: Suhrkamp, S. 141-190.

Ryle, Gilbert (1969): Der Begriff des Geistes. Stuttgart: Reclam.

Sebba, Rachel (1991): The landscapes of childhood. The reflection of childhood's environment in adult memories and children's attitudes. Environment and Behavior 23, S. 295-322.

Simmel, Georg (1911): Die Mode. In: Simmel, Georg: Philosophische Kultur. Gesammelte Essays. Leipzig: Klinkhardt (Philosophisch-soziologische Bücherei; 27), S. 29-64.

Smuda, Manfred (1986): Natur als ästhetischer Gegenstand und als Gegenstand der Ästhetik. Zur Konstitution von Landschaft. In: Smuda, Manfred (Hrsg.): Landschaft. Frankfurt am Main: Suhrkamp, S. 44-69.

Thomas, William Isaac; Thomas, Dorothy Swaine (1928): The Child in America. Behavior problems and programs. New York: Knopf.

Veblen, Thorstein (2007): Theorie der feinen Leute. Eine ökonomische Untersuchung der Institutionen (1899). Frankfurt am Main: Fischer.

Vries, Jan de; Woude, Ad van de (1997): The first modern economy: success, failure, and perseverance of the Dutch economy: 1500-1815. Cambridge: Cambridge Univ. Press.

Wagenitz, Gerhard (1997): Die ,Scala naturae' in der Naturgeschichte des 18. Jahrhunderts und ihre Kritiker. Jahrbuch für Geschichte und Theorie der Biologie 4, S. 179-195.

Wettengl, Kurt (1993) Hrsg.: Georg Flegel 1566-1638. Stilleben. Historisches Museum, Frankfurt; Schirn Kunsthalle, Frankfurt; Stuttgart: Verlag Gerd Hatje

White, Lynn Townsend (1967): The historical roots of our ecological crisis. Science 155, S. 1203-1207.

Winiwarter, Verena; Knoll, Martin (2007): Umweltgeschichte. Köln: Böhlau.

Wittgenstein, Ludwig (2003): Tractatus logico-philosophicus.

Logischphilosophische Abhandlung (1922). Frankfurt am Main: Suhrkamp. 


\section{Anhang}

Jandls Gedicht entstand am 27.5.1962.57 Ernst Jandl hat sein Gedicht in einem Brief an eine Schülerin am 7. Mai 1974 erläutert. Dieser Brief wird hier im Wortlaut wiedergegeben. ${ }^{58}$ Das Verständnis des Dichters zwölf Jahre nach der Entstehung seines eigenen Werkes mutet vor dem Hintergrund der bis zum Jahre 2010 erfolgten Veränderungen in der Welt und dieser Welt selbst sonderbar unterkomplex. Es wird offensichtlich, wie sich Lesart oder Verständnis der Lyrik zeitund leserabhängig verschieben, was ihr zugleich überzeitliche Bedeutung verleiht.

„Im Delikatessenladen“:

Ernst Jandl antwortet einer Schülerin

Wien, 7. Mai 1974

Liebe Christine,

herzlichen Dank für Deinen Brief und das hübsche bunte Bildchen, über das ich mich sehr freue. Nun zum Gedicht „im delikatessenladen“. Delikatessen sind bekanntlich besonders köstliche Dinge zum Essen. In diesem Gedicht betritt ein Mann einen Laden, wo solche besonders köstlichen Dinge, die man essen kann, verkauft werden. Er tut nun so, als erwarte er, dass er dort nicht bloß köstliche Dinge zum Essen kaufen könne, sondern auch köstliche Dinge anderer Art, diese Dinge übrigens in derselben Weise haltbar gemacht wie Speisen, die man in einem Delikatessenladen kaufen kann, also etwa tiefgekühlt oder als Konserve. Zu solchen köstlichen Dingen gehört zum Beispiel eine sonnige Landschaft im Frühling, eine blühende Wiese im Mai, irgendwo in den Bergen. Wenn die Sonne warm scheint, kann man sich dort niederlassen, die Natur genießen und alles andere vergessen. Warum tut er so, als erwarte er, dass er eine solche Wiese im Delikatessenladen kaufen kann? Nun, vielleicht gehört er zu den Leuten, die glauben, dass man im Leben alles kaufen kann; damit hat er natürlich unrecht, und schließlich bekommt er ja seine „Maiwiesenkonserve“ auch nicht. Oder er weiß, dass es Leute gibt, die glauben, dass man im Leben alles kaufen kann, gehört aber selbst nicht $\mathrm{zu}$ diesen Leuten und verlangt im Delikatessenladen die Maiwiesenkonserve, um durch dieses unsinnige Verlangen deutlich zu machen, dass man nicht alles Schöne einfach kaufen kann.

Er bekommt sie nicht, doch er lässt nicht locker, sondern verlangt darauf eine schöne Winterlandschaft, also ebenfalls etwas Köstliches, das man nicht einfach kaufen kann. Wieder hat er keinen Erfolg, das heißt, es zeigt sich wiederum, dass man nicht alle schönen Dinge des Lebens einfach kaufen kann. Jetzt geschieht aber

\footnotetext{
57 Jandl, Poetische Werke, Bd. 5, Nr. 136.

58 Wiedergabe nach F.A.Z.-Archiv: Frankfurter Allgemeine Zeitung, 1.8.2005, Nr. 176, S. 33.
} 
etwas Seltsames: er bemerkt etwas, das zu beiden Landschaften gepasst hätte, zur Frühlingswiese ebenso wie zur Winterlandschaft. Es sind Hasen, die in diesem Delikatessenladen verkauft werden. Es gibt große Delikatessenläden, wo neben tausend anderen Dingen auch Wildbret zum Verkauf angeboten wird. Die Hasen, tot, sind dann meist an den Hinterbeinen zusammengebunden und an einen Haken gehängt, also mit dem Kopf nach unten. Hier hat er in diesem Delikatessenladen nun tatsächlich etwas entdeckt, das zu der Landschaft gehört, die er ursprünglich haben wollte, ein Stück Natur. Wie zur Maiwiese die Sonne und die Blumen, und wie zur Schneehalde die schön beschneite Fichte (und auch die Wintersportler, die er nicht haben wollte), so gehört zu den Hasen in dem Zustand, in dem sie da hängen, also totgeschossen, auch der Jäger. Deshalb also die Frage: „Wo hängen denn die Jäger?" - eine unsinnige und zugleich grausame Frage, die aber in dem Augenblick einen Sinn bekommt, wenn man nicht mehr damit einverstanden ist, dass die einen immer die Gejagten sind, und die andern immer die Jäger, und dass sich daran niemals etwas ändern soll. Aus der Sicht des Jägers ist es ganz richtig, dass die Hasen immer die Gehetzten und Gejagten sind, die schließlich totgeschossen und verkauft werden. Aus der Sicht der Hasen allerdings müsste das gleiche Recht für alle gelten. Warum sollte es den Jägern dann nicht ebenso ergehen wie den Hasen?

Das Gedicht ist vielleicht eine Art Fabel, mit einer Lehre am Schluss. Von dort könnte man vielleicht weiterdenken, ob es hier wirklich nur um Jäger und Hasen geht, oder ob es nicht in unserer menschlichen Welt vorkommen kann, dass die einen immer die Mächtigen sind, und die andern immer die Machtlosen, und dass dieser Zustand als ein rechtmäßiger Zustand bezeichnet und verteidigt wird.

Ich hoffe, dass es mir gelungen ist, Dir und den Mädchen und Jungen in Deiner Klasse das schwierige Gedicht etwas klarer zu machen.

Herzliche Grüße

Dein Ernst Jandl 



\section{Die Ringe des Saturn und Solar \\ Sinnbilder und Schreibstrategien in literarischen Stellungnahmen zur ökologischen Krise von W.G. Sebald und Ian McEwan}

\section{Axel Goodbody}

\section{Einleitung}

Die Ringe des Saturn bestehen aus Eiskristallen und vermutlich meteoritischen Staubteilchen, die den Planeten in dessen Äquatorebene in kreisförmigen Bahnen umlaufen. Wahrscheinlich handelt es sich um die Bruchstücke eines früheren Mondes, der dem Planeten zu nahe, von dessen Gezeitenwirkung zerstört wurde. (Die Ringe des Saturn, S. 9)

There are a dozen proven ways of making electricity out of sunlight, but the ultimate goal is still ahead [...]. I'm talking of artificial photosynthesis, of copying the methods nature took three billion years to perfect. We'll use light directly to make cheap hydrogen and oxygen out of water, and run our turbines night and day, or we'll make fuels out of water, sunlight and carbon dioxide, or we'll build desalination plants that make electricity as well as fresh water. Believe me, this will happen. Solar will expand [...]. Basic science, the market and our grave situation will determine that this is the future - logic, not idealism, compels it. (Solar, S. 154)

Die in den obigen Zitaten sowie im Titel der Werke von W.G. Sebald und Ian McEwan, denen sie entnommen sind, angesprochenen Himmelskörper stellen Sinnbilder des Trübsinns bzw. der Hoffnung dar. Sie signalisieren aber weniger gegensätzliche Auffassungen der menschlichen Natur, des Umgangs mit der 
Umwelt oder der Zukunftschancen der Menschheit als eine Wahl unterschiedlicher Strategien zu deren Darstellung. Während Sebald eine tragisch-düstere Haltung angesichts der Vergeblichkeit menschlicher Bemühungen und des unaufhaltsamen Abbaus aller Materie einnimmt, arbeitet McEwan mit den Mitteln der Satire und der Komik. Es ist, als ob sich der britische Autor weigere, sich Sebaldscher Melancholie hinzugeben, trotz der auch von ihm induzierten menschlichen Blindheit gegenüber den Herausforderungen anthropogener Umweltveränderung (in diesem Fall des Klimawandels).

Die Saturn-Ringe und die Solarenergie weisen beide auf die planetarische Dimension unserer ökologischen Krise hin sowie auf die Schlüsselrolle der Energiefrage für unsere Zukunft. Hier hören aber die Ähnlichkeiten auf, denn Sebald und McEwan greifen diametral entgegengesetzte Bilder und Schreibstrategien auf, um ihr Weltbild zu vermitteln. Während der kalte Planet und dessen in Staubringe aufgelöster Mond Sebald zum Symbol des Todes und der Auslöschung allen Lebens in der Endzeit dienen, steht die Solarkraft im Roman McEwans als Sinnbild für den Traum, den Planeten durch Erschließung einer neuen, unerschöpflichen Naturquelle zu retten. Vereinfacht ausgedrückt, entsprechen diese zentralen Bilder den menschlichen Grundhaltungen des Weinens und des Lachens, des Zweifelns und des Hoffens. Ebenso entsprechen ihnen die narrativen Formen der beiden Werke: elegische Erinnerung an vergangenes Leiden und Schaffen und pikareske Zeitsatire. Im Folgenden sollen die Haupteigenschaften der beiden Schreibmodi herausgearbeitet werden und über ihre jeweilige Eignung zur Vermittlung von Einsichten, die ökologischen Herausforderungen unserer Zeit sowie den Erfolg von Sebald und McEwan bei ihrem Einsatz nachgedacht werden.

\section{Die Ringe des Saturn}

Als ich am Christi Himmelfahrtstag des Vierundvierzigerjahrs auf die Welt kam, zog gerade die Flurumgangsprozession unter den Klängen der Feuerwehrkapelle an unserem Haus vorbei in die blühenden Maifelder hinaus. Die Mutter nahm dies zunächst für ein gutes Zeichen, nicht ahnend, daß der kalte Planet Saturn die Konstellation der Stunde regierte und daß über den Bergen schon das Unwetter stand, das bald darauf die Bittgänger zersprengte und einen der vier Baldachinträger erschlug. (Sebald 1988/1997a, S. 76) 
So schreibt W.G. Sebald im dritten, autobiographischen Teil seiner 1988 erschienenen Erstveröffentlichung, des Langgedichts Nach der Natur. Die Vorstellung, dass die Stellung der Planeten zum Zeitpunkt der Geburt das Schicksal und die Veranlagung des Einzelnen bestimme, ist ein Grundsatz der Astrologie, der auf die Analogien zwischen den einzelnen Bereichen des Kosmos zurückgeht, die eine so große Rolle in der Philosophie von der Antike bis zur frühen Neuzeit spielten. Man ging davon aus, es gehe von den Gestirnen ein direkter Einfluss auf den Mikrokosmos des menschlichen Leibs aus. Laut der Humorallehre beeinflusste das Vorherrschen bestimmter Sternbilder das menschliche Temperament durch Begünstigung eines der vier Körpersäfte. Im 2. Jahrhundert schrieb der griechische Arzt und Anatom Galen, ein Überschuss an schwarzer Galle führe zur Melancholie, d. h. zur Schwermütigkeit und Furchtsamkeit. Zwischen dem Schicksalhaften, dem Krankhaften und dem Natürlichen schillernd, wurde die Melancholie als teils kosmologisch bestimmt aufgefasst, teils als Störung der Gesundheit und teils als das natürliche Temperament derer, deren Leben, vergällt ${ }^{\star}$ war. Galen legte eine Verbindung zwischen der Melancholie und den Sternbildern Waage, Skorpion und Schütze nahe. In der mittelalterlichen Astrologie war es jedoch der traditionell mit Sichel oder Sense dargestellte Saturn, der mit Melancholie und Sorge, Unglück und Armut, Krankheit und Tod verbunden wurde.

Im Florentiner Neuplatonismus erfuhr diese Verbindung zwischen dem Saturn und der Melancholie Bestärkung und nahm eine entscheidende Wendung, indem die Melancholie in eine geistige Auszeichnung verwandelt wurde. Aus dem im christlichen Denken noch mit dem Laster der acedia, der Sünde der Trägheit, verbundenen Zustand wurde eine produktive ,Traurigkeit ohne Ursache“. „Im Neuplatonismus erfährt also das Saturnische seine poetische Aufwertung: Aus der Gleichsetzung von aristotelischer Melancholie und platonischem furor divinus entsteht der moderne Geniebegriff“", erklärt Sigrid Löffler (2003, S. 105) in einem klugen Aufsatz zum Saturnischen bei Sebald. Die Melancholiker steckten sich an dem Schrecken der Welt imaginativ an, machten ihre depressiven Stimmungslagen in der Kunst produktiv. Der moderne Melancholiker erlebe nicht nur seine Schwermut, er lebe sie gleichzeitig aus, ,als intensiviertes Ich-Gefühl und als gesteigerte Selbsterfahrung des poetischen Genies, worin sich Tod, Tristesse und Selbstbewußtsein auf eigentümliche Weise mischen“ (ebd.).

Sebald reiht sich also in seinem Gedicht in eine lange naturphilosophischliterarische Adelskette ein. Auch Die Ringe des Saturn, der 1995 als sein zweites Prosawerk erschien, steht im Zeichen des Saturn und der Melancholie. Das Buch erzählt von einer Fußwanderung in der ostenglischen Grafschaft Suffolk im August 1992, „als die Hundstage ihrem Ende zugingen“, in der Hoffnung, wie er schreibt, „der nach dem Abschluß einer größeren Arbeit in mir sich ausbreitenden Leere entkommen zu können“" (Sebald 1997b, S. 11). Im Rückblick stellt der Erzähler jedoch fest, es erscheine ihm, ,als ob der alte Aberglaube, daß bestimmte Krankheiten des Gemüts und des Körpers sich mit Vorliebe unter dem Zeichen des Hundssterns in uns festsetzen, möglicherweise seine Berechtigung hat“ (ebd.). 
Nun ist der Hundsstern nicht Saturn, sondern Sirius, hellstes Element im Sternbild Großer Hund, dessen Aufgangszeit in der nördlichen Hemisphäre mit der Hitze des Hochsommers verbunden ist. Dass das Buch nicht mehr den ursprünglich beabsichtigten Titel ,Unter dem Hundsstern' trägt (Steinmann 2006, S. 149), ist ein weiteres Zeichen, wie wichtig dem Autor die Symbolik Saturns war. Die trotz des offenbaren Gegensatzes zwischen kaltem Planeten und heißem Stern bestehende Verbindung liegt, wie Holger Steinmann ausführt, in der gemeinsamen Affinität zur Zerstörung: „Grosso modo fungiert hierbei der Hundsstern als Auslöser von Zerstörung, der Melancholiker als die diese Zerstörung reflektierende Instanz.“ (Ebd., S. 151)

Der hypothetische zertrümmerte Saturn-Mond, dessen knappe Beschreibung Sebald im letzten der drei seinem Buch vorangestellten Motti aus der BrockhausEnzyklopädie zitiert, exemplifiziert den Auflösungsprozess aller Materie in kosmischen Staub. Dies wird auch das Los der Erde sein in einer fernen Zukunft. Andererseits steht Saturn für eine abgeklärte, melancholische Sicht auf die menschliche Geschichte, die zu einer vom Erzähler angenommenen Persona wird. Denn der Ich-Erzähler in Die Ringe des Saturn hat zwar alle biographischen Eckdaten mit dem Autor Sebald gemein, darf aber nicht mit ihm gleichgesetzt werden. Er ist vielmehr eine Kunstfigur, eine Inszenierung. Der Planet bezeichnet eine wohl in der Veranlagung des Autors begründete Haltung, aber auch eine entsprechende bewusst gewählte Schreibstrategie. In einer wechselseitigen Überblendung von Fiktion und Dokumenten sammelt er historische, literarische und naturgeschichtliche Bruchstücke und arbeitet sie in unerwarteten Konstellationen in den Bericht über seine Wanderung ein.

Auf der ersten Seite von Die Ringe des Saturn erwähnt Sebald

das lähmende Grauen, das mich verschiedentlich überfallen hatte angesichts der selbst in dieser entlegenen Gegend bis weit in die Vergangenheit zurückgehenden Spuren der Zerstörung (S. 11¹).

Die Landschaften Ostenglands werden hier zu Orten des Untergangs und der Hoffnungslosigkeit, Inbildern des apokalyptischen Grauens der Endzeitlichkeit. In ihnen entziffert der Erzähler eine „Geschichte des Zerstörerischen und der Zerstörungen“ (Löffler 2003, S. 108). Diese Zerstörungen erscheinen zuerst als Ergebnisse unglücklicher Modernisierungsinitiativen (manche werden explizit Folgen des Thatcherismus genannt), erweitern sich aber in ein anthropologisches Prinzip, das sich in Kriegen im Allgemeinen verdichtet, in der Kolonialgeschichte und insbesondere in den beiden Weltkriegen und dem nirgends erwähnten, allenthalben aber zwischen den Zeilen anklingenden Holocaust.

In dieses Kontinuum der menschlichen Zerstörung reiht Sebald unseren Umgang mit der Umwelt ein. Als ein Beispiel der verheerenden Anwendung von dem, was

${ }^{1}$ Im Folgenden wird das Werk Die Ringe des Saturn (1995) mit Seitenangabe zitiert. 
er an einer Stelle als „einer vom Gesamtplan bis in die letzte Einzelheit alles durchwaltenden Vernunft" (S. 62) bezeichnet, führt er unsere Behandlung der Heringe an. Sich u. a. auf die Lektüre einer Mitte des 19. Jahrhunderts in Wien erschienenen Naturgeschichte der Nordsee stützend, schreibt er von der zeitweise enormen Vermehrungstendenz dieser Fischart, die als erschreckendes „Bild einer in ihrem eigenen Überfluss erstickenden Natur“ dazu geführt habe, dass der Hering zum „Hauptemblem sozusagen für die grundsätzliche Unausrottbarkeit der Natur“ geworden sei und der Heringsfang zu einem „der exemplarischen Schauplätze im Kampf des Menschen mit der Übermacht der Natur“. Die Heringsfischerei gehe heute weiter, allerdings werde die Ausbeute immer geringer, und die gelandeten Fänge seien ,oft nur für Fischmehl zu brauchen“. Denn

Tausende von Tonnen Quecksilber, Kadmium und Blei, Berge von Düngemitteln und Pestiziden werden von den Flüssen und Strömen Jahr für Jahr hinausgetragen in den deutschen Ozean. Ein Grossteil der schweren Metalle und der anderen toxischen Substanzen setzt sich in den seichten Gewässern der Doggerbank ab, wo ein Drittel der Fische bereits mit seltsamen Auswüchsen und Gebresten zur Welt kommen. (S. 69-72)

Sebald beschreibt, wie die Fische beim Heringsfang gegen die Netze verzweiflungsvoll anschwimmen, „bis sie sich mit den Kiemen in den Maschen verfangen, um dann bei dem an die acht Stunden dauernden Herausziehen und Aufwinden des Netzes erdrosselt zu werden“. Er fügt hinzu, wie ein gewisser Inspektor des Fischmarkts von Rouen sich veranlasst fühlte, „die Überlebensnotwendigkeit dieser Fische genauer zu erkunden, indem er ihnen die Flossen abschnitt und sie auf andere Weise verstümmelte. Eine solche, von unserem Wissensdrang inspirierte Prozedur ist sozusagen die äußerste Zuspitzung der Leidensgeschichte einer ständig von Katastrophen bedrohten Art." Man beruhige sich beim Gedanken, dass der Mensch beim Heringsfang bloß für einen Bruchteil der im Kreislauf des Lebens andauernd sich fortsetzenden Vernichtung verantwortlich sei, und auch mit der Annahme, dass die besondere physiologische Organisation der Fische sie vor der Empfindung von Angst oder Schmerz schütze, aber ,in Wahrheit wissen wir nichts von den Gefühlen des Herings“ (S. 74f.). Es ist sicher kein Zufall, dass die anschließenden Seiten von einem englischen Landbesitzer berichten, welcher 1945 an der Befreiung des Konzentrationslagers Bergen-Belsen beteiligt, durch dieses Erlebnis fürs Leben gezeichnet wird. Wie Claudia Öhlschläger zeigt (2006, S. 200f.), knüpft Sebald hier und anderswo ein dichtes Beziehungsnetz zwischen kreatürlicher und menschlicher Leidensgeschichte durch Parallelen und Assoziationen.

Seidenkultur spielt eine wichtige Rolle im Buch als Illustration der Schattenseite der Zivilisation. Aus Seide sind nämlich zwar Stoffe und Kleider von wunderbarer Schönheit hergestellt worden, aber mit dem Luxus sind immer wieder problematische Einkommensunterschiede und Machtstrukturen entstanden. Sebald deutet eine besondere Verbindung des Seidenbaus mit autoritären Staatsformen an. 
Versuche im 18. und 19. Jahrhundert, ihn in den deutschen Kleinstaaten einzuführen, seien gescheitert, weil der Unternehmergeist durch das Verwaltungsunwesen erstickt worden sei (S. 343). Von den Nazis sieht Sebald die Vision einer von Seidenkultur vereinigten, sich zu höheren Zwecken fortbildenden Nation mit besonderer Gründlichkeit wieder aufgenommen. Er zitiert aus dem Beiheft zu einem 1939 erstellten Unterrichtsfilm:

Schließlich sei ja die Seidenraupe, so fügt Professor Lange noch an, über ihren offenkundigen Nutzwert hinaus auch ein nahezu idealer Gegenstand für den Unterricht. In beliebiger Menge praktisch unkostenfrei erhältlich und als völlig „zahmes Haustier“ ohne Käfig oder Gehege zu halten, sei die Seidenraupe in jeder Entwicklungsstufe zu den verschiedensten Versuchsanordnungen (Wägungen, Messungen und drgl. mehr) verwertbar. Bau und Besonderheiten des Insektenkörpers seien an ihr aufzuzeigen, desgleichen Domestikationserscheinungen, Verlustmutationen sowie die in der menschlichen Zuchtarbeit notwendigen Grundmaßnahmen der Leistungskontrolle, Auslese und Ausmerzung zur Vermeidung rassischer Entartung. (S. 347f.)

Was dem Leser nicht ohne Weiteres verständlich wird, ist der von Sebald durch wiederholte Nebeneinanderstellung nahegelegte Zusammenhang zwischen Unterdrückung, Ausbeutung und Genozid einerseits und natürlichen Prozessen andererseits wie dem Fortpflanzungsdrang und dem ständigen Verfall der den thermodynamischen Gesetzen unterstellten Materie. Dieser Verfallsprozess wird beispielsweise von der abbröckelnden englischen Südostküste versinnbildlicht, die mitsamt ihren versinkenden Küstenstädten vom Meer unterwaschen und verschlungen wird. In einem weiteren Beispiel gegen Ende des Buchs schreibt Sebald vom allmählichen Verschwinden der großen Bäume, die bei der Anlage von Landbesitzen in der zweiten Hälfte des 18. Jahrhunderts gepflanzt wurden. Das sich seit Mitte der 70er Jahre zusehends beschleunigende, Abnehmen der Bäume in der englischen Landschaft beklagend, stellt er fest, dass die Ausbreitung der holländischen Ulmenkrankheit diese Baumart so gut wie völlig ausgerottet habe, und schreibt von mysteriösen Schäden an Eschen, Eichen, Buchen und Pappeln. Schließlich schildert er über Seiten hinweg die Folgen des Orkans vom Herbst 1987, dem 14 Millionen Bäume zum Opfer fielen. Zwischen den Zeilen mag man hier einen versteckten Hinweis auf extremes Wetter als Folge des anthropogenen Klimawandels vermuten, aber Sebald macht den Zusammenhang nicht explizit. Hier und anderswo präsentiert er die Natur zwar als vom Menschen geschädigt, aber auch als von sich aus keineswegs harmonisches, Zuflucht bietendes Ganzes, sondern in jähen Schwankungen zwischen Vermehrung und massenhafter Zerstörung begriffen, ohne Ziel oder Sinn und gegenüber menschlichen Anliegen grundsätzlich indifferent. 
Auch der Begriff ,Naturgeschichte der Zerstörung, den Sebald in seinem viel besprochenen Essay über Luftkrieg und Literatur später einführte (1999, S. 41f.), scheint zerstörerisches menschliches Handeln in den Kontext eines universalen Naturprozesses zu stellen und an Nihilismus zu grenzen. Ich komme später darauf zurück, dass es eine andere Seite seines Schreibens gibt, die diese trostlose Sicht auf die menschliche Geschichte relativiert. Was ich hier festhalten möchte, ist, dass Sebalds Saturnische Schreibstrategie im Großen und Ganzen als eine trauerndelegische bezeichnet werden kann, die immer wieder durch Gebrauch eines apokalyptischen Tons und Einsatz apokalyptischer Bilder in den Modus der Dringlichkeit übergeht. Damit entspricht sie teilweise der pastoralen, teilweise der apokalyptischen Trope, wie sie von Greg Garrard in seiner Einführung in die ökologisch orientierte Literatur- und Kulturwissenschaft beschrieben werden (Garrard 2004).

\section{Schreibmodus und Gattungswahl als Mittel der umweltkommunikativen Rhetorik}

Garrard geht es zwar primär um Literatur, aber darüber hinaus auch um die rhetorische Analyse von Texten aller Art, die am Umweltdiskurs teilnehmen. Sein Buch ist nach Tropen bzw. metaphorischen Großformen gegliedert, anhand derer die menschliche Interaktion mit der natürlichen Umwelt dargestellt und über diese reflektiert wird. Pastorale, Wildnis, Apokalypse, Wohnen, dem Tier und dem Planeten widmet er einzelne Kapitel, in deren Zentrum damit jeweils ein zentraler Begriffskomplex steht, anhand dessen die Zeitgenossen die Stellung der Menschheit in der Natur auffassen. Verschmutzung und Gesundheit sind weitere quasiuniversale Tropen in der Umweltkommunikation. Diese in der Kulturtradition teils schon seit Jahrhunderten verankerten Schemata bestimmen nicht nur Repräsentationen von Natur und Umwelt, sondern auch unsere Wahrnehmung von ihnen. $\mathrm{Zu}$ den wichtigsten solcher vorgeformten Muster gehören jene, die jüdisch-christlichen Erzählungen, griechischen Mythen und Werken der Weltliteratur entstammen. Sie sind häufig mit starken Affekten wie Reue, Angst vor Bestrafung und Sehnsucht nach Erlösung bzw. einem guten Leben verbunden. Ihre Funktion ist es, sinnstiftende Denkmuster anzubieten, die die Stellung des Menschen in der Natur erklären und Umweltveränderungen verständlich machen. Mit ihnen durch Tradition verbunden sind gleichzeitig literarische Modi und Schreibweisen, Gattungen und narrative Strukturen, Metaphern und Bilder.

Die Ringe des Saturn ist eine schwermütige Klage über die Vergänglichkeit, die Elemente der Totenklage in sich aufnimmt, und um Abschied, Trennung, Sehnsucht und Erinnerung kreist. Das Buch hat aber auch, wie bereits angedeutet, Anteil an dem am weitesten verbreiteten Argumentationsmuster der Umweltkommunikation, nämlich der Apokalypse. Während Apokalypsen ursprünglich Visionen des Weltendes waren, bei dem die gewaltsame Zerstörung einer neuen 
Welt der Harmonie und der Gerechtigkeit vorausging, stellt die moderne Umweltapokalypse eine vom Menschen verschuldete Katastrophe dar, die das Ende jeglicher Gerechtigkeit, Ordnung und Zivilisation herbeiführt und die nicht mehr den Endsieg des Guten über das Böse bereithält.

Auch in McEwans Buch sind umweltapokalyptische Stellen zu finden. Aber er setzt sie durchweg in Kontexte, die den Affekt unterbinden und ironische Distanz schaffen. Nun unterscheidet Garrard (2004, S. 86f.) zwischen komischen und tragischen Spielarten der Apokalypse. Tragische Apokalypse täusche absolute Sicherheit und Autorität vor und setze bedrohliche Veränderungen mit dem Bösen schlechthin gleich. Sie arbeite mit den Kategorien der Schuld und der Erlösung durch Selbstaufopferung des Einzelnen. Die komische Variante der Apokalypse erkennt dagegen laut Garrard im Bösen nur fehlerhaftes Handeln und fasst Rettung als Folge gewonnener Einsicht auf. Komödie laufe nicht auf eine Endkatastrophe hinaus, vielmehr sei sie episodisch und offen. Die Aktionen des tragischen Helden seien vom Schicksal vorbestimmt, oder er müsse zwischen Gut und Böse wählen, ohne dass sein Handeln auf das Weltgeschehen einen Einfluss habe. Der Protagonist in komischen Apokalypsen besitze dagegen Handlungsfreiheit, sei aber in der Regel moralisch zweideutig.

Über das Komische äußert sich Garrard nicht weiter. Jedoch, wie Richard Kerridge in einer Rezension von Solar bemerkt, hat Joseph Meeker dreißig Jahre vor dem Erscheinen von Garrards nützlichem Handbuch, und bereits zwei Jahrzehnte vor der Entstehung des Ecocriticism als theoretisch fundierter Ansatz in den frühen 90er Jahren, den um die Umwelt besorgten Zeitgenossen die Komödie als Grundhaltung empfohlen (Kerridge 2010). Meeker stellte sich folgende Fragen: Wie kann Literatur zum Überleben der Menschheit beitragen? Welche Rolle kann sie bei der Förderung des menschlichen Wohls spielen, welche Einsichten gibt sie in menschliche Beziehungen mit anderen Arten und der Umwelt? Sind Schreiben und Lesen Handlungen, die einer Anpassung ans Leben auf der Erde dienlich sind, oder entfremden sie uns vielmehr von diesem? Aus der strengen Perspektive der Evolution und der natürlichen Auswahl trägt schöngeistige Literatur, die zweifellos zu den häufigsten Quellen der Denkmodelle gehört, die in der Bildung eingesetzt und als Lebensentwürfe vergangener Generationen weiterempfohlen werden, und auf unser Handeln einwirken, eher zu unserem Überleben oder zum Aussterben bei? (Meeker 1997, S. 4). ${ }^{2}$

Überleben fordere Anpassung und Einsicht in den Grad unserer Abhängigkeit von der Natur, schreibt Meeker. Folglich verlangt er von der Literatur, dass sie Beispiele biete, die ein solches Verhalten einüben. Anstelle der tragischen Entscheidung fürs Gute und des Leidens an dem Bösen befürwortet er ein Sicheinfügen in den Weltlauf und die Hinnahme von Einschränkungen anstelle heroischer, zum Scheitern verurteilter Bemühungen, ihn zu überwinden. Schreiben

\footnotetext{
$2 \mathrm{Zu}$ den deutschen Literaturwissenschaftlern, die sich mit diesen und ähnlichen Fragen in der Zwischenzeit beschäftigt haben, gehören v.a. Jost Hermand, Hartmut Böhme und Hubert Zapf.
} 
im komischen Modus halte wenig von vorgegebener Moral, es entlarve vielmehr das Vertreten von Wertnormen als wertlos, die im Leben nicht eingehalten werden können. Es zeige, dass die Menschen zwar oft schwach und dumm sind, dafür aber zäh und überlebensfähig sein können. Indem sie Veränderung und Anpassung an die Umwelt begünstige, besitze komische Literatur ein gemeinsames Grundprinzip mit der Evolution und der Ökologie.

Meeker findet die zwei grundsätzlichen komischen Lebensstrategien, nämlich Flucht vor einer feindlichen Welt und Anpassung an sie, in der Pastorale und im Pikaro- oder Schelmenroman verkörpert. Dabei komme der Vorrang dem Schelmenroman zu, denn dieser vermeide problematische Eigenschaften der Pastorale wie die Illusionen des einstigen statischen Gleichgewichts und einer wiederzugewinnenden ursprünglichen Reinheit. Im Schelmenroman werde der Protagonist nicht als selbst bestimmtes Individuum gestaltet, er erleide vielmehr Abenteuer als ein Umhergetriebener. Durch List und Betrug, Lügen und Schlichen schlage er sich jedoch durchs Leben in einer durch stetigen Wandel und Unsicherheit gekennzeichneten Welt. Am Schluss des Schelmenromans werden keine Probleme dauerhaft gelöst: Es werden keine Feinde besiegt, keine neuen Wahrheiten entdeckt. Aber auf sich gestellt, auf seinen Witz und seine Erfindungsgabe, sei der Picaro der Realist schlechthin, dem die Zukunft gehört.

\section{Solar}

Diesem Schema entspricht weitgehend, wie Kerridge feststellt, McEwans Roman, der im März 2010 erschien, nach einer langen Vorankündigung durch den Verlag als „erster Klimawandel-Roman eines Schriftstellers von Weltrang“.3 Es handelt sich um die Geschichte des Physikers Michael Beard. Als Endzwanziger erhielt Beard für seine geniale Formel zur Bestimmung der Einwirkung von Licht auf feste Materie den Nobelpreis. Nun erfindet er als Mittfünfziger eine künstlich herbeigeführte Photosynthese, die Wasser in seine Konstituenten Wasserstoff und Sauerstoff aufspaltet und den Energiebedarf der Menschheit fast gänzlich ohne $\mathrm{CO}_{2}$-Ausstoß zu erfüllen verspricht. Aber seit Jahren hat Beard nichts Neues oder Wertvolles geleistet, sondern sich auf den Stockholmer Lorbeeren ausgeruht. Immer wieder bei feierlichen Anlässen dieselben Vorträge haltend, hat er seinen Namen zur Schmückung der Briefköpfe von Institutionen und zur Unterstützung von Anträgen auf Forschungsgelder hergegeben. Ein Institut für die Erforschung erneuerbarer Energien, das der Labour-Regierung als Vorzeige-Projekt dienen soll, leitet er nur pro forma.

Beard erweist sich nicht nur als ein von Eigennutz und Bequemlichkeitsdrang getriebener Egoist, sondern auch als ein Säufer und Vielfraß und ein Frauenheld, dessen fünfte Ehe auseinandergeht. Durch eine Kette von

${ }^{3}$ Die deutsche Übersetzung ist im September 2010 bei Diogenes erschienen. 
Umständen wird er noch zum Dieb und Betrüger. Denn die künstliche Fotosynthese ist nicht einmal die Erfindung dieses Anti-Helden, sondern die eines genialen jungen Assistenten, der mit Beards Frau geschlafen hat. Mitten im Streit mit Beard rutscht der junge Mann aus und schlägt mit dem Kopf an der spitzen Kante des Sofatisches tödlich auf. Beard nutzt die Gelegenheit, um den Unfall wie einen Mord aussehen zu lassen, und diesen dann einem Nebenbuhler in die Schuhe zu schieben. Erst später entsinnt er sich der Vorarbeiten des Assistenten und macht sie sich zu eigen. Es rächt sich aber alles am unglücklichen Professor im Augenblick seines Beinahe-Triumphs, denn der zu Unrecht bestrafte erste Liebhaber seiner Frau zerstört die teuren Anlagen zur Herstellung der Sonnenenergie in einem Racheakt, unmittelbar ehe sie in Betrieb genommen werden. Von Verwandten des jungen Physikers vor Gericht zitiert, wird Beard auch um jede künftige Aussicht auf die Früchte seiner Arbeit gebracht. Wie Max Frischs Walter Faber wird er am Ende sogar noch vom eigenen misshandelten Körper bestraft und vom Krebs eingeholt.

Solar baut auf McEwans Beobachtungen der menschlichen Natur und seine Ansichten über politisch-moralische Verantwortung in Atonement (2001), Saturday (2005) und anderen Romanen seit Enduring Love (1997) auf. Der Unterschied zwischen den Geschlechtern, das zerstörerische Potential des männlichen Rationalismus, und der Glaube, dass Rettung am ehesten aus einer Feminisierung der Gesellschaft zu erhoffen sei, sind Themen, die das Buch mit früheren Werken wie dem Oratorium Shall We Die? (1983) und dem Roman The Child in Time (1987) verbinden, die im Zeichen des drohenden Atomkriegs und des Feminismus entstanden. Seine Sicht auf die Zukunft der Menschheit ist aber in Solar nüchterner geworden. Ein Jahr vor dem Erscheinen des neuen Buchs hat Greg Garrard eine Entwicklung „from Ecofeminism to Darwinian Environmentalism“, zu Empirismus und einer ,interactionist view of human nature" in den neueren Schriften McEwans konstatiert und die Vorhersage gewagt, Solar werde diesen Trend weiterführen:

By drawing on key elements of five of his recent novels, one may hazard the conceptual parameters of the next one. In the most general terms, whereas The Child in Time found hope for the human and non-human worlds in politico-moral transformation of individual (male) gender identities and their corresponding ideologies and institutions, McEwan's more recent work implicitly identifies the origin of environmental crisis in the interaction of contingent historical circumstances and the universal (to some extent sexdifferentiated) psychological tendencies known, for convenience, as ,human nature'. (Garrard 2009, S. 705)

Solar hat diese Voraussage im Wesentlichen bestätigt. Das heißt allerdings nicht, das McEwan zum Anhänger der Dawkins'schen These des, egoistischen Gens' im populären Sinne des Begriffs (d. h. als Rechtfertigung des neoliberalen Kapitalismus) geworden sei. Denn darwinistische Selektion schließt selbstloses Verhalten 
von Individuen keineswegs immer aus, sondern geht von einer grundsätzlichen Veranlagung des Menschen sowohl zur Kooperation als auch zur Selbsterhaltung aus. In der Tat inszeniert Solar den Kampf in der Brust des Helden zwischen Eigeninteresse und Engagement für das Wohl kommender Generationen. „The old parliament of his selfhood was in uproarious division", heißt es an einer Stelle im Roman (S. 2624). Beard ist mehrfach erkennbar als Sprachrohr für die Ansichten des Autors, aber McEwan richtet es so ein, dass gerade ein mit menschlichen Untugenden und Schwächen beispiellos Behafteter zum Verfechter regenerierbarer Energien und zum Anwalt des Umweltgewissens in einer Welt wird, die sonst von wirkungslosen Idealisten und kaltherzigen Interessengruppen bevölkert wird.

McEwan rechnet mit der Umweltapokalyptik und dem naiven Idealismus der Umweltaktivisten und -künstler ebenso ab wie mit den geheuchelten Bemühungen der Kernkraftlobby und der Sensationslüsternheit der Medien. Bei der ersten Lektüre wirkt der Roman fast ebenso verwirrend wie Die Ringe des Saturn, weil sämtliche Standpunkte, die vertreten werden, entweder durch den Kontext ironisiert und/oder durch einseitige Darstellung unterminiert werden. Die zwei Kulturen C.P. Snows kommen gleichermaßen schlecht weg: Über die Versuche von wohlmeinenden Künstlern, Umweltbewusstsein durch eine verstärkte Identifikation der Bevölkerung mit bedrohten Tieren herbeizuführen, zieht Beard ebenso sarkastisch her wie über den Anspruch von Schriftstellern, eine Rolle bei der Bekämpfung des Klimawandels zu spielen (etwa durch Bekehrung ihrer Leser), ohne dass man einen Wink vom Autor bekommt, der dies qualifizierte.

Dabei entlarvt die Handlung den Ehrgeiz der Naturwissenschaftler, eine technische Lösung für die Energiefrage zu finden, als trügerische Suche nach einem Weg, der uns erlaube, unser gegenwärtiges Konsumverhalten unbeschadet weiterzuführen. Bei einem Zusammenstoß zwischen dem Physiker und einer Soziologin hinsichtlich der Frage, ob die unterschiedlichen Mentalitäten der Geschlechtler genetisch programmiert oder soziokulturell bestimmt sind, erscheint Beards natur-wissenschaftliche Betrachtungsweise naiv, während der poststrukturalistische, diskursbezogene Ansatz seiner Kontrahentin an der Wirklichkeit vorbeigeht. Hier und anderswo wird der Leser gezwungen, Schwarz-weiß-Ansichten aufzugeben zugunsten einer Einsicht in die Komplexität eines Sowohl-als-auch. Dabei bildet die satirische Gegenüberstellung der wirklichkeitsfernen Ideale und der zynisch-egoistischen Handlungen Beards ein strukturierendes Merkmal des Romans. Beard steht für die Menschheit schlechthin, in der Egoismus, Gier und ein beschränkter Zeithorizont mit Ansätzen zu Einsicht in die Erfordernisse der Zeit und zu altruistischer Kooperationsbereitschaft im Wettstreit liegen. McEwan steigert beide Eigenschaften ins Groteske. Unfähig, seinen Lebensraum in Ordnung zu

${ }_{4}^{4}$ Zitiert wird im Folgenden mit Seitenangabe aus Solar (2010). 
halten, und den Verlockungen des Geschlechts oder des Konsums zu widerstehen, steht er speziell als Vertreter eines arroganten Rationalismus und aggressiven männlichen Egoismus.

Während Sebald auf den Fortschritt als Anhäufung der Zerstörungen melancholisch zurückblickt, bietet McEwan also eine bitterböse satirische Sicht auf die Menschheit als einer Gattung, die von einer Notlösung zur nächsten vorwärts stolpert. Der Wissenschaftsbetrieb wird in seinen Verzerrungen und Machtkämpfen schonungslos bloßgestellt, aber Rettung ist ohne die Mitwirkung von Wissenschaft und Technik undenkbar. Über unseren Umgang mit der Natur und die Frage der Zukunft der Menschheit hinaus gibt es eine Fülle von Themen, die McEwan mit Sebald gemeinsam hat: Kritik des Konsumismus, Sorge um grenzenloses Bevölkerungswachstum, Verstädterung und die Industrialisierung der Landschaft und sich in eine dystopische Vision der Zukunft ausweitende Kritik am neoliberalen Kapitalismus. Während Sebalds Zeitverständnis linear und dystopisch ist, finden wir aber bei McEwan eher ein zyklisches, das immer wieder Aufschub ermöglicht. In einem 2008 geführten Interview sagte McEwan einmal, bei aller Achtung vor großen Dystopien wie Margaret Atwoods Oryx and Crake setze er selbst lieber auf

something small and fierce, that would unwind in a way that's intrinsically interesting ... It's got to be fascinating, in the way that gossip is. It's got to be about ourselves. Maybe it needs an Animal Farm. Maybe it needs allegory. But if you're going in that direction, then you need a lot of wit. (Tonkin 2007)

Offen allegorisch wird McEwan vor allem in seiner Beschreibung der Stiefelkammer bei Beards Aufenthalt in der Arktis. Beard nimmt dort an einem Projekt teil, das ihn als umweltbesorgten Physiker mit Künstlern und Schriftstellern an einer Stelle zusammenführt, wo sie die Folgen des Klimawandels anschaulich erleben sollen. ${ }^{5}$ Beard macht die Erfahrung, dass es einer Gruppe von ökologisch engagierten, rational handelnden Erwachsenen nicht gelingt, Ordnung im Ankleideraum zu halten, wo die für jegliche Exkursion übers Eis überlebenswichtigen Schneeanzüge und Stiefel untergebracht sind. Dass sie sich gegenseitig Handschuhe und Helme, Socken und Brillen klauen, lässt es hoffnungslos utopisch anmuten, dass die Ursachen und Konsequenzen des Klimawandels jemals von einer vereinten Menschheit in den Griff bekommen werden. Es sei denn, wir erfnden Spielregeln, um den natürlichen Egoismus des Einzelnen in Schach zu halten, und finden Wege, um diese durchzusetzen.

McEwan vermeidet alles Didaktische, indem er düstere Wahrhaftigkeit mit einer spannenden Handlung und viel Witz verbindet. In der Handlung spielen Elemente der Gattungen Ehebruchsroman, Thriller, Zeitsatire und Farce alle eine

\footnotetext{
${ }^{5}$ Diese Episode basiert auf den Erfahrungen des Autors im Jahr 2005 anlässlich einer Art/Science Expedition in die norwegischen Tempelfjorde. Diese Fahrt fand im Rahmen des vom Künstler David Buckland organisierten Cape Farewell Projects statt, dessen Ziel es war, „to instigate a cultural response to climate change“. (McEwan 2005).
} 
Rolle. Den eigentlichen Schwerpunkt bilden trotzdem die inneren Kämpfe des Protagonisten, der Widerspruch zwischen seinen guten Vorsätzen und seinem Engagement für die Umwelt einerseits und den körperlichen Trieben und Bequemlichkeiten andererseits, die sie am Ende zunichtemachen. Diesen Fokus auf die menschliche Natur hat McEwan in einem Interview im Jahr 2008 gerechtfertigt:

We will not rescue the earth from our depredations until we understand ourselves a little more, even if we accept that we can never really change our natures. (Roberts 2010, S. 189)

\section{Schluss}

Versucht man, über Stärken und Schwächen der Schreibstrategien Bilanz zu ziehen, die in Sebalds und McEwans Bildern des Saturn und der Sonne verdichtet sind, stellt man fest, dass beide Autoren mit einer Indirektheit in der Aussage und einer Komplexität in der Erzählperspektive vorgehen, die jede platte Didaktik erfolgreich vermeiden, dafür aber Raum für Missverständnisse offen lassen. Sebalds saturnischer Blick scheint zwischen Naturgesetzen und den Auswirkungen menschlicher Gewalt, zwischen vermeidlichen und unvermeidlichen Aspekten der überall beobachteten Zerstörung nicht zu differenzieren. Er bleibt weitgehend im Bann des Verfalls, kostet ihn ja aus. An einer Stelle in Die Ringe des Saturn deutet er beispielsweise die Werkzeuge, die den Engel der Melancholie im Stich Dürers umgeben und dort als Instrumente und Symbole wissenschaftlicher Erkenntnis fungieren, kurzerhand als „Werkzeuge der Zerstörung“ (S. 19) um. Seine Geschichtsauffassung ist vom, die Vergangenheit als permanente Katastrophe wahrnehmenden Rückblick des Engels der Geschichte Walter Benjamins bestimmt. Solche Zivilisationskritik ist kein Einzelfall, sondern findet Parallelen im ökologisch gefärbten Kulturpessimismus anderer deutschsprachiger Werke seit den 1970er Jahren, etwa in Max Frischs Der Mensch erscheint im Holozän, Gerhard Roths Landläufiger Tod, Peter Roseis Entwurf für eine Welt obne Menschen, Ulrich Horstmanns Untier und Christoph Ransmayrs Morbus Kitahara.

Aber Sebald ist kein Vertreter posthumanistischer Sehnsucht nach menschenleerer Natur. Denn bei seiner Betrachtung der Naturgeschichte der Zerstörung richtet er den Blick vor allem, wie Christian Schulte scharfsinnig formuliert hat, auf

das, was von Zivilisation, Kultur und Subjektivität übrig bleibt, wenn deren hypertrophe technische Hervorbringungen $\mathrm{zu}$ Mitteln der Vernichtung umgeschmiedet und zum Einsatz gebracht werden (Schulte 2003, S. 92).

Mit Vorliebe beschreibt er nämlich Glanzleistungen einer sich als zweite Natur gebärdenden Technik, die etwa das Sonnenlicht durch künstliche Beleuchtung ersetzen will. Seine Fortschrittsskepsis drückt sich in Beschreibungen von ehemaligen Festungen und Machtorten aus, Prachtbauten, die architektonischen Überwältigungsfantasien gleichen. Es geht ihm um das Umkippen zivilisatorischer 
Errungenschaften in Unterdrückung und Zerstörung. Deutlicher ist dies zwar in seinem letzten Roman, Austerlitz, aber auch Die Ringe des Saturn steht Theodor W. Adornos und Max Horkheimers Dialektik der Aufklärung nahe. Das Buch besteht aus Variationen des Themas der Entfremdung des Menschen vom Maßstab dessen, was seine menschliche Natur ausmachen könnte.

Dabei richtet Sebald ein besonderes Augenmerk auf die Verluste und das Leiden der Opfer der Geschichte. Die historische Last des Dritten Reiches und des Holocaust ist hier wie in der Auseinandersetzung anderer deutscher Schriftsteller mit der ökologischen Krise bis in die Gegenwart hinein spürbar. Auch in anderer Hinsicht ist Sebalds Schreibhaltung als Korrektiv aufzufassen. Sigrid Löffler deutet seine Melancholie als „die Kehrseite des deutschen Wiederaufbau-Optimismus“:

Seine untröstliche Spurensuche im Staub und in den Ruinen der Vergangenheit verweist auf all das Vernichtete, Verschüttete und Vergessene, das im Schatten des Aufschwungs zu verschwinden drohte, den Nachkriegsdeutschland erlebte. (Löffler 2009, S. 105f.)

Im England der 1970er und 1980er Jahre habe er eine Ehrlichkeit im offensichtlichen Verfall und im Niedergang gefunden, die sich von der mit Geistesverarmung und Erinnerungslosigkeit verbundenen Selbsterneuerung der Deutschen wohltuend absetzt. Sein Schreiben sei gleichzeitig ein Gegengift gegen das kollektive Vergessen und Therapie für die eigene Niedergeschlagenheit, ja „ein strategisches Manöver zur Selbsterhaltung“" (ebd., S. 106).

Dazu kommt, dass man aus Sebalds ganzem Werk das Modell einer anderen Seinsweise herauslesen kann, insofern es die Aufmerksamkeit der Leser auf die Wunder der Natur und die großen Zeugnisse fremder Kulturen lenkt, und eine Haltung der Einfühlung in das Andere einübt. Als Gegenpart der Tyrannen und Zerstörer führt Sebald eine lange Reihe von seelenverwandten Naturforschern, Künstlern und Schriftstellern an, in deren Werken die faszinierende Vielfalt der Natur gepriesen und das kulturell Wertvolle vor dem Verfall und dem Verlust bewahrt wird. Wie der Autor versenken sich diese in das von der Geschichte vergessene Detail. Indem er eine solche Lebensstrategie angesichts des universalen Verfalls und des Todes anbietet, setzt sich Sebald von dem menschenfeindlichen Schluss radikaler Biozentriker ab. Trotz seines Pessimismus bietet er die Perspektive einer andersartigen Beziehung zur Natur, die der Menschheit eine Zukunft gewähren könnte. In diesem Sinne erweist sich seine Melancholie als eine Form des Widerstands. In der Einleitung zu seiner Essaysammlung Die Beschreibung des Unglücks hatte er geschrieben, Melancholie, „das Überdenken des sich vollziehenden Unglücks“, habe „mit Todessucht nichts gemein. Sie ist eine Form des Widerstands. [...] Die Beschreibung des Unglücks schließt in sich die Möglichkeiten seiner Überwindung ein." (Sebald 1985, S. 12) 
So verstanden, bildet Sebalds Auffassung der Aufgabe des Schriftstellers und der besten Mittel, sie zu erfüllen, keinen Widerspruch zu McEwans, der im Interview mit Boyd Tonkin die Ansicht äußerte:

Many others have thought this too: that one way forward is not doom-andgloom but celebration; of what we are, what we have, and what we don't want to lose. (Tonkin 2007)

In Besprechungen von Solar ist beispielsweise von Richard Kerridge bemängelt worden, McEwan sei es nicht gelungen, den in Aussicht gestellten, großen Klimawandel-Roman zu schreiben, denn es fehle eine überzeugend-realistische Darstellung der Spannung zwischen den widersprüchlichen Bedürfnissen und Gefühlen der Menschen in der Auseinandersetzung mit dem Klimawandel. In der Tat ist Beard einerseits physikalisch begabt und verantwortungsvoll um die Rettung der Menschheit besorgt, andererseits ein fauler, feiger Chaot. Seine Persönlichkeit bleibt in McEwans schematischer Darstellung gespalten und ohne psychologische Plausibilität. Der Roman stellt auch keine anderen Personen vor, die eine komplexere Sicht auf die Widersprüche und Spannungen im Leben der Zeitgenossen hergäbe.

Außerdem ist der ambivalente Gesamteindruck des Romans moniert und der Vorwurf mehrfach erhoben worden, der Autor sei offensichtlich ein Wissenschaftsskeptiker und ein Leugner der anthropogenen Erwärmung der Erde. Das Buch sei Ausdruck einer grundsätzlich zynischen Haltung. Dass diese Anschuldigungen auf Missverständnissen beruhen, habe ich bereits angedeutet. McEwans durchaus spannendes und unterhaltsames Werk vermeidet weltfremden Idealismus und billigen Trost, ohne die Hoffnung ganz aufzugeben. Naiv, egoistisch, extravagant, gefühllos und lächerlich legt Beard dennoch eine rastlose Energie an den Tag, um seine persönlichen Krisen zu meistern und zugleich, um sie unabdingbar bei der Entwicklung von Lösungen für die Umweltkrise einzusetzen. McEwan vertraut höchstens auf die Wirksamkeit des aufgeklärten Eigeninteresses, wobei er am Ende seines Romans offen lässt, ob dieses ausreichen wird. In einem Interview kurz vor dem Erscheinen des Buchs hat er die Kritik vorausgesehen, es handele sich bei Solar um den Roman eines Klimaskeptikers. Es sei nicht der Auftrag des Romanschriftstellers, den Planeten zu retten, meinte er. Er sei aber persönlich ,,as keen that it should be saved as anybody“ (Brown 2010). Kann Literatur die Welt retten? Dazu hat McEwan hat im 2008 geführten Interview mit Ryan Roberts Folgendes gesagt:

I don't think it can do much about climate change. I suppose it can reflect the problem and pose the problem in terms that might be useful to people. I think we $d o$ face a test of our nature, and the more we know about that nature, the better we'll be able to face that test. That is why it's so important to look empirically at what we are, how our cognitive abilities shape our interactions with the world and with each other. (Roberts 2010, S. 191) 
Hier liege die Aufgabe des Schriftstellers. Es mag ein allgemeines Kennzeichen des literarischen Beitrags zum Umweltdiskurs sein, dass sowohl Sebald als auch McEwan Strategien der impliziten bzw. ironischen Darstellung verfolgen. Statt Antworten oder Lösungen zu bieten, appellieren sie durch rätselhafte Kombinatorik von historischen Details respektive durch die Gegenüberstellung von übertrieben zugespitzten Argumenten an die Neugier der Leser und an ihre Bereitschaft, sich zugunsten einer Wende in der Menschengeschichte zu engagieren. Beide lassen einen Funken Hoffnung erkennen in der Möglichkeit, dass der Mensch gerade infolge seiner Fehler und Schwächen zur Anpassung und zur Selbstrettung gezwungen wird. 


\section{Literatur}

Brown, Mick (2010): Ian McEwan Interview: Warming to the topic of climate change. The Telegraph, 11. März 2010. http://www.telegraph.co.uk/culture/books/7412584/Ian-McEwan-interviewwarming-to-the-topic-of-climate-change.html.

Garrard, Greg (2004): Ecocriticism (New Critical Idiom Series). London, New York: Routledge.

Garrard, Greg (2009): Ian McEwans Next Novel and the Future of Ecocriticism. In: Contemporary Literature, Winter Bd. 50.4, S. 695-720.

Head, Dominic (2007): Ian McEwan (Contemporary British Novelists). Manchester, New York: Manchester University Press.

Kerridge, Richard (2010) The Single Source. Ian McEwan's Solar. In Culture and Climate Change. Papers from a Symposium in Corsham, 1 July 2010.

Löffler, Sigrid (2003): „Melancholie ist eine Form des Widerstands.“ Über das Saturnische bei W.G. Sebald und seine Aufhebung in der Schrift. In: Arnold, Heinz Ludwig (Hrsg.): Text und Kritik IV/03 (Nr. 158), April 2003 (W.G. Sebald), S. 103-11.

McEwan, Ian (2005): A Boot Room in the Frozen North. Cape Farewell Expedition Website. http://www.capefarewell.com/climatescience/comment-opinion/ian-mcewan.html

McEwan, Ian (2010): Solar. London: Jonathan Cape.

Meeker, Joseph W. (1997): The Comedy of Survival. Literary Ecology and a Play Ethic. 3., erweiterte Ausgabe. Tucson: University of Arizona Press.

Öhlschläger, Claudia (2006): Der Saturnring oder Etwas vom Eisenbau. W.G. Sebalds poetische Zivilisationskritik. In: Niehaus, Michael; Öhlschläger, Claudia (Hrsg.): W.G. Sebald. Politische Archäologie und melancholische Bastelei. Berlin: Erich Schmidt, S. 189-204.

Roberts, Ryan (Hrsg.) (2010): Conversations with Ian McEwan. Jackson MS: University Press of Mississippi.

Schulte, Christian (2003): Die Naturgeschichte der Zerstörung. W.G. Sebalds Thesen zu Luftkrieg und Literatur. In: Arnold, Heinz Ludwig (Hrsg.): Text und Kritik IV/03 (Nr. 158), April 2003 (W.G. Sebald), S. 82-94.

Sebald, W. G. (1985): Die Beschreibung des Unglücks. Zur österreichischen Literatur von Stifter bis Handke. Salzburg: Residenz.

Sebald, W. G. (1997a): Die Ringe des Saturn. Eine englische Wallfahrt. Frankfurt am Main: Fischer. 
Sebald, W. G. (1997b): Nach der Natur. Ein Elementargedicht (1988). Frankfurt am Main: Fischer.

Sebald, W. G. (1999): Luftkrieg und Literatur. Mit einem Essay zu Alfred Andersch. München: Hanser.

Steinmann, Holger (2006): Zitatruinen unterm Hundsstern. W. G. Sebalds Ansichten von der Nachtseite der Philologie. In: Niehaus, Michael; Öhlschläger, Claudia (Hrsg.) W.G. Sebald. Politische Archäologie und melancholische Bastelei. Berlin: Erich Schmidt, S. 145-56

Tonkin, Boyd (2007): Ian McEwan: I Hang on to Hope in a Tide of Fear. The Independent. 6. April, 2007.

http://www.independent.co.uk/arts-entertainment/books/features/ianmcewan-i-hang-on-to-hope-in-a-tide-of-fear-443501.html. 


\section{Oikos, kosmos, textum: Ovids Metamorphosen ${ }^{1}$}

\section{Stefanie Schub}

\section{I}

Noch ehe es Meer, Land und den Himmel gab, der alles überwölbt, hatte die ganze Erde ringsum einerlei Aussehen; man nannte es das Chaos.

(Met. I, 5-7 : Ante mare et terras et, quod tegit omnia, caelum / unus erat toto naturae vultus in orbe, / quem dixere Chaos)

Publius Ovidius Nasos Epos, das unter dem Titel Metamorphosen etwa 250 kunstvoll miteinander verknüpfte Verwandlungsmythen in 15 Büchern mit insgesamt fast 12.000 Versen versammelt, beginnt mit den eben zitierten Worten genau dort, wo eine antike Weltgeschichte beginnen muss: bei der Erschaffung des Kosmos aus dem Chaos, eben am Anfang.

Auch ich möchte meinen Beitrag in einem recht wörtlichen Sinn, von vorn beginnen, ganz am Anfang des Textes nämlich, genauer: bei seinem Titel. Als Metamorphoses oder Metamorphoseon Libri, als Verwandlungen oder als Bücher der Verwandlungen ist Ovids Epos überliefert. Verwandlung: Es ist ein Wort, das Literaturwissenschaftler an unruhige Träume denken lässt, aus denen man als Käfer erwacht, oder an Goethes Versuche, die Entwicklung von Pflanzen und Tieren elegisch zu fassen.

\footnotetext{
${ }_{1}^{1}$ Dem Beitrag liegt die von W.S. Anderson besorgte und in der Bibliotheca Teubneriana erschienene Ausgabe der Metamorphosen zu Grunde. Zitate werden unter Angabe des entsprechenden Buches (in römischen Ziffern) und der entsprechenden Verse (in arabischen Ziffern) nachgewiesen.
} 
Welches Konzept von Verwandlung, von Transformation verbirgt sich aber hinter dem schlichten Titel des antiken Epos? Was ist, und damit möchte ich versuchen einen Weg in den ungemein dichten Text zu finden, die Metamorphose in den Metamorphosen?

\section{II}

Eine mögliche Antwort auf diese Frage findet sich gegen Ende des Epos im fünfzehnten Buch. Es enthält eine Lehrrede des Philosophen Pythagoras (Met. XV, 60-478), die sich vor allem durch ihre evidente Disfunktionalität innerhalb des textuellen Gesamtkonzeptes auszeichnet. Weder findet im eigentlichen Sinn eine Metamorphose statt noch ist die Rede mit der üblichen Sorgfalt an die sie umgebenden Erzählungen angeschlossen. Die Versuchung ist also groß, dieser Passage innerhalb der Metamorphosen eine exponierte Stellung einzuräumen, zumal sie eine der längsten Episoden des gesamten Textes überhaupt ist und Verse wie das bekannte „omnia mutantur“ (Met. XV, 165: „Alles wandelt sich“) enthält, die als Motto oder poetologisches Konzept der Metamorphosen geradezu prädestiniert scheinen. In Altphilologie wie Literaturwissenschaft ist die Pythagorasrede auch immer wieder so rezipiert worden ${ }^{2}$.

Das Verwandlungskonzept der Metamorphosen geht indes mitnichten in der Pythagorasrede auf. ${ }^{3}$ Diese entwirft ein Modell des organischen Wandels, das sich am Verlauf der Jahreszeiten, an der Entwicklung des Menschen im Lauf seines Lebens und an der Vorstellung der sukzessiven Weltalter orientiert. Urheber der Veränderung ist in allen Fällen die Natur:

Und keinem bleibt seine Erscheinungsform, die Natur lässt als Erneuerin der Dinge aus der einen Gestalt eine andere hervorgehen.

(Met. XV, 252f.: Nec species sua cuique manet, rerumque novatrix / ex aliis alias reparat natura figuras)

Unter dieses Gesetz des permanenten Wandels fallen, so führt der Philosoph wortreich aus, menschliches wie tierisches Leben, aber auch landschaftliche Gegebenheiten, Städte und ganze Reiche, mithin die gesamte erfahrbare Welt. Daran schließt sich eine Ausführung der typisch pythagoreischen Metempsychose-Lehre an. Die Seele wird bei Verfall des Körpers in den nächsten (nicht zwangsläufig menschlichen) Körper übertragen, aus den Überresten des alten Körpers entsteht neues Leben. Damit ist die herkömmliche Vorstellung vom Tod als Verlöschen der irdischen Existenz durch ein zyklisches Modell ersetzt:

2 Vgl. z.B. Bartsch (1990, S. 125); Fülleborn (2000, S. 422); Albrecht (2003, S. 148); Dalfen (2005, S. 35f).

3 Dafür sprechen sich u. a. aus Solodow (1988, S. 164ff.); Myers (1994, S. 134); Holzberg (1997, S. 151 ff.); Harzer (2000, S. 99); Williams (2009, S. 163).

Eine Zwischenposition nimmt Schmitzer (2006, S. 56) ein: „Der Lehrvortrag repräsentiert nicht das Gesamtwerk in nuce, sondern ist ein wichtiger Teil, der im Verein mit anderen, ähnlich wichtigen Passagen zur Gesamtdeutung beiträgt, sie aber keineswegs in sich vollständig faßt"“. 
Und geboren werden bedeutet: beginnen etwas anderes zu sein, als man vorher war, und sterben bedeutet: aufhören, eben das zu sein.

(Met. XV, 255ff.: nascique vocatur / incipere esse aliud, quam quod fuit ante, morique / desinere illud idem)

Beim Versuch, diese Vorstellungen ernsthaft auf den Textbestand der Metamorphosen zu übertragen, wird man indes scheitern. Daphnes oder Arachnes Seele etwa, oder unproblematischer für das antike Konzept: ihr menschliches Bewusstsein, wird bei der Verwandlung eben nicht in einen Lorbeerbaum oder eine Spinne übertragen. Vielmehr, und daran entfaltet sich ja so häufig Ovids poetisches Geschick, nimmt ihr Körper plötzlich die neue, ungewohnte Gestalt an. Damit liegen zwei sehr unterschiedliche Konzepte vor, das des Körpertauschs in der Pythagorasrede und das der Körperverwandlung in den übrigen Erzählungen. Zudem ist die einmal verwandelte Gestalt in den Metamorphosen eine streng fixierte. Keine von einem Gott bewirkte Verwandlung kann, so bestimmt es das Gesetz des Kosmos, von einem anderen Gott rückgängig gemacht werden. Die ständige Gestaltfluktuation des pythagoreischen Modells schließt eine solche Rückkehr hingegen keineswegs aus.

Der bedeutendste Unterschied zwischen beiden Konzepten lässt sich aber an anderer Stelle ausmachen, nämlich bei der bereits erwähnten Formel des ,omnia mutantur'. Im Proömium der Metamorphosen bittet Ovid in epischer Tradition die Götter um Beistand für sein Vorhaben:

Von Gestalten zu berichten, die in neue Körper verwandelt worden sind, treibt mich mein Geist: Ihr Götter (habt ihr doch jene Körper verwandelt), beflügelt mein Vorhaben.

(Met. I, 1-3: In nova fert animus mutatas dicere formas / corpora: di, coeptis (nam vos mutastis et illa) / adspirate meis)

Die für das Epos zweifellos programmatische Vokabel ,mutare' (,verwandeln') tritt beinahe nur an dieser Stelle des Textes auf, in den einzelnen Erzählungen selbst wird sie meist vermieden ${ }^{4}$ und durch Ausführung des Verwandlungsvorgangs oder durch umschreibende Wortgruppen wie etwa ,novam formam ducere' (eine neue Gestalt annehmen') ersetzt. Umso leichter lässt sich daher das Auftauchen des Wortes innerhalb der Pythagorasrede als programmatischer Hinweis auffassen, zumal dort wie auch im Proömium kein konkreter Verwandlungskontext vorliegt. Man darf dabei aber nicht übersehen, dass das Verb im Proömium mit einer aktivischen (,mutastis'), in der Lehrrede hingegen mit einer passivischen (,mutantur) Flexionsendung versehen ist. Das mag zwar zunächst als altphilologische Pedanterie erscheinen. Tatsächlich bezeichnen die beiden Formen des Verbums aber sehr genau das Auseinanderfallen beider Konzepte: ,Mutari ' (,sich verwandeln') steht als mediopassivische Form für eine innerlich sich vollziehende Veränderung, während die aktivische Form ,mutare‘ (,jdn. ver-

\footnotetext{
4 Vgl. für eine der wenigen Stellen, an denen sie auftritt, die Daphne-Episode: „Verdirb durch Verwandlung die Gestalt, um deretwillen ich verletzt werde“ (Met. I, 545: „quae facit ut laedar, mutando perde figuram").
} 
wandeln') eine von außen bewirkte Veränderung bezeichnet. Damit ist das pythagoreische Modell als eines des (von der Natur bewirkten) Wandels, das des Textes hingegen als eines der (durch Götter verursachten) Verwandlung markiert. ${ }^{5}$

Ich möchte diese Beobachtung an Hand einiger Aspekte der von Ovid gestalteten mythischen Metamorphosen befestigen und vertiefen. Schon die erste im Text vorgestellte Metamorphose eines Menschen erhält einen Kontext, der sich später als Signatur des Metamorphosevorganges etabliert: Weil er den als Wanderer verkleideten Iuppiter zuerst umzubringen versucht und ihm dann gekochtes Menschenfleisch vorsetzt, wird der arkadische König Lycaon in einen Wolf verwandelt (Met. I, 163-239). Die Metamorphose wird so als Schicksal eingeführt, das die Götter als Strafe für ein schweres, begangenes Unrecht verhängen. Neben diese Strafmetamorphose tritt mit dem kurz darauf folgenden Mythos um Daphne und den mit blinder Liebe geschlagenen Apoll (Met. I, 452-567) die Metamorphose als letzter Ausweg aus drohender Gefahr. An dieses Modell knüpfen im weiteren Verlauf des Epos noch einige Mythen an, in denen verfolgte Nymphen und Menschenmädchen in der Bitte um Verwandlung ihre Zuflucht nehmen. ${ }^{6}$ In beiden Fällen resultiert die Metamorphose aus einer manifesten Grenzsituation. Sie wird als letztmögliche Disziplinarmaßnahme eingesetzt oder der Schändung vorgezogen. Nie aber hat sie der Verwandelte aus freien Stücken als Weg in eine neue Existenzform gewählt und nur in äußerst seltenen Fällen verhängen die Götter sie nicht als Strafe, sondern gewähren sie als Belohnung.

Die Verwandlung selbst ist in beinahe allen Fällen als schock- und schmerzhafte Prozedur akzentuiert. ${ }^{7}$ Nicht selten ist sie mit dem traumatischen Verlust der Sprache und dem Verlust des Körpergefühls oder einer überhaupt beseelten Hülle verbunden: Daphne will davonlaufen, doch ihr Fuß ist bereits mit der Erde verwurzelt; Actaeon, von Diana in einen Hirsch verwandelt, will seine Hunde durch Zurufe davon abhalten ihn anzufallen, ist aber seiner Stimme nicht mehr mächtig; die in eine Kuh verwandelte Io erschrickt vor ihrem eigenen Spiegelbild; Arethusa hat so fürchterliche Angst vor ihrem Verfolger Alphëus, dass sie sich selbst als Quelle ausschwitzt; aus den Tränen, die um den bei lebendigem Leib gehäuteten Marsyas vergossen werden, entsteht ein Fluss.

\footnotetext{
5 Das stimmt auch mit dem Befund überein, zu dem Zgoll (2004, S. 154) nach ausführlichen linguistischen Untersuchungen für die Metamorphose-Vorstellung in der Augusteischen Zeit gelangt: „Metamorphose umschreibt nach dem analytischen Befund einen mit wunderbarer Plötzlichkeit vor sich gehenden, göttlichen Eingriff in die Menschenwelt, durch den die äußere Gestalt eines Menschen einer irreversiblen Wandlung unterzogen und damit eine ,neue, , andere wird“".

${ }^{6}$ So etwa Syrinx und Arethusa. Das Ovidische Epos kennt darüber hinaus noch zwei weitere Varianten der Metamorphose, die für die menschliche Metamorphose aber nicht oder nur in Ausnahmen relevant sind: die als List fungierende Götterverwandlung und die Metamorphose mit aszendenter Bewegung, die als Katasterismus (Verstimung) oder Gründungsmythos auftritt, im Gesamtcorpus aber eher selten zu verzeichnen ist.

${ }^{7}$ Harzer (2000, S. 75) betont diesbezüglich, dass ,,die radikale Diskontinuität physischer Verwandlungen am Leib der menschlichen Figur augenfällig“" werde und arbeitet überdies sehr präzise heraus, dass den einzelnen Verwandlungen in den Metamorphosen ein stark diskontinuierlicher Aspekt eignet. In ähnlicher Weise beschreibt Kuon (2005, S. 4) die Metamorphose in der Antike allgemein als „einmalige, überraschende, ja gewaltsame, wenn überhaupt, dann nur im Nachhinein erklärbare Körpertransformation, wobei zwischen neuem Körper und altem Bewusstsein eine Diskrepanz entsteht".
} 
Besonders evident werden solche Prozesse im Mythos der Callisto (Met. II, 401-530), die von Iuppiter vergewaltigt wird und ihm einen Sohn gebiert. Aus Rache für die ihr angetane Schmach verwandelt Iuno Callisto in eine Bärin mit den bekannten Folgen: Callisto, deren altes Bewusstsein, so der Text ganz explizit, auch im Bärenkörper erhalten bleibt (Met. II, 485: „mens antiqua manet"), erschrickt vor ihrer rauhen Stimme, sie fürchtet sich vor anderen Bären und auch vor Wölfen, obwohl doch, so wird dem Leser eine bereits vollzogene Metamorphose ins Gedächtnis gerufen, „ihr Vater Lycaon unter ihnen war" (Met II, 495: „quamvis pater esset in illis"). Die Erzählung, und das zeichnet sie vor den meisten anderen aus, endet aber nicht an dieser Stelle. Einige Jahre später begegnen sich Callisto, die immer noch eine Bärin ist, und ihr inzwischen erwachsener Sohn im Wald. Als er sich anschickt, seine Mutter zu töten, kann Iuppiter das Unrecht gerade noch verhindern, indem er beide als Sternbilder an den Himmel versetzt. Das wiederum verärgert die nachtragende Iuno, die es einzurichten weiß, dass die neuen Sternbilder - der Große und der Kleine Bär - wenigstens das ganze Jahr lang nicht im Meer baden dürfen. Den durch die Metamorphose beinahe provozierten Muttermord belegt der Text dabei mit dem Begriff ,nefas' (Met. II, 505). Das Lateinische kennt viele Ausdrücke, um eine verbrecherische Tat zu bezeichnen: das ,delictum' für eine Gesetzesübertretung, das ,facinus' für eine Untat oder das ,scelus' für eine Ruchlosigkeit. Der von Ovid verwendete Begriff geht in seiner Bedeutung weit über all diese Möglichkeiten hinaus: Wer ein ,nefas' begeht, macht sich als Frevler eines Verstoßes gegen die göttlichen Natur- und Sittengesetze schuldig. ${ }^{8}$ Verhindern lässt sich dieser Verstoß in der Erzählung nur mit einer zweiten Metamorphose, die ihrerseits noch einmal einer Auflage unterworfen wird. So ist erst nach zwei gravierenden Korrekturen der ursprünglichen Metamorphose der aitiologische Ausgangspunkt der Erzählung, das immer am Himmel stehende Sternbild der beiden Bären, erreicht. ${ }^{9}$

All diese Beobachtungen sprechen dafür, dass die Metamorphose der Callisto keinesfalls als organische Fügung in die kosmologische Ordnung verstehbar ist. Im Gegenteil ist sie als die Ordnung gefährdender Vorgang markiert. Während der Wandel, wie er in der Pythagorasrede beschrieben wird, ein genuin kontinuierliches Modell ist, lässt sich die Metamorphose also als schmerzhafter Sprung in der gewohnten Ordnung, als systemisches Aussetzen begreifen. Damit kann bezüglich der Lehrrede des Pythagoras und ihrer vermeintlichen

\footnotetext{
8 Vgl. dazu den Eintrag unter dem Lemma Verbrechen in Karl Ernst Georges' Deutsch-Lateinischem Wörterbuch, Bd. 2.

9 Doblhofer (1975) hat nachgewiesen, dass mindestens die Bestrafung Callistos durch Iuno und die spätere Begegnung Callistos mit ihrem Sohn, vermutlich aber auch das Badeverbot im Meer Hinzufügungen Ovids zum ursprünglichen Mythos der Callisto sind, in dem sie schlicht von der erzürnten Diana, zu deren Gefolge sie gehört, verwandelt oder mit einem Pfeil getötet wird. Sowohl die mehrstufige Verwandlung als auch die prekäre Situation eines drohenden ,nefas', mithin also die ausdrücklich disparaten Episoden der Erzählung, sind demzufolge als absichtsvolle Ergänzungen identifizierbar.
} 
poetologischen Bedeutung für die Metamorphosen gelten, was in Christoph Ransmayrs Ovid-Roman Die letzte Welt (1991, S. 17) als beinahe tautologische Sequenz formuliert ist: „Naso ist Naso, und Pythagoras ist Pythagoras“. ${ }^{10}$

Dass die Pythagorasrede trotz offensichtlicher Diskrepanzen so häufig als Referenzmodell der Metamorphosen missverstanden worden ist, ist darauf zurückzuführen, dass sie als plakatives Deutungsangebot Teil eines genialen narrativen Taschenspielertricks ist, dass sie - um es mit Solodow (1988, S. 164) noch spitzer zu formulieren - ein „red herring“, eine textuelle Finte, ein Ovidisches Täuschungsmanöver ist.

Die „Stärke der mythologischen Tradition“, formuliert der Philosoph Hans Blumenberg (1971, S. 21) in einem Vortrag, sei ihr „unbedenklicher Verzicht auf Konstanz". In der Arbeit am Mythos (1979, S. 142 u. 148) spricht er später davon, dass es im Mythos ,keine Chronologie, nur Sequenzen“ gebe, dass anders formuliert im Mythos „keine der Geschichten Spuren in der nächsten“ hinterlasse. Das mögen begründete und sehr richtige Charakterisierungen sein, auf Ovids mythologisches Epos trifft indes keine davon zu. Ganz im Gegenteil entfaltet Ovid innerhalb des großangelegten Rahmens von Weltursprung und Regierungszeit des Augustus aus den einzelnen Mythen, den Urgeschichten der Menschheit,11 eine vollständige mythische Welterzählung, eine Urgeschichte der Menschheit. Ihre Kohärenz erhält sie durch eine ausgeklügelte Technik des Übergangs, ${ }^{12}$ die aufeinander folgende Mythen, aber auch die unterschiedlichen Bücher und nicht zuletzt mit Proömium und Epilog auch Anfang und Ende des Epos aneinanderschließt. Im einfachsten Fall sind es Figuren, geografische Besonderheiten oder Mythenbeigaben, die eine Verknüpfung zweier Episoden leisten: Apoll ist Sieger über das Monster Python und in der nächsten Erzählung Liebhaber der Daphne; der Ort, an dem der soeben in einen Stein verwandelte Battus steht, ist Ausgangspunkt einer Reise des Merkur, die den nächsten Mythos anstößt; abgeschreckt vom Tod des Pentheus verehren die ismenischen Frauen den neuen Gott Bacchus, nur die Minyastöchter weigern sich. Kunstvoller sind die fiktiven Erzählsituationen, die Ovid mehrfach einsetzt und die es ihm erlauben, mehrere Mythen ohne direkten Übergang bzw. in eher loser Reihung aneinander zu schließen. ${ }^{13}$

10 Die Seitenangabe bezieht sich auf eine Taschenbuchausgabe des Fischer-Verlags, erstmalig erschienen ist der Roman aber 1988 bei Greno, Nördlingen. Ransmayr verwendet hier Ovids Beinamen Naso, um den Dichter zu bezeichnen.

11 Vgl. zu dieser Charakterisierung des Mythos Blumenberg (1979, S. 166): „Die Grundmuster von Mythen sind eben so prägnant, so verbindlich, so ergreifend in jedem Sinne, daß sie immer wieder überzeugen, sich immer noch als brauchbarster Stoff für jede Suche nach elementaren Sachverhalten des menschlichen Daseins anbieten“.

12 Vgl. dazu u. a. Schmidt (1938); Tsitsiou-Chelidoni (2003).

13 So etwa die Minyastöchter, die sich beim Spinnen Geschichten erzählen (Met. IV, 1-415), der Sängerwettstreit zwischen den Musen und den Töchtern des Pieros (Met. V, 294-678) oder der Gesang des Orpheus (Met. X, 143-739).

Dass diese erzählten Situationen über das Erzählen ebenfalls poetologisches Potenzial besitzen, ist mehrfach erkannt und untersucht worden. Vgl. u. a. Holzberg 1997, S. 134-136, 142-144; Solodow 1998, S. 34-36. 
Neben dieser Übergangstechnik, die zudem eine feste Chronologie der einzelnen Erzählungen im Sinne einer mythischen Weltgeschichte impliziert, bedient sich der Text geschickt des aitiologischen, d. h. des den Ursprung eines Phänomens erklärenden Charakters vieler Verwandlungsmythen. ${ }^{14}$ Wenn Daphne in einen Lorbeer, Lycaon in einen Wolf oder Arachne in eine Spinne verwandelt wird, löst die Metamorphose ja lediglich ein, was in den Namen der Verwandelten von vornherein festgeschrieben scheint: ,Daphne' bedeutet ,Lorbeer', ,Lykos' bedeutet ,Wolf‘, ,Arachne' bedeutet ,Spinne ${ }^{6}{ }^{15}$ Insofern die schmerzhafte prozessuale Komponente des Verwandlungsvorgangs im organisch wirkenden Zustand nach der Verwandlung aufgehoben ist, erhalten die Verwandlungen einen sinnhaften, weil aitiologisch motivierten Anstrich. Dieser aber, und auch das ist eine Besonderheit der Vorgehensweise des Epos, wird im Text immer erst nachträglich hergestellt, denn Ovid verändert die eigentliche Erzählrichtung des Aition. Statt das zu erklärende Phänomen zu benennen und danach die entsprechende Ursprungserzählung mitzuteilen, schildert er zunächst ausführlich die Metamorphose und gibt ihr erst dann eine aitiologische Wendung: Erst nachdem Daphne die schockhafte Verwandlung vollständig durchlebt hat, erklärt Apoll den Lorbeer zu einem kultisch mit ihm in Verbindung stehenden Baum; erst nachdem Callisto fünfzehn Jahre als Bärin gelebt hat und fast von ihrem Sohn auf der Jagd erlegt worden ist, offenbart sich in ihrer Versetzung an den Himmel das aitiologische Ziel ihrer Verwandlung. Weil die aitiologische Metamorphose damit eben nicht erklärend, sondern linear, nicht als Antwort auf die Frage nach einem Phänomen, sondern als Erzählung entwickelt wird, steht sie als schmerzhafter und sinnentleerter Vorgang zunächst erratisch da. Erst in einem zweiten, nachträglichen Schritt lässt der Text die eigentlich kultur- und kontinuitätsstiftende Funktion des Aition sich entfalten.

Die narrative Gesamtstrategie des Epos lässt sich vor dem Hintergrund dieser Beobachtungen also als doppelgesichtig bestimmen: Der Text verbirgt das als diskontinuierlich vorgestellte Modell der Metamorphose hinter einem dezidiert auf Kontinuität setzenden Erzählgestus, die mythische Verwandlungsordnung ist in der Kohärenz der Narration scheinbar aufgehoben. Die Metamorphosen, so ließe sich zusammenfassend sagen, sind nicht das, wofür sie sich vordergründig ausgeben.

\footnotetext{
14 Harzer (2000, S. 39ff). Harzer unterscheidet zusätzlich zwei Verwandlungstypen: die narrativ motivierte, metonymische Verwandlung (Actaeon) und die aitiologisch motivierte, metaphorische Verwandlung (Daphne).

15 Das Epos operiert hier mit einer grundmythischen Vorstellung, die Blumenberg (1979, S. 45) mit der Formel „Geschichte als Vollstreckung des Namens" beschreibt. Namen entfalten im mythischen Verständnis eine eminente Wirkmächtigkeit: Kannte man den Namen eines Gottes oder eines Menschen, erlangte man Macht über ihn; vernichtete man den Namen in einer bestimmten Zeremonie, sollte das den Tod oder eine sonstige Beschädigung des Namensträgers zur Folge haben. Namen bezeichnen so im Mythos nicht nur äußerlich das Individuum, sie konstituieren es in seiner Existenzform.
} 
Dieses spannungsreiche Nebeneinander von postulierter Kontinuität und tatsächlicher Diskontinuität ist indes bereits im Proömium der Metamorphosen festgeschrieben. Trotz seiner in der antiken Literaturgeschichte recht einmaligen Kürze von gerade einmal vier Versen ist es von unübertroffener poetologischer Dichte:

Von Gestalten zu berichten, die in neue Körper verwandelt worden sind, treibt mich mein Geist: Ihr Götter (habt ihr doch jene Körper verwandelt), beflügelt mein Vorhaben und führt meine Dichtung vom ersten Ursprung der Welt bis zu meiner Zeit ununterbrochen herab.

(Met. I, 1-4: In nova fert animus mutatas dicere formas / corpora: di, coeptis (nam vos mutastis et illa), adspirate meis primaque ab origine mundi / ad mea perpetuum deducite tempora carmen)

Ovid hat für sein groß angelegtes Epos eigentlich ein Proömium in Schlagworten verfasst. Es benennt das Thema des Epos: ,in neue Körper verwandelte Gestalten' (,in nova corpora mutatas formas'), es benennt den zeitlichen Rahmen des Epos: ,vom ersten Ursprung der Welt bis zu meiner Zeit' (,prima ab origine mundi ad mea tempora'), es beinhaltet in gebotener und fast lakonischer Kürze den für die Epik traditionellen Anruf der Götter: ,Götter, beflügelt mein Vorhaben' (,di, adspirate meis coeptis') und es liefert den terminologischen Schlüssel zum narrativen Konzept des Epos: das ,carmen perpetuum', das ununterbrochene, das fortlaufende Gedicht. Mit diesem Begriff ruft das Proömium eine spezifische Traditionslinie antiker Epik auf, nämlich die des Heldengedichts im Stil von Homer (Ilias, Odyssee) und Vergil (Aeneis), das sich durch die Konzentration auf einen durchgängigen Handlungsstrang auszeichnet. Auch hier sollte man dem Text allerdings nicht allzu blind vertrauen, denn noch im Verb desselben Satzes (,deducere') codiert das Proömium eine weitere epische Tradition: das ,carmen deductum', das thematische Kataloggedicht nach dem Vorbild von Kallimachus (Aitia) und Hesiod (Eoiai), das aus zwar handlungslogisch unverbundenen, aber thematisch bzw. motivisch miteinander verknüpften Einzelepisoden besteht.

Das Proömium situiert die Metamorphosen damit zwischen zwei eigentlich grundverschiedenen epischen Modellen: zwischen dem auf Chronologie und Handlungssequenz setzenden ,carmen perpetuum' und dem auf Analogie und Serialität basierenden ,carmen deductum'.16 Indem es so historisch und narrativ zugleich, als Geschichte im doppelten Sinn arrangiert ist, bewegt sich das im Epos Erzählte auf dem schmalen Grad zwischen einem Konzept der narrativen Kontinuität und einem der narrativen Diskontinuität.

Es sind genau diese zwei Begriffspole, um die auch die Forschung zu den Metamorphosen beständig kreist. Während ältere Ansätze vor allem die großen Zusammenhänge innerhalb des Epos herausstellen, betonen neuere Ansätze bevorzugt die evidenten Brüche des Textes. Beherrschten früher wahlweise um

${ }^{16}$ Holzberg (1997, S. 124); Harzer (2000, S. 70f.); Wheeler (2000, S. 1); Rosati (2002, S. 277). 
Protagonisten, Themen und Sagenkreise gruppierte Großteile und Pentaden die wissenschaftliche Debatte um die Metamorphosen, ${ }^{17}$ spricht man heute gern von „the very contingency of connectedness“ (Kenney 2009, S. 151) als Thema des Epos, von „the poem's extraordinary productiveness of structures“ (Solodow 1988, S. 13) oder von einem ,ever-changing narrative surface“ (Tissol 1997, S. 96) und kennzeichnet die Struktur des Epos generell als „deceptive“ (Solodow 1988, S. 2) oder ,a-kausal und a-teleologisch“ (Kuon 2005, S. 5). Beide Forschungspositionen sind in ihrer einseitigen Orientierung aber defizitär. Denn wo die ältere Forschung die Dichte und offensichtliche Heterogenität des Textes mit einer allzu homogenen narrativen Struktur überzeichnet, tendiert die jüngere Forschung dazu zu übersehen, dass den Metamorphosen eben doch eine Ordnung zu Grunde liegt, die es ernst zu nehmen gilt, denn das Epos inszeniert sich trotz aller Brüche an seiner Oberfläche doch als souveränes textuelles Gefüge.

Ich möchte das an einer letzten Verwandlungserzählung aus dem Epos verdeutlichen. Dazu greife ich noch einmal auf das Verb ,deducere‘ zurück. Wie die meisten lateinischen Verben besitzt es eine Vielzahl von Bedeutungen, in Verbindung mit Dichtung aber bezeichnet es (wie auch in der festen Wendung , carmen deductum') den Vorgang der kunstvollen Ausarbeitung oder wörtlicher: den des feinen Ausspinnens eines Gedichts. In dieser speziellen Bedeutung entstammt es als terminus technicus eigentlich der Webkunst, ${ }^{18}$ aus der im Lateinischen noch ein zweiter virulent poetologischer Begriff hervorgeht: der des Gewebes, des ,textum'. Damit ist im Besonderen eine bestimmte Erzählung der Metamorphosen aufgerufen, die der Arachne im sechsten Buch (Met. VI, 1-145). ${ }^{19}$

Arachne ist eine bekannte Meisterin der Webkunst und wird von Athene, der Weberin unter den Göttern, zu einem Wettstreit aufgefordert. Beide stellen einen Teppich her, in dessen Gewebe „eine alte Geschichte ausgesponnen wird“ (Met. VI, 69: „vetus in tela deducitur argumentum“) und dessen Schattierungen dem Regenbogen gleichen:

Obwohl in ihm tausend Farben schimmern, täuscht doch gerade der Übergang die Augen des Betrachters: So sehr ist das, was sich berührt, gleich; die äußersten Ränder aber sind verschieden.

\footnotetext{
17 U. a. Ludwig (1965); Crabbe (1981); Holzberg (1997, S. 124 u. 126ff). Zur Zusammenfassung der verschiedenen Positionen vgl. Wheeler (2000, S. 1-3); Schmitzer (2001, S. 96).

18 Vgl. den Eintrag unter dem Lemma ,deduco' in Karl Ernst Georges’ Ausführlichem LateinischDeutschen Wörterbuch, Bd. 1.

${ }^{19}$ Harzer (2000, S. 73f. u. 80ff). Einen solchen Zusammenhang zwischen Dicht- und Webkunst, zwischen Erzähl- und Webprozess erkennt Harzer neben der Arachne-Episode auch schon bei den spinnenden und gleichzeitig Geschichten erzählenden Minyastöchtern im vierten Buch der Metamorphosen. Vgl. auch Harries (1990, S. 64), der die Analogie zwischen Dichter und Weberin als „well-known Hellenistic literary motif“" kennzeichnet.
} 
(Met. VI, 65-67: in quo diversi niteant cum mille colores, / transitus ipse tamen spectantia lumina fallit: / usque adeo, quod tangit, idem est; tamen ultima distant)

Zweierlei möchte ich hier festhalten. Zum einen erfolgt mit der Wiederaufnahme des Verbs ,deducere' ein ausdrücklicher Anschluss an das programmatische Proömium, zumal mit dem Zusatz des, vetus argumentum', das ja als Mythos auch den (wiederum doppelsinnigen) ,Stoff' der Metamorphosen ausmacht. Zum anderen führt der Text an dieser Stelle am Beispiel des Regenbogens seine eigene Übergangstechnik als Täuschung vor. So, wie dessen Farben ineinander übergehen und dabei doch grundverschieden sind, verbirgt die Übergangstechnik des Textes die eigentliche Disparatheit seiner einzelnen Episoden.

Auch der weitere Verlauf der Erzählung bürgt für ihre poetologische Virulenz. Während Athene auf ihrem Teppich die römischen Götter mit ihren Attributen darstellt, entstehen an Arachnes Webstuhl - ein noch direkterer Hinweis ist kaum denkbar - Metamorphose-Erzählungen:

Arachne stellt Europa dar, wie sie vom Trugbild des Stieres getäuscht wurde: Man hätte den Stier und das Meer für echt halten können. Sie selbst schien auf das Land, das sie verlassen hatte, zurück zu blicken und nach ihren Gefährtinnen zu rufen, die Berührung des heranplätschernden Wassers zu fürchten und furchtsam die Fußsohlen zurück zu ziehen.

(Met. VI, 103-107: Maeonis [d.i. Arachne] elusam designat imagine tauri / Europam: verum taurum, freta vera putares; / ipsa videbatur terras spectare relictas / et comites clamare suas tactumque vereri / adsilientis aquae timidasque reducere plantas) ${ }^{20}$

Dem Arachne-Mythos kommt damit eine entscheidende poetologische Rolle innerhalb der Metamorphosen zu. Die Webkunst der Arachne, für die sie mit der Verwandlung in eine Spinne bestraft wird, bezeichnet den Rahmen, in dem sich das Erzählverfahren des Epos entfaltet. Genuin ist ihm die Technik des ,deducere', die aber gleichzeitig als prinzipiell täuschend ausgewiesen ist: Weder gleichen sich die verwobenen Farben noch sind Stier und Meer echt.

\footnotetext{
20 Auf eine wichtige Besonderheit dieser Schilderung der auf dem Teppich dargestellten Erzählungen verweist Harzer (2000, S. 84): „Die Ekphraseis dieser Episode verwandeln die beschriebenen Bilder nicht nur in Text, sie schildern sie selber schon als Text".

Zudem ist der Europa-Mythos als eigenständige Erzählung selbst Teil des Epos (Met. II, 833-875), so dass hier tatsächlich eine ,stoffliche "Übereinstimmung zwischen dem ,textum' der Arachne und dem ,textum` des epischen Erzählers vorliegt.
} 


\section{III}

Nachdem ich der Darstellung der narrativen Technik der Metamorphosen viel Raum gegeben habe, möchte ich nun dem eigentlichen Thema meines Beitrags in einem zweiten Schritt etwas näher kommen. Ich greife dazu noch ein letztes Mal auf das Proömium und seine programmatischen Markierungen zurück. Neben dem Heldenund dem Kataloggedicht verbirgt sich dort nämlich noch eine dritte antike Tradition epischen Erzählens, die ich bislang unterschlagen habe. Wenn das Proömium ankündigt, das Epos werde seinen Ausgang, vom ersten Ursprung der Welt‘ (,prima ab origine mundi) nehmen, dann kennzeichnet es die Metamorphosen auch als kosmologisches Lehrgedicht. ${ }^{21}$ Dessen lateinische Tradition ist vor allem mit dem Namen Lukrez und dem Hexametergedicht De rerum natura (Über die Natur der Dinge) verknüpft, dessen formale wie inhaltliche Vorbilder bei Hesiod (Theogonia), den bis auf wenige Fragmente verlorenen Lehrgedichten der griechischen Naturphilosophen Parmenides und Empedokles und dem hellenistischen Lehrgedicht zu verorten sind. ${ }^{22}$ Ovids Epos beansprucht in seinen einleitenden Versen vor dem Hintergrund dieser Texttradition also nicht nur, eine Weltgeschichte unter dem Zeichen der Metamorphose zu erzählen, sondern es verspricht auch, dabei einen naturphilosophischen Standpunkt einzunehmen, d. h. konkrete Aussagen über die natürliche Welt zu treffen.

Das geschieht zum einen dadurch, dass der Text anders als die meisten antiken Beispiele aitiologischer Dichtung nur wenige Aitia aufnimmt, die die Ursprünge religiöser Kulte oder ritueller Praktiken erklären. Stattdessen konzentriert sich das Epos fast ausschließlich auf die Entstehung von Pflanzen, Tieren, natürlichen Phänomenen und geografischen Besonderheiten, also: Naturaitia. Zum anderen, und damit möchte ich mich im Folgenden beschäftigen, enthalten die Metamorphosen mit dem Bericht über die Entstehung des Kosmos im ersten Buch und der bereits besprochenen Pythagorasrede im letzten, dem fünfzehnten Buch, zwei lange naturphilosophische Passagen, die dem Epos neben Proömium und Epilog einen auffälligen zweiten Rahmen geben. ${ }^{23}$

Ovids Schilderung der Weltentstehung, mit der ich beginnen möchte, entfaltet sich in der Gegenüberstellung elementarer Oppositionen:

Noch ehe es Meer, Land und den Himmel gab, der alles überwölbt, hatte die ganze Erde ringsum einerlei Aussehen; man nannte es das Chaos: eine rohe, ungeordnete Masse, nichts als träges Gewicht und auf einen Haufen geworfene, im Widerstreit befindliche Samen von Dingen, die keinen rechten Zusammenhang hatten. [...] Keinem blieb die eigene Gestalt, im Wege stand eines dem anderen [...]. Diesen Streit schlichtete Gott und die bessere Natur. Er schied nämlich vom Himmel die Erde und von der Erde die Gewässer, und er sonderte von der dichten Luft den klaren Himmel. [...] Kaum hatte er - welcher der Götter es auch sein mochte - das Durcheinander so geordnet, zerschnitten und gegliedert, ballte er zuerst die Erde zusammen.

\footnotetext{
${ }^{21}$ Keith (2002, S. 238).

22 Ackermann (1979, S. 29f).

${ }^{23}$ Myers (1994, S. 6); Hardie (1995, S. 210f.); Wheeler (2000, S. 115).
} 
(Met. I, 5-35: Ante mare et terras et, quod tegit omnia, caelum / unus erat toto naturae vultus in orbe, / quem dixere Chaos, rudis indigestaque moles / nec quicquam nisi pondus iners congestaque eodem / non bene iunctarum discordia semina rerum. [...] nulli sua forma manebat / obstabatque aliis aliud [...]. / Hanc deus et melior litem natura diremit; / nam caelo terras et terris abscidit undas / et liquidum spisso secrevit ab aëre caelum [...]. / Sic ubi dispositam, quisquis fuit ille deorum, / congeriem secuit sectamque in membra redegit, / principio terram [...] glomeravit)

Blinde Formlosigkeit steht in der Kosmogonie klar konturierter Form entgegen, die wirre Regellosigkeit des Chaos kontrastiert mit der harmonischen Ordnung des Kosmos. Die Metamorphosen zeigen die Weltentstehung als Parzellierungsvorgang, als Grenzziehung und Formgebung: Aus dem Chaos als undifferenzierter und ungestalter Masse der Elemente entsteht durch Gliedern, Trennen, Teilen und Abstecken der Kosmos als wahrnehmbare Weltordnung. Die Tätigkeit des dafür verantwortlichen ,deus' ist keine creatio ex nihilo - diese Vorstellung ist der Antike ohnehin fremd. Sie ist nicht „materiales Erschaffen“, sondern ein „Verfriedlichen des Chaos, Ordnungsproduktion“ (Böhme u. Böhme 1996, S. 41). Das entspricht durchaus der eigentlichen Bedeutung des Wortes ,kosmos ${ }^{6}$ als ,Schmuck': Philosophischer terminus technicus für das Weltgefüge ist es erst sekundär, primär bezeichnet es ,jedes zweckmäßig geordnete, überzeugend gegliederte, wohlproportionierte Gebilde“ (Lämmli 1962, S. 22). ${ }^{24}$ Der Kosmos, wie ihn der Weltentstehungsbericht im ersten Buch der Metamorphosen vorstellt, ist Schönheit gedacht als Gesetzmäßigkeit und Ordnung.

Wie an so vielen Stellen des Epos, lassen sich aber auch hier berechtigte Zweifel an der Gültigkeit dieses Konzeptes anmelden. So zeichnet sich die Kosmogonie an mindestens einer Stelle durch merkwürdige Diffusität aus. Als für die Weltordnung verantwortliche Instanzen benennt der Text einen ausdrücklich nicht näher spezifizierten (,quisquis fuit ille deorum) Gott und die ,bessere Natur (,melior natura) - eine Information, die Hejduk (2009, S. 50) zu Recht mit den Fragen „a god? the god? God?“ und „Nature? better than what?“ kommentiert. Diffus bleibt der Text auch in Bezug auf seinen naturphilosophischen Standpunkt: ${ }^{25}$ Statt eine kohärente Position zu beziehen, pflegt er einen überaus eklektischen Umgang mit verschiedensten, einander durchaus widersprechenden naturphilosophischen Positionen, so dass sich vorsokratische Naturphilosophie mit Elementen des Platonismus, der Stoa, des Epikureismus und der Akademie vermischt. Mischung statt klare Begrenzung aber, daran möchte ich noch einmal erinnern, ist in der Kosmogonie der Metamorphosen gerade als Kennzeichen des Chaos und nicht der Ordnung ausgewiesen.

Ich habe zu Beginn meines Beitrags behauptet, die Metamorphosen würden mit der Entstehung des Kosmos am Anfang beginnen. Leider muss ich zugeben, dass ich bei dieser Aussage nicht ganz ehrlich war, denn streng genommen beginnt das Epos innerhalb des ersten Buches nicht nur einmal, sondern sogar viermal von vorn. Nach

\footnotetext{
${ }^{24}$ So auch Gloy (1996, S. 33); Böhme (1996, S. 120).

${ }^{25}$ Lämmli (1962, S. 125 u. 133); Myers (1994, S. 40ff.); Harzer (2000, S. 98f.); Wheeler (2000, S. 12ff).
} 
der Kosmogonie führen ein Kampf zwischen Göttern und Giganten, eine von Iuppiter verhängte Sintflut und ein verheerender Weltbrand zu einer jeweiligen Neuschöpfung des Lebens. Viermal gerät der Kosmos in Gefahr, viermal wird seine Ordnung zwischenzeitlich ausgesetzt, viermal setzt das Epos neu an: Das erste Buch der Metamorphosen, das Buch des Anfangs, das sich in der Kosmogonie als Buch der Ordnungsproduktion akzentuiert, entpuppt sich unter der Oberfläche gerade als ein Buch der Anfänge, in dem Ordnungen lediglich vorübergehend und instabil sind, in dem sie immer wieder neu gewonnen werden müssen. ${ }^{26}$

Ähnliches lässt sich für die zweite naturphilosophische Passage der Metamorphosen feststellen. Die Rede des Pythagoras, die sich als philosophisches Lehrgedicht eigentlich durch diskursive Kohärenz auszeichnen müsste, ist derart von Brüchen und Unstimmigkeiten durchzogen, dass sie in der Forschung als „buntes Patchwork aus mythologischen, religiösen und naturphilosophischen Versatzstücken“ (Harzer 2000, S. 99f.) bezeichnet worden ist. Wenig überraschend, weil schon aus der Kosmogonie bekannt, ist der evidente Eklektizismus der Rede, die sich entgegen der Identität ihres Sprechers nicht mit rein pythagoreischen Standpunkten begnügt. Neu hingegen ist, dass sie neben herkömmlichen naturphilosophischen Positionen auch Erklärungen referiert, die schon aus antiker Sicht lediglich pseudowissenschaftlichen Charakter besaßen: ${ }^{27}$ die unter dem Begriff der ,Bugonie“ bekannte Entstehung von Bienen aus einem verwesenden Stierkadaver etwa oder die von Hornissen aus einem vergrabenen Kriegspferd. Auch die Figur des Pythagoras selbst erfährt vor und in der Passage eine ungewöhnliche Akzentuierung. Denn von dem Philosophen heißt es, er „suche im Geist die Götter auf“ (Met XV, 63: „mente deos adiit“) und ein Gott bewege seine Lippen (Met. XV, 143: „Et quoniam deus ora movet"). Wie der Text in der Lehrrede also naturphilosophische Erklärungsmodelle gleichberechtigt neben ,mirabilia', Wundererscheinungen stellt, verzeichnet er auch den Naturphilosophen zum ,poeta vates', zum Dichterseher. $^{28}$

Obwohl es also zunächst scheint, als stelle Ovid mit den beiden rahmenden naturphilosophischen Passagen in den Metamorphosen der mythisch-aitiologischen Weltordnung seines Epos eine alternative, philosophisch-naturwissenschaftliche gegenüber, sind Mythos und Naturphilosophie bei genauer Betrachtung doch nicht als Oppositionen umgesetzt. ${ }^{29}$ Sowohl in der Kosmogonie und der Pythagorasrede als auch in den übrigen Erzählungen des Epos steht dieselbe Frage im Vordergrund: die Frage nach den Anfängen, nach den Ursachen natürlicher Phänomene: den Verwandlungen, und den Ursachen des Weltgefüges: den Elementen, die so zu den eigentlich ersten Aitia, den ersten Ur-Sachen des Epos werden.

\footnotetext{
26 Holzberg (1997, S. 129f.); Wheeler (2000, S. 16ff). Spentzou (2009, S. 386) spricht in diesem Zusammenhang von den Metamorphosen als einem „fragmented carmen perpetuum" und von den „repetitive openings“ des ersten Buches.

${ }^{27}$ Myers (1994, S. 133ff.); Holzberg (1997, S. 151f).

28 Harzer (2000, S. 103f).

${ }^{29}$ Myers (1994, S. 19-21, 49ff).
} 
Auch durch viele andere Episoden der Metamorphosen hindurch wird nicht der Unterschied, sondern gerade die gleichberechtigte Valenz des mythischen wie des naturphilosophischen Modells der Welterklärung erprobt. So tischt Iuppiter der misstrauischen Iuno eine glatte naturphilosophische Lüge auf, wenn er behauptet, die strahlend weiße Kuh, in die er soeben seine Geliebte Io verwandelt hat, um den Ehebruch vor seiner Frau zu verstecken, sei durch spontane Zeugung aus der Erde entstanden. Oder: Während nach der Sintflut durch mythische Verwandlung aus Steinen das neue Menschengeschlecht entsteht, bringt die Erde durch den naturphilosophisch anerkannten Prozess der Urzeugung aus Wärme und Feuchtigkeit gerade das mythische Monster Python hervor. Darüber hinaus werden viele Metamorphosen als Vorgänge beschrieben, die aus einer naturphilosophischen Dynamik des Elementenhaushaltes im Körper des Verwandelten resultieren. ${ }^{30} \mathrm{Zu}$ denken wäre hier etwa an Echo, die versteinert, weil ,aller Saft des Körpers in die Luft“ (Met. III, 397f.: „et in aëra sucus / corporis omnis abit“) verschwindet, oder an Cyane und Arethusa, die umgekehrt zur Quelle werden, weil durch Tränen oder Schweiß die Flüssigkeit in ihren Körpern überhandnimmt.

Auf diese Weise greifen Mythos und Naturphilosophie ineinander, ihre Grenzen werden verunklärt. Die eigentlich verschiedenen Wahrheiten bzw. Welterklärungsmodelle, für die sie als Wissensformen bürgen, werden zu einer neuen, zu einer poetischen Wahrheit ineinandergeschmolzen. ${ }^{31}$ Indem der Text weder streng mythisch noch streng naturphilosophisch argumentiert, verweist er stattdessen auf seine eigene Erzählordnung, auf seine Verfasstheit als ,textum'. Denn die in der Kosmogonie und der Pythagorasrede vorgestellte Ordnung des Kosmos stimmt auffällig mit der narrativen Technik der Metamorphosen überein. Auch hier trifft vorgebliche Kontinuität und Kohärenz auf textuelle Brüche und Fissuren, auch hier erweist sich eine als stabil gedachte (Erzähl- bzw. Welt-) Ordnung als doppelbödig. Ovids Kosmos, wie er in den naturphilosophischen Passagen der Metamorphosen entworfen wird, funktioniert nach denselben strukturellen Regeln wie das Epos selbst und ist damit weder als mythische noch als naturphilosophische, sondern eigentlich als narrative Ordnung ausgewiesen. Wie die Metamorphosen sich in der Arachne-Episode als Gewebe, als ,textum' präsentieren, wird so auch der in ihnen entworfene Kosmos als ,textum` inszeniert.

Diese Denkfigur ist der lateinischen Literatur- und speziell Philosophiegeschichte indes nicht völlig fremd. Auch Lukrez bedient sich ihrer in seinem Lehrgedicht De rerum natura ${ }^{32}$, freilich nicht im Sinne einer poetischen Freiheit, sondern aus

\footnotetext{
30 Myers (1994, S. 47-49).

31 Myers (1994, S. 15ff., 49ff. u. 133ff.); Schmitzer (2006, S. 45). Vgl auch Böhme u. Böhme (1996, S. 29), die feststellen, dass die Leistung Ovids in den Metamorphosen sei, „Mythos wie Philosophie in Literatur zu transformieren“.

32 Dem Beitrag liegt die von Joseph Martin besorgte und in der Bibliotheca Teubneriana erschienene Ausgabe von De rerum natura zu Grunde. Die Zitierweise folgt der bisher im Beitrag verwendeten.
} 
einer naturphilosophischen Notlage heraus. Als Anhänger des Epikureismus, der die Befreiung von der Angst vor dem Göttlich-Übernatürlichen durch eine empirisch-rationale Erklärung natürlicher Phänomene zu einem zentralen Anliegen seiner Philosophie macht, setzt Lukrez in seinem HexameterGedicht vor allem auf die Beweiskraft der Sinne: Das Gewitter und besonders der Blitz sind, so führt er aus, nicht die furchtbaren Werkzeuge einer göttlichen Strafe, sondern rational erklärbare, jeder Metaphysik entkleidete klimatische Erscheinungen, die Respekt, nicht aber Angst einflößen sollten (DNR VI, 96-422). Nun sind aber gerade die beiden Bestandteile, aus deren Zusammenspiel nach epikureischer Vorstellung der Kosmos besteht, die Atome und das Vakuum, den menschlichen Sinnen eben nicht zugänglich. Während die atomaren Urteilchen schlicht zu klein für das menschliche Auge sind, ist das Vakuum als leerer Bereich zwischen den Atomen und damit als verneinte räumliche Existenz ohnehin nur begrifflich abbild-, nicht aber sinnlich wahrnehmbar.

Lukrez greift deshalb auf die Figur der Analogie zurück. Sie ist in seinem Lehrgedicht nicht nur stets wiederkehrende rhetorische Finesse, sondern vor allem unabdingbarer Bestandteil einer Argumentation, die Nicht-Sichtbares vor Augen führen will und muss. Von den zahlreichen Beispielen für dieses Verfahren, so etwa dem besonders anschaulichen Vergleich der Atome mit im Sonnenlicht wirbelnden Staubkörnchen (DNR II, 112-141), möchte ich dabei vor allem eines hervorheben:

Damit du eher glaubst, dass es viele Körperchen gibt, die vielen Dingen gemeinsam sind (wie die Buchstaben bei den Wörtern), als dass du glaubst, dass irgendein Ding ohne Urteilchen bestehen könne.

(DNR I, 196-198: ut potius multis communia corpora rebus / multa putes esse, ut verbis elementa videmus, / quam sine principiis ullam rem existere posse)

Etwas später im Text wird diese vorerst nur angedeutete Analogie zwischen Dingwelt und Wortwelt ausführlicher expliziert:

Ja, auch in unseren Versen siehst du vielfach Buchstaben, die verschiedenen Wörtern gemeinsam sind, und doch musst du gestehen, dass die Verse wie die Worte ganz voneinander verschieden sind, im Inhalt wie im klingenden Laut. So stark wirkt bei den Buchstaben allein die veränderte Reihenfolge. Und doch vermögen die Urelemente der Dinge weit mehr Möglichkeiten mit sich zu bringen, aus denen unterschiedliche Dinge entstehen können.

(DNR I, 823-829: Quin etiam passim nostris in versibus ipsis / multa elementa vides multis communia verbis, / cum tamen inter se versus ac verba necessest / confiteare et re sonitu distare sonanti. / tantum elementa queunt permutato ordine solo; / at rerum quae sunt primordia, plura adhibere / possunt unde queant variae res quaeque creari)

In einem sehr ähnlichen Wortlaut taucht diese Passage im Verlauf des Textes noch zweimal auf (DNR II, 688-694 u. DNR II, 1013-1022). Nun ist zwar unsicher, ob Lukrez' Lehrgedicht in einer letztgültigen oder lediglich in einer Arbeitsfassung 
überliefert ist. Möglicherweise könnten diese auffälligen Wiederholungen also auch durch den unfertigen Zustand des Textes bedingt sein und hätten in einer öffentlichkeitsfähigen Fassung vielleicht noch beseitigt werden sollen. Immerhin scheint die Analogie zwischen Atom, Buchstabe und Vers aber so wichtig gewesen zu sein, dass sie an mehreren Stellen des Gedichts zumindest erwogen, unter Umständen sogar tatsächlich eingesetzt wurde. Dafür spricht auch, dass der Text über diese konkreten Analogiehinweise hinaus eine Verbindung zwischen seiner eigenen Verfasstheit und der Verfasstheit des von ihm beschriebenen Kosmos herstellt. Denn für den zufälligen Zusammenschluss der einzelnen Atome zu Stoffen und Körpern bietet De natura rerum Begriffe wie ,nexus', ,contextum' und ,textura' an; in Bezug auf sein Vorgehen im Lehrgedicht selbst verwendet Lukrez entsprechend das Verb ,pertexere' (DNR VI, 42: ,zu Ende weben/ausführen') ${ }^{33}$. Insofern die Struktur des Atomzusammenhangs im Begriffsfeld des ,textum ${ }^{6}$ als Analogon zur Struktur des Hexametergedichts in diesem begreif- und sichtbar wird, gerät der Text zum „linguistic simulacrum of the entire universe“ (Farrell 2007, S. 90), gerät die Vers-Ordnung zur Welt-Ordnung, das ,textum` des Lehrgedichts zum Kosmos und umgekehrt.

Inszeniert Ovid in den Metamorphosen also ein groß angelegtes intertextuelles Spiel mit Lukrez, indem er das Epos in seiner textuellen Verfasstheit spielerisch erzeugen lässt, was das Lehrgedicht als Argument und Illustration seines naturphilosophischen Standpunktes zwangsläufig benötigt, nämlich: den Kosmos als ,textum` zu zeigen? Eine intensive Auseinandersetzung mit Lukrez' De natura rerum als lateinischem Prototyp kosmologischer Lehrdichtung ist den Metamorphosen jedenfalls auch jenseits der besprochenen Analogiebildung zwischen Text und Kosmos problemlos nachzuweisen ${ }^{34}$ und durchzieht dabei folgerichtig vor allem den naturphilosophischen Rahmen des Epos, sprich: Kosmogonie und Pythagorasrede.

Ovid nutzt darüber hinaus aber ein Angebot seiner intertextuellen Vorlage, das sich bei Lukrez schon auf Grund seines philosophischen Standpunktes, der keine intentionale Weltentstehung und folglich auch keine entsprechende kosmogonische Instanz kennt, nicht hätte entfalten können: Wenn Kosmos und Text, wenn Weltgefüge und Hexametergedicht in Analogie zueinander treten, dann muss diese Verbindung in einem zweiten Schritt auch für den Gott der Kosmogonie und den epischen Erzähler gelten können. Genau diesen Schritt gehen die Metamorphosen, wenn zu Beginn des ersten Buches ein namenloser Gott, der „Baumeister der Welt" (Met. I, 57: „,fabricator mundi“"), das Chaos im Kosmos vollendet und am Ende des letzten Buches im Epilog des Epos die namenlose Erzählerfigur ihr gewichtiges Opus für abgeschlossen erklärt: „Nun habe ich ein

\footnotetext{
33 Das Lehrgedicht enthält zudem einen kleinen Abschnitt über die Entstehung der Webkunst, in dem dieses Begriffsfeld noch einmal eine eminente Rolle spielt (DNR V, 1350-1360).

${ }^{34}$ Myers (1994, S. 47-49, 53ff., 140); Hardie (1995, S. 208ff).
} 
Werk vollendet“ (Met. I, 871: „Iamque opus exegi“).35 Die Metamorphosen erhalten so einen nunmehr dritten Rahmen. Sie entfalten sich zwischen den zwei Erzählungen einer Urheber- bzw. Autorschaft, die sich nicht durch originäres Schöpfen, sondern durch Ordnen bereits vorhandener Materialien, nicht durch Erzeugen, sondern durch Kompilieren vollzieht. So wie der Gott der Kosmogonie das Chaos der Elemente und Stoffe lediglich in eine lebensfähige Ordnung überführt, betätigt sich auch der Erzähler der Metamorphosen eigentlich als Mythograph, der seinen gesammelten Stoff selbstverantwortlich zu narrativen Sequenzen und ganzen Büchern formt.

Ich fasse zusammen: Die Metamorphosen beginnen und schließen mit der Herstellung eines ,kosmos', den das Epos damit in den beiden, ihm zugehörigen Bedeutungen zugleich aktualisiert: philosophisch als Weltordnung in der Kosmogonie des ersten Buches mit ihrer ordnenden Gottheit und ästhetisch als Schmuck bzw. Kunstwerk in Bezug auf das Epos als solches mit seinem kompilierenden Erzähler. Insofern kosmogonische und dichterische Tätigkeit, Welt- und Textproduktion auf diese Weise ineinander fallen, wird Ovids Erzählerfigur zum ,poeta creator', zum bei Lukrez implizit angelegten „creator of the universe that he describes“" (Hardie 2007, S. 126), zum epischen ,alter deus', dessen Apotheose der Epilog der Metamorphosen zumindest ankündigt:

Aber mit meinem besseren Teil werde ich, unsterblich, über die hohen Sterne hinausgetragen werden und mein Name wird unzerstörbar sein.

(Met. XV, 875f.: parte tamen meliore mei super alta perennis / astra ferar; nomenque erit indelebile nostrum)

\footnotetext{
35 Der Epilog des Epos steht in der Tradition der sogenannten Sphragis (,Siegel'), der kurzen Selbstvorstellung des Dichters am Anfang oder Ende seines Werks. Als wohl bekannteste erhaltene Sphragis kann wahrscheinlich das „exegi monumentum aere perennius“ (car. 3, 30: „Ich habe mir ein Denkmal errichtet, dauerhafter als Erz") des Horaz gelten. Dem Epos als einer traditionell um Objektivität bemühten Gattung ist die Sphragis aber eigentlich fremd, weil sie sich nur schwer mit den in der Regel großen Stoffen der epischen Dichtung (Mythenzyklen, Philosophie, Historiografie) verträgt. Der von der Sphragis vorgeschriebenen Ich-Form angemessener sind die kleineren Gattungen lateinischer Dichtung wie Elegie oder Ekloge, die im Gegensatz zum Epos ihren Stoff aus einem explizit subjektiven Erfahrungshorizont beziehen. Schon hier nimmt Ovids epische Sphragis also eine gewisse Sonderstellung ein, obwohl er nicht der erste lateinische Dichter ist, der auch ein Epos mit einer persönlichen Signatur versieht. Schon der altlateinische Epiker Ennius stellt sich im Proömium seiner Annales selbstbewusst als ,zweiter Homer` (,alter Homerus') vor, während Vergil im Schlusswort der Georgica eine ausführliche Beschreibung seines Lebens am Golf von Neapel liefert (Albrecht 2002).

Aufschlussreicher in Bezug auf die Analogie zwischen kosmogonischer Gottheit und Erzähler scheint mir eine weitere Besonderheit des Epilogs der Metamorphosen zu sein. Obwohl Ovid den eigenen Namen in seinen Werken ,much more frequently [...] than any other ancient poet" (McKeown 1989, S. 4), nämlich im Ganzen 52 mal, nennt und er mit dem Schlussstück der Tristia $(4,10)$ auch die erste (aus den Wurzeln der Sphragis hervorgegangene) poetische Autobiografie der lateinischen Literaturgeschichte verfasst, verzichtet er in den Metamorphosen darauf, genaue Angaben über seine persona zu machen. Stattdessen bleibt der Erzähler namenlos wie der ominöse Gott der Kosmogonie, zu dem er damit in auch nominelle Analogie tritt.
} 


\section{IV}

Ich bin nun an einem Punkt meiner Überlegungen angekommen, an dem ich eine Deutung meiner Beobachtungen versuchen und damit zum Schluss kommen möchte. Ich habe in einem ersten Schritt zu zeigen versucht, wie in und zwischen den Verwandlungserzählungen des Epos die Kohärenz des ,carmen perpetuum' neben der Diskontinuität der Metamorphose steht. In einem zweiten Schritt habe ich auf dieselbe narrative Struktur auch in den naturphilosophischen Passagen der Metamorphosen aufmerksam gemacht. Dort verbindet sich die Kohärenz der auf Ordnungsproduktion ausgerichteten Kosmogonie und des Lehrgedichts mit der Diskontinuität multipler Anfänge und eklektischer Fissuren.

Diese spezifische Verfasstheit des Epos als ,kosmos' und ,textum' zeigt zum einen an, dass mythisches Erzählen und naturphilosophisches Erklären methodisch denselben Weg beschreiten: Beide fragen nach den Aitia, den Ursachen. Sie zeigt darüber hinaus aber auch an, dass zwischen beiden eine strukturell-funktionale Verwandtschaft besteht. Wie der Mythos im eigentlichen Sinn eine Welt- und Lebensbewältigungsstrategie ist, ${ }^{36}$ ist auch für die Naturphilosophie das Wissen um natürliche Phänomene kein Selbstzweck. Ovids Epos, so lässt sich der Eklektizismus des Textes deuten, setzt nicht eine bestimmte naturphilosophische Position um, sondern erfasst vielmehr, was allen philosophischen Schulen gemeinsam ist, was ihre Wahrnehmung der natürlichen Welt als Grundannahme strukturiert. Aus der narrativ-strukturellen Verschränkung von Kosmos und Text, natürlicher und menschlicher Ordnung innerhalb des Epos lässt sich die für die Antike charakteristische Nähe von Naturphilosophie und Ethik ablesen. ${ }^{37}$

Wenn Aristoteles etwa die Entelechie, also „die volle Verwirklichung des der Möglichkeit nach Seienden“, „das Ins-Werk-Setzen (enérgeia) des Möglichen (dýnamis)“ (Gloy 1995, S. 109) als Grundprinzip der natürlichen Welt bestimmt, steht analog dazu in seinen ethischen Schriften das, ergon', der den Anlagen gemäße Gebrauch der menschlichen Kapazitäten, als Weg zur ,eudaimonia‘, zur Glückseligkeit im Vordergrund.

Wenn Platon seinerseits die Lehre von den drei Seelenvermögen des Menschen (Begehren, Mut und Vernunft) zur argumentativen und praktischen Basis seiner politisch-gesellschaftlichen Theorie macht, dann zeigt er damit, „wie sich das Handeln in der Polis an der Physis orientieren könne“ (Martens 1989, S. 31), dass die „Prozesse innerhalb einer Polis [...] denselben Bewegungsgesetzen [gehorchen] wie die Prozesse innerhalb der Natur" (Picht 1990, S. 365). Dieser Zusammenhang gilt in Übertragung auch für das einzelne Individuum. Das Bildungsideal der ,ka-

\footnotetext{
36 So das Hauptargument in Blumenbergs Arbeit am Mythos (1979). In diesem Sinn spricht auch Solodow (1988, S. 74) von mythologischen Themen in antiker Literatur als „a form of language, a common mode of discourse on the topics of human life".

${ }^{37}$ French (1994, S. xif., 166-171); Taylor (2007, S. 60).
} 
lokagathia' (das ,Schöne-Gute), das bei Platon (etwa im Symposion) eine große Rolle spielt, lässt sich als Konzept identifizieren, in dem ästhetisch Schönes, theoretisch Gesetzmäßiges bzw. Wahres und ethisch Gutes zusammenfallen. ${ }^{38}$ ,Kosmos ${ }^{6}$ wird hier als Ordnung in dreifacher Hinsicht fassbar: als Ordnung in der Natur, als Ordnung in der Polis und als Ordnung im Menschen. ${ }^{39}$ An Platons konsequenter Verschaltung von Physik und Ethik, Natur- und Moralphilosophie zeigt sich besonders deutlich: Insofern die ,physis“ als ,kosmos', also als qualitative Ordnung ${ }^{40}$ verstanden wird, kann sie zur Basis ethischer und lebensweltlicher, also ebenfalls qualitativer Fragestellungen werden.

Auch Stoa und Epikureismus machen die spezifische Konstitution der ,physis zur Grundlage ihrer Lebenslehre ${ }^{41}$. Dabei führen so unterschiedliche Konzepte wie das stoische, das den Kosmos als providentielle Weltvernunft, als ,logos ${ }^{6}$ (,Wort', ,Vernunft') und ,fatum ' (,Schicksal') bestimmt, und das epikureische, das den Kosmos als Gebilde aus zufälligen Atomzusammenschlüssen versteht, zu einer im Grunde übereinstimmenden Begriffsbildung in Bezug auf das ethisch richtige Leben. Als zentrale Zielvorgabe philosophischer Betätigung gilt beiden Schulen die Ataraxie (,Unerschütterlichkeit), wenn auch die jeweiligen praktischen Auslegungen dieses Begriffs, in Übereinstimmung mit den generell inkongruenten Vorstellungen vom Kosmos, erheblich voneinander abweichen. Während Ataraxie in stoischer Prägung die tätige Anerkennung des und Fügung in das ,fatum', die kosmische Ordnung meint, ist sie im Epikureismus als Schonung der fragilen Atomkonstitution von Körper und Seele durch ein angst- und erschütterungsfreies Leben gedacht.

Ein letztes, gewissermaßen zusammenfassendes Beispiel: Ausdrücklich betont Lukrez in seinem epikureischen Lehrgedicht: „Mit diesen gelehrten Worten werde ich dir viel Trost spenden“ (DNR V, 113: „multa tibi expediam doctis solacia dictis“). Die Antike kennt kein im modernen Sinn wissenschaftliches Ethos. ${ }^{42}$ Wissen wird nicht um seiner selbst willen erworben, sondern um eine ethisch angemessene Lebensweise zu ermöglichen. Was man über den Kosmos weiß, so das Credo des antiken Naturphilosophen, verrät vor allem etwas über das eigene Leben. Die Ordnung des Kosmos gerät in der antiken Naturphilosophie damit zu

\footnotetext{
38 Gloy $(1995$, S. 96).

39 Taylor (1989, S. 7f., 21, 115ff.); Gloy (1995, S. 145).

40 Der neuzeitliche Begriff des Universums ist im Gegensatz dazu in cartesischer Tradition eine quantitative, nämlich räumliche Vorstellung (Picht 1990, S. 89).

${ }^{41}$ Martens (1989, S. 43).

Zur Verbindung von Ethik und Naturphilosophie bei Seneca vgl. Gauly (2004, S. 87-190).

42 Prägnant bei French (1994, S. xiii): ,there was no such thing as science in the ancient world“.

Das lässt sich auch daran ablesen, dass nicht einmal Lukrez, der doch auf Grund seiner atomistischen, rationalen Weltsicht als Vertreter der ,modernsten' antiken Naturphilosophie gilt, auf die Nennung mehrerer unterschiedlicher Erklärungen für natürliche Phänomene verzichtet und sie sogar ausdrücklich einfordert (DNR VI, 703f.). Wichtig ist für den epikureischen Standpunkt nicht die wissenschaftliche Korrektheit oder Eindeutigkeit solcher Kausalthesen. Entscheidend ist vielmehr, dass es überhaupt Erklärungsmodelle gibt (und hier gilt dann: je mehr, desto besser), die einen direkten Einfluss der göttlichen Sphäre auf das menschliche Leben auszuschließen vermögen.
} 
einer den Menschen zentral mitbetreffenden Ordnung, wie sie auch Ovids Epos in seiner Verschränkung von natürlicher und textueller Ordnung, kosmogonischer Gottheit und epischem Erzähler inszeniert. ${ }^{43}$

Aus diesem Textbefund ergeben sich mindestens drei Deutungsmöglichkeiten, die ich im Folgenden in ihren möglichen Umrissen kurz skizzieren möchte. Sie betreffen den philosophischen Gehalt des Textes, die Figur des Dichters als ,alter deus', die ich aus der Auseinandersetzung der Metamorphosen mit Lukrez' De natura rerum entwickelt habe, und den aus dem Epos ableitbaren antiken Begriff des Kosmos.

Zum einen lässt sich also nach dem Ort der Metamorphosen innerhalb der antiken und vor allem der lateinischen Philosophiegeschichte fragen. Als (natur-) philosophisches Epos sind die Metamorphosen bislang noch nicht untersucht worden, wohl weil sie sich, wie oben gezeigt, einem kohärenten philosophischen Standpunkt konsequent verweigern und stattdessen einen fast spielerischen Umgang mit sehr verschiedenen Positionen pflegen. Vielleicht liegt aber gerade in diesem unübersehbaren und geradezu herausfordernd ostentativen Eklektizismus eine philosophische Schlüsselfigur des Ovidischen Epos vor.

Ich habe bereits angedeutet, dass man diesen Eklektizismus als textuelles Signal einer generalisierenden statt partikulären Ansicht auf die antike Naturphilosophie verstehen kann. Er lässt sich aber auch als strukturelle Reflexion auf den spezifisch römischen Rezeptionsmodus griechischer Philosophie begreifen, insofern ein eklektisches Vorgehen als grundlegende Methode der Aneignung griechischer Philosophie in Rom bestimmbar ist. ${ }^{44}$ Dabei muss gleich der lateinische Text, mit dem man die römische Philosophiegeschichte in der Regel einsetzen lässt, als Ausnahme in zweifacher Hinsicht gelten: Lukrez' De natura rerum referiert nicht nur zusammenhängend die kosmologische Haltung einer einzigen philosophischen Schule, der Epikureer; sein Lehrgedicht ist auch das seltene schriftliche Zeugnis einer Zeit, in der Philosophie in Rom vorrangig entweder mündlich oder in griechischer Sprache betrieben wurde. ${ }^{45}$ Erst Cicero bemüht sich in seinen Schriften systematisch um die adäquate Überführung philosophischer Begriffe in eine lateinische Terminologie, um so den bis dahin (und auch später noch) prekären Status des Lateinischen als Medium der Philosophie aufzuheben. Weil Cicero damit aber weniger genuin philosophische als vielmehr philologische Interessen verfolgt, rezipiert er auch nicht eigentlich eine spezifische Philosophie, sondern einzelne Philosopheme.

\footnotetext{
43 Vgl. Albrecht (1981, S. 2342), der Ovid das Verdienst zuschreibt, den Mythos neu belebt und ihm die Aufgabe zurückgegeben zu haben, „die ihm ursprünglich eigen war: Wege zur Deutung der Natur und des mit ihr verknüpften menschlichen Schicksals zu erschließen“.

${ }^{44}$ Maurach (21997, S. 1f).

${ }^{45}$ Gauly (2004, S. 38-51).
} 
Zieht man diese Entwicklung lateinischer Philosophiegeschichte vor Ovid in Betracht, wären die Metamorphosen also auch mit Blick auf ihren Eklektizismus im Grunde ein Meta-Epos. So wie sie als Epos über verschiedene epische Erzählmodelle (Helden-, Katalog- und Lehrgedicht) fungieren ${ }^{46}$ und so wie sie naturphilosophische Passagen enthalten, die die Prämissen der antiken Naturphilosophie sinnfällig machen und die überdies gerade ein mythologisches Gedicht rahmen und so das (zwischen gegenseitiger Marginalisierung und gegenseitiger Einbeziehung changierende) Verhältnis von Mythos und Naturphilosophie in ihrer Textgestalt umsetzen, läge mit ihnen auch ein lateinisches Rezeptionsbeispiel griechischer (Natur-)Philosophie vor, das gleichzeitig auf die Rezeptionsbedingungen griechischer Philosophie in Rom überhaupt aufmerksam macht.

Zum zweiten möchte ich den Blick noch einmal auf das besondere Verhältnis zwischen kosmogonischer Gottheit und epischem Erzähler in den Metamorphosen richten. Ich habe deren Verschaltung dabei mit Bedacht auf den Begriff des ,alter deus' gebracht, weil er eine Verknüpfung augenfällig werden lässt, die sich in Bezug auf die lateinische Epik sonst eher nicht aufdrängt. Denn der ,poeta alter deus', der Dichter als zweiter Gott gehört als poetologisches Konstrukt eigentlich zu den festen Größen der Genieästhetik des ausgehenden 18. und beginnenden 19. Jahrhunderts. Vom Sturm und Drang bis zur Romantik vollzieht sich eine Bewegung, die die Grenzen zwischen Innerlichkeit und Äußerlichkeit, Ich und Welt, moralischem Eindruck und künstlerischem Ausdruck, Ethik und Ästhetik ${ }^{47}$ grundsätzlich in Frage stellt. Indem es erzählend aus sich heraus neue Welten schafft, erprobt das Genie die poetische und poietische Selbstermächtigung an und mit der Welt: Dichten und Schöpfen, Sprechen und Sein fallen in eins.

Wenn schon nicht das ausgereifte Konzept, so doch wenigstens die Keimzellen dieses produktiv-ästhetischen Umgangs mit den natürlichen Dingen lassen sich nun auch bei Ovid ausmachen, der in seinen Metamorphosen die qualitative, die ästhetische (,Schönheit') wie poietische ${ }^{48}$ (,Kunstwerk') Dimension des philosophischen Kosmos-Begriffs poetologisch ernst nimmt und sie für sein eigenes episches Erzählkonzept fruchtbar macht. In der eigentlich ersten Metamorphose des Epos, der des Lycaon in einen Wolf, kommentiert der Text das Ergebnis der Verwandlung mit einem prägnanten „fit lupus“ (Met. I, 237: „Er wird

\footnotetext{
46 Darüber hinaus stehen die Metamorphosen generell zwischen dem Epos (als Hexametergedicht) und der Elegie (durch die sehr selbständigen einzelnen Episoden, die langen elegischen Klagen) sowie zwischen der Langform des Epos und seiner Kurzform, dem Epyllion. Ovid beteiligt sich mit seinem Epos damit an Diskussionen über Gattungsgrenzen und dem Epiker zur Verfügung stehende Formen.

47 Der Philosoph Charles Taylor hat in den Sources of the self (1989, S. 362ff.) sehr ausführlich dargestellt, wie die Verinnerlichung der ,moral sources“ im 18. Jahrhundert, die Entdeckung eines von externen Einflüssen unabhängigen, eines autonomen Gewissens (,moral sense) die Entwicklung einer Ästhetik der Originalität, der Imagination und des Ausdrucks bedingt.

48 Mit dieser poietischen Konnotation arbeitet übrigens auch Platon, wenn er im Timaios seinen Demiurgen den Kosmos handwerklich-künstlerisch herstellen lässt.
} 
ein/der Wolf"). Das Fehlen von Artikeln im Lateinischen lässt aus der Übersetzung dieser zwei Worte eine ontologische Grundsatzentscheidung werden: Wird aus Lycaon ein Wolf unter vielen? Oder wird er zum Prototyp einer Gattung, zu dem Wolf schlechthin? Wird aus Lycaon, dessen wilder und grausamer Charakter auch nach seiner Verwandlung erhalten bleibt, ein Wolf, weil ihm das Wesen dieses Tieres am nächsten kommt? Oder ist es vielmehr der Wolf, der seinem Urvater Lycaon erst seine spezifischen Züge verdankt? Anders formuliert: Setzt das Epos in dieser markanten Episode die schlichte Darstellung oder die ursprüngliche Entstehung eines natürlichen Phänomens in Szene, zeigt es seine Charakterisierung oder seine Genese?

Die Metamorphosen führen hier ein Sprechen vor, das den Kosmos, indem es ihn mythisch erzählbar macht, ununterscheidbar zugleich beschreibt und herstellt: „Im Sprechen über die Dinge sind die Dinge da“, wie es Gadamer in einem Essay über Griechische Philosophie und modernes Denken (1999, S. 159) formuliert. Die Metamorphosen führen ein Sprechen vor, das zwischen der Beschreibung im Sinne einer Schilderung des Kosmos und der Be-Schreibung im Sinne einer Einschreibung in den Kosmos, das zwischen Text und Kosmos, zwischen Schrift und natürlicher Welt, zwischen Buchstabe und Leben nicht unterscheidet: Das lateinische Wort ,elementum` bedeutet Element bzw. Atom und Buchstabe zugleich, es bezeichnet ganz im Sinne romantischer Wortmystik das Urteilchen des Kosmos wie das Urteilchen der Schrift. ${ }^{49}$ In eben diesem Sinn findet im Epilog der Metamorphosen die eigentlich letzte Verwandlung des Epos statt:

Nun habe ich ein Werk vollendet, das nicht Iuppiters Zorn, nicht Feuer, nicht Eisen, nicht das nagende Alter wird vernichten können. Wann er will, mag jener Tag, der nur über meinen Leib Gewalt hat, meines Lebens ungewisse Frist beenden. [...] Mein Name wird unzerstörbar sein, und so weit sich die römische Macht über den unterworfenen Erdkreis erstreckt, werde ich vom Mund des Volkes gelesen werden und [...] durch alle Jahrhunderte im Ruhm fortleben.

(Met. XV, 871-879: Iamque opus exegi, quod nec Iovis ira nec ignes / nec poterit ferrum nec edax abolere vetustas. / cum volet, illa dies, quae nil nisi corporis huius / ius habet, incerti spatium mihi finiat aevi [...] / nomenque erit indelebile nostrum / quaque patet domitis Romana potentia terris, / ore legar populi, perque omnia saecula fama / [...] vivam)

Es ist die Verwandlung des Dichters in sein Werk, der wir in den Schlussversen der Metamorphosen beiwohnen, eben die Verwandlung von Leben in Buchstabe und von Buchstabe in Leben zugleich, wie es das emphatische, vivam' (ich werde leben') als letztes Wort des Epos signalisiert.

\footnotetext{
49 Hier liegt eine Traditionslinie des Wort-Welt-Verhältnisses vor, die sich weit über die Romantik (man denke etwa an Eichendorffs Wünschelrute) hinaus bis zu Inger Christensens Gedicht Alphabet von 1981 verfolgen lässt.
} 
Aus diesem Sprechen, das die natürliche Weltordnung mit der menschlichen Erzählordnung identifiziert, und damit komme ich zum dritten und letzten Punkt meiner Ausführungen, wird erst in der Neuzeit ein distanzierendes Sprechen, ein Sprechen über den Kosmos, die Natur, später: das Ökosystem. Die zentrale Kategorie eines solchen Sprechens ist dann nicht mehr die der Bedeutsamkeit beider Sphären, menschlicher wie natürlicher, füreinander, sondern die der Funktion, die Mensch und Natur innerhalb der indifferenten naturgesetzlichen Ordnung des Universums oder auch des Ökosystems einnehmen: „We might say that we moved from living in a cosmos to being included in a universe" (Taylor 2007, S. 59). ${ }^{50}$ Der Kosmos, wie ihn die Metamorphosen in Anlehnung an die antike Naturphilosophie vorführen, kann natürlich kein Universum im neuzeitlichen Sinn sein. Er ist aber eben auch kein ,oikos' (urspr. ,Hausgemeinschaft') im Sinne einer objektivierten, beobachtbaren Ordnung. Vielmehr zeigt er sich als ein den Menschen involvierendes ,textum', dessen doppelsinnige Beschreibung konkrete Bedeutung für die persönliche Existenz hat: Arachne kostet die Beschreibung dieses ,textum' in Form ihres Teppichs die menschliche Gestalt, dem Erzähler-Ich hingegen garantiert sie in Form seines Epos das ruhmvolle Weiterleben.

Der moderne Begriff des Ökosystems, das lässt sich an den Metamorphosen ablesen, beerbt die antike Kosmosvorstellung nur mittelbar. Zwar reaktiviert er die Geschlossenheit und Ganzheit des Kosmoskonzeptes, in einem wesentlichen Punkt aber kann er ihm nicht mehr folgen. Statt eine textuelle, und das heißt: sinnhafte Ordnung der Welt zu entwerfen basiert das Ökosystem auf Funktionalitätszusammenhängen und Kausalketten. Der ethisch-qualitative Gehalt des Kosmosbegriffs, den Ovid in seinen Metamorphosen auf so beeindruckende Weise poetologisch wendet, bleibt ihm fremd. Es gilt daher, vor allem im Umgang mit antiken Texten den viel beschworenen, ökologischen Sündenfall` der Neuzeit als unhintergehbaren historischen Bruch ernst zu nehmen, den auch das ästhetisch (und damit letztlich künstlerisch, nicht aber lebensweltlich) grundierte Naturverhältnis der Romantik und in seiner Nachfolge die ganzheitlichen Naturkonzepte der Moderne nicht beseitigen, sondern lediglich verdecken können.

Außerhalb entsprechender Textzeugnisse lässt sich über den antiken Kosmos nur auf zwei Weisen sprechen: naiv (esoterisch) oder sentimentalisch (ökologisch).

\footnotetext{
50 Von Taylor (2007, S. 60) entlehne ich auch die Kategorien der Bedeutsamkeit und der Indifferenz bzw. Funktionalität, die er dem Kosmos („,meaningful“) und dem Universum (,,utterly unresponsive to human meanings") zuschreibt.
} 


\section{Literatur}

Ackermann, Erich (1979): Lukrez und der Mythos. Wiesbaden: Steiner.

von Albrecht, Michael (1981): Mythos und römische Realität in Ovids

„Metamorphosen“. In: Aufstieg und Niedergang der römischen Welt 31.4, S.

2328-2342.

von Albrecht, Michael (2002): Verwandlungs- und Apotheosenberichte in Ich-

Form und die Geburt der poetischen Autobiographie bei Ovid. In: Walz,

Dorothe (Hrsg.): Scripturus vitam. Lateinische Biographie von der Antike bis in die Gegenwart. Heidelberg: Mattes, S. 627-636.

von Albrecht, Michael (2003): Ovid. Eine Einführung. Stuttgart: Reclam.

Ausführliches lateinisch-deutsches und deutsch-lateinisches Handwörterbuch.

Ausgearbeitet von Karl Ernst Georges. Hannover [u. a.]: Hahn 1995.

Bartsch, Kurt (1990): Dialog mit Antike und Mythos. Christoph Ransmayrs Ovid-

Roman „Die letzte Welt“. In: Modern Austrian Literature 23, S. 121-133.

Blumenberg, Hans (1971): Wirklichkeitsbegriff und Wirkungspotential des Mythos.

In: Fuhrmann, Manfred (Hrsg): Terror und Spiel. Probleme der

Mythenrezeption. München: Fink, S. 11-66.

Blumenberg, Hans (1979): Arbeit am Mythos. Frankfurt am Main: Suhrkamp.

Böhme Gernot; Böhme Hartmut (1996): Feuer, Wasser, Erde, Luft. Eine

Kulturgeschichte der Elemente. München: Beck.

Böhme, Gernot (1996): Ästhetische Erkenntnis der Natur. In: Gloy, Karen (Hrsg.):

Natur- und Technikbegriffe. Historische und systematische Aspekte von der

Antike bis zur ökologischen Krise, von der Physik bis zur Ästhetik. Bonn:

Bouvier, S. 118-145.

Boyd, Barbara Weiden (2002) Hrsg.: Brill's Companion to Ovid. Köln, Leiden: Brill.

Crabbe, Anna (1981): Structure and Content in Ovid's „Metamorphoses“. In:

Aufstieg und Niedergang der römischen Welt 31.4, S. 2274-2327.

Dalfen, Joachim (2005): Warum erleben Gestalten des antiken Mythos viele

Metamorphosen? In: Coelsch-Foisner, Sabine (Hrsg.): Metamorphosen.

Heidelberg: Winter, S. 21-38.

Doblhofer, Ernst (1975): Beobachtungen zur Callisto-Erzählung in Ovids

„Metamorphosen“. In: Lefèvre, Eckard (Hrsg.): Monumentum Chiloniense.

Studien zur augusteischen Zeit. Amsterdam: Hakkert, S. 496-513. 
Farrell, Joseph (2007): Lucretian Architecture. The Structure and Argument of the „De natura rerum“. In: Gillespie Stuart; Hardie Philip (Hgg.): The Cambridge Companion to Lucretius. Cambridge: Cambridge University Press, S. 76-91.

French, Roger Kenneth (1994): Ancient Natural History. Histories of Nature. London: Routledge.

Fülleborn, Ulrich (2000): Mythopoesie und das Unverfügbare von Natur und Geschichte in Ransmayrs „Die letzte Welt“. In: Fülleborn, Ulrich (Hrsg.): Besitz und Sprache. Offene Strukturen und nicht-possessives Denken in der deutschen Literatur. München: Fink, S. 417-428.

Gauly, Bardo Maria (2004): Senecas „Naturales Quaestiones“. Naturphilosophie für die römische Kaiserzeit. München: Beck. (= Zetemata 122).

Gadamer, Hans-Georg (1999): Griechische Philosophie und modernes Denken. In: Gadamer, Hans-Georg: Der Anfang des Wissens. Stuttgart: Reclam, S. 151-160.

Gillespie, Sturat; Hardie, Philip (2007) Hgg.: The Cambridge Companion to Lucretius. Cambridge: Cambridge University Press.

Gloy, Karen (1995): Das Verständnis der Natur, Bd. 1: Die Geschichte des wissenschaftlichen Denkens. München: Beck.

Gloy, Karen (1996): Platons Naturbegriff im „Timaios“. In: Gloy, Karen (Hrsg): Natur- und Technikbegriffe. Historische und systematische Aspekte von der Antike bis zur ökologischen Krise, von der Physik bis zur Ästhetik. Bonn: Bouvier, S. 29-41.

Hardie, Philip (1995): The Speech of Pythagoras in Ovid, Metamorphoses 15. Empedoclean Epos. In: The Classical Quarterly 45, S. 204-214.

Hardie, Philip (2007): Lucretius and later Latin Literature in Antiquity. In: Gillespie, Stuart; Hardie, Philip (Hgg.): The Cambridge Companion to Lucretius. Cambridge: Cambridge University Press, S. 111-130.

Harries, Byron (1990): The Spinner and the Poet. Arachne in Ovid's „Metamorphoses“. In: Proceedings of the Cambridge Philological Society 36, S. 64-82.

Harzer, Friedmann (2000): Erzählte Verwandlung. Eine Poetik epischer Metamorphosen. Tübingen: Niemeyer.

Hejduk, Julia Dyson (2009): Ovid and Religion. In: Knox, Peter E. (Hrsg.): A Companion to Ovid. Chicester: Wiley-Blackwell, S. 45-58.

Holzberg, Niklas (1997): Ovid. Dichter und Werk. München: Beck.

Keith, Alison (2002): Sources and Genres in Ovid's Metamorphoses 1-5. In: Boyd, Barbara Weiden (Hrsg.): Brill's Companion to Ovid. Köln, Leiden: Brill, S. 235-269. 
Kenney, E. J. (2009): The Metamorphoses. A Poet's Poem. In: Knox, Peter E.

(Hrsg.): A Companion to Ovid. Chicester: Wiley-Blackwell, S. 140-153.

Knox, Peter E. (2009) Hrsg.: A Companion to Ovid. Chicester: Wiley-Blackwell.

Kuon, Peter (2005): Metamorphosen. Ein Forschungsprogramm für die

Geisteswissenschaften. In: Coelsch-Foisner, Sabine (Hrsg.): Metamorphosen. Heidelberg: Winter, S. 1-8.

Lämmli, Franz (1962): Vom Chaos zum Kosmos. Zur Geschichte einer Idee.

Basel: Reinhardt.

Lucretius Carus, Titus (1992): De rerum natura. Recensuit Jospeh Martin. Stuttgart:

Teubner. (= Bibliotheca scriptorum graecorum et romanorum Teubneriana).

Ludwig, Walther (1965): Struktur und Einheit der Metamorphosen Ovids. Berlin: de Gruyter.

Martens, Ekkehard (1989): Platon. In: Böhme, Gernot (Hrsg.): Klassiker der

Naturphilosophie. Von den Vorsokratikern bis zur Kopenhagener Schule.

München: Beck, S. 29-44.

Maurach, Gregor (1997): Geschichte der römischen Philosophie. Eine Einführung. 2. Aufl. Darmstadt: Wiss. Buchges.

McKeown, James C. (1989): Ovid, Amores. A commentary on Book One. Leeds: Cairns. (= Arca 22).

Myers, K. Sara (1994): Ovid's Causes. Cosmogony and Aetiology in the „Metamorphoses“. Ann Arbor: University of Michigan Press.

Ovidius Naso, Publius (1993): Ovidii Nasonis Metamorphoses. Hg. von Williams S. Anderson. Stuttgardiae [u. a.]: Teubner. (= Bibliotheca scriptorum graecorum et romanorum Teubneriana).

Picht, Georg (1990): Der Begriff der Natur und seine Geschichte. 2. Aufl. Stuttgart: Klett-Cotta.

Ransmayr, Christoph (1988): Die letzte Welt. Mit einem Ovidischen Repertoire. Nördlingen: Greno. (= Die andere Bibliothek; 44).

Ransmayr, Christoph (1991): Die letzte Welt. Mit einem Ovidischen Repertoire. Frankfurt am Main: Fischer.

Rosati, Gianpiero (2002): Narrative Technique and Narrative Structures in the „Metamorphoses“. In: Boyd, Barbara Weiden (Hrsg.): Brill's Companion to Ovid. Köln; Leiden: Brill, S. 271-304.

Schmidt, Reinhard (1938): Die Übergangstechnik in den „Metamorphosen“ des Ovid. Zeulenroda: Sporn.

Schmitzer, Ulrich (2001): Ovid. Hildesheim: Olms. 
Schmitzer, Ulrich (2006): Reserare oracula mentis. Abermals zur Funktion der Pythagorasrede in Ovids „Metamorphosen“. In: Studi Italiani di Filologia Classica 99, S. 32-56.

Solodow, Joseph B. (1988): The World of Ovid's „Metamorphoses“. Chapel Hill: University of North Carolina Press.

Spentzou, Efrossini (2009): Theorizing Ovid. In: Knox, Peter E. (Hrsg.): A

Companion to Ovid. Chicester: Wiley-Blackwell, S. 381-394.

Taylor, Charles (1989): Sources of the Self. The Making of the Modern Identity. Cambridge: Cambridge University Press.

Taylor, Charles (2007): A Secular Age. Cambridge: Harvard Univ. Press.

Tissol, Garth (1997): The Face of Nature. Wit, Narrative, and Cosmic Origins on Ovid’s „Metamorphoses“. Princeton: Princeton University Press.

Tsitsiou-Chelidoni, Chrysanthe (2003): Ovid, Metamorphosen. Buch VIII. Narrative Technik und literarischer Kontext. Frankfurt am Main: Lang.

Wheeler, Stephen M. (2000): Narrative Dynamics in Ovid's „Metamorphoses“. Tübingen: Narr. (= Classica Monacensia 20).

Williams, Gareth D. (2009): The Metamorphoses. Politics and Narrative. In: Knox, Peter E. (Hrsg.): A Companion to Ovid. Chicester: Wiley-Blackwell, S. 154-169.

Zgoll, Christian (2004): Phänomenologie der Metamorphose. Verwandlungen und Verwandtes in der augusteischen Dichtung. Tübingen: Narr. (= Classica Monacensia 28). 



\title{
Ecology / Economy \\ Henry David Thoreau geht spazieren
}

\author{
Frank Kelleter
}

\section{1 „To speak a word for Nature“: \\ Thoreau und die ökologische Imagination}

In einem Essay mit dem schlichten Titel Walking fasst Henry David Thoreau 1862 die Beweggründe seines literarischen Schaffens zusammen. ${ }^{1}$ Wo er darüber schreibe, was er auf seinen Spaziergängen durch die Wälder Neu-Englands gesehen habe, wolle er ein Wort für die Natur sprechen - "to speak a word for Nature" (S. 225). Den Zentralbegriff seiner Literatur setzt Thoreau groß, so wie es andere Autoren der Zeit mit dem Wort God tun. Im Duktus der amerikanischen Transzendentalisten ist das nichts Ungewöhnliches. Thoreau zeigt sich in seinem Text als Anhänger jener selbstbewussten Gruppe von Schriftstellern und Sozialreformern, die sich ab den 1830er Jahren im Städtchen Concord, Massachusetts um den ehemaligen Pfarrer Ralph Waldo Emerson scharte und dort, eine Generation verspätet, die amerikanische Romantik begründete.

„To speak a word for Nature“ ist aber nicht bloß eine romantische Formel. In trügerisch einfacher Semantik verdichtet diese Absichtserklärung das schwierige Ausgangsproblem der gesamten Literatur Henry David Thoreaus. Es geht um die

\footnotetext{
1 Wie viele Essays Thoreaus entstand Walking aus Vorträgen, die zu unterschiedlichen Gelegenheiten überarbeitet wurden. Die Erstveröffentlichung erfolgte kurz vor Thoreaus Tod im Atlantic Monthly; der dort erschienene Text geht auf einen Vortrag aus dem Jahr 1851 zurück, den Thoreau im Folgenden in verschiedenen Versionen unter den Titeln Walking und The Wild hielt. Ich zitiere aus der Ausgabe der Collected Essays and Poems (2001); zur Textgeschichte vgl. dort auch S. 660.
} 
Spannung, die besteht zwischen der menschlichen Sprache und dem, was in dieser Sprache als Natur bezeichnet wird. Für Thoreau ist das ein ökologisches Problem im eigentlichen Sinn: das Problem einer Beziehungslehre. Der Versuch, „to speak a word for Nature", wird deshalb schon im nächsten Satzteil eng geführt auf den Versuch, ,to regard man as an inhabitant, or a part and parcel, of Nature“ (S. 225). Den Mensch als Bewohner der Natur zu beschreiben, als abhängigen Teil eines Systems lebendiger Beziehungen: Dieses Anliegen macht durch seine pure Existenz, mehr noch durch seine Dringlichkeit deutlich, dass ein solcher Blick auf die Natur sich nicht natürlicherweise einstellt. Nature doesn't come naturally to buman language. Für Thoreau steht fest, dass die Natur nicht für sich selbst spricht; es muss für sie gesprochen werden. Und so wie die Natur eines Wortes bedarf, so muss auch der Mensch sich als Bewohner der Natur erst einmal erkennen. Der seltsame Mangel an Selbstverständlichkeit, der diese ökologischen Einsichten trägt, weist darauf hin, dass hier von Lebensformen die Rede ist, die sich zwar gegenseitig als Umwelt dienen, von denen eine aber die eigenartige Fähigkeit entwickelt hat, solches Verhältnis wahrzunehmen, zu beschreiben, zu befragen und sich damit immer auch außerhalb der natürlichen Wechselbeziehungen zu wähnen.

„To speak a word for Nature“: Was im Englischen eco-criticism heißt, wird bis heute von dem Wunsch einer solchen Fürsprache getragen. Das Bemühen, wissenschaftliche Beschreibungsformen für die vielfältigen Beziehungen zwischen menschlicher Literatur und außermenschlicher Umwelt zu finden, hat offenbar eine mehr als nur wissenschaftliche Motivation. In der amerikanischen Variante dieses Unternehmens gilt Henry David Thoreau seit Beginn als Pionier und spiritus rector. Selbst unter den Transzendentalisten, bis auf den letzten Mann und die letzte Frau Vorkämpfer grüner Lebensphilosophien, Apostel ökologischen Bewusstseins, nimmt Thoreau eine Sonderstellung ein. Das verdankt sich vor allem seinem 1854 veröffentlichten Buch Walden, or Life in the Woods, einem autobiographischen Bericht über Thoreaus selbst gewähltes Exil in der Wildnis vor den Toren Concords, wo er mit eigenen Händen eine Hüte baute, in der er zwei Jahre lang ohne gewinnbringende Tätigkeit lebte.

Die Fiktionalisierungsstrategien, mit denen Walden dieses Lebensexperiment in Literatur verwandelt, waren schon Thoreaus Zeitgenossen bekannt (unter anderem kondensierte das Buch den Aufenthalt am Walden Pond auf ein Jahr, um das Erzählgeschehen als zyklische Abfolge zu strukturieren), aber das hinderte Leser zu keiner Zeit an der Schlussfolgerung, Thoreau habe in die Tat umgesetzt, wovon Emerson nur predigte. Die Natur in Walden stellt sich im emphatischen Sinn als eine erlebte dar: Wo Emerson und andere Transzendentalisten vom sicheren Standpunkt ihrer kultivierten Gärten aus über die Natur philosophierten, da hatte sich Thoreau in die Wildnis selbst gewagt und das auch nicht nur als Tourist. Von diesem Effekt lebt Walden bis heute und dieser Effekt wird in Thoreaus späteren Schriften noch verstärkt, wenn dort der autobiographische Impuls mehr und mehr zugunsten einer Beobachterperspektive aufgegeben wird, die die Natur ohne Umweg über eine erste Person 
Singular zur Sprache kommen lassen möchte. Das Ergebnis sind Texte wie The Succession of Forest Trees (1860) und Faith in a Seed (1993), deren Darstellungs- und Argumentationsstil in der Forschung gerne als naturwissenschaftlich bezeichnet wird, ungeachtet ihrer naturromantischen Grundstimmung.

Es ist jedenfalls kein Zufall, dass eines der Gründungsdokumente des amerikanischen eco-criticism, Lawrence Buells 1995 veröffentlichte Studie The Environmental Imagination, der Analyse des Gesamtwerks Henry David Thoreaus gewidmet ist. Thoreau, Nature Writing, and the Formation of American Culture lautet der bemerkenswerte Untertitel des Buches, und aus der Lektüre eines einzigen Autors, ja stellenweise eines einzigen Textes, nämlich der zentralen Schrift Walden, entwickelt Buell ,a broad study of environmental perception, the place of nature in the history of western thought, and the consequences for literary scholarship and indeed for humanistic thought in general of attempting to imagine a more, ecocentric' way of being." (Buell 1995, S. 1)

Ein literaturwissenschaftlicher Blick auf diese Art von Literaturwissenschaft erbringt mindestens zwei Befunde. Erstens fällt auf, dass Buell seinen Gegenstand als Obligation begreift. Buells Interesse an einer Analyse des Naturverständnisses von Thoreau ist untrennbar verbunden mit seinem Interesse, dieses Naturverständnis fortzuschreiben. Buell - und mit ihm weite Teile literaturökologischer Forschung - fühlt sich der environmental imagination, die er untersucht, verpflichtet. ${ }^{2}$

Zweitens lohnt es sich, auf die Eigentümlichkeit einer Situation hinzuweisen, in der wir davon ausgehen, dass uns die Lektüre eines einzigen Autors, ja vielleicht eines einzigen Buches, Aufschluss gibt über ein universales System lebendiger Beziehungen. Diese Situation wird nicht weniger eigentümlich dadurch, dass sie in der Geschichte menschlichen Wissens konstant anzutreffen ist. Nun haben wir natürlich gelernt, dass ein Text immer als Kreuzungspunkt anderer Texte fungiert, weshalb Einzeltexte im strengen Sinn vielleicht gar nicht existieren (so man nicht an das voraussetzungslose Wort Gottes glaubt). Auch der naturwissenschaftliche Umgang mit Texten, etwa den Schriften Charles Darwins, beruht auf der Einsicht, dass Wissen in Texten akkumuliert, so dass es zwar naturwissenschaftliche Klassiker gibt, doch Klassikerstatus leitet sich dabei gerade aus den vielen späteren Texten ab, die ein solcher Einzeltext ermöglicht hat und durch die er weiter geführt und letztlich ersetzt wird. Studenten der Evolutionsbiologie lernen die Grundlagen ihres Gebietes nicht aus einer Lektüre der Origin of Species, sondern aus aktuellen Lehrbüchern.

Buell hat offensichtlich etwas anderes im Sinn, wenn er Walden und weitere Schriften Thoreaus als herausragende Ausdrucksformen einer ökologischen Imagination empfiehlt. Für ihn sind diese Texte Literatur im emphatischen Sinn, also: sprachliche Kunstwerke, Artefakte aus Worten, in denen und mit denen das menschliche Verhältnis zur umgebenden Welt selbst zum Thema und zum Problem wird. So drängt sich die Frage auf, was wir aus literarischen Texten

\footnotetext{
2 Zur weiteren Ausdifferenzierung des anglo-amerikanischen eco-criticism vgl. Alexander Starres Beitrag in diesem Band.
} 
eigentlich über die naturale Umwelt und ihre Geschichte lernen können? Enthält das literarische Datenmaterial wertvolle Hinweise auf die Entwicklung menschlicher Ideen über die Natur? Erfüllt die Literatur vielleicht selbst eine ökologische Funktion in der komplexen Beziehungsgeschichte zwischen Mensch und Umwelt? Beide Fragen eröffnen relevante Forschungsperspektiven und doch bleibt ein Gefühl der Unangemessenheit angesichts der so wenig selbstverständlichen, dabei so dringlichen Art und Weise, mit der im menschlichen Erzählen und Dichten von Natur die Rede ist. Erinnern wir uns deshalb, dass die Ökologie selbst das Wort im Namen trägt, den logos. Ein Wort für die Natur zu sprechen - ökologisch zu reden, zu beschreiben - setzt menschliche Sprache unverzichtbar voraus. Die Frage, was wir aus literarischen Texten über die Natur lernen, sei deshalb mit Blick auf Thoreau wie folgt umformuliert: Was lernen wir eigentlich von der Literatur der Natur über die Natur der Literatur?

\section{2 "The bare possibility of going somewhere“ Natur und Nation in Thoreaus Wanderungen}

Gehen wir aber zunächst einen Schritt zurück. Fragen wir anhand der beiden genannten Forschungsperspektiven, wie sich in den Schriften Thoreaus der Wandel amerikanischer Naturbilder im 19. Jahrhundert niederschlägt - und wie diese Schriften umgekehrt das Verhältnis von Amerikanern und ihrer naturalen Umwelt zwischen der Ära Jackson und dem Bürgerkrieg formieren und beeinflussen.

Als Thoreau zu Beginn von Walking schreibt, er wolle den Menschen als Bewohner und Teil der Natur darstellen, erläutert er, dies erfordere, den Menschen ausdrücklich nicht als ein Gesellschaftswesen zu sehen (,rather than a member of society“, S. 225). Später heißt es, „society“ sei „that culture which is exclusively an interaction of man on man, - a sort of breeding in and in, which produces at most a merely English nobility, a civilization destined to have a speedy limit“ (S. 248). Die Kontrastierung von Natur und Gesellschaft ist für den amerikanischen Transzendentalismus kennzeichnend; sie zeigt, dass hier eine historisch spezifische Variante ökologischen Schreibens vorliegt, eine bestimmte environmental imagination. Vor dem Hintergrund einsetzender Industrialisierung, der durchgreifenden Nutzbarmachung territorialer Ressourcen und der geographischen Expansion der noch jungen Nation reicht es offenbar nicht mehr aus, die Natur als ein gleichermaßen verlässliches wie selbstgenügsames Regelwerk zu beschreiben, dessen gesetzmäßiges Funktionieren der Ordnung menschlicher Interaktionen als Vorbild dienen kann. Der aufgeklärte Gedanke eines politischen Naturrechts (natural right), so eng verknüpft mit dem Gedanken empirisch beobachtbarer Naturgesetze und im Gespann mit ihm ein ideologischer Grundpfeiler der amerikanischen Revolution und Staatsgründung, wird in der Ära Jackson mit einem neuen, in vielerlei Hinsicht opponierenden 
Naturbegriff konfrontiert, der Amerikas unkultivierte Wildnis als das erhabene Andere rationalisierender Landschaftszurichtung feiert. ${ }^{3}$

Entsprechend betont Thoreau die Ziellosigkeit seiner Wanderungen durch die amerikanischen Wälder. Spaziergehen ist für ihn eine hochgradig nutzlose Tätigkeit, eine Kunst im romantischen Sinn, „the art of Walking“ (S. 225): das Gegenteil jeder Mittel-Zweck-Beziehung. Thoreaus Unbehagen am zielgerichteten Streben auf Ertrag und Mehrung, letztlich am Instrumentalismus des kapitalistischen Vorteilsdenkens, spricht aus jedem Satz. Die Tatsache, dass bei Spaziergängen die Hälfte des Weges in der Regel dazu genutzt wird, um wieder nach Hause zu laufen, erscheint ihm so als bedeutsamer Ausdruck eigentumsfixierter Effizienz (S. 226). Wie Karl Marx, der in Europa zur selben Zeit aus der Geschichte menschlicher Ressourcennutzung eine umfassende politische Ökonomie ableitet, sieht Thoreau die Gesamtheit sozialer Beziehungen davon bestimmt, wie die Menschen sich zu ihrer naturalen Umwelt verhalten. Ähnlich erkannte schon Emerson einen engen Zusammenhang zwischen profitorientierter Arbeitsteilung und Selbstentfremdung durch Arbeit, zwischen Ausbeute und Ausbeutung. ${ }^{4}$ Umgekehrt bedeutet das: Ein ökologisch sinnvolles Naturverhältnis würde die menschliche Existenz selbst verändern. Emerson und Thoreau gehen davon aus, dass sich der Mensch, der sich als abhängiger Bestandteil seiner naturalen Umwelt erkennt, damit eine neue Seinsmöglichkeit erschließt. Bei Emerson erscheint diese Utopie konsequent und dramatisch als Aufhebung aller materialen Interessen, als ekstatische Überwindung der eigenen Körperlichkeit; eine berühmte Passage aus Nature (1836) lautet:

In the woods ... I feel that nothing can befall me in life . . Standing on the bare ground, - my head bathed by the blithe air, and uplifted into infinite space, - all mean egotism vanishes. I become a transparent eye-ball; I am nothing; I see all; the currents of the Universal Being circulate through me ... (Emerson 1983, S. 10)

Damit scheint die Spaltung zwischen denkender und nicht-denkender Materie überwunden und die Natur endlich: selbstverständlich.

Im Vergleich zu Emerson geht Thoreau mit solch sublimen Versprechungen sparsamer um. Das mag mit seiner Einsicht in die sprachliche Struktur der romantischen Metaphysik zu tun haben, also: mit seinem Wissen um die Beteiligung menschlicher Dichtung und Rhetorik an ökologischer Fürsprache. Ich

\footnotetext{
${ }^{3}$ Vgl. Kelleter (2002).

4 Vgl. The American Scholar (1837): „Man is not a farmer, or a professor, or an engineer, but he is all. [...] In the divided or social state, these functions are parcelled out to individuals, each of whom aims to do his stint of the joint work, whilst each other performs his. [...] The state of society is one in which the members have suffered amputation from the trunk, and strut about so many walking monsters, - a good finger, a neck, a stomach, an elbow, but never a man. Man is thus metamorphosed into a thing, into many things. The planter, who is Man sent out into the field to gather food, is seldom cheered by any idea of the true dignity of his ministry. [...] The priest becomes a form; the attorney, a statute-book; the mechanic, a machine; the sailor, a rope of the ship." Emerson (1983, S. 54). Alle folgenden Emerson-Zitate nach dieser Ausgabe.
} 
werde darauf zurückkommen. Thoreaus Lob der Nutzlosigkeit jedenfalls ist Emersonianisch genau darin, dass es alles menschliche Wollen, alle körperliche Begehrlichkeit, in einer willenlosen Umwelt auflösen möchte. Ein Spaziergang darf unter solchen Umständen kein Ziel haben; als abhängiges Naturwesen erkennt und verhält sich der Mensch erst, wenn er in der Landschaft aufgeht, statt sie zu durchmessen. Ein in Thoreaus Aufsatz eingelassenes Gedicht formuliert das so:

$$
[\ldots]
$$

What is it, what is it,

$$
\text { But a direction out there, }
$$

And the bare possibility

Of going somewhere? (S. 232)

Einer, der richtig spaziert - einer, der die Kunst des Spazierengehens beherrscht -, wird sich deshalb immer in einem neuen Land finden, egal wohin er läuft: „, One who pressed forward incessantly and never rested from his labors, who grew fast and made infinite demands on life, would always find himself in a new country“. (S. 241)

In einem neuen Land? Thoreau schreibt diese Sätze, wie alle seine Texte, in einem neuen Land. Fragt man also, wie diese Texte und Sätze in das zeitgenössische Verhältnis von Mensch und Natur eingreifen - fragt man, wie sie bestimmte amerikanische Praktiken der Naturnutzung ermöglichen und unterstützen -, so mag Folgendes wichtig werden: Wie gesehen, beharrt Thoreau auf der Gesellschaftsferne echter Spaziergänge: „having no particular home, but equally at home everywhere“ (S. 225), scheint der authentische Spaziergänger alles andere als ein wertvolles Gesellschaftsmitglied zu sein, geschweige denn ein Patriot. 5 Zielloses Wandern führt laut Thoreau an einen Ort mit Sicherheit nicht: den von Kirche, Staat und Volk („Church and State and People“, S. 226). Wie aber so oft im romantischen Schreiben erfordert utopische Heimatlosigkeit auch hier eine passende Negation. Keine „bare possibility of going somewhere“ ohne die geheime Vorstellung eines Zielortes, der Aufhebung verspricht. ${ }^{6}$ Wohin läuft Thoreau also, wenn er in amerikanischen Wäldern umherschweift? Die Antwort lautet: immer nach Amerika. "I believe there is a subtle magnetism in Nature," schreibt er, ,which, if we unconsciously yield to it, will direct us aright. ... There is a right way“. (S. 233)

Dieser rechte Weg, stellt der Erzähler erstaunt fest, führt ihn auf all seinen Wanderungen auch ohne Kompass in immer dieselbe Richtung: „It always settles between west and south-southwest. The future lies that way to me. ... Eastward I only go by force“. (S. 234) Wo er eben noch die Auflösung materieller Interessen,

\footnotetext{
5 Vgl. Walden: „Nations are possessed with an insane ambition to perpetuate the memory of themselves by the amount of hammered stone they leave." Thoreau (1985, S. 368. Alle folgenden Walden-Zitate nach dieser Ausgabe.)

${ }^{6}$ Zur Dialektik romantischer Heimatlosigkeit vgl. Kelleter (1997).
} 
das Ende territorialen Besitzstrebens, als höchsten Ausdruck einer echten Naturbegegnung lobte, da fährt er nun fort: „I should not lay so much stress on this fact, if I did not believe that something like this is the prevailing tendency of my countrymen. I must walk toward Oregon, and not toward Europe“. (S. 234) Damit zurrt die Utopie herrschaftsfreier Wanderschaft, die Metaphysik der „nonreturning curves, in this case opening westward“" (S. 234), zur simplen Paraphrase einer translatio imperii zusammen: „mankind progresses from east to west" (S. 234), summiert Thoreau.

Es lohnt sich festzuhalten: Thoreaus Ablehnung von „Church and State and People“ hindert ihn nicht daran, eine Vorstellung nationaler Identität zu entwickeln. Im Gegenteil: Sein romantisches Naturverständnis erlaubt einen Begriff amerikanischer Nationalität, der umso machtvoller ist, je mehr er sich dem Machtwillen europäischer Nationalismen enthoben glaubt. Mit großer Selbstverständlichkeit verbindet dann auch der Untertitel von Lawrence Buells Studie die Phrasen nature writing und the formation of American culture. Dem liegt die Vorstellung eines idealen Amerika zugrunde, einer stets Neuen Welt, in der die Nation eben nicht durch den Staat und seine Organe gemacht wird, sich auch nicht auf soziale Solidaritätsanlässe wie gemeinsame Herkunft oder kulturelle Bindungen wie einen gemeinsamen Glauben oder eine eigene Sprache berufen muss. Stattdessen entspringt die Existenz der Nation direkt aus ihren naturalen Existenzbedingungen. ${ }^{7}$ Für ein neues Land, und eine postkoloniale Immigrationsgesellschaft allemal, ist das ein verführerisches Naturmodell, denn es weist einen Weg aus der gefühlten Abwesenheit historisch gewachsener Traditionen. (Wie sehr diese Kopplung von Natur und Nation dann genau jene handgreiflichen Umwelteingriffe begünstigt, gegen die sie entworfen wurde, zeigen etwa die sentimentalen Indianererzählungen der Zeit, deren Kritik an Jacksons Imperialismus an dessen Durchsetzung durchaus beteiligt ist.) $)^{8}$

Sicherlich also nimmt die romantische Literatur in den 1830er bis 1860er Jahren eine im weitesten Sinn nationalökologische - eine Beziehungen steuernde Funktion ein. Für die Frage, was man von der Literatur der Natur über die Natur der Literatur lernen kann, ist jedoch ein anderer Aspekt wichtig. Wie gesehen, kulminiert Thoreaus Erstaunen über seine von unsichtbarer Hand gelenkten Wanderrouten in der Einsicht, dass diese individuellen Bewegungen eine allgemeine Tendenz der menschlichen Geschichte zum Ausdruck bringen. In Vorwegnahme einer Gedankenfigur, die 1866 in Ernst Haeckels biogenetischer Grundregel zur vollen Entfaltung kommt, erklärt Thoreau: „I know not how significant it is $[\ldots]$ that an individual should thus consent in his pettiest walks with

\footnotetext{
7 Vgl. Walking zum Zusammenhang von nachhaltigem Wirtschaften und nachhaltiger Nationalität: „The civilized nations - Greece, Rome, England - have been sustained by the primitive forests which anciently rotted where they stand. They survive as long as the soil is not exhausted. Alas for human culture! little is to be expected of a nation, when the vegetable mould is exhausted, and it is compelled to make manure of the bones of its fathers" (243).

8 Zum Motiv des vanishing Indian siehe Berkhofer (1978); Dippie (1982); Lubbers (1994).
} 
the general movement of the race“. (S. 235) Dieses „I know not“ ist irreführend, denn Thoreaus Text weiß sehr wohl, was es mit dieser Entsprechung auf sich hat. So wie sich nämlich im echten Wanderer - ,who presse[s] forward incessantly and never rest[s] from his labors, who grow [s] fast and ma[kes] infinite demands on life, [to] always find himself in a new country" - so wie sich in diesem vitalen Abenteurer die aufstrebende junge Republik selbst spiegelt, growing fast indeed, so stehen für Thoreau die Realitäten eines Einzellebens und die naturale Ordnung in einer irgendwie gearteten Repräsentationsbeziebung. „[T] hese facts are symbolical“ (S. 237), schreibt Thoreau. Damit kehren wir zum Ausgangsproblem der Thoreauschen Literatur zurück: zur Frage nach der Beziehung zwischen der menschlichen Sprache und einer Natur, die diese Sprache einerseits ermöglicht und ihr andererseits als Gegenstand dient.

\section{3 „All things considered“ \\ Die Sprache der Natur in Walking und Walden}

Wenn Thoreau in den Erscheinungen und Läufen der Natur, darunter seinen eigenen Bewegungen als zielloser Spaziergänger, eine Symbolik vermutet, entwirft er die naturale Umwelt selbst in Analogie zu einem kunstvoll geformten Sprachtext. Die Vorstellung, die Natur könne wie ein Buch gelesen werden, ist natürlich nicht neu; in Neu-England gehört sie zur Grundausstattung des intellektuellen Erbes. Die puritanische Typologie des 17. Jahrhunderts betrachtete die koloniale Umwelt von Anfang an als göttlichen Text, der mehr oder weniger genaue Botschaften für die Siedler bereit hielt. Naturale Umwelt fungierte hier als Medium zwischen dem Menschen und seinem Schöpfer. Zweihundert Jahre später ist die Situation komplizierter. Thoreaus Beharren auf der Natürlichkeit menschlicher Existenz - also seine Einsicht in die ökologischen statt gottgegebenen oder umgekehrt sozialen Bedingungen des Menschseins - ersetzt den religiösen Auftrag, die Natur zu lesen, mit dem romantischen Auftrag, die Natur zur Sprache kommen zu lassen: „to speak a word for Nature." Welche literarischen Probleme solch ökologische Fürsprache mit sich bringt, zeigt sich im folgenden Abschnitt aus Walking:

Where is the literature that gives expression to Nature? He would be a poet who could impress the winds and streams into his service, to speak for him; who nailed words to their primitive senses, as farmers drive down stakes in the spring, which the frost has heaved; who derives his words as often as he used them, - transplanted them to his page with earth adhering to their roots; whose words were so true and fresh and natural that they would appear to expand like the buds at the approach of spring, though they lay half-smothered between two musty leaves in a library. (S. 244)

Die puritanisch grundierte Vorstellung, dass die Natur der menschlichen Sprache ähnlich sei, weil sie wie diese mit einer göttlichen Ordnung korrespondiert - diese in 
der Kultur Neu-Englands tief sitzende Annahme, die sich noch in Emersons postchristlichen Schriften findet, ${ }^{9}$ wird hier zugunsten der Hoffnung einer vollen Immanenz von Sprache und Umwelt aufgegeben. Sprache und Natur entsprechen sich nicht, sondern die Sprache, die der Natur Ausdruck gibt, würde selbst zur Natur.

Worte, die aus der Erde wachsen, an deren Wurzeln der Schlamm klebt, die aufgehen wie Blüten; Worte, die hiermit ihren Ursprungssinn, ihre Natürlichkeit, zu erkennen geben: Dieses Sprachverständnis ist maximal weit entfernt von der Beobachtung, ein Wort und seine Bedeutung stünden in willkürlicher Beziehung, so wie es von John Locke 1689 im Essay Concerning Human Understanding konstatiert wurde. Stattdessen glauben Thoreau und Emerson, dass die Bedeutung von Worten motiviert ist, und zwar motiviert aus menschlichen Naturbegegnungen. Das Interesse der Transzendentalisten an Etymologie darf in diesem Sinn als Teil ihres Bemühens um ökologisches Sprechen verstanden werden. ${ }^{10}$ So vermerkt Thoreau an einer Stelle in Walking, die Kunst des Spaziergehens könne die wahre Bedeutung der uns nächsten Worte eröffnen: ,the idea which the word Concord suggests ceases to be suggested“. (S. 252) Das Wort benennt nichts mehr außerhalb seiner selbst, es lebt in seiner Bedeutung. Das Wort wird Atem. Einerseits.

Andererseits kulminiert Thoreaus Vision einer natürlichen Sprache in folgenden, antiklimatischen Sätzen, die sich unmittelbar an die oben zitierte Stelle anschließen:

I do not know of any poetry to quote which adequately expresses this yearning for the Wild. Approached from this side, the best poetry is tame. I do not know where to find in any literature, ancient or modern, any account which contents me of that Nature with which even I am acquainted. You will perceive that I demand something which no Augustan nor Elizabethan age, which no culture, in short, can give. (S. 245)

Eine Unmöglichkeit also. Denn welches menschliche Sprechen wäre nicht Ausdruck menschlicher Kultur? Thoreaus Dilemma entspringt einem unaufhebbaren Paradox im Wort Natur: Ausgesprochen, beschworen, beschrieben, erkannt, gedeutet oder sonst wie zum Gegenstand menschlicher Reflexion gemacht, doppelt sich Natur in einem Teil ihrer selbst und erscheint merkwürdig unnatürlich, verliert Selbstverständlichkeit. Nature doesn't come naturally to buman language. Der Gegensatz, der bei Thoreau zwischen den Attributen einer Natursprache und ihrer reflektierten, mithin kulturellen Existenz besteht, verweist auf die Struktur eines Wunsches, stärker noch: einer Forderung, einer „demand“, wie er es nennt - in jedem Fall: der Erfahrung eines Mangels. Es ist dieser erfahrene Mangel an Natürlichkeit, der Literatur hervorbringt.

\footnotetext{
${ }^{9}$ Vgl. Nature: „It is not words only that are emblematic; it is things which are emblematic. Every natural fact is a symbol of some spiritual fact" (S. 20). Wenig später spricht Emerson von einer „radical correspondence between visible things and human thoughts“: „all spiritual facts are represented by natural symbols“ (S. 22).

${ }^{10}$ Vgl. Emerson, The Poet (1844): „Language is fossil poetry“ (Emerson 1983, S. 457).
} 
Und so handelt Walden, Thoreaus Meisterwerk, vor allem von der Notwendigkeit der Literatur als einer besonderen Art menschlicher Naturbegegnung. Auf den ersten Blick erzählt das Buch von der freiwilligen Rückbesinnung seines Autors auf die grundlegendsten Existenzbedürfnisse. Hinter diesem Experiment der Lebensvereinfachung tut sich aber rasch ein sprachliches, ja artistisches Experiment auf: Indem der Erzähler sein Leben auf die "gross necessaries of life“, „the grossest groceries" (S. 332) Nahrung, Unterkunft, Kleidung und Wärme ausrichtet, eröffnet sich ihm ein neues Verständnis dieser Dinge. Bisherige Zuschreibungen verblassen und werden durch ursprünglichere Wortbedeutungen ersetzt: „Most men appear never to have considered what a house is" (S. 350), lautet ein typischer Satz aus Walden. Entsprechend geht es dem Text darum, die alltägliche Bedeutung grundlegender Worte (bouse, shelter, property) und, darauf aufbauend, komplexer Gedankenfiguren zugunsten ihres angeblich natürlichen Sinns aufzulösen. Wie der Erzähler gleich zu Beginn vermerkt, schreibt er mit dem Ziel, seine Mitbewohner in Concord anzusprechen, „to squeeze their old notions out of them“ (S. 342). Gelingt dies, ist die menschliche Sprache nicht mehr dieselbe: „solitude will not be solitude, nor poverty poverty, nor weakness weakness". (S. 580) Es geht, in einem Wort, um die Neubenennung der Welt - oder nietzscheanisch gesprochen: um eine Umwertung aller Werte, eine Inventur und Bereinigung menschlicher Vokabulare und Konzeptionsmöglichkeiten.

Wie aber gesehen, weiß Thoreau um die Unmöglichkeit einer Menschensprache, in der Erde und Schlamm selbst das Wort ergreifen (ein Ideal eher seines Zeitgenossen Walt Whitman). Deshalb wählt er für seine eigene Rede von der Natur einen anderen Stil. „To speak a word for Nature“, „to regard man as an inhabitant of Nature" heißt in letzter Instanz nun, die NichtDeckungsgleichheit alltäglicher und literarischer Sprache herauszustellen, also: ironisch zu sprechen. Im Erzählverlauf betrifft dies zuerst und in zentraler Weise den Gebrauch des Wortes economy, welches auch als Titel für das erste, lange Kapitel von Walden dient. Vor dem Hintergrund seiner romantischen Anliegen scheint Thoreaus äußerst ausführliche Beschäftigung mit den Schwierigkeiten menschlicher Haushaltsführung, menschlichen Planens und menschlichen Nutzdenkens überraschend. Tatsächlich liegt hierin die Pointe seiner Literaturökologie. Im folgenden Abschnitt beschreibt der Erzähler, wie er lebte, bevor er in die Wälder an den Walden Pond zog:

For many years I was self-appointed inspector of snow storms and rain storms, and did my duty faithfully; surveyor, if not of highways, then of forest paths and all across-lot routes, keeping them open, and ravines bridged and passable at all seasons, where the public heel had testified to their utility.

I have looked after the wild stock of the town, which give a faithful herdsman a good deal of trouble by leaping fences; and I have had an eye to the unfrequented nooks and corners of the farm; though I did not always know whether Jonas or Solomon worked in a particular field to-day; that was none of 
my business. I have watered the red huckleberry, the sand cherry and the nettle tree, the red pine and the black ash, the white grape and the yellow violet, which might have withered else in dry seasons.

In short, I went on thus for a long time, I may say it without boasting, faithfully minding my business, till it became more and more evident that my townsmen would not after all admit me into the list of town officers, nor make my place a sinecure with moderate allowance. My accounts, which I can swear to have kept faithfully, I have, indeed, never got audited, still less accepted, still less paid and settled. However, I have not set my heart on that. (S. 337)

Was geschieht hier? Die Diskrepanz zwischen dem gewählten Vokabular und den beschriebenen Handlungen ist atemberaubend. Das dominante Wortfeld der Passage stammt aus dem Bereich der Ökonomie - der Ausdruck business ist ein Schlüsselbegriff, hier wie in Walden insgesamt ${ }^{11}$-, aber erzählt wird vom vorsätzlichen Nichtstun. Thoreau nennt sich einen „inspector of snow-storms“ und „surveyor of forest-paths“, um zu beschreiben, wie er planlos durch die Landschaft strich, Wetter und Tiere beobachtete. Er kümmerte sich um das Vieh der Stadt in eben dem Sinn, dass ihm bei seinen Streifzügen durch die Landschaft auch mal entlaufene Schweine über den Weg liefen. Kein amtlicher Aufseher von irgendwas, verrichtete er sein Geschäft in der Natur auf andere Weise als sein Wirtschaftsenglisch vermuten lässt. Wer die vorherrschende rhetorische Figur der Ironie im Text bemerkt, kann sich bildlich vorstellen, auf welche Weise dieser begnadete Spaziergänger die genannten Wildpflanzen wässerte.

Das Wort, das hier für die Natur gesprochen wird, stellt seinen literarischen Charakter erstaunlich offen zur Schau. Die rhetorische Figur der Ironie - die herausgehobene Nichtübereinstimmung von Gemeintem und Gesagtem - beherrscht die Naturbeschreibungen von Walden von Beginn bis zum Ende des Buches. Dass es sich dabei nicht bloß um stilistische Spielereien handelt, sondern um ein Kernanliegen dieser environmental imagination, wird spätestens deutlich, wenn der Erzähler die doppelte Bedeutung ökonomischer Ausdrücke auf sein eigenes Schreiben bezieht. Die Begriffe my accounts und being audited benennen in der maßgeblichen Logik wirtschaftlicher Vergleiche zum einen Thoreaus Kontoführung, die seitens der Dorfbewohner nie einer Buchprüfung unterworfen wurde (wie auch, wussten diese Landbesitzer doch nicht, dass sie die Arbeitgeber des Spaziergängers waren). Zum anderen beschreibt der Ausdruck keeping an account das literarisches Schreiben und damit die Herstellung des Buches Walden selbst. „Nothing was given me of which I have not rendered some account“ (S. 370), sagt der Erzähler an anderer Stelle, und in der Tat ist Buchführung ein treffender Ausdruck für den erzählerischen Modus des gesamten ersten Kapitels. Dieses besteht

\footnotetext{
${ }^{11}$ Vgl. etwa: „My purpose in going to Walden Pond was not to live cheaply nor to leave dearly there, but to transact some private business with the fewest obstacles; to be hindered from accomplishing which for want of a little common sense, a little enterprise and business talent, appeared not so sad as foolish“ (S. 338).
} 
nämlich zu weiten Teilen aus Statistiken und Tabellen, in denen Thoreau akribisch aufzeichnet, wie viel Geld er für welche Werkzeuge und Geräte ausgegeben hat, wie viel Arbeitszeit und finanzielles Kapital in den Bau seiner Hütte am See geflossen sind, und welche Ausgaben, etwa für Nahrungsmittel, gegen welche Einnahmen, etwa durch den Verkauf selbst angebauten Gemüses, verrechnet werden können.

Ruft man sich Thoreaus Lob der Nutzlosigkeit ins Gedächtnis, kann sein Interesse an profitablen Tauschgeschäften im Kapitel „Economy“ nur erstaunen. In der Tat sind all diese Rechnungen ironisch. Aber was für eine Art von Ironie! Vor dem Hintergrund des transzendentalistischen Vorhabens einer Umwertung aller linguistischen Werte zeigt sich, dass Thoreau seine ironischen Kontrastbildungen sehr ernst nimmt. Die Diskrepanz zwischen Gesagtem und Gemeintem (etwa wenn ein Landstreicher als tüchtiger Unternehmer beschrieben wird) verschiebt sich hier in letzter Konsequenz auf die Diskrepanz zwischen zwei Arten menschlichen Sprachgebrauchs: eine Diskrepanz, deren überraschende Pointe darin besteht, dass der romantische Nichtsnutz tatsächlich einer höchst ertragreichen Tätigkeit nachgeht. Die Diskrepanz besteht nicht mehr zwischen der Sache und den Worten, sondern zwischen einem alltäglichen Sprachgebrauch, der den Menschen als Gesellschaftswesen behandelt, und einem außergewöhnlichen, literarischen Sprachgebrauch, der den Menschen als Naturwesen erkannt hat. Die Ironie gilt dem sozial etablierten Verständnis von Wirtschaftlichkeit, so wie die Polemik des Buches insgesamt die umgangssprachliche Verwendung solcher Worte wie food, shelter, clotbing usw. der Lüge überführt.

Den Menschen als abhängigen Teil eines größeren Naturgeschehens zu sehen, heißt für Thoreau demnach eine Sprachkritik zu praktizieren, die die tatsächliche Ökologie lebendiger Beziehungen zu Wort kommen lässt. So rechnet er in einer seiner Kostentabellen aus, dass ihm der Umzug von der Stadt in den Wald einen Gesamtprofit von \$ 8 im Jahr eingebracht habe. Zum besseren Verständnis dieses auf den ersten Blick mageren Ertrags erläutert der Erzähler: „All things considered, that is, considering the importance of a man's soul and of to-day . . . I believe that that was doing better than any farmer in Concord did that year". (S. 366) To do better ist erneut ein ökonomischer Ausdruck, doch seine Ironie liegt sicherlich nicht im dürftigen numerischen Maß einer solchen Wertsteigerung (\$8 im Jahr), sondern in der Gedankenlosigkeit, mit der die fraglos besser verdienenden Bauern von Concord das Missverhältnis zu ihren Gunsten auslegen. Die Ironie liegt in den Worten ,all things considered“, denn in einer umfassend umweltbewussten Gesamtrechnung darf Thoreau zufolge eines nicht fehlen: „considering the importance of a man's soul and of to-day". Ist diese Sicht- und Beschreibungsweise erst einmal eingenommen, dann erweist sich auch das Urinieren im Wald als eine ökologisch höchst nutzbringende Tätigkeit.

Semantische Umwertungen aus der Perspektive einer übergreifenden Umweltlehre: Diese abstrakte Formel umschreibt den ganz und gar nicht abstrakten Reiz von Walden, das bemerkenswert spielerische Charisma dieses Buches, seine selbst- 
bewusst literarische Qualität. Wo sonst kann man lesen, und lesend verstehen, dass ein Reisender seine Nachbarstadt schneller erreicht, wenn er dorthin läuft statt die Eisenbahn zu nehmen? Wer nämlich zu Fuß geht, erklärt Thoreau, der kann sich direkt auf den Weg machen, während der Eisenbahnfahrer sich erst noch seine Fahrkarte verdienen muss - und am Ende hat er mehr Zeit damit verbracht, zu arbeiten als zu reisen (vgl. S. 364). Der Wunsch nach natürlicher Existenz und nutzlosem Leben mündet hier in einer ironischen Sprache des resoluten Utilitarismus. Für eine Natur zu sprechen, die nicht für sich selbst spricht, heißt bei Thoreau unumgänglich, Aussagen im Bereich menschlichen Nutzens und menschlicher Bedürfnisse zu treffen. Es geht diesem Schreiben nachdrücklich ums Ganze: um das menschliche Leben selbst. Der Wunsch des Erzählers von Walden ist es, so sagt er, sein Leben nicht zu spielen, sondern von Anfang bis Ende ernsthaft zu leben. ${ }^{12}$ Nicht um die Natur zu sehen, zieht er demnach in die Wälder, sondern um dort die eigene Menschlichkeit als natürlich zu erfahren. Das Ergebnis ist unweigerlich Literatur, Fiktion. In der es heißt:

I went to the woods because I wished to live deliberately, to front only the essential facts of life, and see if I could not learn what it had to teach, and not, when I came to die, discover that I had not lived. I did not wish to live what was not life, living is so dear; nor did I wish to practise resignation, unless it was quite necessary. (S. 394)

\section{Schluss: Ökologie / Ökonomie}

Gemessen an den utopischen Ansprüchen, die Thoreau an eine aus der Erde selbst entspringende „literature that gives expression to Nature“ stellt, müssen die kalkulierten Ironien von Walden als gescheitert gelten. Was also kann man von dieser Literatur der Natur über die Natur der Literatur lernen? Vielleicht dies: dass selbstverständliche Natur nur als Wunsch aus Worten existiert, dass Ökologie nur als Problem menschlicher Kultur und Sprache denkbar ist. Kein Zweifel somit, dass literarische Texte Aufschluss geben über die Wandlungen und Schwankungen im menschlichen Verständnis von Natur. Und sicherlich übernehmen sie damit eine Steuerungsfunktion im Verhältnis von Mensch und naturaler Umwelt. Der Übergang von einem Naturverständnis zu einem nächsten ist nicht denkbar ohne die Konkurrenz textlich verfasster Naturmodelle. Kulturrevolution findet nicht einfach in Texten statt, sie wird durch Texte betrieben, gehorcht den Regeln literarischen Wettstreits und intertextueller Distinktion (und nicht nur dem, was dieser oder jener Autor in seiner Umwelt gesehen hat). Leben, das sich selbst beschreibt, streitet sich darüber.

\footnotetext{
12 Vgl.: „I mean that [students] should not play life, or study it merely, while the community supports them at this expensive game, but earnestly live it from beginning to end“ (S. 363).
} 
Bemerkenswert bleibt die historische Beharrlichkeit, mit der sich Texte und ganze Kulturen darüber streiten, was die herrschenden Beziehungsverhältnisse zwischen Mensch und Natur seien - und damit die Spaltung zwischen denkender und nichtdenkender, dichtender und nicht-dichtender Materie immer aufs Neue bestätigen. Zahllos sind die literarischen Inszenierungen, philosophischen Forderungen, naturwissenschaftlichen Nachweise einer Überwindung des kategorial fehlerhaften Dualismus von Mensch und naturaler Umwelt. Was bleibt, ist der Dualismus von Mensch und naturaler Umwelt im fortgesetzten Wunsch, ihn zu überwinden. ${ }^{13}$

Mit einem letzten Wort über die Natur ist demnach kaum zu rechnen. Stattdessen scheint die menschliche Erfahrung von Natur vor allem eines hervorzubringen: immer neue, oft letzte Worte über und für die Natur. Mit Thoreau erreichen wir dabei eine Form von nature writing, die sich ihrer sprachkritischen Impulse und damit ihrer Konkurrenzbeziehung zu anderen Formen menschlicher Rede über die Natur hochgradig bewusst wird. Das Ergebnis ist romantische Ironie: eine Ironie, die ihren Gegenstand eminent ernst nimmt: eine Rhetorik, die Wissen und Hoffnung in der Schwebe halten möchte.

Wer will, kann das Konstruktionswissen dieser Literatur gegen ihre romantischen Hoffnungen in Stellung bringen. Bereits im zeitgenössischen Umfeld findet eine solche De-Konstruktion von Thoreaus nature writing statt, in Edgar Allan Poes verbissener Auseinandersetzung mit den Transzendentalisten Neu-Englands. Aus solcher Perspektive ist es durchaus der Rede wert, dass der Erzähler von Walden aus seiner Erzählung eines weitgehend ausklammert, nämlich die Tatsache, dass sein autobiographischer Protagonist nicht deshalb nur in eine Waldhütte zog, um echtes Leben zu leben, sondern auch und vor allem, um dort ein Buch zu schreiben. Thoreau verrichtete in seiner natürlichen Abgeschiedenheit ein hohes Pensum schriftstellerischer Arbeit und produzierte mehrere hundert Seiten Literatur am Walden Pond. ${ }^{14}$

Für uns, 160 Jahre später in einer anderen Umwelt mit anderen Sprachpraktiken hält diese Situation immer noch einiges bereit. Nicht zuletzt die Einsicht, dass für die menschliche Sprache jede Ökologie eine Ökonomie beinhaltet, so wie jedes ziellose Umherwandern einen heimlichen Zielort ansteuert. Es gibt keine Natur ohne Nutzen: ein Dilemma, das sich für Thoreau nur noch ironisch ausdrücken lässt, mit einer Rhetorik, die wie keine andere die NichtDeckungsgleichheit von Mensch und Umwelt erfahrbar macht. Vielleicht sind wir hier an einem Ursprung aller Literatur angelangt (über den in evolutionären Literaturtheorien nur selten spekuliert wird, wohl weil sein Paradox nicht mehr ins

\footnotetext{
13 Vgl. die Debatte über Neonaturalismus im Journal of Literary Theory: Kelleter (2007); Eibl (2007); Kelleter (2008).

$14 \mathrm{Vgl}$. den ersten Absatz von Walden, der das literarische Projekt anspricht, um es sogleich durch ein anderes zu verdecken: „When I wrote the following pages, or rather the bulk of them, I lived alone, in the woods, a mile from any neighbor, in a house which I had built myself, on the shore of Walden Pond, in Concord, Massachusetts, and earned my living by the labor of my hands only. I lived there two years and two months. At present I am a sojourner in civilized life again“" (S. 325).
} 
Erklärungsmuster natürlicher Adaption passt): beim Wunsch, die Natur möge in menschlichen Kommunikationen selbst das Wort ergreifen. Wie der Wunsch nach einem gotterfüllten Sprechen, und eng verwandt mit diesem, erfüllt sich dieser Wunsch im Lauf der menschlichen Geschichte endlos in Mythen, Religionen, Erzählungen, zuletzt ironischen Selbstreflexionen - um durch jede dieser Erfüllungen erneut vereitelt und wieder aktualisiert zu werden. Leben, das sich selbst beschreibt, hört damit nicht mehr auf. 


\section{Literatur}

Berkhofer, Robert F. (1978): The White Man's Indian: Images of the American Indian from Columbus to the Present. New York: Knopf.

Buell, Lawrence (1995): The Environmental Imagination: Thoreau, Nature

Writing, and the Formation of American Culture. Cambridge: Harvard University Press.

Dippie, Brian (1982): The Vanishing Indian: White Attitudes and U.S. Indian Policy. Middletown: Wesleyan University Press.

Eibl, Karl (2007): On the Redskins of Scientism and the Aesthetes in the Circled Wagons. In: Journal of Literary Theory 1.2, S. 421-441.

Emerson, Ralph Waldo (1983): Essays and Lectures. Hg. von Joel Porte. New York: Library of America.

Kelleter, Frank (1997): Die Moderne und der Tod: Das Todesmotiv in moderner Literatur, untersucht am Beispiel Edgar Allan Poes, T.S. Eliots und Samuel Becketts. Frankfurt am Main: Peter Lang.

Kelleter, Frank (2002): Amerikanische Aufklärung: Sprachen der Rationalität im Zeitalter der Revolution. Paderborn: Schöningh.

Kelleter, Frank (2007): A Tale of Two Natures: Worried Reflections on the Study of Literature and Culture in an Age of Neuroscience and Neo-Darwinism. In: Journal of Literary Theory 1.1, S. 153-189.

Kelleter, Frank (2008): The Polemic Animal (or, How I Learned to Stop Worrying and Love Partisan Politics). A Reply to Karl Eibl. In: Journal of Literary Theory 2.1, S. 127-154.

Lubbers, Klaus (1994): Born for the Shade: Stereotypes of the Native American in United States Literature and the Visual Arts, 1776-1894. Amsterdam: Rodopi.

Thoreau, Henry David (1985): A Week on the Concord and Merrimack Rivers. Walden; or Life in the Woods. The Maine Woods. Cape Cod. Hg. von Robert F. Sayre. New York: Library of America.

Thoreau, Henry David (2001): Collected Essays and Poems. Hg. von Elizabeth Hall Witherell. New York: Library of America. 


\section{Der verbrecherische Hahnenfuß: Wilhelm Lehmanns Bukolisches Tagebuch ${ }^{1}$}

\section{Heinrich Detering}

Vor der Lektüre des Lederstrumpf wurden wir gewarnt. Es gebe da furchtbar lange Landschaftsschilderungen, die müsse man überspringen und sich möglichst zielstrebig der action zuwenden, damit dauere es ohnehin lange genug. „Landschaftsschilderungen“ oder „Naturbeschreibungen“: solche Vokabeln benennen für viele Leser den Inbegriff dessen, was sie in Romanen als abschreckend empfinden; sie halten auf und zögern hinaus, worauf allein es doch ankommt: die Handlung.

Mir ging es schon mit dem Lederstrumpf ganz anders. Das einzig wirklich Fesselnde an Coopers Prosa, deren melodramatische Verstiegenheiten und psychologische Klischees der scharfblickende Mark Twain kritisiert hat, waren diese Ausblicke auf unendlich weite Waldlandschaften, über die meeresartigen Buchten der Großen Seen, die nur von wilden Tieren durchstreiften Berge von Ländern, die indianische Namen wie „Massachusetts“ oder „Connecticut" trugen. Männer wie den einsamen Reiter Chingachgook in dieser Umgebung zu sehen, tat dem jugendlichen Leser gut; in seiner Gestalt, seiner Kleidung, seinem Pferd schien sich dieses Land selbst verkörpert zu haben, und für den Leser war er, der letzte der Mohikaner, so etwas wie der wandernde Blickpunkt, durch dessen kundige und allzeit wach spähende Augen man diese Wälder und

\footnotetext{
${ }^{1}$ Dieser Beitrag geht zurück auf einen Vortrag vor der Wilhelm-Lehmann-Gesellschaft in Eckernförde, der in deren Schriften veröffentlicht wurde: Merlinszeit. Wilhelm Lehmann braucht ein Haus in Eckernförde. Hg. von Uwe Pörksen. Göttingen: Wallstein 2010 (= Journal der Wilhelm-LehmannGesellschaft; 4).
} 
Berge, Seen und Ströme erblickte, als sei man selbst hier aufgewachsen, ein Einheimischer, ein Mann der Wildnis.

Später - nicht sehr viel später eigentlich - kamen Bücher hinzu, die ein ähnliches Leseglück bereithielten, nur dass die Landschaften sich geändert hatten, vertrauter und gerade darum doch auch wieder fremder wurden. Mit ihnen aber stellte sich dann auch ein bestimmter Typus von Enttäuschung ein, der seitdem nie wieder ganz verschwunden ist. Das muss erklärt werden. Nach wunderbaren Wanderungen mit meinem Vater durch den Bayerischen Wald, zu den Felsen des Dreisessel im bayerisch-österreichisch-böhmischen Dreiländereck und zum Rosenbergergut, auf dem der österreichische Dichter namens Adalbert Stifter gelebt haben sollte (man sah die Totenmaske an der Wand), las ich zuhause zum ersten Mal die Novelle, die in ebendieser märchenhaft weltfernen Landschaft spielende Erzählung. Sie heißt Der Hochwald und beginnt mit einer unvergesslichen - ja: Landschaftsschilderung. Einer Naturbeschreibung. In einer, wie ich heute weiß, auch erzähltechnisch nie dagewesenen Virtuosität und dabei vollkommen ruhig und gelassen lässt Stifter seine Erzählkamera aus den Tiefen eines dunklen Waldstücks in die Totale hinaufgleiten, hoch über die Wälder und Länder, und überblickt mit einemmal aus buchstäblich himmlischer Perspektive, was kein Mensch dieser erzählten Welt jemals sehen könnte: alle Schauplätze der kommenden Handlung, als ein zusammenhängendes Ganzes; dann zoomt er sich wieder hinein in einen einzigen verborgenen Waldwinkel, streift zwischen den Stämmen umher und über Wiesen, macht die Stille hörbar, zeigt uns die überwachsenen Ruinen einer seit unvordenklichen Zeiten zerfallenen Burg und verharrt beim Anblick eines schwarzen, runden Waldsees, der - und das ist so etwas wie eine Pointe in dieser Naturbeschreibung - auf den Erzähler, den Betrachter, uns Leser zurückblickt, ein dunkles Auge, aus dem diese Landschaft selbst uns anschaut.

Und dann, mitten in dieser traumverlorenen Einsamkeit, geschieht das Entsetzliche. Der Erzähler fordert uns auf, die Burgruine in Gedanken bitte rasch wieder zur alten Schönheit erstehen zu lassen, in Windeseile zieht er vor unseren Augen Mauern und Wände wieder hoch, möbliert die Räume und setzt, dies alles ist das Werk weniger Zeilen, in sie hinein zwei Figuren, die sich unterhalten. Wir sind in der Zeit des DreiBigjährigen Krieges, die Figuren sind da, die Handlung kann beginnen. Aber was heißt hier Handlung? Die ganze unvergleichliche Eröffnungssequenz hindurch hat der Erzähler uns gezeigt, wie der Wald selbst reines Geschehen sein kann - und nun sitzen, wie Staffagefiguren des Historismus, die lieblichen Burgfräulein mitten im Bild und verdecken die Aussicht. Dieselbe Enttäuschung wiederholt sich im Laufe der folgenden Kapitel, nur etwas langsamer. Kaum nämlich haben wir uns an den erleichternden Gedanken gewöhnt, dass diese Mädchen und ihr braver Vater doch nur Varianten Chingachgooks sind, des letzten Mohikaners, dass wir mit ihrem noch von keiner Straßenlaterne geblendeten Blick, von keinem Motorenlärm betäubten Ohr diese Landschaft wahrnehmen, wie keiner von uns sie heute mehr wahrnehmen kann, kaum haben wir mit ihrer Hilfe wieder diese Bäume, Wiesen, Seeufer in Einzelheiten 
erlebt, von denen wir nicht im Traum gewusst hätten, und in einer glühenden Eindringlichkeit, einer suggestiven Intensität der Farben, der Laute und Gerüche, als hätten wir vor der Lektüre verbotene Substanzen konsumiert - kaum also war der Wald, im Ganzen und in seinen unendlich verzweigten Gliedern, zur eigentlich handelnden Figur geworden, geschah doch wieder das Unvermeidliche, Vertraute, Banale, das immer und immer wieder Geschehende: Irgendein schwedischer Ritter tritt aus dem Tann, redet feierlich von der Verwandtschaft der germanischen Völker, das eine Burgfräulein verliebt sich in ihn, das zweite sieht der Romanze zu, der Ritter muss in den Krieg ziehen, die Geschichte geht ihren Gang, und aus ist der Traum von Wald und Wiese. Was Figur war, wird Kulisse.

Diese Enttäuschung war, ich sagte es schon, die erste von vielen. Wer vermochte einen Gang über die öde Heide so zu schildern wie Theodor Storm, der Zauberer, der einen Fußweg durch die weitläufigen Wiesen nördlich von Husum so vergegenwärtigte, dass man die Insekten im hohen Gras schwirren hörte, den Duft von Pflanzen ahnte, die womöglich im Augenblick der Lektüre längst ausgestorben waren, die Ahnungen endloser Ferne spürte, die ihm beim Aufblicken von diesem belebten Boden zu den Füßen des Wanderers über die offene Landschaft durch den Sinn gingen? Und dann hielt der Wanderer an den überwachsenen Mauern einer seit unvordenklichen Zeiten zerstörten Burg an, dachte laut, dies müsse das alte Grieshuus sein, und prompt tat wieder der Historismus sein unfassbar banales Zerstörungswerk und bevölkerte die Ruine, die Heide, das Land mit irgendwelchen Rittern und Fräuleins, die redeten wie die Römer bei Felix Dahn, nämlich ,historisch', und die Landschaft, die eben noch der eigentliche Held gewesen war, zum Hintergrund eines Kriegs- und Liebeshändels erniedrigten. Ich war tatsächlich fassungslos, immer wieder machte ich neue Anläufe und stürzte von neuem ab. Selbst in den höchsten Rängen ging es mir so, ich gestehe es mit einer gewissen Verlegenheit, in Prousts Recherche, deren erster Band mir geradezu vorkam wie das weltliterarisch größte Muster dieser Kippfigur. Denken Sie nur: 248 Seiten lang haben wir Marcel auf den Wegen seiner Kindheit begleitet, durch die Weißdornhecken von Combray, zu Dorfkirchen und Gehöften, und auch wenn wir dabei einer Menge Leute begegnet sind, ganzen Familien sogar und unterschiedlichen sozialen Ständen, so waren sie doch immer und allesamt Teil dieses fremden und verzauberten Landes, um das allein es in der wunderbar epischen Fülle von Marcels Erinnerung ging - bis auf Seite 249 Eine Liebe von Swann beginnt und alles, aber wirklich alles sich darum dreht, ob ein Mädchen namens Odette wieder einen Neuen hat oder doch noch beim Alten bleibt. Nicht dass ich je an der unendlich subtilen Erzählkunst dieses und der folgenden Bände gezweifelt hätte. Nur trauerte ich noch immer den Weißdornhecken nach und den blühenden Gärten in der Gegend von Guermantes, auf die man ja leider bis zum letzten warten muss.

So geht es fast immer. Wo die Literatur zu tun begann, was doch zu ihren schönsten und wichtigsten Aufgaben gehörte: uns die Welt zu zeigen, die wir im Alltag bloß behandeln, in der wir unsere eigenen Geschichten ausagieren und die 
wir darum ohne die Literatur fortwährend übersehen würden - da rannten unerbittlich wieder die Leute ins Bild und machten sich mit Liebesgeschichten oder Kriegshändeln wichtig, als sei dies alles nichts als ihre Bühne.

Mit dieser Enttäuschung war ich zu meinem Erstaunen nicht allein. Mit ungläubiger Erleichterung las ich viel später in einem Essay über Storms Erzählungen, dass es dessen Verfasser an genau derselben Stelle in Storms Zur Chronik von Grieshuus genau so gegangen war wie mir. Dieser Verfasser hieß Wilhelm Lehmann. ${ }^{2}$

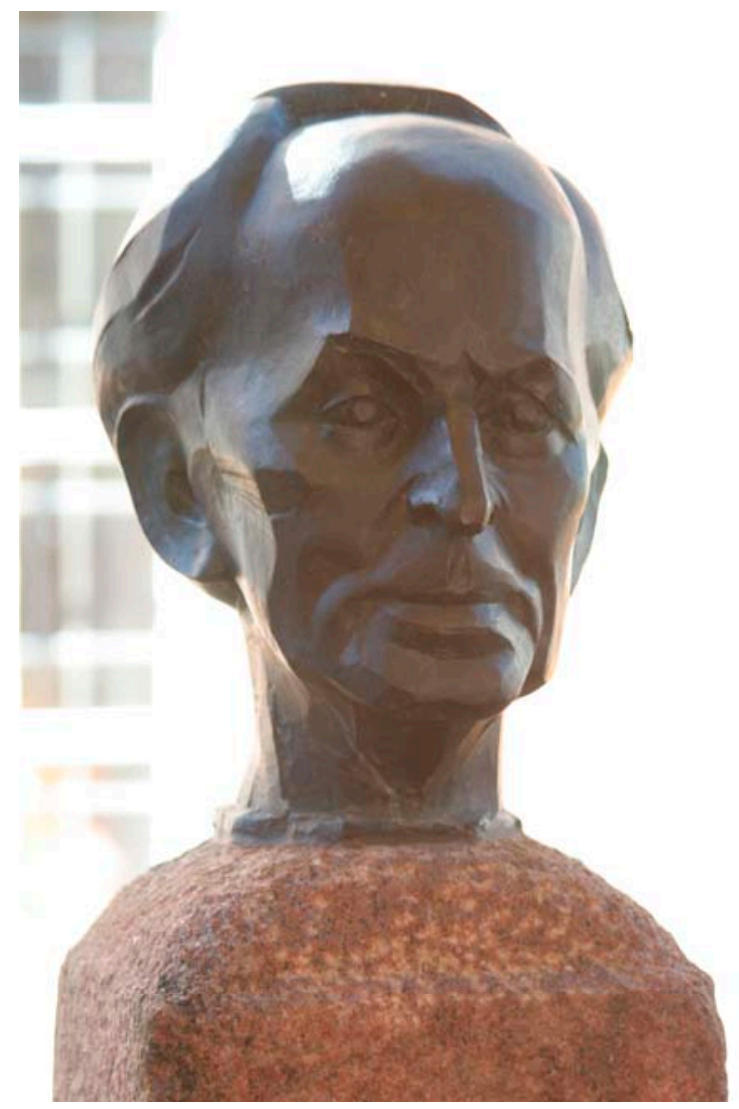

Abb. 1: Wilhelm Lehmann.

Büste von Manfred Sihle-Wissel auf dem Eckernförder Rat-hausplatz (Foto: Lutz Eneik)

${ }^{2}$ Lehmann (1956). 
Und er hatte, wie ich nun erfuhr, aus derselben Enttäuschung heraus genau das Buch geschrieben, das ich immer hatte lesen wollen. Es spielte, das besagte der Untertitel, in „den Jahren 1927-1932“", und es hieß Bukolisches Tagebuch. ${ }^{3}$ Dieses Buch ist etwas Grundsonderbares, nach meiner Überzeugung ein Hauptwerk dieses Dichters; und auch wenn es als einzige Einzelausgabe seiner Werke noch immer im Buchhandel erhältlich ist, steht, so scheint mir, seine Bekanntheit im umgekehrten Verhältnis zu seinem poetischen Rang. Das Bukolische Tagebuch ist kein Tagebuch, wie man es nach dieser Gattungsbezeichnung erwartet, auch kein aus Tagesgeschehen und Reflexionen gemischtes literarisches Tagebuch wie etwa bei Lehmanns Zeitgenossen Ernst Jünger, sondern es ist ein Tagebuch im ganz wörtlichen Sinne der Erga kai Hemérai, der Werke und Tage des Hesiod. Es ist der Roman einer alltäglichen Natur-Welt als Figur, nicht als Grund; die Epopöe einer Landschaft als Landschaft, und es laufen wahrhaftig keine anderen Figuren durch die Szene und winken in die Kamera.

Dabei geht es doch von der ersten bis zur letzten Seite auch um Menschen; nichts wäre so abwegig wie der scheinbar naheliegende Tadel, Lehmann ergehe sich in menschenferner und weltfremder Waldeinsamkeit, ein neuromantischer wie die Literaturkritik in der Nachkriegszeit gern spottete - Bewisperer von Astern und Huflattich. Der erste Mensch, der in Lehmanns Tag- und Nachtwanderungen durch die Landschaften der Eckernförder Bucht eine Rolle spielt, ist eben dieser Wanderer selbst - nicht etwa weil er sich mit sich selbst beschäftigte, sondern in der Weise, in der er, und diesen Ausdruck sollte man beim Wort nehmen, von sich absieht. Wir glauben diesen Erzähler schon nach wenigen Seiten zu kennen, weil wir ja fortwährend seinen Blicken folgen, mit ihm ganz Auge und Ohr sind für Vogelrufe und Spinnweben, Strandhafer und Weißdornhecken. Was in ihm vorgehen mag, in welchen sozialen Beziehungen er lebt, in wen er verliebt ist und was seine berufliche Karriere macht: das alles ist verschwunden, weil der geheimnisvolle Weg hier ganz nach außen geht und nicht nach innen, weil hier keine gefühlige Innerlichkeit in Rede steht, sondern nichts Geringeres als die Welt - verstanden, gesehen, gehört, gerochen, betastet als das Zuhandene und Erlebte, als tragender Grund, umgebende Alltagswirklichkeit und wirkliches, mit größter Aufmerksamkeit und nicht nachlassender Neugier beäugtes Gegenüber. Die Einsicht, dass „Mücke und Gras, Qualle und Wasser und Wolke Welten für sich sind“ (S. 206) ${ }^{4}$, formuliert die Voraussetzung für diese Begegnung, dieses wahrhaft romanwürdige Ereignis.

Lehmann schildert seine Alltagswelt so, als erblickte er sie - und als erblickten wir sie mit ihm - zum ersten Mal. So sehen einige seiner Abende aus: „Gegen den abglimmenden Himmel versteinen blaugrau vierzehn Fischreiher.“ (S. 212) Oder: „Blauer Rauch der Kartoffelkrautfeuer zögert durch die ergrauende Luft. Es wird

\footnotetext{
31948 schrieb Lehmann noch eine schmale Fortsetzung, auf die ich hier nicht eingehe.

4 Zitiert wird nach der Werkausgabe Band 8 unter Angabe der Seitenzahl; um das Auffinden der zitierten Passagen auch in der Einzelausgabe zu ermöglichen, gebe ich aber jeweils auch die Daten der Einträge an. Hier: 20.5.1928.
} 
wasserweibkühl.“ (S. 222) Oder: „abends beginnen die Frösche zu quaken, und die Nacht berührt nur kurz die gern atmende Erde.“ (S. 245) In der Nacht dann stehen die Baumstämme ,aalfarbig dunkel“ (S. 292), und darüber fliegt „,schattenzart der graue Fliegenschnäpper.“ (S. 247) Wenn hier ein Schmetterling durch das Zimmer flattert, dann sieht das aus wie folgt: „Weiße Querbänderung, Zacken der Vorderflügel und ein verhaltenes Gelbbraunrot, von dick aufliegenden weißen Punkten durchsetzt, glühte und hauchte surrend ans Fenster." (S. 195) Und in der Simultaneität der Sinneseindrücke entstehen Formen einer Synästhesie, die verwandten Ausdrucksformen des Expressionismus die Präzision der Wahrnehmung voraus hat und die darum wohl noch niemand vor Lehmann so formuliert hatte: „Stücke des Amselgesangs stemmen sich gegen den Wind, der die Magnolie entblättert.“ (S. 295)5

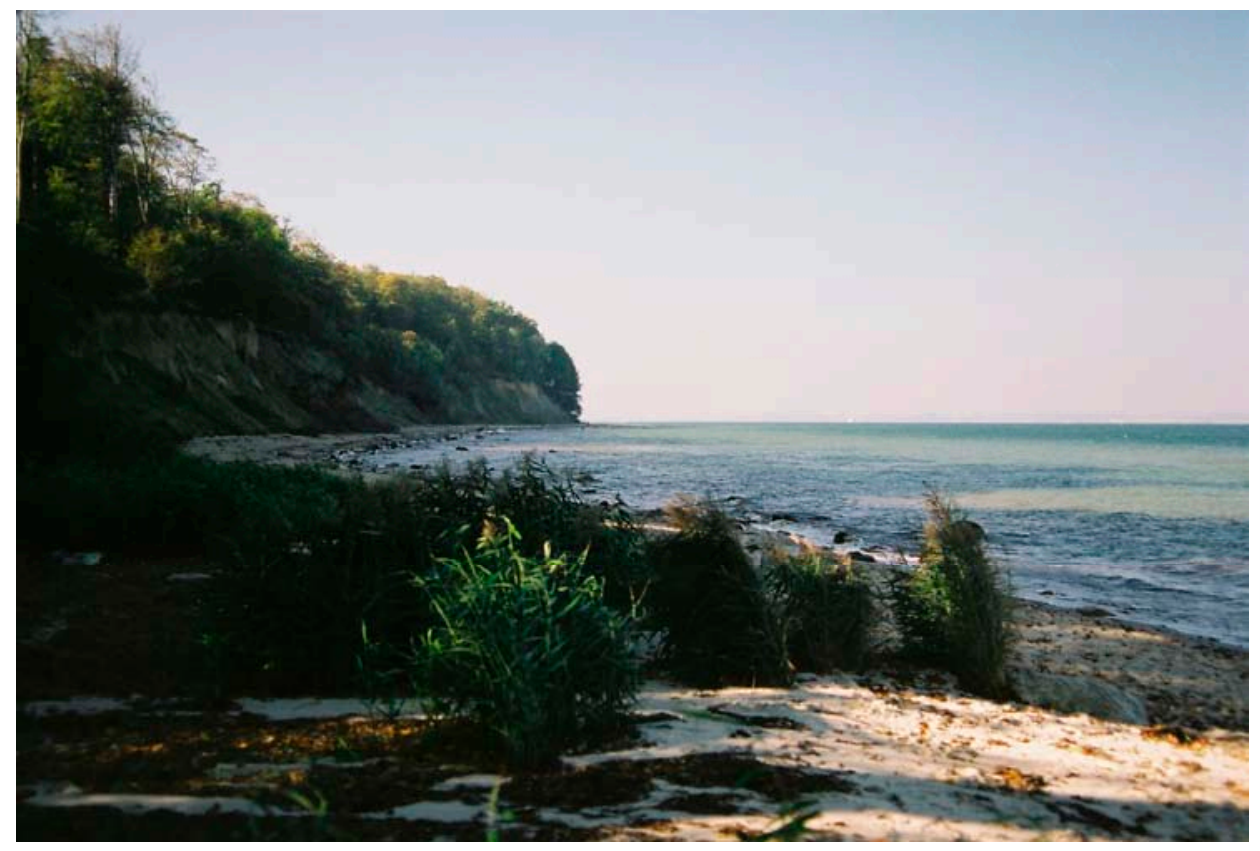

Abb. 2: Eckernförder Steilufer (Foto: Maren Ermisch)

Es gibt hier Schilderungen von großer Zartheit, es rührt einen, wie sie dastehen: „Als ich das Steilufer [...] entlangging, blätterten meine Finger einen vorjährigen, grauschwarzen Kelch der Flockenblume auf [...], und ich entdeckte ein hellrot gezeichnetes Räupchen. Geborgen wie die Phantasie in der derbsten Wirklichkeit lag es da.“ (S. 233) Aber Lehmann sucht nicht das Idyll, sondern die Wirklichkeit. Mit derselben präzisen Aufmerksamkeit, mit der er vermerkt: „Die Lappen des

${ }^{5}$ Einträge vom 15.7.1928; 10.10.1928; 10.5.1929; 10.5.1931; 24.6.1929; 27.2.1928; 9.6.1931. 
Blasentangs sind blank wie Gelatine“ (S. 234) oder „Der wilde Knoblauch züngelt als zierlich geschwungenes, grünes Peitschchen“"(S. 199), notiert er auch die folgende Beobachtung - und man fragt sich, ob jemals vor ihm ein Dichter das gesehen hat -: „Die Fliegen finden sich erstarrt, an Scheiben und Wände geklebt mit einem ausstrahlenden kleinen Gewebe dünner Fäden, einem Pilzgeflecht, das sich ihrer Eingeweide bemächtigt hat." (S. 259) ${ }^{6}$ Und immer wieder finden sich bei diesem lyrischen Epiker Prosa-Passagen, die als solche manchmal Versform annehmen, wie von selbst. Über einen Starenschwarm im Baumwipfel: „Die ganze Krone schwatzt und quirlt und schnalzt. In muskulösem Fluge verstricken sie sich dann zu Wolken Lebens.“ (S. 218) Oder: „Klein verschwindet der Dampfer in der weiten Bucht.“ (S. 220) Oder: „Der Wind stößt plötzlich nach Norden um, er beißt den Nebel weg - die Wiesen liegen tot vergilbt.“ (S. 305) Manchmal bedürfte es nur eines anderen Zeilenumbruchs, und eine Art fragmentarischer Odenstrophe würde sichtbar: „Doch unter dem Schutz des starken Gebälks träumen die Gutshöfe, die Wasserburgen dem Winter zu." (S. 220)7

Lehmanns Bukolische Tagebuch ist damit das genaue Gegenteil nicht nur alles konventionellen Erzählens, sondern auch jener unsäglich platten und programmatisch so genannten „Heimatkunst“, die „los von Berlin“ und zurück zu Blut und Boden wollte und die leider gerade im Schleswig-Holstein der späten Kaiser- und dann der Zwischenkriegszeit eine ihrer traurigsten Brutstätten hatte, von Adolf Bartels' völkischer Verklärung eines längst anachronistisch gewordenen Großbauerntums bis zu Gustav Frenssens Glaube der Nordmark, der ihm 1938 noch die Goldene Ehrennadel des Führers einbrachte, und bis zur nachträglichen Vereinnahmung auch noch von allem reaktionären Muff so spinnefeind fernen Dichtern wie eben Theodor Storm zu Vorkämpfern einer faschistischen Heimatdichtung. Dieser Wilhelm Lehmann ist auch kein südschleswigscher Hermann Löns und kein Ganghofer der Ostseeküste. Sondern er ist ein Avantgardist mit Blick für die Botanik. Wer das Programm seines Bukolische Tagebuch verstehen will, muss ganz andere Autoren zum Vergleich heranziehen.

Niemand, so scheint mir, erklärt das, worum es auch Lehmann eigentlich geht, so präzise und pointiert wie einer der Wortführer der russischen Avantgarde im weltgeschichtlichen Umbruchsjahr 1914, der Dichter und Dichtungstheoretiker Viktor Skklovskij, den Lehmann vermutlich so wenig gekannt hat wie Šklovskij ihn. Ich zitiere eine Passage aus Šklovskijs frühem Essay Die Erweckung des Wortes von 1914:

Heute ist die alte Kunst tot, eine neue ist noch nicht geboren; tot sind auch die Dinge, - wir haben die Empfindung der Welt verloren; wir sind wie der Geiger, der den Bogen und die Saiten nicht mehr fühlt, wir sind nicht mehr Künstler unseres Alltags, wir lieben unsere Häuser und unsere Kleider nicht und trennen uns leicht von einem Leben, das wir nicht empfinden. Nur die Schaffung neuer

\footnotetext{
${ }^{6}$ Einträge vom 14.1.1929; 28.1.1929; 27.3.1928; 30.10.1929.

${ }^{7}$ Einträge vom 15.9.1928, 20.9.1928, 1.4.1932 und vom 10.10.1928.
} 
Formen in der Kunst kann dem Menschen das Erlebnis der Welt zurückgeben, die Dinge erwecken und den Pessimismus töten. Wenn wir in einem Anfall von Zärtlichkeit oder Bosheit einem Menschen liebend zusprechen oder einen Menschen beleidigen wollen, dann genügen uns die verschlissenen, abgenagten Worte nicht, dann ballen und zerbrechen wir sie, damit sie das Ohr treffen, damit man sie sehen kann und sie nicht nur wiedererkennt.

Die Nähe dieser Sätze zu Hofmannsthals Chandos-Brief oder zu Rilkes Malte Laurids Brigge ist unverkennbar, und sie ist genauso bemerkenswert wie diejenige zu Döblins und Bertolt Brechts Suche nach einem „,anti-aristotelischen Roman“ und zu den impliziten Grundlagen von Lehmanns Prosa. Dass sein Bukolische Tagebuch die Welt im Garten, am Strand und im Moor wiederentdecken will und nicht in den Sinneseindrücken der Großstadt, sollte über diese grundlegende Verwandtschaft nicht hinwegtrügen. Lehmanns Nähe zur Avantgarde wird schlagend sichtbar, wenn man etwa seine Pflanzenbilder zum Vergleich neben die eines zeitgenössischen Autors stellt, der den Futuristen sehr viel offensichtlicher verwandt war als der vermeintlich neuromantische Lehmann.

Die Tigerlilie. Lilium tigrinum. Sehr stark zurückgebogene Blütenblätter von einem geschminkten, wächsernen Rot, das zart, aber von hoher Leuchtkraft und mit zahlreichen ovalen, schwarzblauen Makeln gesprenkelt ist. [...] Staubgefäße von der narkotischen Farbe eines dunkelrotbraunen Sammets, der zu Puder zermahlen ist. Im Anblick erwächst die Vorstellung eines indischen Gauklerzeltes, in dessen Inneren eine leise, vorbereitende Musik erklingt. (Jünger 1979, S. 179)

Es ist Ernst Jüngers surrealistisches Prosabuch Das abenteuerliche Herz, das mit diesen Sätzen beginnt, geschrieben in demselben Jahr 1929, in dem Lehmann am Bukolische Tagebuch arbeitet; und es ist gut möglich, dass Jünger in Berlin die Vorabdrucke aus dieser Arbeit zur Kenntnis genommen hat. Will man Lehmanns Schreibgestus im historischen Kontext bestimmen, so müsste er wohl irgendwo zwischen Oskar Loerkes Naturdichtung und Jüngers „stereoskopischem“ Schreiben seinen Ort finden, und nicht weit entfernt von Viktor Šklovskij oder Alfred Döblin - jenem Alfred Döblin, der mitten aus seiner futuristischen Großstadtdichtung heraus 1923 den Entschluss gefasst hatte, den bedeutendsten Avantgarde-Preis der Weimarer Republik, den Kleist-Preis, zwischen zwei jungen Autoren zu teilen. Der eine hieß Robert Musil, der andere Wilhelm Lehmann.

Wer Döblins Prosa dieser Jahre mit derjenigen Lehmanns vergleicht, wird nicht nur den offensichtlichen Gegensatz der Sujets und Motive bemerken, sondern auch die erst auf den zweiten Blick wahrnehmbare Ähnlichkeit der sinnlichen Sensibilität, die Hingebung an den einzelnen Anblick, den besonderen Laut, die kleinste körperliche Erschütterung. „Ein sanfter Pfiff von der Straße herauf“, beginnt der Prolog zu Döblins Roman Die drei Sprünge des Wang-lun 1916: 
Metallisches Anlaufen, Schnurren, Knistern. Ein Schlag gegen meinen knöchernen Federhalter. [...] Die Straßen haben sonderbare Stimmen in den letzten Jahren bekommen. Ein Rost ist unter die Steine gespannt; an jeder Stange baumeln meterdicke Glasscherben, grollende Eisenplatten, echokäuende Mannesmannröhren. Ein Bummern, Durcheinanderpoltern aus Holz, Mammutschlünden, gepreßter Luft, Geröll. Ein elektrisches Flöten schienenentlang. Motorkeuchende Wagen segeln auf die Seite gelegt über den Asphalt; meine Türen schüttern. Die milchweißen Bogenlampen prasseln massive Strahlen gegen die Scheiben, laden Fuder Licht in meinem Zimmer ab. (Döblin 2007, S. 7)

Das elektrische Flöten der Trambahn und das Flöten des Rotkehlchens - sie sind einander näher als Borby und Berlin. Wie Döblin im weiteren Verlauf dieses Prologs den Fortschrittswahn mit dem variierten Bibelvers kontrastiert „Im Leben dieser Erde sind zweitausend Jahre ein Jahr", so liest man in Lehmanns Tagebuch: „das Nu der Schöpfung bedeutet nach irdischem Zeitmaß ein Jahrtausend oder mehr“ (S. 217) ${ }^{8}$. Und wie Döblin sein Buch schließlich „dem weisen alten Manne / Liä Dsi“ (Döblin 2007, S. 8) widmet, so sind auch Lehmanns Aufzeichnungen durchzogen von Anspielungen auf die taoistische Philosophie.

Schon auf der neunten Seite zitiert Lehman zum ersten Mal, ohne den Namen zu nennen, ein Wort des Laotse; weitere folgen. ${ }^{9}$ Das wichtigste aber erscheint erst Ende April 1929: Das betrachtende Auge wird, so schreibt Lehmann, „von der zarten Kraft des Salomonssiegels überredet, daß das Leise stärker als das Laute, das Zarte als das Grobe, das Weiche als das Harte ist.“ (S. 242) $)^{10}$ Das Salomonssiegel zitiert hier gewissermaßen eine zentrale Passage aus dem Büchlein Taoteking des Laotse, in dem um dieselbe Zeit auch Döblin und kurz nach ihm der junge Bertolt Brecht auf ebendiese Verse stießen. Der Satz, dass das Zarte stärker als das Harte sei, wird noch zweimal wiederholt; dreimal erklingt er im Laufe des Bukolische Tagebuch, wie ein langsamer Gong. Mit den Augen des Laotse blickt Lehmanns Tagebuch in die Welt, weil er „sich gewöhnt hat, die Landschaft als einen schwingenden Zustand zu betrachten, in dem ein Augenblick in den anderen vergleitet, die Hügel wie Wolkengestalten schwimmen, Form zu Form eilt" (S. 263) ${ }^{11}$.

\footnotetext{
830.8 .1928$.

${ }^{9}$ Der anglistisch orientierte Lehmann las Laotse nicht wie Brecht und andere Dichter der Moderne in der deutschen Nachdichtung Richard Wilhelms, sondern, wie Verena Kobel-Bänninger im vorzüglichen Kommentar der Werkausgabe erläutert, in der englischen Übersetzung: Laozi: The Sayings of Lao Tzu. London 1909 (jetzt im DLA).

10 Wiederholt zu Ostern 1930 (8, 264) und am 5.1.1931 (8, 285).

11 18.3.1930. Der Anklang an Rilkes Orpheus-Sonett Wandelt sich rasch auch die Welt / wie Wolkengestalten ist wohl beabsichtigt.
} 
Auch der immer wieder genannte, zitierte oder umschriebene Goethe wird in solchen Sätzen mit taoistischen Augen gelesen - oder umgekehrt Laotse mit Goethe, an dem Lehmanns Aufmerksamkeit für organische Metamorphosen, Gestaltwandel und schöpferische Formung erklärtermaßen geschult ist. ${ }^{12}$ In den ersten Augusttagen 1929 wird aus dem Gedicht eines ungenannten Verfassers zitiert: „Und durchs Auge schleicht die Kühle / Sänftigend ins Herz hinein.“ (S. 252) Das steht in einer Dichtung, die wie eine unsichtbare Brücke zwischen Goethe und dem Taoteking erscheint: in Goethes Chinesisch-deutschen Jabres- und Tageszeiten.

Solche Bezüge fügen sich so zwanglos ins Natur-Geschehen ein, dass man sie, wenn man nicht bewusst darauf achtet, kaum bemerkt. Gerade darum ist Lehmanns Diarium ein Goethe'sches und ein taoistisches Buch, das Zeugnis einer ganz und gar weltzugewandten Lebens-Mystik. Wie Laotse selbst lehrt die Anemone, wie man zu leben hat: „niemandem zugehörig, jedem ausgeliefert, Hingabe ans Unermeßliche." (S. 290) ${ }^{13}$ In manchen Momenten, so erfährt Lehmann und so lässt er uns im Lesen erfahren, werden wir als Beobachtende ganz eins mit der beobachteten Welt, dann ,denken wir in Düften - dann ist es, als geriete unter der menschlichen Aufmerksamkeit jede Gebärde des Planeten vollkommener, und die Flucht der Zeit sammelt sich zu ewiger Gegenwart." (S. 248) ${ }^{14}$ Es ist die Erfahrung des Mystikers, und das Medium seiner Meditation ist nicht die Beobachtung, sondern erst das Schreiben über sie. Wie Hofmannsthal formuliert hatte, ein Gedicht erkenne man daran, dass es „sicher [...] schweben [macht] im Sturz des Daseins“ (Hofmannsthal 2009, S. 148), so soll für Lehmann das Schreiben dieses Tagebuchs nicht weniger bewirken als die Aufhebung jener Zeit, die in der Datierungen der Einträge als Oberflächenphänomen festgehalten wird.

Diese stets mitlaufenden Reflexionen über die linear verstreichende Zeit der Datumsangaben, die mit den Jahres- und Tageszeiten zyklisch in sich zurückkehrende, kreisende Zeit und die Aufhebung der Zeit im stehenden Augenblick des entzückten Daseins: sie erweisen sich mit dem Fortgang des Buches auch als strukturbestimmend. Aufzeichnungen aus den Jahren 1927 bis 1932 kündigt der Untertitel an, doch im Verlaufe dieses Jahrfünfts tritt eine unmerkliche Beschleunigung ein. Je weiter die lineare, die geschichtliche Zeit voranschreitet, desto deutlicher tritt aus der Flucht der Erscheinungen das Wiederkehrende hervor; es ist, als würden in einem Orchester unter dem Gewimmel der Streicher- und Bläserstimmen nach und nach die ruhig schwingenden Bassläufe hörbar. Man kann das nachzählen.

12 „Sehr schön“, notiert Lehmann Mitte März 1930, „kann man an der Christrose den Wandel des Organs im Goetheschen Sinne beobachten, $[\ldots]^{“}(8,261)$.

13 25.3.1931.

14 24.6.1929. 
Das Tagebuch setzt im Herbst 1927 ein, 55 Seiten braucht es für die Zeit bis Ende 1928. Das Jahr 1929 ist dann bereits nach 30 Seiten zu Ende, das Jahr 1930 nach 23. Für das Jahr 1931 werden noch zwanzig und für das Jahr 1932 werden nur etwas mehr als fünf Seiten benötigt; diese letzten Einträge stammen aus dem März, April, August und Oktober: Vorfrühling, Frühling, Sommer und Herbst. Denkt man sich eine konsequente Fortsetzung dieses Buches über das letzte Datum hinaus, es würde in kurzer Zeit gleichsam aus sich selbst heraus verstummen; was danach übrig bliebe als eine derart markierte Lücke, eine deiktische Ellipse, das wäre die Antwort des Schweigens. Und genau so lautete dann ja auch bekanntlich der Titel des Gedichtbandes, den Lehmann zweieinhalb Jahre nach dem Ende dieses Tagebuchs dem Lärmen der mittlerweile an die Macht gelangten Naziherrschaft entgegenstellte.

Der Geschichte aber wendet dieses Buch, wendet der neugierig beobachtende und mitschreibende Wanderer in ihm, so demonstrativ den Rücken zu, dass es fast schon nicht mehr demonstrativ ist. Als sei da gar nichts gewesen außer dem Schwalbenzug und dem stummen Sterben der Quallen, vergehen die Jahre, die in den täglichen Datierungen nur noch wie bedeutungslose Zahlen erscheinen, 192S. 1929, 1930. Ein einziges Mal blitzen die Schrecken der Zeitgeschichte herein in diese Jahres- und Tageszeiten. Das geschieht am 14. Oktober 1929, wenn auf „,meine Klagen über die Wirtschaftslage“ (über die wir nichts weiter erfahren) der Gutsverwalter antwortet, „,man solle die Zeit nicht mit unfruchtbarem Räsonnieren vergeuden“, woraufhin er „vom Eigensinn der Dinge“ spricht (S. 257). Mag sein, dass die Weltwirtschaftskrise, die hier ja immerhin in Rede gestanden hätte, keine Kleinigkeit ist. Aber klein sind ja auch die eigensinnigen Dinge nicht, die Levkojen zum Beispiel, für deren Schönheit man die letzten schäbigen Münzen gern hingibt, als seien sie ohnehin nur wertloses Zeug: „Für drei häßliche Fünfpfennigstücke erhalte ich die rotviolette Pracht." (S. 279)15

Kein Zweifel, diese Abwendung von der Geschichte hat etwas Großartiges, und sie ist ja auf ihre Weise sehr wohl eine geschichtliche Stellungnahme. Über seinen politisch engagierten Freund Frank Warschauer hat der junge, noch nicht marxistische Brecht 1920 notiert: „Er hat zuviel Ziel in sich, er wickelt in alle Verhältnisse Sinn, er glaubt an Fortschritt“ - und Brecht hat dann hinzugefügt: „Aber er zeigt mir Lao-tse, und der stimmt mit mir [...] überein“. (Brecht 1994, S. 168) ${ }^{16}$ Dass „das Leise stärker ist als das Laute, das Zarte als das Grobe, das Weiche als das Harte ist", das ist, im Zitat des Laotse, auch Lehmanns Glaubensbekenntnis im Bukolische Tagebuch. Aber man erinnere sich: Als Brecht, ins Exil gejagt, nach einer Orientierung suchte zwischen dem von den Nazis verwüsteten Deutschland auf der einen und dem stalinistischen Terror auf der anderen Seite, da erzählte er die Legende von Laotse und dem Büchlein Taoteking noch einmal. Und diesmal, 193S. lässt er den Weisen, der sich schon aus der bösen Welt zurückziehen wollte ins

15 10.9.1930.

16 Ausführlicher dazu Detering (2008). 
Schweigen, auf das Drängen des armen Zöllners von seinem Ochsen absteigen und die Lehre davon zu Papier bringen, wie man die Gewalt besiegen kann. Lehmanns Laotse, vom Bukolische Tagebuch bis zur Antwort des Schrweigens, handelt entschieden anders als Brechts Laotse: er weist den Zöllner zurück. Für ihn gibt es, wenn die Güte im Lande wieder einmal schwächlich ist und die Bosheit an Kräften wieder einmal zunimmt, nur den Weg in die Ruhe der geschichtsfernen Gegenwelt. Alles andere erscheint ihm illusionär, verfehlt, verboten.

Gleich im ersten, unter der Überschrift Der Wanderer und der Weg schon vorab veröffentlichten Prosastück, spricht Lehmann von der Dichtung als „der einzigen zweiten Welt der hiesigen“ (S. 177). Sie ist ihm Mythos und Religion und Politik, sie allein gibt dem Dasein Sinn und wehrt alle Mächte des Bösen ab - allein indem sie die Wurzeln des Daseins, dies ist für Lehmann der eigentliche Vorgang der Mythogenese, in Worte fasst. Manchmal scheint das Traumziel dieser Prosa erreicht, dann werden die Schrift und die Zeichensprache der Natur beinahe eins. Am 19. November 1928 liest man: Die „Kapsel einer Kaiserkronenstaude vom August her entleert flache, hellbraune Samenblätter zwischen meine Buchstaben.“ (S. 225) Und im Juni 1930 kommt es ihm beim Schreiben seines Tagebuchs so vor, „als besitze man die wache Sinnlichkeit Merlins.“ (S. 270) ${ }^{17}$ Lebenslang hat er diesen Vergleich geliebt, und hier ist er wahrhaftig am Platz. Der Zauberpriester des keltischen Mythos sieht dem Dichter-Wanderer in der bukolischen Welt der Eckernförder Bucht tatsächlich ähnlich.

Die Wirksamkeit dieses Programms freilich hängt von den Veröffentlichungsumständen mehr ab, als dem Autor lieb sein konnte. Die Erstveröffentlichung des Bukolische Tagebuch erschien in Fortsetzungen in der Berliner Sonntagszeitung Die Grüne Post von 1927 bis 1932 und 1935, unter dem Titel Vor den Toren; als Autor firmierte, horribile dictu, ein „Kantor Lehmann“. Es ist im Ernst die Rolle des armen Dorfschulmeisters, die dem Verfasser damit zugeschrieben wird (und einmal nennt er sich im Text wirklich selber so: „der Kantor"); als müsse das Berliner Zeitungspublikum an diese Prosa erst durch biedermeierliche Genre-Erinnerungen gewöhnt werden. Einzelne Texte wurden dann 1933 und 1935 auch in der in Wien und Prag erscheinenden Kulturzeitschrift Die Welt im Wort und im Berliner Tageblatt veröffentlicht, unter den Titeln Monatsbilder, Abschied vom Oktober, November und Land im November und unter dem korrekten Autornamen Wilhelm Lehmann. Das Erscheinen der ersten Buchausgabe aber, die doch schon seit den dreißiger Jahren geplant war (ein umfangreiches Typoskript hat sich erhalten), verzögerte sich dann infolge von NS-Herrschaft und Krieg bis in das Jahr 1949. Und auf einmal (und ohne dass sich Wesentliches am Text geändert hätte) wirkte auf viele Leser fatal, was im Erstdruck so unanfechtbar groß und schön gewesen war.

17 6.6.1930. 
Das war begreiflich, und es war doch verfrüht. Denn genau dort, wo das Buch tatsächlich ins Schweigen überging, auf der letzten Seite, die ja eben nicht einfach das Ende, sondern ein Ausblick sein sollte: genau an dieser Stelle hat Lehmann 1949 energisch in den Text eingegriffen, durch die Streichung der letzten neun Wörter. Das Schlussnotat, der letzte Eintrag, vom 14. Oktober 1932, lautet in dieser überarbeiteten Version:

Es ist so still, wie es nur im Herbst sein kann. Der Baum opfert. Die kleinen wilden Äpfel umwallt es wie Weihrauch. Sie fallen in den Schlamm, sie geben sich zurück der Stille, die nach dem dumpfen Klang anschwillt. Wachstum löst sich in Duft auf. Das Opfer wird angenommen. (S. 309)

In den Vorabdrucken hatte es danach noch geheißen: „Paradiesische Ruhe, herrliche Wehmut nach dem Ende der Zeiten.“ (S. 707) Das streicht der Autor 1949 ersatzlos - und gibt mit diesem kleinen Eingriff dem gesamten Buch eine andere Wendung. Nun endet es in dieser sonderbaren, halb magischen halb liturgischen Wendung: mit einem Opfer, das die Natur selber bringt - als sei es ein Sühnopfer für alle Sünde, an die man beim Apfelbaum denken darf, aber nicht muss. So war vom Autor dieser Prosa ein Wort zur Zeit zu bekommen, nur so und auf keine andere Weise. So hatte er 1932 und 1935 gegen die Zeit reden wollen, so wollte er es 1945 tun, so setzte er beharrlich die Natur gegen die Geschichte.

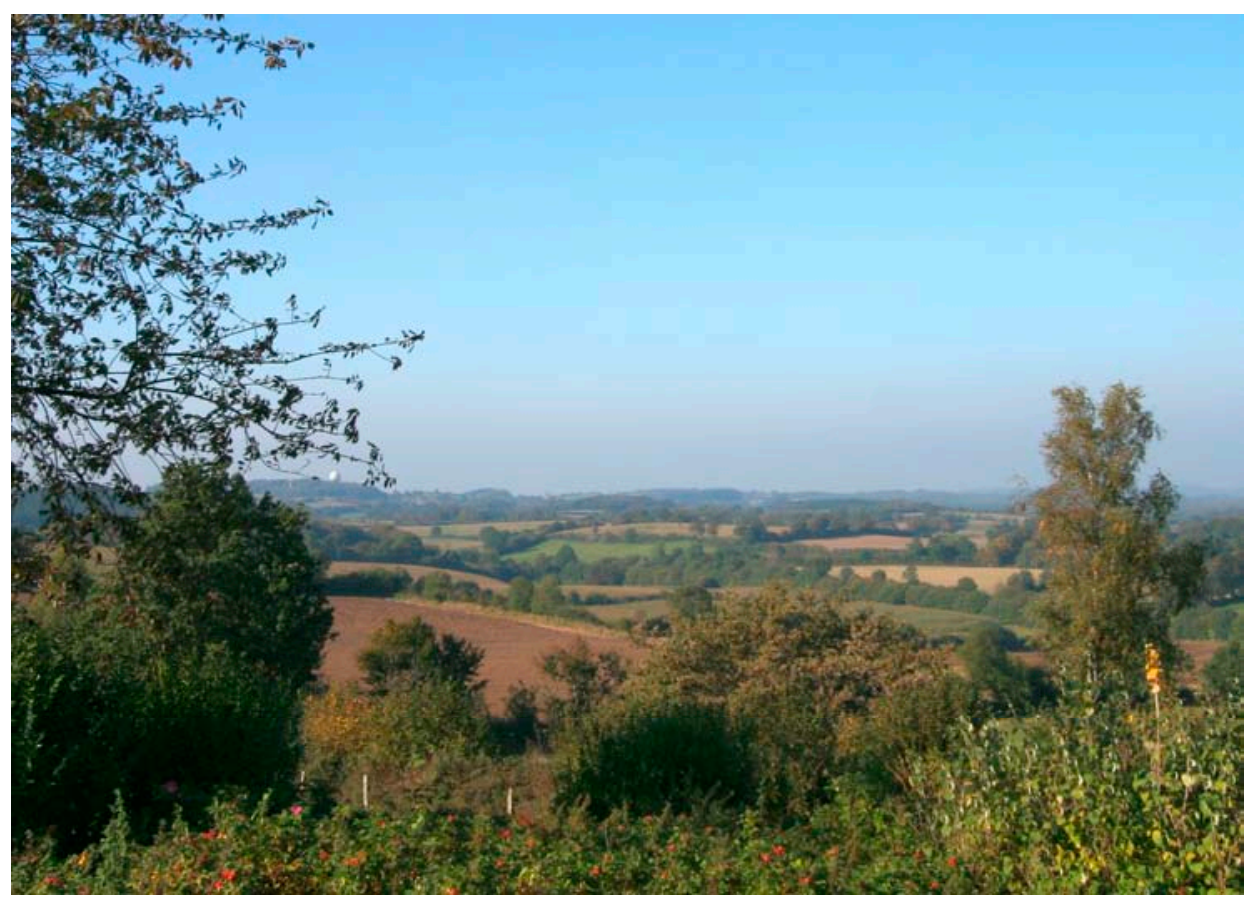

Abb. 3: Eckernförder Knicklandschaft im Herbst (Foto: Lutz Eneik) 
Seither freilich hat sich für uns auch die Natur als sehr geschichtsverfallen erwiesen. Dank Lehmanns Beobachter-Genauigkeit müssen wir beim Lesen des Bukolische Tagebuch auch zur Kenntnis nehmen, wie viel mittlerweile, im Laufe weiterer achtzig Jahre der technisch-industriellen Revolution, zurückgegangen oder ganz verschwunden ist aus dieser Eckernförder Landschaft. Von den Schwärmen der Brachvögel und dem Tönen der Bekassine spricht Lehmann mit einer Selbstverständlichkeit, als wären diese Tiere gar nicht wegzudenken aus der Eckernförder Bucht. Aber er bemerkt einmal auch: ,Jedes Tier, das vergeht, jede Art Lebewesen, die ausstirbt, verdünnt das Weltvokabular, bringt uns weiter zurück von der Wahrheit, die nur aus dem Zusammenklang aller Wesen sich heraufarbeitet.“ (S. 226)18

Wer sich für die ökologische Geschichte der Natur interessiert und für die Naturdichtung und also folglich für diejenige Forschungsrichtung, die in den angelsächsischen Literaturwissenschaften der letzen Jahrzehnte Ecocriticism genannt worden ${ }^{19}$ und nur um den Preis einer Bedeutungsverengung ins Deutsche zu übertragen ist, der kann hier auf eine sehr überraschungsreiche literarische Entdeckungsreise gehen. Nicht eine eng weltanschauliche, das moralisch Gute mit dem ästhetisch Gutgemeinten verwechselnde Literatur ist gemeint, wie sie in Deutschland eine zeitlang unter so schauerlichen Labels wie dem Wort „Ökolyrik“ im Umlauf war, sondern eine Literatur, die aufmerksam ist für die Wechselbeziehungen zwischen dem Menschen und seiner biologischen Mitwelt, für Austauschprozesse, gegenseitige Abhängigkeiten, im strikten biologischen Sinne ökologische Vernetzungen.

Wie der deutsche Ecocriticism sich in diesem Sinne und mit überraschenden Ergebnissen etwa Goethes Farbenlebre oder den Wanderjabren zuwandte (und erst aus dieser Distanz dann auch neue Zugänge zu gegenwärtigen ökologischen Prozessen und ihren künstlerischen Repräsentationen fand), so interessierte sich der amerikanische Ecocriticism mit Vorliebe für Goethes amerikanische Schüler: Ralph Waldo Emerson und dessen Freund und Mitstreiter Henry Thoreau. ${ }^{20}$ Das hatte zunächst sicher damit zu tun, dass Thoreau mit seiner erz-amerikanischen Entscheidung, im zivilisierten Massachusetts ein Holzhaus im Wald am See zu bauen und sich dorthin zurückzuziehen, wie ein früher Apostel der Maxime ,Zurück zur Natur' erschien und dass überdies sein radikaldemokratisches Credo von der - so der Titel seines berühmten Traktats - Pflicht zum Ungehorsam gegenüber dem Staat ihn Jugendbewegungen vom deutschen Wandervogel bis zu den amerikanischen '68ern als Zeitgenossen erscheinen ließ. Aber literarisch war es doch vor allem das Buch, das Thoreau aus seinem Naturabenteuer gemacht hatte, in dem die Frage nach den Beziehungen von ökologisch fokussierten Beobachtungen und literarischen

\footnotetext{
1819.11 .1928$.

19 Vgl. dazu den Beitrag von Alexander Starre in diesem Band.

${ }^{20} \mathrm{Vgl}$. dazu ausführlich den Beitrag von Frank Kelleter in diesem Band.
} 
Darstellungsformen reich instrumentierte Antworten fand: den romanhaften Bericht Walden, der nach dem See „Walden Pond“ benannt und zu einem der amerikanischen Klassiker des 19. Jahrhunderts wurde.

So haben die Ecocritics Thoreau neu gelesen - und so hat ihn Wilhelm Lehmann gelesen. Nicht weniger als sein Vorbild und Anreger ist für ihn der

merkwürdige Thoreau [...], der im März 1845, achtundzwanzig Jahre alt, Bleistiftfabrikant und Schriftsteller, die Stadt Concord in Massachusetts verließ und zwei Jahre in der Einsamkeit der Wälder neben dem See Walden in einem selbsterbauten Hause lebte und in einem herrlichen Buche, das er nach jenem See benannte, von der wimmelnden Fülle seiner Einsamkeit berichtet hat. (S. 229) ${ }^{21}$

Was Lehmann an diesen Theoreau und sein Bukolische Tagebuch an Walden anschließt, ist die unablässige Aufmerksamkeit für jedes einzelne Phänomen der umgebenden Natur, die fortwährende Frage nach dem eigenen Ort in ihr und im Gegenüber zu ihr, und eine sehr spezifische Verbindung einer noch ,romantisch“ zu nennenden Naturmystik und einer naturwissenschaftlichen Neugier, die aller nebulösen Schwärmerei abhold ist. Wie Thoreau den See, aus dem er sich mit Fischen versorgt, mühsam in Breite und Tiefe vermisst, wie er Bäume und Boden prüft, um auf ihm und aus ihnen seine haltbare Hütte errichten zu können, so will auch Lehmann mithilfe einer aufgeklärten Wissenschaft die Naturphänomene verstehen und benennen lernen, die er dann - aber erst dann - zu Gegenständen mystischer Versenkung und liebender Verehrung erhebt.

Wie ein Thoreausches Leitmotiv hallt durch seine Aufzeichnungen dieses Lob der Genauigkeit. Weil es auch ihm um das zu tun ist, was Šklovskij die entautomatisierende „Erweckung des Wortes“ nennt, formuliert er seinen Vorsatz so: „Erzeigen wir den einzigen Vorgängen der Natur die Reverenz, sie kennenzulernen“ (S. 262)22. „Namen sind Gehäuse des Wissens“ (S. 197), bemerkt er am 11. März 192S. und drei Monate später fügt er erläuternd hinzu. „Und darum bin ich namengierig und freute mich, als ich erfuhr, daß die Pflanze, die jetzt auf überschwemmt gewesenem Boden und im flachen Wasser an Ufern, auf Feldern und Wegen reichlich blüht, der ,verbrecherische Hahnenfuß ${ }^{\text {‘st. “ (S. 208) }}{ }^{23}$ Die Namen: ,ich möchte sie alle wissen, alle ,bestimmen“. Denn die richtigen Namen gehören zum Wesen, nicht der Einzelne schuf sie in schnellem Einfall, die Welt dichtete sie." (S. 255)24

Man könnte hinzufügen: Und nicht nur aus diesem existenzphilosophisch getönten Suchen nach den in der Sprache sedimentierten Verhältnissen des Menschen zu seiner Welt resultiert diese Namengier, sondern auch aus dem Bemühen um das, was Šklovskij die notwendige

\footnotetext{
21 17.12.1928.

22 Mitte März 1930.

23 15.6.1928.

245.9 .1929$.
} 
„Entautomatisierung“ nannte - der dichterischen Sprache von der Konvention, aber auch der Weltwahrnehmung selbst vor der alles verallgemeinernden, einebnenden Sprache, die uns zwingt, bloß, wiederzuerkennen' statt zu ,sehen'. Es ist der schiere Klang von Wörtern wie Fliegenschnäpper, Flockenblume, Blasentang, der diesen Effekt erzeugen kann; es ist aber auch - und schon dieser aufklärerische Grundzug trennt Lehmanns Prosa um Welten vom Schwulst der Heimatkunst - das Vergnügen am Wissen, in dessen Beleuchtung das Altbekannte aussieht wie neu: „Überaus reizvoll ist es, sich klarzumachen, daß die zweiklappige ,Nuß' der Walnuß im Grunde dem Stein der Pflaume entspricht und daß der Teil, den wir essen, das Paar der verschrumpften Keimblätter ist." (S. 281)25 Poesie und Wissen gehen hier Hand in Hand, sind eigentlich wieder ungeschieden eins. ${ }^{26}$

Aber, fragt der skeptische Leser weiter, muss man, will man das alles wirklich so genau wissen? Lehmanns Antwort lautet, dass es überhaupt gar nicht genau genug sein könne, weil das, was wir ,die Welt nennen, nichts ist als eben die Gesamtheit des Einzelnen, der Einzelnen, der Einzelheiten - weil, und so steht es sinngemäß in diesem Buch, weil ja auch jeder Mensch ein Einziger und Einmaliger ist. Ich zitiere eine Passage, die aus diesem Gedanken so etwas wie ein poetologisches Programm entwickelt:

Wir verallgemeinern zuviel, zu hastig durchstoßen wir die Fülle der Erscheinungen mit einigen Formeln. Aber je allgemeiner wir werden, desto leerer werden wir, und im großen Ganzen den Umriß des Einzigen, Unwiederholbaren zu wahren - das ist das schwierige Geheimnis. Der Mensch ist längst herrisch genug, eine Einzelbiographie zu beanspruchen für das Leben eines Tieres sind oft auch die Sinne geschärft, aber zu wenig unternimmt man, die Geschichte, die Schicksale einer Pflanze, etwa eines Pflaumenbaumes, einer Efeustaude, aufzuzeichnen. Die Pflanze hat freilich das ihr gemäße Tempo, und die Schnelligkeit, die eine bloß hastige, ungeduldige Epoche zu ihrem Götzen gemacht hat, vergeht vor der gesammelten, unübertriebenen Zeit, die sich eine Hopfenranke nimmt, um die Telegrafenstange hinauf zu gelangen. (S. 251) ${ }^{27}$

\footnotetext{
2512.10 .1930 .

26 Vereinzelte Sentimentalitäten, die sich einstellen, sobald er nicht mehr sieht und hört, sondern weltabgewandt räsoniert, und die ihm leider kein Lektor gestrichen hat, verlieren sich im Laufe des Romans - „die Vögel müssen aufpassen, daß die Bitternis der Welt ihre Liebe nicht zerreißt", 8.2.1928 $(8,191)$-, ebenso wie überflüssige, weil nur aufgesetzte Mythisierungen: „Das Märchen nimmt ihn in seine Arme“, 27.2 .1928 (8, 195); „Die Arche Noah öffnet die Tür“, 11.3.1928 (8, 197).

${ }^{27}$ Ende Juli 1929.
} 
Denn „jedes Lebewesen erzeugt seinen eigenen Rhythmus“ (S. 281) ${ }^{28}$. Sähe man die einzelnen Blätter einer Eiche wirklich an, statt sie bloß wiederzuerkennen, so könnte man bemerken: „Je nach ihrer Stellung sind die Blätter verschieden gestaltet. Sie wandeln die berühmte Form ab wie die Musik ein bestimmtes Motiv“. Und ebenso gilt: „Auch der Efeu hat seine Geschichte.“ (S. 283) 29

Unter unseren Zeitgenossen hat ein anderer Nachfahre Stifters ziemlich genau denselben Gedanken ins Zentrum seiner Poetik gestellt: Peter Handke, nur ohne Rekurs auf Lehmann, den verachteten Bewisperer des Huflattichs. In einem Band mit kurzen Prosastücken hat er 1990 der großen Weltgeschichte diejenige der alltäglichen Begebenheiten gegenübergestellt, und er hat ihn dem Begründer jener Geschichtsschreibung gewidmet, die in der griechischen Antike die summarische Darstellung durch die Aufmerksamkeit für das Einzelne ersetzte. Noch einmal für Thukydides heißt also der Band, und die in ihm gesammelten Texte tragen Überschriften, wie Lehmann sie im Bukolische Tagebuch hätte formulieren können: „Epopöe des Wetterleuchtens“ und „Einige Episoden vom japanischen Schneien“ am Ende „Kleine Fabel der Esche von München“. Es ist tatsächlich die Einzelbiographie eines bestimmten Baumes am Münchner Siegestor, einer Esche, die so einmalig ist wie wir alle, was Handke hier aufzeichnet - im Sinne Lehmanns: „die Geschichte, die Schicksale einer Pflanze.“ (S. 251) ${ }^{30}$ (Unter den jüngeren Gegenwartsautoren hat sich, soweit ich sehe, der Erzähler Klaus Böldl am konsequentesten diesem Projekt verschrieben; sein Island-Buch Die fernen Inseln, erschienen bei S. Fischer 2003, gehört noch immer zu den eindrucksvollsten Beispielen dieses Schreibens.) ${ }^{31}$

Deshalb geht, so scheint mir, auch der naheliegende Einwand ins Leere, Prosa wie diese verstoße gegen die erste Grundregel, durch die sich Dichtung und Bildende Kunst unterscheiden; Lessings Laokoon mit seiner sehr begründeten Kritik einer „malenden Poesie“ widerspricht Lehmanns Poetik bei näherem Hinsehen mit keinem Satz. Aber es gebe hier doch keine Handlung, argwöhnt der Leser, so müsse dieser Text auf die Dauer eben doch ermüdend statisch, starr und langweilig werden? Aber, so fragt Lehmann dagegen: „,Was flammt da auf, selbst den dichten Novembernebel durchschneidend wie mit funkelnder Schere? Wer sieht den Spindelbaum im Sommer an?" Und dann erzählt er die kleine Epopöe des Spindelbaums:

Jetzt aber hat sich jeder Blütenstand in ein kleines, fünfeckiges, mit roter Seide überzogenes Kästchen verwandelt. Just in der Spätherbstschwermut springt

\footnotetext{
28 12.10.1930.

29 Beides 27.11.1930; vgl. die Schilderung der Anemone am 25.3.1931 (8, 289f.).

${ }^{30}$ Ende Juli 1929.

${ }^{31}$ Nicht zufällig berufen sich Böldl wie Handke dabei auf die Malerei Cézannes. Vgl. dazu sowie zur Cézanne-Rezeption bei Autoren wie Rilke, Carl Einstein und Robert Walser den Band Hoffmann (2008).
} 
das Kästchen auf und stößt fünf lebhaft orangefarbene Samenkörner heraus (wenn du diese zerschneidest, gesellt sich als dritte Farbe ein zartes Grün). Orangegelb und rosenrot jubiliert der ganze Busch, wie exaltiert steht er da, den vor ein paar Monaten nur ein paar graue Motten kannten. (S. 260) 32

Nun kennen auch wir ihn, den Spindelbaum im November, und wir würden ihn ungern wieder vergessen. Denn wer die Welt mit Lehmann liest, der kann manchmal eine Ahnung jenes Zustands erlangen, den er selber gegen Ende seines Tagebuchs so resümiert: „aufmerksam in der Gegenwart des anderen Wesens, staunend, daher glücklich“ (S. 297) ${ }^{33}$.

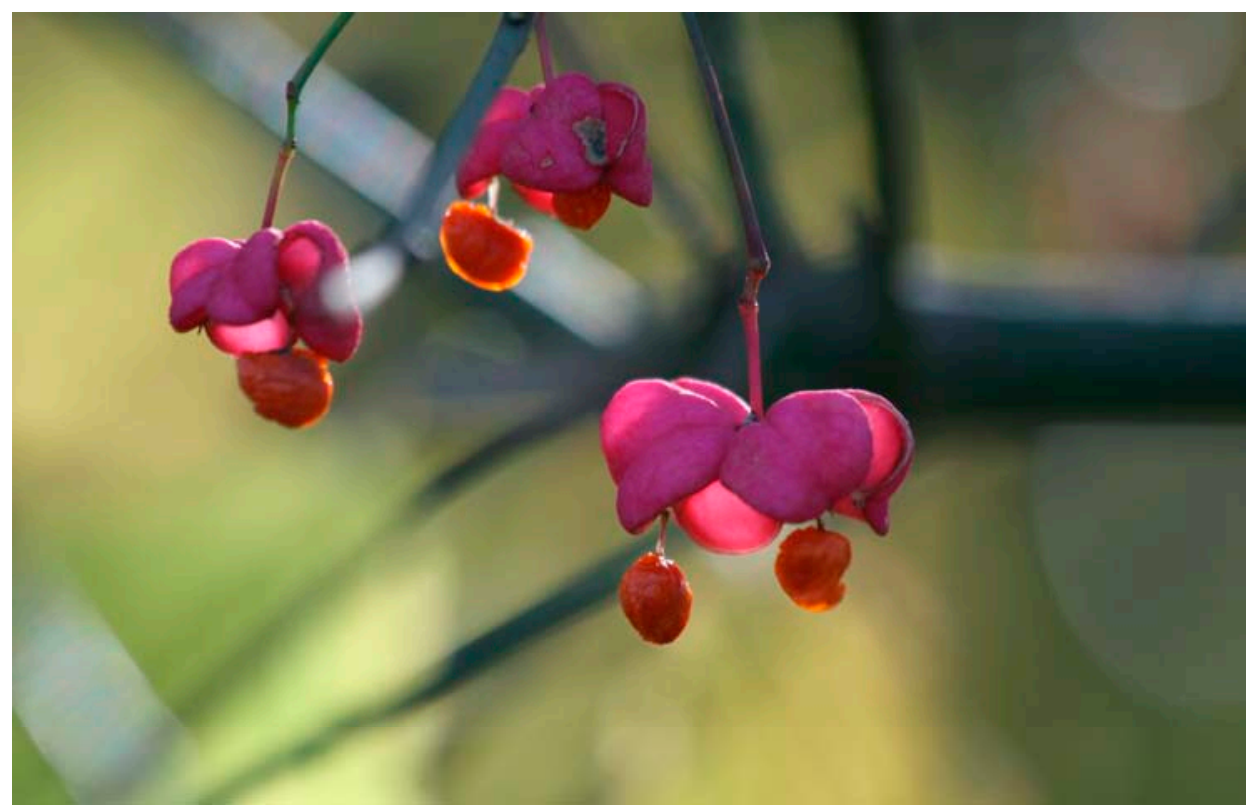

Abb. 4: Der Spindelbaum im November. (Foto: Lutz Eneik) 


\section{Literatur}

Böldl, Klaus (2003): Die fernen Inseln. Frankfurt am Main: Fischer.

Brecht, Bertolt (1994): Journale I. 1913-1941. Frankfurt am Main: Suhrkamp (= Brecht, Bertolt: Große kommentierte Berliner und Frankfurter Ausgabe. Hg. von Werner Hecht [u.a.]; 26).

Detering, Heinrich (2008): Bertolt Brecht und Laotse. Göttingen: Wallstein.

Detering, Heinrich (2010): Der verbrecherische Hahnenfuß. Wilhelm Lehmanns >Bukolisches Tagebuch zwischen Romantik und Avantgarde. In: Merlinszeit. Wilhelm Lehmann braucht ein Haus in Eckernförde. Hg. von Uwe Pörksen. Göttingen: Wallstein (= Sichtbare Zeit. Journal der Wilhelm-LehmannGesellschaft; 4), S. 15-31.

Döblin, Alfred (1915): Die drei Sprünge des Wang-lun. Chinesischer Roman. Berlin: Fischer.

Döblin, Alfred (2007): Die drei Sprünge des Wang-lun.Chinesischer Roman. Hg. von Gabriele Sander und Andreas Solbach. Düsseldorf: Walter (= Döblin, Alfred: Ausgewählte Werke in Einzelbänden).

Frenssen, Gustav (1936): Der Glaube der Nordmark. Stuttgart: Gutbrod.

Handke, Peter (1990): Noch einmal für Thukydides. Salzburg, Wien: Residenz.

Hoffmann, Torsten (2008) Hrsg.: Lehrer ohne Lehre. Zur Rezeption Paul Cézannes in Künsten, Wissenschaften und Kultur (1906-2006). Freiburg i. Br. [u.a.]: Rombach. (= Rombach-Wissenschaften. Reihe Litterae; 158).

Hofmannsthal, Hugo von (2009): Der Dichter und diese Zeit. Ein Vortrag. In: Hofmannsthal, Hugo von: Reden und Aufsätze 2. Hg. von Konrad Heumann und Ellen Ritter. Frankfurt am Main: Fischer. (= Hofmannsthal, Hugo von: Sämtliche Werke; 33), S. 127-148.

Jünger, Ernst ([1938] 1979): Das abenteuerliche Herz. Zweite Fassung. Figuren und Capriccios. In: Jünger, Ernst: Essays III. Das abenteuerliche Herz. Stuttgart: Klett-Cotta (= Jünger, Ernst: Sämtliche Werke. Band 9), S. 177-330

Laozi: The Sayings of Lao Tzu. Translated from the Chinese, with an Introduction. 2. Auflage. London 1909.

Lehmann, Wilhelm (1935): Antwort des Schweigens. Berlin: Widerstands-Verlag.

Lehmann, Wilhelm (1948): Bukolisches Tagebuch aus den Jahren 1927-1932. Fulda: Parzeller.

Lehmann, Wilhelm (1956): Nachwort. In: Storm, Theodor: Meistererzählungen. Hg. von Wilhelm Lehmann. Zürich: Menasse, S. 793-804. 
Lehmann, Wilhelm (1982): Antwort des Schweigens. In: Lehmann, Wilhelm:

Gesammelte Werke in acht Bänden. Band 1. Sämtliche Gedichte. Hg. von

Hans Dieter Schäfer. Stuttgart: Klett-Cotta, S. 7-54.

Lehmann, Wilhelm (1999a): Bukolisches Tagebuch aus den Jahren 1927-1932. In:

Lehmann, Wilhelm: Gesammelte Werke in acht Bänden. Band 8.

Autobiographische und vermischte Schriften. Hg. von Verena Kobel-

Bänninger. Stuttgart: Klett-Cotta, S. 175-309.

Lehmann, Wilhelm (1999b): Bukolisches Tagebuch 1948. In: Lehmann, Wilhelm:

Gesammelte Werke in acht Bänden. Band 8. Autobiographische und vermischte Schriften. Hg. von Verena Kobel-Bänninger. Stuttgart: Klett-Cotta, S. 309-324.

Lehmann, Wilhelm (2006): Die Gegenwart Theodor Storms. In: Lehmann, Wilhelm: Gesammelte Werke in acht Bänden. Band 6. Essays I. Hg. von Wolfgang Menzel. Stuttgart: Klett-Cotta, S. 102-113.

Proust, Marcel (1979): Auf der Suche nach der verlorenen Zeit. Band 1. In Swanns Welt. Deutsch von Eva Rechel-Mertens. Frankfurt am Main: Suhrkamp.

Rilke, Rainer Maria (1923): Die Sonette an Orpheus. Geschrieben als ein Grab-Mal für Wera Ouckama Knoop. Leipzig: Insel.

Šklovskij, Viktor (1914): Die Erweckung des Wortes. Zitiert nach: Mierau, Fritz (Hrsg.): Die Erweckung des Wortes. Essays der russischen Formalen Schule. Leipzig: Reclam, S. 5.

Stifter, Adalbert (1980): Der Hochwald (1841). In: Stifter, Adalbert: Studien.

Buchfassungen. Erster Band. Hg. von Helmut Bergner und Ulrich Dittmann.

Stuttgart [u.a.]: Kohlhammer (= Adalbert Stifter: Werke und Briefe. Historischkritische Gesamtausgabe; 1,4), S. 209-318.

Storm, Theodor (1988): Zur Chronik von Grieshuus (1884). In: Storm, Theodor:

Novellen 1881-1888. Hg. von Karl Ernst Laage. Frankfurt am Main:

Deutscher Klassiker Verlag (= Theodor Storm: Sämtliche Werke in vier Bänden; 3), S. 198-293.

Thoreau, Henry David (1854): Walden. Or life in the woods. Boston: Ticknor a. Fields. 


\section{Der Schwarm und das Netzwerk im multiskalaren Raum Umweltdiskurse und Naturkonzepte in Schätzings Ökothriller}

\section{Gabriele Dürbeck, Peter H. Feindt}

\section{Einleitung}

Die globale Umweltkrise hat auch in den Literatur- und Kulturwissenschaften Anlass gegeben, Repräsentationen des Mensch-Umwelt-Verhältnisses zu untersuchen. Das Forschungsfeld Literatur und Ökologie hat sich international seit Beginn der 1990er Jahre etabliert (Goodbody 1998; Gersdorf u. Mayer 2005; Zapf 2008). Es steht im weiteren Kontext des aus den USA stammenden interdisziplinären Ansatz des Ecocriticism (vgl. die Zeitschrift Interdisciplinary Studies in Literature and Environment ISLE (1992ff.), Buell 1995 u.v.a.), ${ }^{1}$ der auch literarische Texte und Ideen im Hinblick auf ,ihre Kohärenz und Brauchbarkeit als Antworten auf die Umweltkrise" untersucht (Kerridge u. Sammells 1998, S. 5 [unsere Übs.]).

Spätestens seitdem die globale Umweltkrise durch den Bericht an den Club of Rome von 1973 im öffentlichen Bewusstsein verankert und durch Überblicksarbeiten wie das Millenium Ecosystem Assessment (MEA 2007) sowie den vierten Bericht des Intergovernmental Panel on Climate Change (IPCC 2007) wissenschaftlich erhärtet ist, wird das Thema in der zeitgenössischen fiktionalen Literatur verarbeitet und reflektiert und hier nicht zuletzt im Genre des Öko- und Wissenschaftsthrillers. Die Tiefsee und deren ökologische Veränderung ist im deutsch-

\footnotetext{
1 Zur Entwicklung des us-amerikanischen Ecocriticism vgl. den Beitrag Alexander Starres im vorliegenden Band.
} 
sprachigen Raum bislang wohl am erfolgreichsten in Frank Schätzings Ökothriller Der Schwarm (2005) dargestellt, auf den sich die folgende Analyse konzentriert. Gegenstand von Schätzings in mehr als zwei Millionen Exemplaren verkauftem Thriller ist eine globale Umweltkatastrophe, die das Überleben der Menschheit bedroht. Im Laufe des Romans stellt sich heraus, das eine Anzahl lokaler Zwischenfälle und Naturkatastrophen Elemente eines globalen Angriffs auf die Menschheit sind, mit dem eine mysteriöse Schwarm-Intelligenz im Ozean, ein Superorganismus, Rache für die anhaltende Verseuchung der Meere nimmt. ${ }^{2}$ Die Handlung enthält Aspekte verschiedener Umweltprobleme - vom Klimawandel über die Verschmutzung und Übernutzung der Meere bis hin zum Artensterben und steht daher für die globale Umweltkrise insgesamt.

Der Ökothriller ist eingeschrieben in verschiedene Groß-Narrative des MenschNatur-Verhältnisses, unter denen die Apokalypse eine Leitmetapher ist (Buell 1995, S. 285). ${ }^{3}$ Im Zentrum stehen Naturausbeutung und Zerstörung als Schuld, die Rache der Natur am Menschen, die Natur als intelligenter und koordinierter Gegenspieler. Daneben stehen utopische Motive wie die Vorstellung eines Dialogs mit der Natur als einer außermenschlichen, gleichwertigen Intelligenz.

Das relativ junge Genre des Ökothrillers ist Heizmann ${ }^{4}$ zufolge durch folgende Merkmale charakterisiert, die alle auch auf Schätzings Der Schwarm zutreffen: Die Handlung spielt an vielen verschiedenen Schauplätzen, welche die Globalität der Umweltkrise anschaulich machen; es besteht Anspruch auf Aktualität; es geht um Natur/ Umwelt einerseits und Wissenschaft/Technologie andererseits; die Handlungsfolge ist geprägt durch Spannungsdramaturgie und eine Tendenz zur Eskalation; konventionelle Darstellungsmuster herrschen vor; dabei überwiegt die Darstellung von Typen oder so genannten flat characters, die häufig im Rahmen von Gut-Böse-Schemata agieren; es besteht eine Nähe zu Darstellungskonventionen des Films, besonders in Hinsicht auf Realitätseffekte; häufig findet sich eine Mischung verschiedener Genres (Science Fiction, Essay, Dokumentarliteratur u. a.); und nicht zuletzt wird für die Erklärung der Ereignisse ein mythisch-spiritueller Diskurs in Anspruch genommen.

Wenn man die bekanntesten Beispiele des Genres betrachtet, lassen sich im Wesentlichen zwei Tendenzen unterscheiden. Auf der einen Seite sind es Romane, die angesichts der globalen Umweltkrise das Publikum aufklären und durch die

\footnotetext{
2 Andere Umweltthriller, wie Bernhard Kegels Der Rote (2007) oder Cord Hagens Der Schlund (2007), die in der Tiefsee spielen und gleichermaßen apokalyptische Bilder und Katastrophenszenarien zur Darstellung der globalen Umweltkrise bemühen - bei dem einen geht die Gefahr für den Menschen von Riesenkalmaren aus, bei dem anderen von fleischfressenden Tiefseefischen - erreichen jedoch nicht die Breitenwirkung von Schätzings Der Schwarm.

${ }^{3} \mathrm{Zu}$ weiteren zentralen Tropen und Konzepten des Ecocriticism wie Umweltverschmutzung, Wildnis, Siedlung (dwelling), Tier oder die Erde (the Earth) vgl. Garrard (2004).

${ }^{4}$ Vgl. den Vortrag Jürgen Heizmanns „Bebende Erde, tobende Meere. Zum Phänomen des Ökothrillers“ in der Sektion 13: „Klimachaos und Naturkatastrophen in der deutschen Literatur Desaster und deren Deutung" auf dem XII. Kongress der Internationalen Vereinigung für Germanistik (Warschau, 2. August 2010), indem er sich v.a. auf Dirk Flecks Romane GO! Die Ökodiktatur (1993, überarb. Neuaufl. 2006) und Das Tabiti-Projekt (2007), Kegels Der Rote und Ulrich Hefners Die dritte Ebene (2008) bezogen hat.
} 
drastische Darstellung der katastrophalen Folgen einer rücksichtslosen Naturausbeutung sensibilisieren wollen, von Axel Goodbody (2006, S. 23) zurecht als Warnliteratur bezeichnet (vgl. auch Kerridge 2000, S. 248); $;$ im Science Fiction-Modus haben sie häufig die Funktion von Dystopien (Lehnert 1991, S. 298). Dem stehen Romane von Seiten der Klimaskeptiker gegenüber, welche die anthropogenen Ursachen der Umwelt- und Klimakrise bezweifeln oder sogar leugnen und die Umwelt- und Klimawissenschaft als Verschwörung darstellen. ${ }^{6}$

Im vorliegenden Beitrag wird am Beispiel von Schätzings Schwarm untersucht, wie die globale Umweltkrise repräsentiert wird, wie das Wissen davon vermittelt wird und inwiefern Lösungsansätze zur Behebung der Krise angeboten werden. Die folgenden Überlegungen nehmen insofern zentrale Fragestellungen des Ecocriticism auf (Glotfelty 1996, Heise 2006). Neben der Kohärenz und Brauchbarkeit des Textes wird angesichts der Globalität des Themas und der Handlung auch auf das Raumkonzept eingegangen. Die Darstellung räumlicher Dimensionen wird nicht nur im Ecocriticism erforscht (Heise 2001, S. 128), sondern hat im Zuge des spatial turn in den Literatur- und Kulturwissenschaften generell seit den späten 1980er Jahren verstärkt Aufmerksamkeit erlangt. ${ }^{7}$

Drei Schritte gliedern die folgenden Überlegungen:

- Erstens wird untersucht, wie die Globalität der Umweltkrise repräsentiert wird. Es zeigt sich, dass die Schauplätze des Romans über den ganzen Globus verteilt sind, jedoch mit einer impliziten Zentrum-Peripherie-Logik.

- Zweitens hat die Globalität des Themas und seiner Darstellung Folgen für Verortung und Vermittlung von Wissen. So ergibt sich der Sinn der zunächst unheimlichen lokalen Zwischenfälle erst aus einer globalen Perspektive. Das Lokale und das Globale werden in einer Logik der Multiskalarität miteinander verknüpft, die impliziert, dass nur ein interdisziplinär organisiertes Netzwerk das als global dargestellte Problem erfassen könne.

- Drittens beinhaltet die Handlung einen Diskurs über die Überlegenheit verschiedener Organisationsmodelle und deren Intelligenz. Im Kern des Plots wird die bedrohliche Schwarmintelligenz als dem Menschen überlegener Superorganismus (Selbstorganisation, Vernetztheit) konstruiert, der ein radikales Umdenken der Menschheit herausfordert.

\footnotetext{
5 Wie wichtig die Warnfunktion populär-kultureller Produktionen unter Umweltwissenschaftlern eingeschätzt wird, zeigt etwa die Untersuchung der Wirkung von Roland Emmerichs Kinokassenschlager The Day after Tomorrow von Reusswig et al. (2004).

${ }^{6}$ So etwa Michael Crichtons Öko- und Technothriller State of Fear (2004), dt. Welt in Angst (2004), zurecht als „State of Confusion“ bezeichnet.

http://www.realclimate.org/index.php/archives/2004/12/michael-crichtons-state-of-confusion/, zuletzt besucht am 03. Juli 2010.

7 Einen Überblick über neue Raumtheorien und -konzepte im spatial turn gibt Bachmann-Medick 2006, S. 284-328.
} 
Durch die Gegenüberstellung von Netzwerk und Schwarm stellt der Roman verschiedenartige Natur-Gesellschafts-Verhältnisse und deren Konsequenzen zur Diskussion, deren Wertung am Ende des Beitrags resümiert und kritisch beleuchtet wird.

\section{Globalitåt mit inhärenter Zentrum-Peripherie-Logik}

Zunächst stellt sich die Frage, wie die Globalität der Umweltkrise dargestellt wird. Insbesondere der erste Teil des Romans Der Schwarm weist häufige und abrupte Schauplatzwechsel auf. Dieses Verfahren dient nicht nur der genrebedingten Erzählökonomie, sondern verbindet einzelne Orte und Regionen über den ganzen Globus in einem Erzählraum. Die Geschehnisse werden dabei von einem traditionellen, allwissenden Erzähler präsentiert. Diese Fokalisierung konstruiert eine Wissensposition, die voraussetzt, dass der Zusammenhang lokal verstreuter katastrophaler Ereignisse nur durch eine globale Perspektive erkannt werden kann, die dem Leser aber zunächst vorenthalten bleibt. Der Roman nimmt sowohl auf der Handlungsebene wie auch im Darstellungsmodus die Privilegierung einer globalen Perspektive vor, die implizit als die gültige erscheint.

Diese Globalitätsperspektive entspricht einem wesentlichen Strang des ökologischen Diskurses seit Anfang der 1970er Jahre, der sich auf globale Phänomene wie Ressourcenknappheit, Klimawandel, Artensterben, Wüstenbildung und Übersäuerung der Meere bezieht. War der traditionelle Naturschutzdiskurs auf lokale Phänomene wie Zersiedelung, Gewässerverschmutzung oder das Verschwinden von Tier- und Pflanzenarten begrenzt, wird heute die Aufmerksamkeit für lokale Phänomene zumeist in einen globalen Kontext gestellt. ${ }^{8}$

In Schätzings Roman entsteht die globale Perspektive aus einer Akkumulation von Fakten zu den unterschiedlichsten Schauplätzen. Das Globale erscheint damit im ersten Teil als Summe lokaler Fakten, deren Zusammenhang der Leser und die handelnden Figuren aber zunächst nur erahnen. Die geschilderten Katastrophen, ausgelöst durch sogenannte Anomalien in der Tiefsee, ereignen sich vor allem in Küstenregionen. Das Meer und das Maritime erscheinen als das Andere, Bedrohliche, Unheimliche. Dabei ist auffällig, dass die Dramaturgie einer impliziten eurozentrischen Zentrum-Peripherie-Logik im Sinne von Wallersteins (2004) sozioökonomischem Weltsystem, aber auch aus der Perspektive der Lokalität des zunächst und vorwiegend mitteleuropäischen Lesepublikums folgt.

Ausgangspunkt sind kleinere Katastrophen in der Peripherie: Vor der Küste von Peru verschwindet plötzlich ein Fischer; gleichzeitig gibt es Vorfälle vor den Küsten Argentiniens und Chiles; eine Invasion giftiger Quallen tötet Menschen vor der Küste Costa Ricas. Von da an dringt die Katastrophe immer weiter ins Zentrum vor: Die Quallen tauchen auch in Australien auf; im kanadischen

\footnotetext{
${ }^{8}$ Für eine ausführliche Darstellung der Entwicklung des Umweltdiskurses vgl. Huber (2001, S. 274ff.) und in Bezug auf politische Mobilisierungsfähigkeit Feindt (2002).
} 
Vancouver greifen Wale Menschen an; in einem französischen Feinschmeckerrestaurant zerplatzen Hummer und verseuchen Hunderte von Menschen tödlich; anomale Würmer destabilisieren vor Norwegen die Methanhydratschicht in der Nordsee und bringen den Kontinentalschelf zum Einsturz, der folgende Tsunami verwüstet halb Nordeuropa; etwas später fordert eine Krebsplage in Long Island und New York Hunderte von Menschenleben.

$\mathrm{Da}$ die Abfolge der Ereignisse offenbar als Steigerungsdramaturgie konzipiert ist, suggeriert sie zugleich eine Zentrum-Peripherie-Hierarchie der dargestellten Orte. Die Spannung steigt, je mehr sich die Katastrophe dem Zentrum nähert. Diese Logik lässt zwei Deutungen zu: Zum einen kann die Lokalisierung von kleineren Katastrophen an der Peripherie, die nur lokale und vereinzelte Gegenmaßnahmen auslösen, als Kritik einer Vernachlässigung von Ländern außerhalb der westlichen Hemisphäre verstanden werden. Zum anderen kann der Roman eine warnende Funktion erst voll entfalten, wenn das avisierte Lesepublikum sich angesprochen fühlt, das größtenteils wohl nicht an der Peripherie vermutet wird.

Durch einen Nebenstrang der Handlung wird indessen eine weitere binäre Raumcodierung durchkreuzt. Als von amerikanischer Seite die Angriffe zunächst als terroristischer Anschlag islamischer Fundamentalisten interpretiert werden $(488)^{9}$, ereignet sich durch einen aggressiven Planktonschwarm in der Straße von Hormuz zwischen Persischem Golf und Indischem Ozean eine weitere Großkatastrophe, von der auch der Nahe Osten betroffen ist. In der Folge setzt sich im Roman die Auffassung durch, dass eine dichotomische Codierung der Welt entlang der weltreligiösen Systeme Christentum und Islam nicht aufrecht zu erhalten sei. Dadurch wird deutlich, dass territorial und national begrenzte Perspektiven die Globalität des Problems nicht erfassen können. Allerdings ist anzumerken, dass die Straße von Hormuz vor allem aus einer eurozentrischen und geostrategischen Perspektive von Bedeutung ist, stellt sie doch einen Engpass auf den Schifffahrtsrouten der Öltanker aus der Golfregion dar.

\section{Multiskalarität, Netzwerk, Vernetzung}

Wenn sich in der Dramaturgie des Romans die unheimlichen Zwischenfälle über den Globus verbreiten, konstituiert dies nicht nur eine laterale Bewegung, sondern es gibt einer kleinen Gruppe von Wissenschaftlern den Anlass, nach Zusammenhängen zwischen den Anomalien im Meer mit desaströsen Auswirkungen an verschiedensten Orten der Erde zu suchen. Diesen finden sie letztendlich im Wirken eines global operierenden maritimen Superorganismus. In den Überlegungen der Wissenschaftler, aber auch in der Handlungsabfolge des Romans, ergibt sich dabei ein wechselseitiger Bezug zwischen den räumlich verstreuten Ereignissen, die

${ }_{9}^{9}$ Im Folgenden wird der Roman Der Schwarm (2005) mit Seitenangabe zitiert. 
zunächst lokal erlebt, aber aus dieser Perspektive unerklärbar bleiben, und deren globalem Zusammenhang, der im Laufe des Romans von einzelnen Wissenschaftlern - und mit ihnen von den Lesern - entdeckt wird.

Im Roman wird auf diese Weise eine Dialektik zwischen der Vielzahl lokaler Erfahrungsräume und einem globalen Bedeutungsraum konstruiert, die an Konzepte multiskalarer Räume und Strukturen erinnert, wie sie in der Humangeographie seit den späten 1980er Jahren intensiv diskutiert werden und auch in der neueren Umweltforschung Anwendung findet. ${ }^{10}$ Zwei Ebenen sind zu unterscheiden, auf denen das Konzept multiskalarer Strukturen erzählerisch umgesetzt wird. Erstens folgt die Romanhandlung auf der Ereignisebene der Naturkatastrophen einem naturwissenschaftlich-objektivistisches Konzept von Multiskalarität. Multiskalare Phänomene entstehen als Ergebnis von Prozessen, die in verschiedenen Raumdimensionen vom Lokalen, Regionalen bis hin zum Globalen unterschiedliche Dynamiken aufweisen, die aber miteinander in Wechselwirkung stehen und sich zum Teil wechselseitig konstituieren; ein Beispiel sind lokale Prozesse der Landnutzungsänderung und globale Prozesse des Biodiversitätsverlusts oder des Klimawandels. In analoger Weise geht es im gesamten ersten Teil des Romans um die Frage, ob ein Zusammenhang zwischen den Anomalien im Meer mit desaströsen Auswirkungen an verschiedensten Orten der Erde erkennbar ist. Während Medien und Politiker einen solchen Zusammenhang standhaft leugnen und zwischenzeitlich sogar eine Nachrichtensperre verhängen, wird er von einzelnen Wissenschaftlern explizit hergestellt. Die Multiskalarität der Ereignisses erscheint in der Romanhandlung insofern als Gegenstand einer Kontroverse.

Anders als die zeitgenössische Umwelt- und Klimawissenschaft verfügen die Wissenschaftler im Schwarm aber zunächst über keine klare Hypothese, die sie dazu veranlassen würde, nach Daten für deren Erhärtung oder Falsifizierung zu suchen. Vielmehr führt erst der Austausch von Beobachtungen die Wissenschaftler in ihrem informellen Netzwerk zur induktiven Suche nach einer Erklärung, mit der sie die verstreuten Phänomene in einen kausalen Zusammenhang bringen können. ${ }^{11}$

Dies führt zur zweiten Ebene, auf der Multiskalarität die Romanhandlung organisiert, nun als reflexives Konzept. Insbesondere Erik Swyngedouws weit rezipiertes Konzept skalarer Konfigurationen als „regulatorische Ordnung(en) oder Netzwerke sowie deren diskursive und theoretische Repräsentationen“ (Swyngedouw 2004, S. 33 [unsere Übs.]) ist hilfreich, um diesen Aspekt der Raumkonstruktion in Schätzings Roman zu untersuchen. Räumliche Skalen sind demnach nicht gegeben, sondern werden laufend in Bezug auf Ausdehnung, Inhalt,

\footnotetext{
10 An dieser Stelle kann nicht auf die unterschiedlichen Konzeptionen und die vielfältige Kritik an der Verwendung des Skalenkonzepts für sozialwissenschaftlichen Fragestellungen eingegangen werden. Siehe dazu z.B. die grundlegende Kritik von Marston et al. (2005).

11 Unter den Wissenschaftlern sind der Meeresbiologe Sigur Johanson und der Verhaltensbiologe Leon Anawak sowie die Wissenschaftsjournalistin Karen Weaver die ersten, die einen Zusammenhang der Ereignisse vermuten. Durch den Gebrauch von Informationstechnologie wie auch auf pragmatisch-organisatorischer Ebene (Erweiterung des Teams) stellen sie ein hohes Maß an Vernetzung und Konnektivität her.
} 
relative Bedeutung und wechselseitige Beziehungen redefiniert, herausgefordert und restrukturiert" (ebd. [unsere Übs.]). Zwischen verschiedenen Skalen besteht eine ,ineinander verschachtelte (wie eine russische Puppe), aber teilweise hierarchische Beziehung“ (ebd. [unsere Übs.]). „Die Mobilisierung von skalaren Narrativen [...] wird zu einem integralen Teil politischer Machtkämpfe und Strategien“ (ebd., S. 34, [unsere Übs.]).

Diese Perspektive findet sich in der Romanhandlung, wenn Netzwerke von Wissenschaftlern persönliche und mediale Informationen von verschiedenen Orten austauschen und theoretisch miteinander in Beziehung setzen. Ihre Hypothesenbildung schreitet von der lokalen zur globalen Ebene voran und setzt insofern ein theoretisches Konzept möglicher globaler Zusammenhänge zwischen den lokal verstreuten Zwischenfällen voraus. Die Zusammensetzung des wissenschaftlichen Netzwerks und später der Wissenschaftler in der internationalen task force im Krisenzentrum Chateau Desaster und auf dem Flugzeugträger USS Independence ist international, inter- und transdisziplinär und repräsentiert insofern ein globales Netzwerk. Als task force, die von der amerikanischen Regierung zur Katastrophenbekämpfung eingesetzt ist und von der Außenwelt abgeschirmt wird, verändert sich jedoch die Organisationsstruktur dieses Netzwerks grundlegend, worauf zurückzukommen ist.

Indem der Roman die Diskussionen zwischen den Wissenschaftlern und ihre Hypothesenbildung ausführlich nachzeichnet, privilegiert er zugleich diskursive und theoretische Repräsentationen des Globalen. Diese müssen sich im Laufe der Handlung aber erst gegen Widerstände durchsetzen, ehe die amerikanische Regierung sie zur Grundlage ihrer Katastrophenbekämpfungsstrategie macht, allerdings nur scheinbar. Denn im vierten Teil des Romans stellt sich heraus, dass die US-Regierung in Wirklichkeit an einem Kampfstoff zur Auslöschung des Superorganismus arbeitet. Hierbei agiert sie wie in älteren Kalte Krieg-Szenarien verdeckt, zentralistisch und hierarchisch, womit ein Geheimdienst-Narrativ (Horn 2007) mit Verschwörungsmotiven aktiviert wird. Das kooperative Modell des Netzwerkes wird unterlaufen, indem den Wissenschaftlern zwar der Freiraum für ihre Kreativität zugestanden, ihre Forschung aber letztlich für die Vernichtung des Gegners instrumentalisiert wird. Die Herstellung eines globalen Handlungsraums durch Vernetzung von Akteuren wird somit in einer freundlichkooperativen und einer agonistisch-destruktiven Variante gezeigt. Die Mobilisierung eines globalen Narrativs wird dabei als Gegenstand von Machtkämpfen selbst Teil der Handlung.

In der Anlage des Romans ist das Globalitäts-Narrativ quasi-objektiv ,richtig ‘. ${ }^{12}$ Mit dem vernetzt-emergenten Wirken des Superorganismus wird die globale Ebene zugleich als Referenzpunkt für Wahrheitsansprüche im erzählten Universum

\footnotetext{
12 Eine zentralistische Lösung, welche die kooperativen Netzwerke ausschalten will, wird abgewiesen, wenn alle Vertreter der US-Regierung, ihres Geheimdiensts und deren wissenschaftlichen Handlanger im dramatischen Showdown mit dem Untergang der USS Independence am Ende des vierten Teils umkommen.
} 
verankert. Die zunächst unheimlichen lokalen Zwischenfälle werden erst im Kontext des Globalitäts-Narrativs erklärbar. Die Erklärung selbst scheint dabei zunächst jede relevante Handlungsmöglichkeit auf die globale Ebene zu verlagern.

Tatsächlich wird die lokale Ebene jedoch nicht als irrelevant dargestellt. Der Informationsaustausch und Diskussionszusammenhang im Netzwerk der Wissenschaftler verknüpft lokales Wissen mit einer globalen Interpretationsperspektive. Weil Anomalien zunächst im Horizont lokalen, kontextualisierten Wissens erkannt werden, erscheint dieses als notwendig für den Erkenntnisprozess im globalen Horizont. Im Prozess der Wissensgenerierung repräsentieren die verschiedenen Wissenschaftler multiple heuristische und epistemologische Skalen, indem sie entweder eine globale (Johanson, Anawak), lokale (Greywolf, Inuit) oder gar transplanetarische Perspektive (Crowe/SETI $)^{13}$ vertreten.

Im Laufe der Handlung entsteht Erkenntnis, indem diese Perspektiven miteinander verknüpft werden; Vernetzung zwischen globalen und lokalen Wissenshorizonten ist demnach ein Element der Handlung selbst. So wird beispielsweise das Wesen des Superorganismus erst erkennbar, indem traditionelles, lokal situiertes Inuit-Wissen mit einer globalen Perspektive und Gedanken aus der Forschung über extraterrestrische Intelligenz verbunden wird. Die ,russische Puppe erweist sich als geeignete Metapher für die im Roman enthaltene multiskalare Konfiguration: Das lokale Wissen wird in die globale Perspektive eingefalzt und erhält durch den globalen Kontext eine neue Bedeutung; durch die Annahme einer global wirksamen Schwarmintelligenz sind die lokalen Katastrophen als Folge anthropogener Verschmutzungen an den jeweiligen Orten interpretierbar. Ebenso verändern die globalen Phänomene im Lichte des zunächst lokal und an der Peripherie verorteten Inuit-Wissens ihre Bedeutung. So führt der Vorschlag „Begreift sie als Teil von euch. [...] Nehmt Kontakt auf“" (S. 639), den der Wissenschaftler Anawak auf seiner viertägigen Reise in Nordpolarmeer von einem Schamanen erhält, zur Strategieänderung eines Teils des wissenschaftlichen Teams, indem es die sogenannte Yrr als ein Teil desselben Systems zu begreifen lernt.

Insgesamt enthält der Roman somit ein globales Narrativ mit sogar interplanetarischen (SETI) Anklängen, in dem jedoch die Bedeutung lokalen Wissens nicht negiert wird. Beide Ebenen müssen vielmehr durch kooperative Netzwerke, hier von Wissenschaftlern und Umweltaktivisten, verknüpft werden. Als Teil einer multiskalaren Konfiguration konstituieren sich das Lokale und das Globale in der Weltgesellschaft wechselseitig; und nur dadurch können sie die Komplexität und Reichweite multiskalarer Phänomene in der Natur einholen.

\footnotetext{
13 SETI steht für Search for Extra Terrestrial Intelligence, wie im Roman bereits an früher Stelle erläutert wird (Schwarm, S. 46) Die Figur Samantha Crowe erinnert zudem stark an die SETIAstronomin Jill Cornell Tarter (geb. 1944), deren Arbeit auch in Carl Sagans Roman Contact dargestellt wird; in der Filmversion (1997) wird die Protagonistin Dr. Ellie Arroway von Jodie Foster gespielt, Regie: Robert Zemecki.
} 


\section{Bezüge des Romans zu zeitgenössischen Umweltdiskursen}

Im zeitgenössischen politischen Umweltdiskurs ist das globale Narrativ keinesfalls unumstritten, weil es mit bestimmten Problembeschreibungen und Lösungsansätzen einhergeht. In empirischen Diskursanalysen zum Klimawandel beispielsweise werden drei Diskurse unterschieden (Bäckstrand u. Lövbrand 2007), die sich in Schätzings Schwarm in unterschiedlicher Weise wiederfinden:

- Der Green Governmentality-Diskurs betont das planetarische Ausmaß des Umweltproblems und sieht die Lösung in einer internationalen, zwischenstaatlichen Kooperation zwischen Regierungen, basierend auf wissenschaftlichem Wissen - big government kombiniert mit big science. In diesen Diskurs schreibt sich Schätzings Roman auf der Handlungsebene weitgehend ein, verhält sich dazu jedoch in gewisser Weise kritisch. Denn die amerikanische Regierung und Teile der von ihr beauftragten wissenschaftlichen task force nehmen die Natur als Bedrohung wahr. Der Roman greift hier eine Tendenz im klimapolitischen Diskurs auf, den Klimawandel vor allem als Sicherheitsproblem zu thematisieren. ${ }^{14}$ Der Roman verhält sich dazu insofern kritisch, als diese konfrontative Perspektive zur Eskalation der Gefährdung führt, anstatt zur Problemlösung beizutragen; ein antiamerikanischer und verschwörungstheoretischer Unterton ist dabei unüberhörbar.

- Der Diskurs der ökologischen Modernisierung versteht Umweltprobleme vor allem als das Ergebnis von Marktversagen. Problemlösungen müssen demnach dabei ansetzen, Märkte und Preise so zu verändern, dass ökologische Innovationen gefördert werden. Im Roman wird diese Perspektive von einzelnen Figuren artikuliert, insbesondere von dem am Kieler Forschungsinstitut GEOMAR angesiedelten, halb-authentischen Professor Gerhard Bohrmann. Auf die Gestaltung der Handlungsebene des Romans hat der Diskurs der ökologischen Modernisierung jedoch wenig Einfluss; das Wirtschafts- und Innovationsgeschehen bezieht sich einseitig auf die Ausbeutung der Natur als Ressource und wird insofern in kritischer Weise dargestellt.

- Der Diskurs der ökologischen Zivilgesellschaft (civic environmentalism) betont die Zusammenhänge zwischen Umweltproblemen und Lebensstilen sowie die Bedeutung von Inklusion, Beteiligung und Wertewandel für eine ökologische Wende. Dieser Diskurs ist im Schwarm auf der Handlungsebene in der selbst organisierten Vernetzung von Wissenschaftlern und Aktivisten stark verankert. Die Interpretation der Vorgänge als

\footnotetext{
${ }^{14}$ Etwa in Papieren des Pentagon bereits zur Jahrhundertwende. In den letzten zehn Jahren werden zunehmend sicherheitsbezogene Aspekte des Klimawandels wie die Gefährdung der Nahrungsmittelsicherheit, massenhafte Migration, die Gefährdung von Küstenzonen oder wachsende Konflikte um knappe Wasserressourcen hervorgehoben. Zur „securatization“ des Klimadiskurses vgl. Trombetta (2008).
} 
globale ökologische Katastrophe muss in der Romanhandlung zudem gegen das wissenschaftliche Establishment durchgesetzt werden. Ökologisches Verstehen wird insofern als bottom-up-Prozess mit einer AntiEstablishment-Komponente dargestellt.

Insgesamt lässt sich konstatieren, dass Schätzings Roman Elemente verschiedener Umweltdiskurse miteinander verknüpft, aber spezifische Auslassungen aufweist. Auf der Handlungsebene wird das Globalitäts-Narrativ zum einen mit einer wissenschaftlichen Vernetzungs- und einer zivilgesellschaftlichen bottom-upPerspektive kombiniert. Zum anderen enthält die Vorstellung des Wirkens des Superorganismus Anklänge an Konzepte des öko-systemaren Denkens, das den traditionellen Naturschutzdiskurs Anfang der 1970er ablöste. Fragen des Wirtschafts- und Innovationsprozesses werden von Figuren angesprochen, aber nicht in die Handlung integriert. Zusammenhänge zwischen ökologischen Problemlagen und Lebensstilen werden nicht thematisiert.

\section{Ganzheitliche Naturvorstellungen und Schwarm als vernetztes System}

Im Roman werden im Wesentlichen zwei unterschiedliche Naturauffassungen gegeneinander gestellt: eine anthropozentrische und eine systemische. In der anthropozentrischen Auffassung gilt Natur als Ressource für den Menschen, der sie sich ,untertan mache'. Diese prometheische Auffassung, die bis auf die frühneuzeitliche Naturwissenschaft zurückgeht, ${ }^{15}$ ist stark in der christlich-abendländischen Tradition verankert (Sutton 2004, S. 24). Die systemische Naturauffassung hingegen geht davon aus, dass der Mensch nicht die Krone der Schöpfung ist, sondern ,Gast ${ }^{\varsigma}$ auf dem Planeten Erde, der Respekt vor Natur und Umwelt haben sollte, in deren System er einbegriffen ist. ${ }^{16}$ In der Welt des Romans werden die beiden unterschiedlichen Naturauffassungen einzelnen Figurenkonstellationen zugeordnet, die sich im dritten und vierten Teil zunehmend zu zwei feindlichen Gruppen formieren.

Die Vorstellung einer rational erfassbaren, nach Gesetzen funktionierenden Natur, die darüber hinaus zum Nutzen des Menschen zur Verfügung steht, ${ }^{17}$ bildet die Voraussetzung für den Plot von Schätzings Schwarm. Schon in den ersten beiden Teilen wird die anthropozentrische Wissenschaftsauffassung kritisch reflektiert, indem nach den Zusammenhängen der verstreuten Anomalien und dabei nach alternativen Erklärungsansätzen gesucht wird. Die alternativen Erklärungsansätze, die

\footnotetext{
15 Nach Bacon besteht Naturerkenntnis darin, dass „die durch Beobachtung gewonnenen Daten mittels Verstandesaktionen zu theoretischen Zusammenhängen" verbunden werden und Natur im Sinne einer „dynamisch-mechanistischen [...] Gesetzlichkeit“" als „Bereich technischer Verfügbarkeit denkbar" wird (Kaulbach 1984, S. 469f.).

16 Dementsprechend spricht Sutton (2004, S. 13) von „reverence and respect“, die von den meisten Umweltschützern als angemessenes Verhältnis gegenüber der Natur befürwortet werden.

17 Vgl. dazu den kritischen Beitrag von Bernd Herrmann im vorliegenden Band.
} 
den Menschen als Teil komplexer und vernetzter ökologischer Systeme sehen, werden im Roman sowohl in drei vormodernen Varianten dargestellt als auch in einer aktuellen Variante, und zwar dem Organisationsmodell des Schwarms.

$\mathrm{Zu}$ den vormodernen Varianten: Bereits im Prolog mit dem mysteriösen Verschwinden eines peruanischen Fischers heißt es im ersten Satz des Romans, „das Schicksal erfüllte sich, ohne dass die Welt Notiz davon nahm“" (S. 11). Das Zitat registriert zunächst das Unglück als persönliches Verhängnis, verweist aber zugleich auf das Kollektiv-Schicksal der Peruaner an der Küste von Huanchaco, die zwar noch vereinzelt traditionellen Fischfang betreiben, aber nur die Arbeit in Fischmehl- und Fischölfabriken sowie der Tourismusbranche ihr Einkommen sichern kann. Es wird dargestellt, dass die Einheimischen seit Jahrhunderten von der Fischerei, also vom und mit dem Ozean, lebten. Dabei ist das Meer nicht nur ihre zentrale Ressource, sondern wird zugleich als höhere Macht verstanden, die sich auch gegen den Menschen, etwa in Form des Wetterphänomens El Niño, richten kann und dann durch Opfergaben besänftigt werden muss. Damit führt der Prolog in das Thema der Umweltkrise ein, indem ein traditionelles naturreligiöses Mensch-Natur-Verhältnis einem einseitig ökonomisch orientierten Naturverhältnis, das zur irreversiblen Ausbeutung der Fischfanggründe führt, entgegengesetzt wird.

b) Im Mittelteil des Buches unternimmt der, Ökologe‘ Anawak eine eigenwillige Exkursion zu den kanadischen Inuit am Nordpolarmeer. Dabei lernt er von ihnen eine ganzheitliche Naturauffassung als Überlebensstrategie in einer äußerst widrigen Umwelt kennen. Es wird explizit geäußert, dass die Inuit Natur „als Bestandteil der beseelten Welt" (S. 627) verstehen, in welches der Mensch ohne Vormachtstellung integriert ist. Im Roman dient die Figur des kanadischen Umweltaktivisten Greywolf dazu, diese ganzheitliche Naturauffassung zu füllen. Einen Aggressionsakt von Walen deutet er als „Rache der Natur“ (S. 154) und klagt damit die Vertreter eines anthropozentrischen Naturbilds an, welche die Natur ohne Rücksicht auf Verluste ausbeuteten. Die Konnotation „Rache“ schreibt der Natur jedoch den Charakter einer mit Willen ausgestatteten Entität zu und hat insofern naturreligiöse Untertöne.

c) Darüber hinaus lässt sich Anawak durch die Naturauffassung der Nuu-chaanulth-Indianer der nordamerikanischen Westküste zu einem respektvollen Umgang mit der Natur inspirieren. Wenn ihr Wahlspruch „Hishuk ish ts'awalk“ - „Alles ist eins“ (S. 309) - in Indianersprache zitiert wird, wird ethnische Authentizität suggeriert. Dieses vormoderne Naturbild erhält im Roman eine gewisse Autorität, indem es als Motto vorangestellt ist und auf der Handlungsebene einen Schlüssel zum Verständnis der Schwarmintelligenz bereitstellt.

Dabei wird unterstellt, dass die Idee einer Intelligenz im Meer mit einem vormodernen Naturbegriff vereinbar ist, indem Einheits- und Ganzheits- sowie naturreligiöse Vorstellungen ebenfalls für das Schwarmwesen in Anspruch genommen werden. Mit den vormodernen Auffassungen teilt der Schwarm den „Naturspiritualismus“ (Horn 2009, S. 120), den Robin Detje (2004) in seiner 
Rezension des Romans als „hymnischen neuen Öko-Pantheismus“ ironisiert hat. Das Modell einer esoterisch-intuitiven Kommunikation mit dem „seiner selbst bewusst gewordene[n] Ozean“ (S. 965) im fünften Teil des Romans, welche die Perspektive einer Versöhnung zwischen Mensch und Natur sowie einer Abwendung der Gefahr eröffnet, trägt jedoch utopische Züge und bringt insofern einen gewissen Pessimismus hinsichtlich des Realitätsgehalts der Versöhnungsperspektive zum Ausdruck. ${ }^{18}$ In dieser Hinsicht kann zugunsten einer kritischen Funktion fiktionaler Ökoliteratur als „Sensorium und symbolische Bilanzierungsinstanz für kulturelle Fehlentwicklungen" (Zapf 2008, S. 33) argumentiert werden, wenn die Versöhnung von Mensch und Natur nur noch als individuell-spirituelle Utopie gestaltet werden kann.

Der Schwarm selbst ist im Roman als ein Superorganismus konzipiert, der mit kollektiver Intelligenz ausgestattet ist. Vorbilder sind der Ameisenstaat und andere ,soziale Insekten ${ }^{6}$ wie Bienen, Wespen oder Termiten, für deren systemische Organisationsform der Biologe William Morton Wheeler (1928) Anfang des 20. Jahrhunderts den Begriff des Superorganismus geprägt hat. ${ }^{19}$ Die komplexe Struktur des maritimen Superorganismus, die aus dem Zusammenschluss äußerst einfach organisierter Einzeller hervorgeht, ist mehr als die Summe ihrer Teile. Im Roman fragen sich die Wissenschaftler, wie ,aus einem Konglomerat von Zellen ein höheres Ganzes" entstanden sei (S. 711). Das Schwarmwesen wird als Organisations- und Lebensform dargestellt, das seine Gestalt beständig verändern, sich mit den unterschiedlichsten Organismen verbinden, sich blitzschnell teilen und wieder verschmelzen kann, wobei jede Zelle individuell aktiv ist. Anders als es bei den bekannten Superorganismen aus dem Insektenreich der Fall ist, werden im Roman mikrobiologische Mutationsprozesse mit phänotypischen Formänderungen des Schwarms kurzgeschlossen - ein Skalensprung von der Mikro- zur Makroebene, der zur Unheimlichkeit der Handlung wesentlich beiträgt. Die Kommunikation wird durch Pheromone gesteuert, deren Ausschüttung einen kollektiven Zusammenschluss der Einzeller zu einen größeren Gebilde ermöglicht.

Wie jüngst gezeigt worden ist, denkt Schätzing in seiner Konzeption des Schwarms frühere Vorstellungen von biologischer Selbstorganisation weiter (Horn 2009, S. 121), ja sein Roman wird als „wohl expliziteste Umsetzung globaler

\footnotetext{
18 Wanning (2008, S. 346) hingegen sieht im utopischen Ende des Romans mit der ,stetige[n] Heilsgewissheit“ eine „ideologische, vielleicht sogar gefährliche Lösung“. Zu diesen Ergebnis kommt sie, indem sie Schätzings Erzählstrategie vom Verfahren in Becks Weltrisikogesellschaft (2007) abhebt, worin der Soziologe die globalen soziale Probleme mit einer neuen Begrifflichkeit (Risiko, Nebenfolgen, Globalisierung etc.) beschreibe, aber nicht mit Lösungen aufwarte. Die Interpretation der utopischen Wendung im fünften Teil des Romans als „Lösung“ ist dabei insofern fragwürdig, als die entsprechende Episode, das quasi-spirituelle Erleben einer imaginativen Einheit mit der Königin des Superorganismus durch eine Vertreterin des Teams, erzähltechnisch mehrfach gebrochen und damit relativiert wird: als subjektives Erleben und als Aufschub. Die Passage artikuliert eine pantheistische Utopie, stellt aber bei genauer Lektüre keine Lösung des zentralen Konflikts dar.

${ }_{19}$ Zur Karriere des Ameisenstaates als Sozialmodell von der Antike bis hin zur aktuellen Soziobiologie und Kybernetik vgl. Werber (2009).
} 
Vernetztheit" gepriesen (Horn 2007, S. 492). ${ }^{20}$ Zugleich lässt sich eine Resonanz zur so genannten Gaia-Hypothese feststellen, wonach die gesamte Biosphäre als Superorganismus vorgestellt worden ist. ${ }^{21}$

Das Konzept der Schwarmintelligenz ist auch im Bereich der Organisations- und Managementlehre aufgegriffen worden. Hier steht die Emergenz komplexer Organisationsmuster aus der Interaktion dezentralisierter Agenten im Vordergrund, die einfachen Regeln folgen. Die emergenten Strukturen zeichnen sich durch drei Eigenschaften aus, die für die Effizienz und das Überleben einer Organisation ausgesprochen wertvoll sind: Flexibilität, Robustheit und Selbstorganisation (Bonabeau u. Meyer 2004, S. 108). Diese Eigenschaften weist auch der maritime Superorganismus in Schätzings Roman auf, der sich in verschiedensten Lebewesen an unterschiedlichen Orten des Globus als robuste, gallertartige Masse in immer neuen Erscheinungsformen zeigt. Im fünften Teil interpretiert die Wissenschaftsjournalistin Weaver das „Schauspiel“ der sich beständig in der Gestalt verwandelnden „Königin“ des Schwarms, von deren biolumineszierender Erscheinung sie darüber hinaus ästhetisch fasziniert ist, als „Beweis für die Existenz ausgeprägter, definitiv nicht-menschlicher Intelligenz" (S. 970).

Dem Schwarm wird die Fähigkeit zu biologischem Lernen zugeschrieben, indem er durch Verschmelzung die Informationen anderer Organismen aufnehmen kann und über ein „Rassengedächtnis“ (S. 860) verfügt, wie es im Roman heißt. Die beschleunigte biologische Weitergabe von Information wird damit als evolutionärer Vorteil konstruiert, da der Mensch über einen solchen materiellen Mechanismus der unmittelbaren Weitergabe von Information nicht verfügt. Außerdem löst sich hier die Vorstellung stabiler Artengrenzen auf. Die Idee des Superorganismus, worin Vorstellungen u.a. aus Mikrobiologe, Biophysik, Kybernetik und Computerwissenschaft verarbeitet sind, offeriert eine posthumanistische Vorstellung mit einem veränderten Mensch-Natur-Verhältnis.

Im Roman führt das Verständnis des Superorganismus bei einigen der Wissenschaftler zur Formulierung einer anti-anthropozentrischen Sichtweise: „Wir können und müssen die Yrr nicht verstehen. Aber wir müssen dem, was wir nicht verstehen, Platz einräumen“ (S. 775). Die Erkenntnis, dass der Schwarm älter als die Menschheit und ihr evolutionär überlegen sei, macht die Positionierung des Menschen an der ,Spitze der Schöpfung' fragwürdig. In der Welt des Romans hat diese Einsicht die Konsequenz, dass ein Teil des Teams die Frontstellung zu der als feindlich erachteten Macht im Meer aufgibt und das Freund-Feind-Schema zwischen Mensch und Natur überwindet. Dies bedeutet allerdings, dass sich der Mensch „systemkonform“ zum Superorganismus verhalten muss, wie Horn (2007,

\footnotetext{
${ }^{20}$ Horn (2007) orientiert sich in der Auffassung von „Vernetztheit“ u.a. an Thacker (2004).

${ }^{21}$ Diese radikal-ökologische Hypothese, dass die Natur als ein sich selbst regulierendes System aus dem Gleichgewicht geraten sei, wurde von der Mikrobiologin Lynn Margulis und dem Biophysiker und Chemiker James Lovelock in den 1960er im Gefolge des neuen ökologischen Systemdenkens entwickelt. Diese Hypothese führt jedoch nicht notwendig zum Diskurs der ökologischen Modernisierung, wie Lovelocks provokative Befürwortung der Atomkraft belegt (Lovelock 2007).
} 
S. 496) zu Recht bemerkt. Zudem löst sich das Freund-Feind-Schema keineswegs auf, sondern verschiebt sich lediglich, indem die Angehörigen des Teams, die einen systemischen Naturbegriff anhängen, nun den Vertretern der task force entgegengesetzt werden, die eine anthropozentrische Naturauffassung verfechten und es auf die Auslöschung des Schwarms abgesehen haben.

\section{Fazit: Drei Konstellationen des Mensch-Natur-Verhältnisses}

Mit dem heterogen zusammengesetzten Netzwerk aus Wissenschaftlern, Umweltaktivisten, Regierungsvertretern und Geheimdiensten einerseits und der Schwarmintelligenz andererseits werden im Roman zwei prinzipiell verschiedene Organisationsmodelle gegenübergestellt. Der Schwarm ist ein kollektives, durch Selbstorganisation bestimmtes System, bei dem das Verhalten der Individuen durch Informationsströme gelenkt wird und in einer komplexeren Organisationsstruktur aufgeht. Im Netzwerk hingegen verbleibt den Individuen die Autonomie über ihr Denken und Handeln, die Fortsetzung der Kooperation ist fortlaufend auf die Motivation der Mitglieder des Netzwerks angewiesen. Wo im Schwarm Informationsübertragung durch biologische Materie stattfindet, wird im Netzwerk der Prozess der Wissensgenerierung als dynamische Generierung und Überprüfung von Ideen und Hypothesen dargestellt.

Im Übergang vom locker verknüpften Netzwerk zur task force vollziehen sich jedoch Prozesse der Formalisierung und Hierarchisierung, die später zu internen Konflikten führen. Die Verschiebung der Freund-Feind-Konstellation zu einer neuen Frontstellung innerhalb des Teams zeigt, dass ein aus Individuen zusammengesetztes Netzwerk scheitern kann, wenn die Individuen zur Kooperation nicht fähig oder willens sind. Dies impliziert, dass Individuen Entscheidungen treffen können. Anders als für Elemente eines Superorganismus gelten für sie die Kategorien von Verantwortung, Fehlbarkeit und Schuld. Diese sind die Voraussetzung dafür, dass der zentrale Plot funktioniert, der die Katastrophen als Rache für die Verfehlungen des Menschen darstellt.

Insgesamt stellt der Roman aber nicht die Machtlosigkeit des Menschen gegenüber einer numinosen, rächenden Natur aus und propagiert auch nicht die spirituelle Versenkung in den Kosmos, sondern führt drei verschiedene Konstellationen des Mensch-Natur-Verhältnisses und deren Konsequenzen vor Augen.

Erstens die prometheische Unterwerfung der Natur durch den Menschen, die in die Katastrophe führt; zweitens die Unterwerfung des Menschen unter eine systemische Natur, deren Organisationsmuster deutlich als effizient und intelligent, aber auch als autoritär und kollektivistisch dargestellt werden; die spirituellästhetische Bezauberung der Wissenschaftsjournalistin Weaver durch die Schwarm-Königin im fünften Teil des Romans hat insofern Züge einer Unterwerfung unter eine als überwältigend erlebte Autorität; und drittens ein aus Individuen zusammengesetztes Netzwerk, dessen Verhältnis zur Natur an die 
Einsicht in ökologische Grenzen gekoppelt ist; dies ist die demokratische Vision, in der die netzwerkförmige Vergesellschaftung die Freisetzung von Kreativität und Erkenntnis ermöglicht und sich die gesellschaftliche Vernunft um die ökologische Einsicht erweitert.

Die drei Konstellationen zeichnen sich zudem durch unterschiedliche räumliche Konfigurationen aus: Die prometheische Konstellation ist durch die globale Durchsetzung einer instrumentellen Ausbeutungslogik gekennzeichnet, die sich über lokale Besonderheiten hinwegsetzt und mit einer ausgeprägten Hierarchie zwischen zentralen und peripheren Orten einhergeht. In der spirituellen Naturversenkung wird das lokale Erleben zum unmittelbaren Einssein mit dem Kosmos die Differenz kollabiert; das Individuum unterwirft sich dem ökologischen System, in dessen Zentrum eine „Königin“ die dezentral operierende biologischen Intelligenz zu steuern scheint. Im Netzwerk hingegen besteht ein Dialog zwischen lokalen und globalen Wissenshorizonten, die den multiskalaren Wechselwirkungen komplexer und vernetzter Ökosysteme lose korrespondiert; kreative Bewegungen, die das Netzwerk transformieren, können sowohl aus den Zentren wie der Peripherie kommen.

Während die prometheische Haltung im Roman deutlich negativ bewertet wird, bleibt die Handlung zwischen der zweiten und dritten Haltung mehrdeutig. Die ästhetisch eindringlich aufgeladene Darstellung der zweiten Haltung in der Begegnung mit der Schwarm-Königin (S. 970) vermittelt tatsächlich den Eindruck einer öko-spirituellen Erzählabsicht. Am Ende bleibt die Handlung aber unabgeschlossen, die Gefahr erscheint lediglich „ausgesetzt“ (S. 983), wie ein Tagebucheintrag einer der Wissenschaftlerinnen zum Jahrestag des Untergangs der USS Independence im Epilog reflektiert. Die ,Prometheisten“ sind nicht eingebunden, spiritueller Öko-Autoritarismus und ökologisch aufgeklärte Demokratie stehen unvermittelt nebeneinander. Dies lässt sich als Ausdruck einer Schizophrenie der Naturverhältnisse einer Gesellschaft verstehen, die ungebremste Ressourcenausbeutung, spirituelles Naturerleben und ökologische Modernisierung zugleich strukturell etabliert und situativ entkoppelt hat und somit dauerhaft nebeneinander praktiziert. Unklar bleibt jedoch, ob diese Schizophrenie vom Erzähler bewusst gestaltet oder Ausdruck einer Erzählhaltung ist, die Tendenzen des gesellschaftlichen Umweltdiskurses aufnimmt und in Erzählelemente übersetzt, ohne sie jedoch einer kritischen Reflexion zuzuführen. 


\section{Literatur}

Bäckstrand, Karin; Lövbrand, Eva (2007): Climate Governance Beyond 2012:

Competing Discourses of Green Governmentality, Ecological Modernization and Civic Environmentalism. In: Pettenger, Mary E. (Hgg.): The Social Construction of Climate Change. Power, Knowledge, Norms, Discourses. London: Ashgate, S. 123-148.

Bachmann-Medick, Doris (2006): Spatial turn. In: Bachmann-Medick, Doris:

Cultural Turns. Neuorientierungen in den Kulturwissenschaften. Reinbek bei Hamburg: Rowohlt, S. 284-328.

Beck, Ulrich (2007): Weltrisikogesellschaft. Auf der Suche nach der verlorenen Sicherheit. Frankfurt am Main: Suhrkamp.

Bonabeau, Eric; Meyer, Christopher (2004): Swarm Intelligence. A Whole New Way to Think about Business. http://0301.netclime.net/1_5/K/D/M/ Harvard\%20Business\%20Rev.pdf, zuletzt besucht am 30. Sept. 2010.

Buell, Lawrence (1995): The Environmental Imagination. Thoreau, Nature Writing and the Formation of American Culture. London: Princeton University Press.

Detje, Robin (2004): Die Rache des Killerschleims. In: Süddeutsche Zeitung, 4. März 2004, S. 16.

Feindt, Peter Henning (2002): Alle gegen Niemand. Zur Entwicklung des Umweltund Nachhaltigkeitsdiskurses in Deutschland. In: Forschungsjournal Neue Soziale Bewegungen, Jg. 13, Heft 4, S. 20-28.

Garrard, Greg (2004): Ecocriticism. London, New York: Routledge.

Gersdorf, Catrin; Mayer, Sylvia (2005) Hgg.: Natur - Kultur - Text. Beiträge zu Ökologie und Literaturwissenschaft. Heidelberg: Universitätsverlag Winter.

Glotfelty, Cheryl (1996): Introduction. In: Glotfelty, Cheryl; Fromm, Harold (Hgg.): Ecocriticism Reader. Landmarks in Literary Ecology. Athens [u. a.]: The University of Georgia Press.

Goodbody, Axel (1998.) Hrsg.: Literatur und Ökologie. Amsterdam [u. a]: Rodopi.

Goodbody, Axel (2006): Nature's Revenge: The Ecological Adpation of Traditional Narratives in Fifty Years of German-speaking Writing. In: Tamkang review, a quarterly of literary and cultural studies 37.1, S. 1-27.

Heise, Ursula K. (2001): Ecocriticism/Ökokritik. In: Nünning, Ansgar (Hrsg.): Metzler Lexikon Literatur- und Kulturtheorie. Stuttgart [u. a.]: Metzler S. 128129.

Heise, Ursula K. (2006): Greening English: Recent Introductions to Ecocriticism. In: Contemporary Literature, Bd. 47.2, S. 289-298. 
Horn, Eva (2007): Der geheime Krieg. Verrat, Spionage und moderne Fiktion. Frankfurt am Main: Fischer.

Horn, Eva (2009) Das Leben eine Schwarm. Emergenz und Evolution in moderner Science Fiction. In: Horn, Eva; Gisi, Lucas Marco (Hrsg.): Schwärme. Kollektive ohne Zentrum. Eine Wissensgeschichte zwischen Leben und Information. Bielefeld: Transcrip, S. 101-124.

Huber, Joseph (2001): Allgemeine Umweltsoziologie. Opladen: Westdeutscher Verlag.

Intergovernmental Panel on climate Change IPCC (2007) Fourth Assessment Report. http://www.ipcc.ch/, zuletzt besucht am 8. Oktober 2010.

Kaulbach, F. (1984): Art. „Natur [V. Neuzeit]“. In: Ritter, Joachim: Gründer, Karlfried (Hgg.): Historisches Wörterbuch der Philosophie. Bd. 6. Basel [u. a.]: Schwabe, S. 467-479.

Kerridge, Richard; Sammells, Neil (1998) Hrsg.: Writing the Environment. Ecocriticsm and Literature. London [u. a]: Zed Books.

Kerridge, Richard (2000): Ecothrillers. Environmental Cliffhangers. In: Coupe, Laurence (Hrsg.): The Green Studies Reader. From Romanticism to Ecocriticism. London [u. a]: Routledge, S. 242-249.

Lehnert, Gertrud (1991): Endzeitvisionen in der Science Fiction. In: Kaiser, Gerhard R. (Hrsg.): Poesie der Apokalypse. Würzburg: Königshausen \& Neumann, S. 297-312.

Lovelock, James E. (2007): Gaias Rache. Warum die Erde sich wehrt. Übs. von Hartmut Schickert. Berlin: List.

Marston, Salliea; Jones,Johnpaul; Woodward, Keith (2005): Human geography without scale. In: Transactions of the Institute of British Geographers, Bd. 30, S. 416-432.

MEA (2006) Millenium Ecosystem Assessment http://www.maweb.org/en/Index.aspx, zuletzt besucht am 7. Oktober 2010

Reusswig, Fritz; Schwarzkopf, Julia; Pohlenz, Philipp (2004): Double Impact. The Climate Blockbuster „The Day after Tomorrow“ and its impact on the German cinema public. Potsdam Institute for Climate Impact Research (PIK), No. 92.

Schätzing, Frank (2005): Der Schwarm. Roman. Frankfurt am Main: Fischer.

Sutton, Philip W. (2004): Nature, Environment and Society. New York: Palgrave Macmillan. 
Swyngedouw, Erik (2004): Globalisation or, Glocalisation'? Networks, Territories and Re-Scaling. In: Cambridge Review of International Affairs, 17.1, S. 25-48.

Thacker, Eugene (2004): Networks, Swarms, Multitudes [2 Teile]. ctheory.net. http:/ / www.ctheory.net/articles.aspx?id=422 und $=423$, zuletzt besucht am 29. September 2010.

Trombetta, Maria Julia (2008): Environmental Security and Climate Change.

Analysing the Discourse. In: Cambridge Review of International Affairs, 21.4, S. 585-602.

Wallerstein, Immanuel (2004): Das moderne Weltsystem, Bd. 3: Die große Expansion. Wien: Promedia.

Wanning, Berbeli (2008): Yrrsinn oder die Auflehnung der Natur.

Kulturökologische Betrachtungen zu Der Schwarm von Frank Schätzing. In: Zapf, Hubert (Hrsg.): Kulturökologie und Literatur. Beiträge zu einem interdisziplinären Paradigma der Literaturwissenschaft. Heidelberg: Universitätsverlag Winter, S. 339-357.

Werber, Niels (2009): Schwärme, soziale Insekten, Selbstbeschreibungen der Gesellschaft. Eine Ameisenfabel. In: Horn, Eva; Gisi, Lucas Marco (Hgg): Schwärme. Kollektive ohne Zentrum. Eine Wissensgeschichte zwischen Leben und Information. Bielefeld: transcript, S. 183-202.

Wheeler, William Morton (1928): Social Insects. Their Origin and Evolution. London: K. Paul, Trench, Trubner \& Co.

Zapf, Hubert (2008): Einleitung. In: Zapf, Hubert (Hrsg.): Kulturökologie und Literatur. Ein transdisziplinäres Paradigma der Literaturwissenschaft. Heidelberg: Universitätsverlag Winter, S. 15-44. 


\section{Autorenverzeichnis}

\section{Heinrich Detering (Prof. Dr. Dr. h.c.)}

nach Lehrtätigkeiten in München und Kiel seit 2005 Professor für Neuere Deutsche und Vergleichende Literaturwissenschaft an der Universität Göttingen. Gastprofessuren in Skandinavien und den USA. Preis der Kritik 2003, Poetikdozentur Mainz 2004/05, Dr. h. c. Universität Aarhus (Dänemark) 2008, Leibniz-Preis der DFG 2009, Honorarprofessor an der Huazhong University of Science and Technology (HUST) in Wuhan/China 2010. Wissenschaftliche und literarische Buchpublikationen, zuletzt: „Bertolt Brecht und Laotse“ (2008), „Wrist. Gedichte“ (2009), „Der Antichrist und der Gekreuzigte. Friedrich Nietzsches letzte Texte“ (3. Auflage 2010).

\section{Gabriele Dürbeck (PD Dr.)}

1995-2001 Wissenschaftliche Assistenz in Rostock; 2002/03 PostdocStipendiatin und Wissenschaftliche Mitarbeiterin am Graduiertenkolleg „Reiseliteratur und Kulturanthropologie“ in Paderborn; seit 2004 Vertretungs- und Gastprofessuren an den Universitäten Rostock, Wuppertal, Hamburg, University of Cincinnati/ Ohio, Hannover und Göttingen. Arbeitsgebiete: Literarische Anthropologie, Reiseliteratur, Postkoloniale Studien in der Germanistik, Literarische Darstellung von Naturkatastrophen und Klimawandel. Bücher: Einbildungskraft und Aufklärung. Perspektiven der Philosophie, Anthropologie und Ästhetik um 1750 (1998); Stereotype Paradiese. Ozeanismus in der deutschen Südseeliteratur 1815-1914 (2007). 


\section{Maren Ermisch (M.A.)}

Studium der Neueren Deutschen Literaturwissenschaft, Germanistik und Englischen Philologie an der Christian-Albrechts-Universität Kiel; 2001 Magisterabschluss mit einer Arbeit über Thomas Mann; 2003-2006 Wissenschaftliche Volontärin im Heinrich-und-Thomas-Mann-Zentrum Lübeck; 2007-2009 freie Mitarbeiterin der Kulturstiftung Hansestadt Lübeck und Projektmanagerin in den Ev.-Luth. Kirchenkreisen Lübeck, Eutin und Oldenburg; seit 2009 wissenschaftliche Mitarbeiterin am Lehrstuhl von Prof. Dr. Dr. h. c. Heinrich Detering; hier Mitarbeit an der Großen Brandenburger Ausgabe der Werke Theodor Fontanes und Koordination der Leibniz-Projekte am Lehrstuhl.

\section{Peter H. Feindt (Dr.)}

lehrt und forscht seit 2007 zunächst als Senior Lecturer und seit 2010 als Reader for Environmental Policy an der School of City and Regional Planning, Cardiff University; davor nach einer politikwissenschaftlichen Promotion wissenschaftlicher Mitarbeiter und Leiter einer Nachwuchsgruppe am Forschungsschwerpunkt Biotechnik, Gesellschaft und Umwelt der Universität Hamburg; zahlreiche Forschungsprojekte und Publikationen in den Bereichen Umwelt- und Agrarpolitik, politische Partizipation und Demokratietheorie, Regieren in komplexen Mehrebenensystemen, politische Kommunikation.

\section{Axel Goodbody (Prof. Dr.)}

Professor of German Studies and European Culture an der University of Bath, Großbritannien, Grundstudium (Germanistik und Romanistik) am Trinity College Dublin; Lektor für englische Sprache und Kultur an der Universität Kiel; Promotion (Kiel) mit einer Arbeit zum Thema ,Natursprache` in der deutschen Romantik und der neueren Naturlyrik; Veröffentlichungen zur DDR-Literatur, zur Literatur des Exils, zu literarischen und filmischen Repräsentationen von Natur und Technik, und zur ökokritischen Theorie. Mitbegründer und erster Vorsitzender (2004-2006) der Europäischen Gesellschaft für das Studium von Literatur, Kultur und Umwelt; Mitherausgeber der online-Zeitschrift „Ecozon@. Journal for European Ecocriticism“ und der Buchreihe „Nature, Culture and Literature“ (Rodopi).

\section{Bernd Herrmann (Prof. Dr.)}

nach dem Studium der Zoologie, Anthropologie, Geologie \& Paläontologie und Biomathematik Diplom in Biologie 1970 an der FU Berlin, dort auch Promotion und Habilitation für Anthropologie, seit 1978 Professor für Anthropologie an der Universität Göttingen, 1995/96 Fellow des Wissenschaftskollegs Berlin, Mitglied der Nationalen Akademie LEOPOLDINA seit 1998, kooptiertes Mitglied der 
Philosophischen Fakultät in Göttingen, Gastprofessuren in Halle, Florenz, London, Wien, Thessaloniki, 2004-2010 Sprecher des Graduiertenkollegs „Interdisziplinäre Umweltgeschichte"; Autor und Herausgeber von Schriften der Biologie vor- und frühgeschichtlicher, mittelalterlicher und frühneuzeitlicher Bevölkerungen, der Archaeometrie biogener Materialien sowie zur Umweltgeschichte in Mittelalter und Früher Neuzeit.

\section{Julia Hoffmann (M.A.)}

Studium der Komparatistik, Englischen Philologie und Kulturanthropologie/ Europäischen Ethnologie an der Universität Göttingen, 2009 Magisterabschluss, seit 2009 Promotion zum Thema „Kinder-und Jugendliteratur gegen den Nationalsozialismus" sowie Projektmitarbeiterin am Lehrstuhl Prof. Heinrich Detering, Seminar für Deutsche Philologie: Betreuung und Erschließung der historischen Kinder- und Jugendbuchsammlung Jürgen Seifert, Koordination verschiedener Projekte zum Thema Kinder- und Jugendliteratur, Mitglied der Gesellschaft für Kinder- und Jugendliteraturforschung.

\section{Manfred Jakubowski-Tiessen (Prof. Dr.)}

nach Lehr- und Forschungstätigkeiten in Kiel, Greifswald und am Max-PlanckInstitut für Geschichte seit 2006 Professor für Geschichte der Frühen Neuzeit an der Universität Göttingen. Gastprofessur in Aarhus (Dänemark). Sprecher des Graduiertenkollegs „Interdisziplinäre Umweltgeschichte“, Publikationen zur Sozial-, Mentalitäts-, Religions- und Umweltgeschichte der Frühen Neuzeit, letzte umweltgeschichtliche Veröffentlichungen u.a.: Von der Gottesgabe zur Ressource. Konflikte um Wald, Wasser und Land in Spanien und Deutschland seit der Frühen Neuzeit, hg. zus. mit M. L. Allemeyer u. S. Rus Rufino, Essen 2007 (ebenfalls auf Spanisch) - Die Auswirkungen der „Kleinen Eiszeit“ auf die Landwirtschaft: Die Krise von 1570, in: Zs. f. Agrargeschichte und Agrarsoziologie 58, 1 (2010) S. 31-50.

\section{Frank Kelleter (Prof. Dr.)}

Studium der Amerikanistik, Anglistik und Germanistik an der Universität des Saarlandes, Washington University St. Louis (USA) und Johannes GutenbergUniversität Mainz. Lehr- und Forschungstätigkeit in Mainz, an der University of Michigan in Ann Arbor, New York University, University of California Berkeley. Seit 2002 Lehrstuhlinhaber für Nordamerikastudien an der Universität Göttingen. Wichtigste Publikationen: „Die Moderne und der Tod“ (1997), „Con/Tradition“ (2000), „Amerikanische Aufklärung“ (2002), „American Studies as Media Studies“ (hg. mit Daniel Stein, 2008). Sprecher und Initiator der DFG-Forschergruppe „Ästhetik und Praxis populärer Serialität" (seit 2010). 


\section{Ulrike Kruse (M.A.)}

Studium der Germanistik, Allgemeinen und Vergleichenden Literaturwissenschaft sowie der Neueren Geschichte an der Universität Potsdam, seit 2009 Stipendiatin am DFG-Graduiertenkolleg „Interdisziplinäre Umweltgeschichte“ an der Universität Göttingen, Promotion bei Professor Bernd Herrmann über „Natur-Diskurse in Hausväterliteratur und volksaufklärerischen Schriften vom späten 16. bis zum frühen 19. Jh.“

\section{Stefanie Schuh (M.A., M.St.oxon)}

Studium der Komparatistik, Germanistik und Latinistik in Tübingen und Oxford als (Hölderlin-)Stipendiatin der Studienstiftung des deutschen Volkes. Magisterabschluss 2008, Masterabschluss 2009. Seit 2009 Promotion an der Universität Göttingen bei Professor Heinrich Detering zum Thema „Der Detektivroman und die Organisation von Wissen im 19. Jahrhundert". Seit 2010 Stipendiatin der Graduiertenförderung der Konrad-Adenauer-Stiftung und Lehrbeauftragte am Philologischen Seminar der Universität Tübingen, Bereich Latinistik.

\section{Alexander Starre (M.A.)}

Studium der Englischen Philologie und Medien- und Kommunikationswissenschaft in Göttingen und Los Angeles (UCLA). 2008-2010 Wiss. Hilfskraft und Lehrbeauftragter in der Abteilung Nordamerikastudien am Göttinger Seminar für Englische Philologie (Lehrstuhl Prof. Dr. Frank Kelleter). Koordination des Antrags zur Einrichtung der DFG-Forschergruppe „Ästhetik und Praxis populärer Serialität", Organisation begleitender Workshops. Seit 2010 Wissenschaftlicher Mitarbeiter und Studiengangskoordinator „American Studies“ (BA/MA). Promotionsvorhaben: „Writing Metamedia: Contemporary American Literature and the Matter of the Book", Forschung und Publikationen im Ecocriticism.

\section{Urte Stobbe (Dr.)}

Studium der Deutschen Philologie, Mittleren und Neueren Geschichte und Politikwissenschaft in Göttingen, Udine (Italien) und UC Berkeley. 2005-2008 Stipendiatin der International Max Planck Research School (IMPRS), 2008 Promotion: „KasselWilhelmshöhe, Ein hochadeliger Lustgarten im 18. Jahrhundert" in Göttingen (erschienen 2009), 2008 bis 2010 Postdoc am DFG-Graduiertenkolleg „Interdisziplinäre Umweltgeschichte“. Seit 2010 Projektmitarbeiterin am Lehrstuhl Prof. Dr. Frank Rexroth, Seminar für Mittlere und Neuere Geschichte Göttingen. Derzeit forscht und publiziert sie im Bereich Gartenkunstgeschichte, Kulturtourismus und Landschaftsästhetik. 
Ceit den 1990er Jahren werden Fragen nach dem Verhältnis zwischen VeränSderungen in der naturalen Umwelt und deren literarischen Repräsentationen im Bereich der Literaturwissenschaft unter dem Begriff Ecocriticism subsumiert und diskutiert. In diesem Band werden umwelthistorische Perspektiven ebenfalls in die Diskussion eingebunden. Dabei ist einerseits zu fragen, wie der Wandel im menschlichen Verhältnis zur »Natur « (und den sich wandelnden Bedeutungsnuancen dieses Begriffs) zu unterschiedlichen Zeiten in literarischen Texten verhandelt wird und welche neuen literarischen Ausdrucksformen er womöglich provoziert. Andererseits ist auch zu fragen, wie sich literarische und kulturelle Muster auf die Gestaltung der naturalen Umwelt auswirken können. Inwiefern korrespondieren dabei literarische Modellierungen des Wandels diachron und synchron mit Veränderungsprozessen in der Natur? Diese doppelte Fragestellung schließt auch die Möglichkeit einer wechselseitigen Kritik umwelthistorischer und literarischer Perspektiven ein.

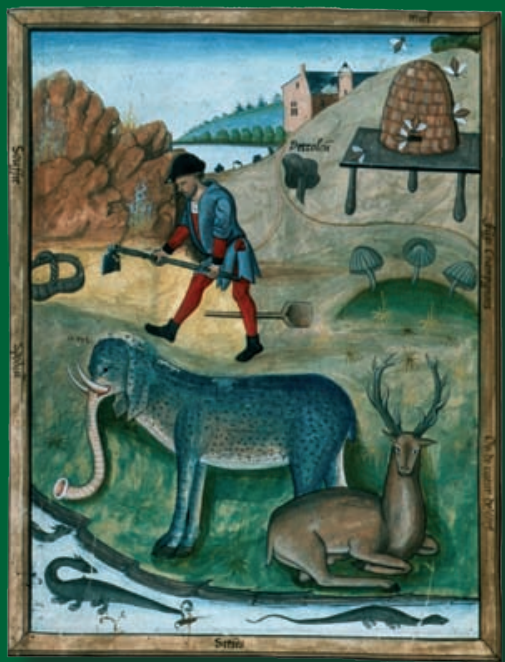

ISBN: $978-3-941875-86-9$ 